\title{
INSPIRATION BY NATURE: BIOMIMETIC RESEARCH INFORMS ADAPTABLE BUILDING SKIN SYSTEM FOR NATURAL VENTILATION AND DAYLIGHT IN HOT DRY CLIMATE (YAZD, IRAN)
}

\author{
A Thesis \\ Presented to \\ the Faculty of California Polytechnic State University, \\ San Luis Obispo
}

In Partial Fulfillment of the Requirements for the Degree Master of Science in Architecture

\author{
by \\ Parisa Navidi Farimani \\ January 2014
}


(C) 2014

Parisa Navidi Farimani

ALL RIGHTS RESERVED 
TITLE:

Inspiration By Nature: Biomimetic Research Informs Adaptable Building Skin System for Natural Ventilation and Daylight in Hot Dry Climate (Yazd, Iran)

AUTHOR :

Parisa Navidi Farimani

DATE SUBMITTED:

January 2014

COMMITTEE CHAIR:

Dr. Mark Newell Cabrinha, AIA., Ph.D., Associate Professor of Architecture Department

COMMITTEE MEMBER:

Carmen Trudell, AIA., M.S.ARCH., Assistant Professor of Architecture Department

COMMITTEE MEMBER:

James Doerfler, AIA., CSI., M.ARCH., Professor Interim Department Head of Architecture Department 


\begin{abstract}
Inspiration By Nature: Biomimetic Research Informs Adaptable Building Skin System for Natural Ventilation and Daylight in Hot Dry Climate (Yazd, Iran)

\section{Parisa Navidi Farimani}

Many plant species, including Barrel Cacti, have developed long-term evolutionary adaptable traits to survive in extreme climates. The most important trait of cacti in extreme hot dry climates is to reduce water evaporation and increase water storage. The exterior skin of a cactus plays an important role in preventing water evaporation through heat transmission.

On the other hand, there have been many passive design strategies applied to the space planning and building design of architecture in hot dry climates. The goal of these passive design strategies is to regulate the penetration of heat into building spaces while creating a strong ventilation system to help bring cool air inside the building.

In this paper, adaptations of the Barrel Cactus' exterior skin, along with architectural passive design strategies for hot dry climates (in this case Yazd, Iran) will be discussed and integrated with one another through the concept of Biomimicry. The goal is to design an exterior building skin that is attuned to the environmental conditions of a hot dry climate, based on the successful applicable behaviors demonstrated in the Barrel Cactus. Key architectural features such as natural ventilation and daylight will be informed by the evolutionary cacti adaptations and passive architectural strategies in the design of the building skin in order to increase the possibility of consistent comfort for users of an office building.

Key words: Biomimicry in Architecture, Evolutionary Adaptation in Barrel Cactus Skin, Environmental Changes Effects, Passive design Strategies of Yazd Architecture, Optimum Adaptable Building Skin System, Interior Comfort Zone Requirements 


\section{TABLE OF CONTENTS}

$\begin{array}{lll}2 & \text { Page }\end{array}$

LIST OF TABLES X Xiii

LIST OF FIGURES X xvi

PAPER INTRODUCTION Xxiv

CHAPTER 1: $\quad 1$

Dynamic and Evolutionary Adaptation of Barrel Cacti 1

Introduction 1

1.1. Dynamic/Instant Adaptation of Barrel Cacti 5

1.1.1. Photosynthesis Adaptability 5

CAM Metabolism

1.2. Evolutionary Adaptation of Barrel Cacti 6

1.2.1. Form Adaptability 6

a. The Numbers of Cactus Stomata 6

b. Globe Configuration $\quad 7$

1.2.2. Material Adaptability 9

a. Reflective Waxy Coating 9

b. Skin Thickness 10

1.2.3. Structure Adaptability 11

a. Cooling Ribs 11

$\begin{array}{ll}\text { b. Spines } & 12\end{array}$

1.2.4. Growth Adaptability 14

Self-shading Behavior of Barrel Cacti 14 
$\begin{array}{ll}\text { CHAPTER 2: } & 18\end{array}$

Analysis of Passive Design Strategies in Yazd, Iran 18

$\begin{array}{ll}\text { Introduction } & 18\end{array}$

$\begin{array}{ll}\text { Yazd, Iran } & 19\end{array}$

$\begin{array}{ll}\text { Yazd Climatic Data } & 22\end{array}$

Passive Design Strategies in Yazd, Iran 25

2.1. Formal Strategies $\quad 25$

Dome-Shaped Roofs $\quad 25$

2.2. Material Base Strategies 28

High Thermal Mass $\quad 28$

2.3. Structural Strategies $\quad 30$

2.3.1. Ventilation System 30

"Windcatcher" 30

2.3.2. Cooling System 33

a. "Windcatcher" + Evaporation System 33

("Qanat" or Water Pond)

b. "Solar Chimney" + Evaporation System 36

("Qanat" or Water Pond)

CHAPTER 3: $\quad 39$

Adaptation in Barrel Cactus vs. Architectural Design Strategies in Yazd, Iran 39

$\begin{array}{ll}\text { Introduction } & 39\end{array}$

3.1. Dynamic Adaptability in Barrel Cacti vs. Dynamic Strategy in 41 
Traditional Architecture of Yazd, Iran

3.2. Form Adaptability in Barrel Cacti vs. Passive Design

Strategy in Traditional Architecture of Yazd, Iran

3.3. Material Adaptability in Barrel Cacti vs. Passive Design

Strategy in Traditional Architecture of Yazd, Iran

Case Studies

Al Hamra Tower (Kuwait City, Kuwait)

3.4. Structure Adaptability in Barrel Cacti vs. Passive Design

Strategy in Traditional Architecture of Yazd, Iran

3.5. Biomimicry in Architecture

Case Studies

Eastgate Building, Harare, Zimbabwe (Architect Mick

Pearce collaborated with engineers at Arup Associates)

BioArch Project, Yazd, Iran (Students at Art Institute of Isfahan in Iran)

\section{CHAPTER 4:}

$\begin{array}{ll}\text { Design Analysis and Calculation } & 60\end{array}$

$\begin{array}{ll}\text { Introduction } & 60\end{array}$

4.1. Exterior Skin Design Process 66

$\begin{array}{ll}\text { Introduction } & 67\end{array}$

4.1.1. Analysis of a Typical Flat Exterior Skin 69

4.1.1.1. Ecotect Analysis to Calculate the Incident 69 
Solar Radiation $\left(\mathrm{Q}_{\mathrm{sun}}\right)$

4.1.1.2. Calculate the Amount of Solar Radiation

Absorbed by the Concrete Wall ( $\left.\mathrm{Q}_{\text {in }}\right)$

4.1.1.3. Calculate the Temperature of the Concrete

Wall Based on the Absorbed Solar Radiation

4.1.2. Analysis of a Corrugated Building Skin;

Cooling Ribs Analysis

4.1.2.1. Ecotect Analysis to Calculate the Incident

Solar Radiation $\left(\mathrm{Q}_{\mathrm{sun}}\right)$

4.1.2.2. Calculate the Amount of Solar Radiation

Absorbed by the Concrete Wall ( $\left.\mathrm{Q}_{\text {in }}\right)$

4.1.2.3. Calculate the Temperature of the Concrete

Wall Based on the Absorbed Solar Radiation and

Outside Temperature

4.1.2.4. Calculate the Difference in Air Density Due

to the Temperature Difference of the Surfaces

4.1.2.5. Calculate the Heat Loss by Convection Due

to the Difference in Air Density

4.1.3. Analysis of a Curved Corrugated Building Skin;

Globe Configuration Effect

4.1.3.1. Ecotect Analysis to Calculate the Incident

Solar Radiation $\left(\mathrm{Q}_{\text {sun }}\right)$

4.1.3.2. Calculate the Amount of Solar Radiation 
Absorbed by the Concrete Wall ( $\left.\mathrm{Q}_{\text {in }}\right)$

4.1.3.3. Calculate the Temperature of the Concrete

Wall Based on the Absorbed Solar Radiation

4.1.3.4. Calculate the Difference in Air Density Due

98

to the Temperature Difference of the Surfaces

4.1.3.5. Calculate the Heat Loss by Convection Due

to the Difference in Air Density

4.1.3.6. Calculate of the Ventilation Rate Based on

the Difference in the Surface Temperature

Self-shading Behavior of the Ribs

Introduction

4.2.1. Calculate $\mathrm{Q}_{\text {in }}$ for the Rib Section (Figure 4.2.1)

per $\mathrm{M}^{2}$ based on the Ecotect Analysis on the $1^{\text {st }}$ Floor, $10^{\text {th }}$ Floor and $18^{\text {th }}$ Floor

4.2.2. Convert the Unit of the $\mathrm{Q}_{\text {in }}(\mathrm{W} / \mathrm{M} 2)$ to $\mathrm{BTU} / \mathrm{H}^{*} \mathrm{ft}^{2}$ for US Standards

4.2.3. Calculate the $\mathrm{Q}_{\text {in }}$ over the Vertical Square Feet of a

Single Flat Rib Portion of the Exterior Skin to Eliminate the $\mathrm{ft}^{2}$ Unit

4.2.4. Using Interpolation to Calculate the Heat Gain for the Remaining Floors and Finding the Total Heat Gain at the Center of the Air cavity \#1 based on the Values 
Determined in Step 3

4.2.5. Find the Temperature at the Center of the Air cavity based on the $\mathrm{Q}_{\text {in }}$ for Each Individual Floor Mentioned in Step 3

4.2.6. Based on the Values Derived in Step 5, Use

Interpolation to Calculate for the Average Temperature at the Center of the Air cavity in order to Calculate the Heat Loss due to the Ventilation Rate in the Air cavity \#1

4.2.7. Calculate the Ventilation Rate due to the Heat Stacking Effect and Venturi Effect

4.2.8. Calculate the Amount of Heat Energy Dissipated due to Heat Stacking Effect and Venturi Effect as a Result of Step 7 and Determine the Amount of Heat Gain Remaining in Air cavity \#1

4.2.9. Calculate the Ventilation Rate due to the

Summer Wind Effect Combined with the Venturi Effect

4.2.10. Calculate the Amount of Heat Energy Dissipated due to the Combined Effect of the Summer Winds, Stack Effect and the Venturi Effect

\subsection{Interior Skin Design Process}

Introduction

4.3.1. Interior Heat Gain and Ventilation Rate 
the Building for the $10^{\text {th }}$ Floor on June $21^{\text {st }}$ at 12:00

4.3.1.2. Calculating the Ventilation Rate based on

the Amount of Heat Gain and Comfort Temperature

4.3.1.3. Propose the Design Solutions to Solve for

the Interior Ventilation Rate

a. Solar Chimney 146

b. Evaporation System 148

4.3.2. Daylight Design Consideration 152

4.3.2.1. Calculate the Total Outdoor Daylight

Illumination

4.3.2.2. Calculate the Daylight Illumination in Air Cavity \#2 $\left(\mathrm{P}_{1}\right)$

4.3.2.3. Calculate the Daylight Factor in the Air Cavity \#2 $\left(\mathrm{P}_{1}\right)$

4.3.2.4. Interior Daylight Illumination based on

Illumination in Air Cavity \#2 and the Daylight Factors at $\mathrm{P}_{2}$ and $\mathrm{P}_{3}$

4.3.2.5. Proposed Daylight Design Solution to

Reduce the Direct Daylight Illumination at $\mathrm{P}_{2}$ and $\mathrm{P}_{3}$

CONCLUSION 
a. Globe Configuration Effect of the Exterior Skin

b. Cooling Ribs Effect (Self-ventilating system) of the Exterior Skin

2. Flat Ribs of the Exterior skin

a. Self-shading Behavior of the Ribs

b. Thermal Mass

Skin Gap Design Process

Interior Skin Design Process

1. Natural Ventilation within the Air Cavity \#2

a. Reducing the Surface Temperature of the Building Skin 


\section{LIST OF TABLES}

Table

Page

4.1.1: HOURLY AND DAILY CALCULATION OF THE QIN

BASED ON THE AMOUNT OF INCIDENT SOLAR RADIATION

(QSUN) AND ABSORPTION RATIO OF THE EXTERIOR SKIN $(\alpha)$

4.1.2: HOURLY SURFACE TEMPERATURE $\left({ }^{\circ} \mathrm{F}\right)$ CALCULATION

78

4.1.3: HOURLY CALCULATION OF THE Q ${ }_{\text {IN }}$ BASED ON

84

THE AMOUNT OF INCIDENT SOLAR RADIATION (Q $\left.{ }_{\text {SUN }}\right)$ AND

ABSORPTION RATIO OF THE EXTERIOR SKIN $(\alpha)$

4.1.4: HOURLY TEMPERATURE DIFFERENCES FOR THE

85

VERTICAL FLAT EXTERIOR SKIN VS. THE CORRUGATED

EXTERIOR SKIN

4.1.5: AIR DENSITY CALCULATION DUE TO THE

DIFFERENCE IN THE TEMPERATURE OF THE CORRUGATED SKIN JUNE $21^{\text {ST }}$

4.1.6: HEAT LOSS THROUGH CONVETION ON THE CORRUGATED SKIN

JUNE $21^{\text {ST }}$

4.1.7: HOURLY CALCULATION OF THE QIN BASED ON

THE AMOUNT OF INCIDENT SOLAR RADIATION (Q

ABSORPTION RATIO OF THE EXTERIOR SKIN $(\alpha)$

4.1.8: HOURLY SURFACE TEMPERATURES

98

4.1.9: AIR DENSITY CALCULATION DUE TO THE

TEMPERATURE DIFFRENECE

JUNE $21^{\text {ST }}$

4.1.10: HEAT LOSS THROUGH THE CONVETION ON THE

100

CORRUGATED SKIN VS. CURVED CORRUGATED SKIN

4.1.11: VENTILATION RATE DUE TO THE CONVETION

104

ON THE CURVED CORRUGATED SKIN

4.1.12: HOURLY SURFACE TEMPERATURE OF THE FLAT

106

VERTICAL SKIN VS. $5^{\circ}$ TILTED (SELF-SHADED) FLAT SKIN 
4.2.6: THE AMOUNT OF HEAT ENERGY DISSIPATED 


\section{LIST OF FIGURES}

Figure $\quad$ Page

0.1: INTRODUCTION DIAGRAM AND DESIGN METHODOLOGY xxvii

1.1: DYNAMIC AND EVOLUTIONARY ADAPTATION OF 4

BARREL CACTI

1.2.1.1: A MICROSCOPIC IMAGE OF THE SURFACE OF A CACTUS 6

STEM; THE OVAL SHAPED OBJECTS WITH DARKS IN THE

MIDDLE ARE STOMATA, THE PORES THROUGH WHICH CACTI

AND OTHER PLANTS BREATHE

1.2.1.2: FORMAL ADAPTABILITY (GLOBE CONFIGURATION)

OF BARREL CACTI

1.2.1.3: FORMAL ADAPTABILITY (GLOBE CONFIGURATION)

OF BARREL CACTI ${ }^{10}$

1.2.2.1: REFLECTIVE WAXY COATING OF BARREL CACTI 9

1.2.2.2: SKIN DEPTH OF THE BARREL CACTUS 10

1.2.3.1: MECHANISMS FOR COOLING IN THE BARREL CACTUS 12

1.2.3.2: SPINES REFLECT THE DIRECT SOLAR RADIATION AND HELP 12 TO SHADE THE SKIN OF A CACTUS

1.2.3.3: SPINES CATCH THE RAINWATER AND EVAPORATION WATER 13

1.2.3.4: SPINES CRETAING A MICRO-CLIAMTE AREA 14

1.2.4.1: CONSISTENT GROWTH ADAPTABILITY OF 15

BARREL CACTI FOR MILLIONS OF YEARS

2.1: CHAPTER 2 ANALYSIS DIAGRAM 19

2.2: A "QANAT" CANAL 20

2.3: PORTION OF YAZD SKYLINE 21

2.4: YAKHCHAL OF YAZD PROVINCE 21

2.5: YAZD CLIMATIC DATA 22 
2.6: 3DIMENSIONAL WEEKLY SUMMARY MAXIMUM

TEMPERATURE OF YAZD, IRAN

AUTODESK ECOTECT 2011

2.7: 3DIMENSIONAL WEEKLY DIRECT SOLAR RADIATION

OF YAZD, IRAN

AUTODESK ECOTECT 2011

2.8: TOTAL AVERAGE SOLAR RADIATION OF YAZD, IRAN

AUTODESK ECOTECT 2011

2.1.1: DOME-SHAPED ROOFS

YAZD, IRAN

2.1.2: INCIDENT SOLAR RADIATION ANALYSIS ON A SPHERE

YAZD, IRAN

AUTODESK ECOTECT 2011

2.1.3: AMIR CHAKMAK MOSQUE FACADE SYSTEM

2.2.1: AN OLD BUILDING WITH HIGH THERMAL IN YAZD, IRAN

2.3.1.1: OLD "WINDCATCHERS" ("BADGIRS") IN YAZD, IRAN

2.3.1.3: BUILDING SECTION SHOWING A UNI-DIRECTIONAL

"WINDCATCHER" MECHANISM BASED ON THE VENTURI EFFECT

2.3.1.4: BUILDING SECTION SHOWING A BI-DIRECTIONAL

"WINDCATCHER" MECHANISM BASED ON THE VENTURI EFFECT

2.3.2.1: BUILDING SECTION SHOWING A UNI-DIRECTIONAL

"WINDCATCHER" MECHANISM COMBINED WITH

"QANAT COOLING SYSTEM"

2.3.2.2: BUILDING SECTION SHOWING A BI-DIRECTIONAL

"WINDCATCHER" MECHANISM COMBINED WITH

"QANAT COOLING SYSTEM"

2.3.2.3: BUILDING SECTION SHOWING A SOLAR CHIMNEY

COMBINED WITH THE CENTRAL COURTYARD CREATING NATURAL COOLING SYSTEM IN YAZD, IRAN

3.1: THE RELATIONSHIP BETWEEN ADAPTATION IN NATURE AND 
BARREL CACTI VS. PASSIVE DESIGN STRATEGY IN TRADITIONAL ARCHITECTURE OF YAZD, IRAN

3.3.1: MATERIAL ADAPTABILITY (REFLECTANCE VALUE OF THE MATREIAL) IN BARREL CACTI VS. PASSIVE DESIGN STRATEGY IN TRADITIONAL ARCHITECTURE OF YAZD, IRAN

3.3.2: MATERIAL ADAPTABILITY (SKIN THICKNESS) IN

BARREL CACTI VS. PASSIVE DESIGN STRATEGY IN TRADITIONAL ARCHITECTURE OF YAZD, IRAN

3.3.3: AL HAMRA BUILDING, KUWAIT CITY, KUWAIT. APPLYING THERMAL MASS AS PART OF THE PASSIVE DESIGN STRATEGY

3.4.1: STRUCTURE ADAPTABILITY (VENTILATION/COOLING)

IN BARREL CACTI VS. PASSIVE DESIGN STRATEGY IN TRADITIONAL ARCHITECTURE OF YAZD, IRAN

3.5.1: TERMITE-INSPIRED BUILDING, HARARE, ZIMBABWE

3.5.2: SNAIL-INSPIRED PROJECT, YAZD, IRAN

3.5.3: SNAIL-INSPIRED PROJECT, YAZD, IRAN

3.5.4: CHAPTER 3 ANALYSIS CHART: THE RELATIONSHIP

4.3: THREE LAYERS OF THE DESIGN PROCESS 
4.1.2: INCIDENT SOLAR RADIATION ANALYSIS OF THE FLAT

BUILDING SKIN

JUNE $21^{\text {ST }} 8: 00$ - YAZD, IRAN

AUTODESK ECOTECT 2011

4.1.3: INCIDENT SOLAR RADIATION ANALYSIS OF THE FLAT

BUILDING SKIN

JUNE $21^{\text {ST }}$ 10:00 - YAZD, IRAN

AUTODESK ECOTECT 2011

4.1.4: INCIDENT SOLAR RADIATION ANALYSIS OF THE FLAT

BUILDING SKIN

JUNE $21^{\text {ST }} 12: 00$ - YAZD, IRAN

AUTODESK ECOTECT 2011

4.1.5: INCIDENT SOLAR RADIATION ANALYSIS OF THE FLAT

BUILDING SKIN

JUNE $21^{\text {ST }}$ 14:00 - YAZD, IRAN

AUTODESK ECOTECT 2011

4.1.6: INCIDENT SOLAR RADIATION ANALYSIS OF THE FLAT

BUILDING SKIN

JUNE $21^{\text {ST }}$ 16:00 - YAZD, IRAN

AUTODESK ECOTECT 2011

4.1.7: INCIDENT SOLAR RADIATION ANALYSIS OF THE FLAT

BUILDING SKIN

DECEMBER $21^{\text {ST }}$ 8:00 - YAZD, IRAN

AUTODESK ECOTECT 2011

4.1.8: INCIDENT SOLAR RADIATION ANALYSIS OF THE FLAT

BUILDING SKIN

DECEMBER $21^{\mathrm{ST}} 10: 00$ - YAZD, IRAN

AUTODESK ECOTECT 2011

4.1.9: INCIDENT SOLAR RADIATION ANALYSIS OF THE FLAT

BUILDING SKIN

DECEMBER $21^{\text {ST }} 12: 00$ - YAZD, IRAN

AUTODESK ECOTECT 2011

4.1.10: INCIDENT SOLAR RADIATION ANALYSIS OF THE FLAT

BUILDING SKIN

DECEMBER $21^{\text {ST }} 14: 00$ - YAZD, IRAN

AUTODESK ECOTECT 2011

4.1.11: INCIDENT SOLAR RADIATION ANALYSIS OF THE FLAT 
BUILDING SKIN

DECEMBER $21^{\text {ST }} 16: 00$ - YAZD, IRAN

AUTODESK ECOTECT 2011

4.1.12: INCIDENT SOLAR RADIATION (QSUN)

4.1.13: HOURLY TEMPERATURE ON JUNE $21^{\text {ST }}$

AUTODESK ECOTECT 2011

4.1.14: HOURLY TEMPERATURE ON DECEMBER $21^{\text {ST }}$

AUTODESK ECOTECT 2011

4.1.15: INCIDENT SOLAR RADIATION ANALYSIS OF CORRUGATE SKIN

JUNE $21^{\text {ST }} 8: 00$ - YAZD, IRAN

AUTODESK ECOTECT 2011

4.1.16: INCIDENT SOLAR RADIATION ANALYSIS OF CORRUGATE SKIN

JUNE $21^{\text {ST }}$ 10:00 - YAZD, IRAN

AUTODESK ECOTECT 2011

4.1.17: INCIDENT SOLAR RADIATION ANALYSIS OF CORRUGATE SKIN

JUNE $21^{\text {ST }} 12: 00$ - YAZD, IRAN

AUTODESK ECOTECT 2011

4.1.18: INCIDENT SOLAR RADIATION ANALYSIS OF CORRUGATE SKIN

JUNE $21^{\text {ST }}$ 14:00 - YAZD, IRAN

AUTODESK ECOTECT 2011

4.1.19: INCIDENT SOLAR RADIATION ANALYSIS OF CORRUGATE SKIN

JUNE $21^{\text {ST }}$ 16:00 - YAZD, IRAN

AUTODESK ECOTECT 2011

4.1.20: CONVECTION ON THE CORRUGATED SKIN

DUE TO THE DIFFERENCE IN AIR DENSITY

4.1.21: $20^{\mathrm{TH}}$ LEVEL OF CURVED CORRUGATED PLAN SECTION

4.1.22: INCIDENT SOLAR RADIATION ANALYSIS

93

JUNE $21^{\text {ST }} 8: 00$ - YAZD, IRAN

GECO ANALYSIS 
JUNE $21^{\text {ST }}$ 10:00 - YAZD, IRAN

GECO ANALYSIS

4.1.24: INCIDENT SOLAR RADIATION ANALYSIS

94

JUNE $21^{\text {ST }}$ 12:00 - YAZD, IRAN

GECO ANALYSIS

4.1.25: INCIDENT SOLAR RADIATION ANALYSIS

94

JUNE $21^{\text {ST }}$ 14:00 - YAZD, IRAN

GECO ANALYSIS

4.1.26: INCIDENT SOLAR RADIATION ANALYSIS

95

JUNE $21^{\text {ST }}$ 16:00 - YAZD, IRAN

GECO ANALYSIS

4.1.27: CONVECTION ON THE CORRUGATED SKIN DUE TO

DIFFERENCE IN AIR DENSITY

4.1.28: DESIGNED BUILDING SECTION; $5^{\circ}$ TILTED FLAT RIBS

OF THE EXTERIOR CURVED CORRUGATED SKIN CREATING

SELF-SHADING BEHAVIOR TO SHADE THE LOWER FLOORS JUNE $21^{\text {ST }}$

4.2.0: SKIN GAP DESIGN ANALYSIS FACTORS

4.2.1: PLAN SECTION OF THE $20^{\mathrm{TH}}$ LEVEL OF THE

DESIGNED BUILDING SKIN

4.2.2: SECTION OF THE AIR CAVITY \#1 SHOWING THE

INLET/OUTLET RATIO

4.2.3: INCREASE IN THE VENTILATION RATE DUE TO

DIFFERENTIAL OPENING SIZES

4.2.4: AUTODESK ECOTECT WIND ANALYSIS

129

JUNE - YAZD, IRAN

4.2.5: LOCAL SUMMER WINDS CREATING NEGATIVE

PRESSURES ON THE SOUTH SIDE OF THE BUILDING PULLING THE AIRFLOW OUT OF THE AIR CAVITY

4.2.6: A PORTION OF THE HEAT GAIN ABSORBED BY THE 

SYSTEM AND SOLAR CHIMNEY CREATES PRESSURE DIFFERENCES THAT IMPROVES THE NATURAL VENTILATION INSIDE THE DAYLIGHT DUCT AND INSIDE THE BUILDING SPACES

4.3.5: LOCAL SUMMER WINDS WITH THE HELP OF EVAPORATION SYSTEM AND SOLAR CHIMNEY CREATE PRESSURE DIFFERENCES THAT IMPROVE THE NATURAL VENTILATION INSIDE AIR CAVITY \#2 AND INSIDE THE BUILDING SPACES

4.3.6: THREE DESIGNED WINDOWS LOCATED AROUND

THE AIR CAVITY \#2 
THROUGH THE 8'x8' OPENING

4.3.14: DESIGNED DAYLIGHT ELEMENT BLOCKING

171

THE DAYLIGHT IN THE SUMMERTIME AND PROVIDING MORE

DIFFUSED DAYLIGHT FOR THE INTERIOR SPACES

4.3.15: DESIGNED DAYLIGHT ELEMENT REDUCING THE

172

AMOUNT OF DIRECT DAYLIGHT WHILE IT IS STILL REFLECTING CERTAIN AMOUNT OF DIFFUSED DAYLIGHT FOR THE INTERIOR SPACES

4.3.16: DAYLIGHT ELEMENTS ON THE 8'x8' APERTURES

174

OF THE EXTERIOR SKIN

4.3.17: DAYLIGHT ELEMENTS ON THE EXTERIOR SKIN

174

5.1: PERSPECTIVE SECTION OF THE BUILDING SKIN SHOWING

191 ALL THE DESIGN STRATEGIES 


\section{PAPER INTRODUCTION}

Although solar radiation is critical for species to grow and evolve, the heat produced by the Sun's radiation increases the internal and surface temperature of living organism species in hot dry climates and therefore can have fatal consequences. Hence, natural light and heat, the major components of insolation, have provided conflicting results for the species in hot dry climate. Nature has some great examples to show how to overcome these stresses through adaptation strategies in hot dry climates. There are many examples in nature where natural species, such as plants, are capable of responding to solar radiation, temperature change, humidity and other physical environmental changes based on efficient evolutionary adaptations. Among all the species in hot dry climates, the Barrel Cactus has developed many evolutionary adaptable solutions over millions of years of surviving in extreme climates that allow the cactus to reduce its water evaporation and therefore increasing water storage. While there are many internal chemical botanical factors to help reduce water evaporation, the exterior skin of a cactus plays a very important role in balancing daylight and heat gain to prevent heat transmitting through the skin and causing water evaporation.

The design of building facades in today's large-scale building designs in hot dry climates needs to be revisited to address natural daylight, thermal comfort and natural ventilation. Today's solutions are neither designed for daylighting and temperature changes during the day, nor are they designed for changes throughout the year. Buildings should be designed to accommodate natural lighting, thermal comfort, and natural ventilation that are adapted specifically to diurnal and seasonal environmental changes in hot dry climates. In this thesis, adaptability is approached through the optimization of the 
form, material and structure of the building skin system relative to its performance with respect to user comfort. Looking at the traditional small-scale buildings of hot dry climates, such as in Yazd, Iran, gives many formal, material and structural examples of passive design strategies that balance daylight and heat gain. Passive strategies in Yazd are essentially centered around different ventilation systems such as wind catchers and/or central courtyards to keep the heat out and/or bring the cool air inside the building in order to create pleasant microclimate spaces for the occupants.

Integrating the evolutionary adaptations of the Barrel Cactus with the passive building strategies of the architecture of Yazd into the design of an office building skin system can provide a better understanding of the behavior of the building skins; therefore allowing for optimization of the design solution for such a climate. Further design considerations such as natural daylight, heat gain and natural ventilation must be considered in the design of the building skin to provide comfort for the users of an office building.

The first chapter will explain the function of the evolutionary adaptation of Barrel Cactus in a hot dry climate. Evolutionary adaptable solutions of Barrel Cacti have occurred over millions of years in order to balance daylight and heat gain and also create a natural ventilation and cooling system to offset any heat gain to survive in extreme climates. The same challenge (choosing between daylight and heat and natural ventilation system) exists in the design of the buildings in hot dry climates. Hence, the evolutionary adaptable behaviors of the Barrel Cactus that have the potential to be translated into the design of a building skin will be discussed in the first chapter. 
The second chapter explains the passive design strategies that have been applied in the architectural design of the small and medium scale buildings in a hot dry climate such as Yazd, Iran. Ventilation systems will be the main focus of this chapter and will be presented as the most significant passive design solution to cool down the interior of the building and/or direct the hot air out.

The third chapter will connect the first two chapters together to have a better understanding of biomimicry. In this chapter, many of the evolutionary adaptable solutions of Barrel Cactus that discussed in the first chapter will be compared with the traditional architectural solutions in Yazd, Iran. Although local designers and builders of Yazd, Iran might not have initially looked to nature for architectural design lessons to provide better design solutions, the results of some of their solutions may seem similar to the evolutionary adaptation of Barrel Cactus. While this may be coincidental, it will be fully explored in this chapter. Some case studies regarding the biomimicry in architecture will be explained in this chapter.

Finally in the last chapter, building skin system inspired by the Barrel Cactus and traditional design strategies of Buildings in Yazd will be introduced and analyzed. Future design optimization, such as heat gain and ventilation consideration, integrated with the evolutionary adaptation and passive adaptable strategies propose an intelligent office building skin that increases the possibility of consistent comfort for users of an office building while decreasing the energy consumption of the building. Further energy calculations along with the effect of various material properties, will be explained and analyzed in this chapter. Figure 0.1 explains the methodology of the design of an office building skin system in Yazd, Iran. The design methodology starts with the climatic 
analysis of Yazd. Autodesk Ecotect2011 would be helpful to give variable amount of insolation for different times of the year for the specific climate and building model. Dynamic and evolutionary adaptation of Barrel Cactus and traditional architecture of Yazd are able to be analyzed based on the climatic data in Ecotect in order to design an adaptable building skin for the same climate. Also based on the same analyzed climatic data, as designers, further design concern such comfort for the users an office building will be taken to the consideration. Comfort zone could be defined as natural daylight and ventilation and minimum amount of heat gain in hot dry climate.

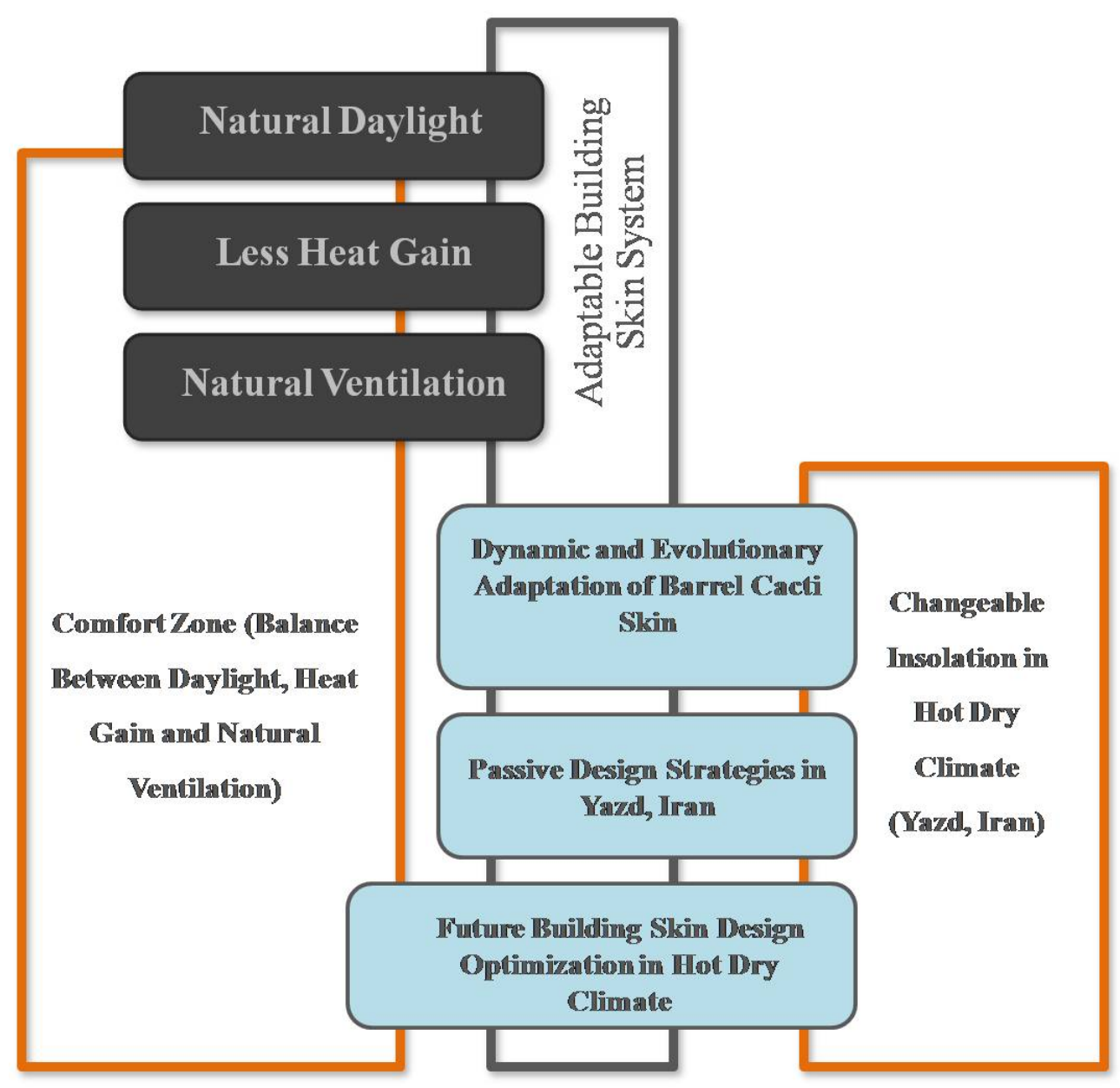

FIGURE 0.1: INTRODUCTION DIAGRAM AND DESIGN METHODOLOGY 


\section{CHAPTER 1:}

\section{Dynamic and Evolutionary Adaptation of Barrel Cacti}

\section{Introduction}

Adaptation in plants refers to any microscopic and/or macroscopic alteration or conversion of behavior of the plants, which enable them to survive in extreme conditions of intense sun or shade, cold or heat, wet or dry microclimates. Adaptation in plants could be categorized into two groups. First, the adaptation that has evolved over millions of years (evolutionary) based on the slowly changing environmental effects of its climate. This sort of adaptation which could be called an evolutionary adaptation explains the current form and structure of plants in the specific climates. For example, at the macroscale level, leaf shapes might be broad and flat (like oak leaves) or "needle-shaped"1 (like red pine needles) based on the amount of solar radiation in specific climates. At the micro-scale level, an evolutionary adaptation example is that of the cuticle. The cuticle is one of the most important leaf properties that make the leaf surface adaptable to environmental changes. In some cases the cuticle, which exists mostly in the outer level of the leaf surface, protects the plant against overheating by reflecting solar radiation and/or by heat transfer via turbulent airflow and convection. ${ }^{2}$ The second kind of adaptation is when plants dynamically adapt themselves with environmental changes of a specific climate at a specific time. This kind of adaptation is more dynamic and instant compared to the evolutionary adaptation. The period of the time that alteration and adaptation happens is much shorter when compared to the evolutionary adaptation. For example, when "stoma" ${ }^{3}$ (pore in leaves which are responsible for gas exchange) close and open during the day to do the gas exchange for photosynthesis. Another simple 
example is when a branch of a plant begins to orbit or change direction of its growth to gain maximum exposure to the Sun in order to grow. Although the dynamic/instant adaptation might be the result of the evolutionary adaptation, the distinction between the dynamic adaptation and evolutionary adaptation is that the mechanism of the adaptation is either dynamic or fixed. Therefore, whenever the author talks about the evolutionary adaptation, it means the firm/solid character of the living species that has been formed through millions of years and whenever the author talks about the dynamic/instant adaptation, it means the type of the behavior that requires a dynamic mechanism to be performed in a short amount of time compared to evolutionary adaptation.

Both evolutionary and dynamic adaptations in hot dry climates are clearly expressed in the morphology and anatomy of Barrel Cacti. Based on the different climatic conditions and environmental changes within hot dry climates due to the daily and seasonal changes in solar radiation, adaptability in individual Barrel Cactus plants can be variable. Although the responsive variable adaptation in Barrel Cacti is explained at various scales from micro to macro, the most important consideration of cacti is balancing the natural light and heat to increase water storage in extreme climates. Its ability to regulate the temperature of the interior space of the cactus and increase water storage based on its form, structure and material of its skin must also be considered along with the cactus' ability to self-shade and self-ventilate its skin thus decreasing the effect of heat generated by direct solar radiation. Adaptability of the exterior skin (form, structure and material) has been achieved through millions of years of evolution and configuration. Therefore, most of the adaptations in cacti are evolutionary methods expressed on the exterior skin of the cactus. Figure 1.1 shows the methodology of 
explanation of the first chapter. This chapter is divided into two parts. First, dynamic adaptation which will be explained as "CAM Metabolism" which explains the function of the stomata of the Barrel Cactus' skin during the photosynthesis process. The second part of the chapter includes explanation of evolutionary adaptation described "Form Adaptability", "Material adaptability", "Structure Adaptability" and "Growth Adaptability". Although this chapter will discuss both types of adaptability in Barrel Cacti, evolutionary adaptation will be the most important factor when it comes to design. 


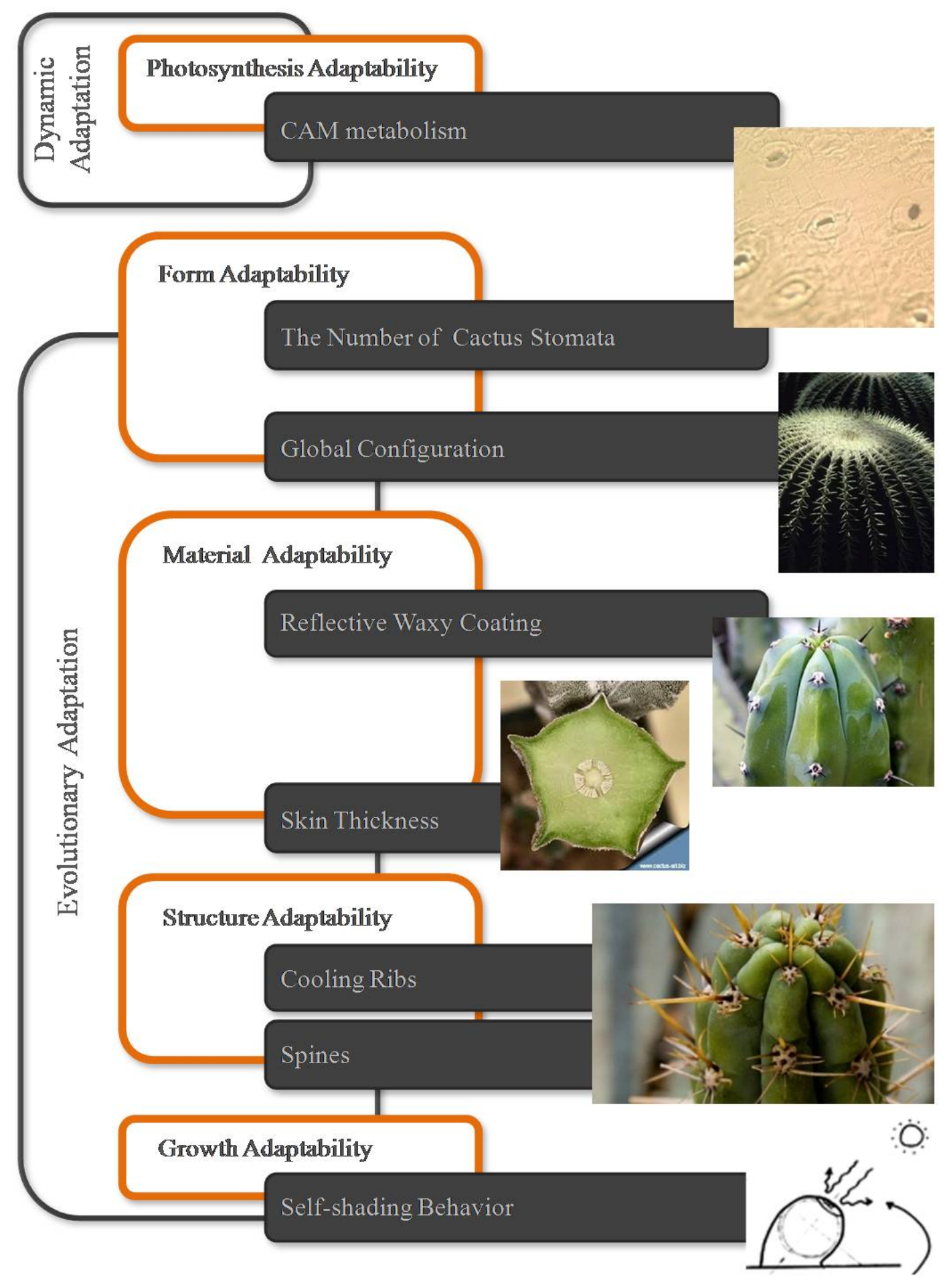

FIGURE 1.1: DYNAMIC AND EVOLUTIONARY ADAPTATION OF BARREL CACTI 


\subsection{Dynamic/Instant Adaptation of Barrel Cacti}

\subsubsection{Photosynthesis Adaptability}

\section{CAM Metabolism}

One of the most impressive adaptations of the Barrel Cactus is an adaptation known as "Crassulacean Acid Metabolism (CAM)". ${ }^{4}$ Instead of normal photosynthesis, in which all necessary raw materials are taken in and used at once, CAM allows the plant to keep its stomata closed during the day to minimize water loss. ${ }^{5}$ Stomata are openings on the exterior skin of most plants' green tissues that allow for a gas exchange during the photosynthesis. "Nearly all plants open their stomata to carry out this breathing process during the day. As a result, most plants are opening their stomata when it is hottest and are therefore releasing huge amounts of water through evaporation. In areas where there is plenty of water this really isn't much of a problem." 6

There is no water to waste in a hot dry climate. The cactus therefore does the exact opposite of what almost all plants do; it opens its stomata to "breath" during the night and closes them during the day. ${ }^{7}$ The Barrel Cactus opens its stomata during the night to collect carbon dioxide from the environment and stores it as malic acid until photosynthesis begins in the morning. Once daylight appears, the cactus closes its stomata and sort of holds its breath, converting the malic acid back into carbon dioxide for use in photosynthesis. ${ }^{8}$ 


\subsection{Evolutionary Adaptation of Barrel Cacti}

\subsubsection{Form Adaptability}

\section{a. The Numbers of Cactus Stomata}

Not only the function of the stomata has been evolved to reduce water loss but also the quantity and the design of the stomata have been evolved to conserve more water. Many plants have large amounts of relatively small stomata all over their green tissues specifically on the surfaces of their leaves. In Barrel Cacti because of the evolutionary adaptation there are no leaves compared to the typical plants in mild climate. Leaves increase the exposed surfaces to the direct solar radiation and therefore non-broad leaf plants such as Barrel Cactus are the evolved adaptable plants in hot dry climate. Leaves in cacti evolved and changed to spines and therefore the stomata are on the surface of the stem of the Barrel Cactus instead of the surfaces of the leaves/spines.

Figure 1.2.1.1 shows the microscopic image of the surface of a cactus stem.

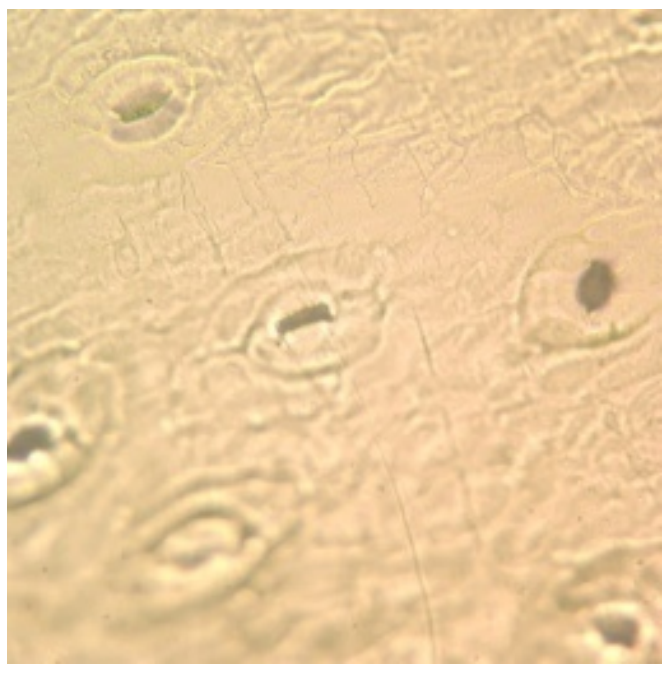

FIGURE 1.2.1.1: A MICROSCOPIC IMAGE OF THE SURFACE OF A CACTUS STEM; THE OVAL SHAPED OBJECTS WITH DARKS IN THE MIDDLE ARE STOMATA, THE PORES THROUGH WHICH CACTI AND OTHER PLANTS BREATHE $^{9}$ 
Microscopically looking at the exterior surface of the Barrel Cactus, there have been less stomata when compared to the typical plants with relatively the same size. Because water is very important to grow and hard to harvest in hot dry climate, the pores on the surface of the Barrel Cactus (stomata) are also made out of larger cells when compared to typical plants with broad leaves. Even when the stomata are closed in typical plants, there are always the chances of leaking water vapor. In the climate with enough precipitation this might not make any problems but in hot dry climate as water is very essential to survive cacti have been evolved to overcome this problem. The cells that stomata have been made out of are much bigger compared to the cells of the stomata of the typical pants so "this allows the cacti to firmly close their stomata so water vapor does not accidentally leak out." ${ }^{10}$

\section{b. Globe Configuration}

The stems of many cacti and specifically Barrel cacti are globe shaped, which is an optimal shape for water storage. A globe maximizes volume while minimizing the surface area. Minimizing surface area keeps water loss through the stomata to a minimum.

There is also another benefit in regards to the globe shape of the Barrel Cactus that help minimize water loss; only a small area of the globe shape is exposed to direct solar radiation during the day, as the rest of the surface is either in shade or exposed to solar radiation at a severe angle. Figure 1.2.1.2 and 1.2.1.3 show that the small portion of the cactus configuration is exposed to the Sun and a large portion of the Barrel Cactus is either indirectly exposed to the Sun or it is in shade. 


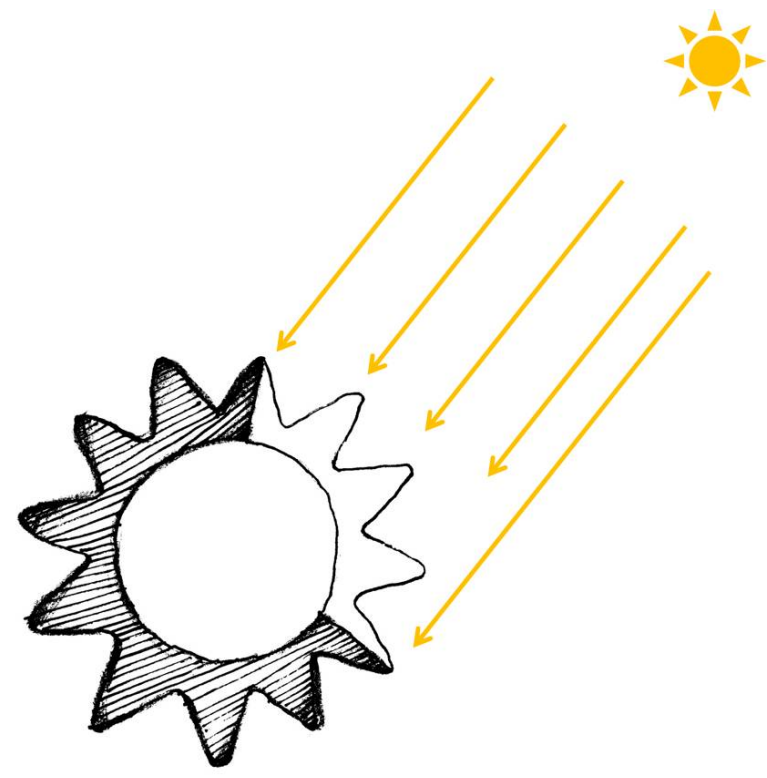

FIGURE 1.2.1.2: FORMAL ADAPTABILITY (GLOBE CONFIGURATION) OF BARREL CACTI

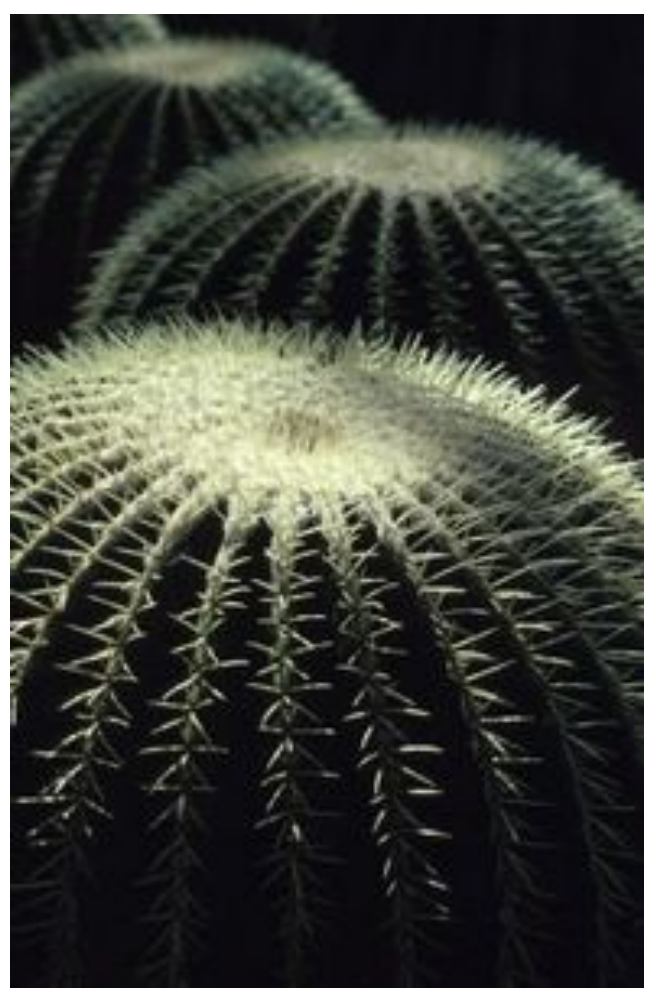

FIGURE 1.2.1.3: FORMAL ADAPTABILITY (GLOBE CONFIGURATION) OF BARREL CACTI ${ }^{11}$ 
Due to the fact that the surface, which is exposed to direct solar radiation, is constantly changing during the day as the Sun moves from east to west, water preservation is further enhanced. This constant change in the portion of cactus that is exposed directly to solar radiation is very helpful in helping to control the heat gain that the cactus experiences throughout the day, thus helping to protect its stored water.

\subsubsection{Material Adaptability}

\section{a. Reflective Waxy Coating}

One of the evolutionary adaptations of the Barrel Cactus in hot dry climates is to produce a waxy cover to increase the solar radiation reflectance and decrease the water loss. The outer skin of the stem of the Barrel Cactus is not only covered by a thick waxy coating to reflect the solar radiation, but some Barrel Cacti produce extra waxy barriers during the hottest time of the day to prevent water leaving the stem. Figure 1.2.2.1 shows a Barrel Cactus with a thickened waxy coating during the hottest times of the day to increase the reflective value of the material.

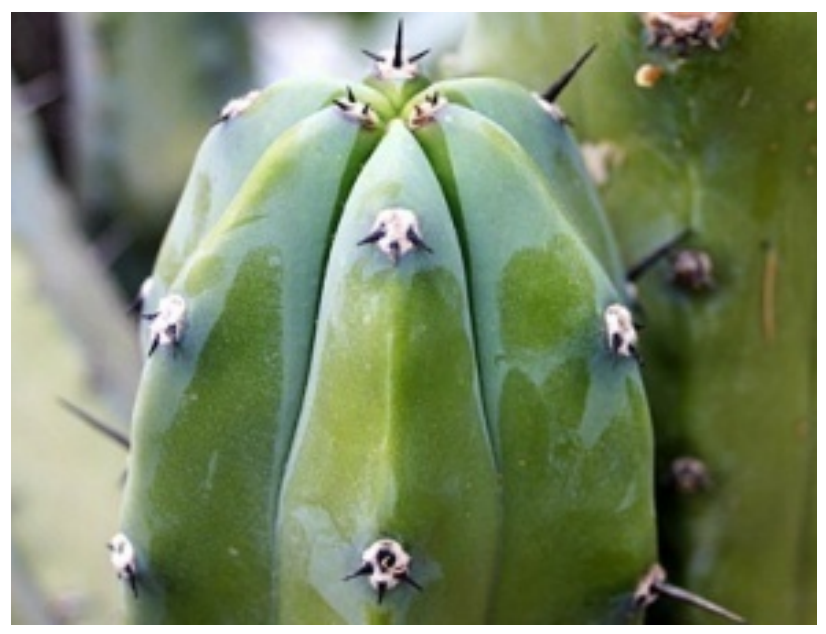

FIGURE 1.2.2.1: REFLECTIVE WAXY COATING OF BARREL CACTI ${ }^{12}$ 


\section{b. Skin Thickness}

The skin of most Barrel Cactus in hot dry climates is pretty thick and dense to store water. This helps the cacti delay any water evaporation by delaying the heat transfer to the interior of the cactus that can result in a more stable water storage which is needed to survive. Therefore, thick skin is capable of storing water better than thin skin. Also it would be harder for predators to reach the water inside a thick skinned cactus. Therefore, thick skin not only keeps the water storage safe from the predators but also creates a microclimate zone inside the cactus which allows for a cooler internal temperature when compared to that of the outside temperature during the hottest times of the day. As discussed before, because stomata are open during the night to exchange gas and begin the photosynthesis process, any heat that penetrated during the day to the internal portion of the cactus can be ventilated through the open stomata at night. Figure 1.2.2.2 shows the section of a Barrel Cactus with high material thickness for the exterior skin.

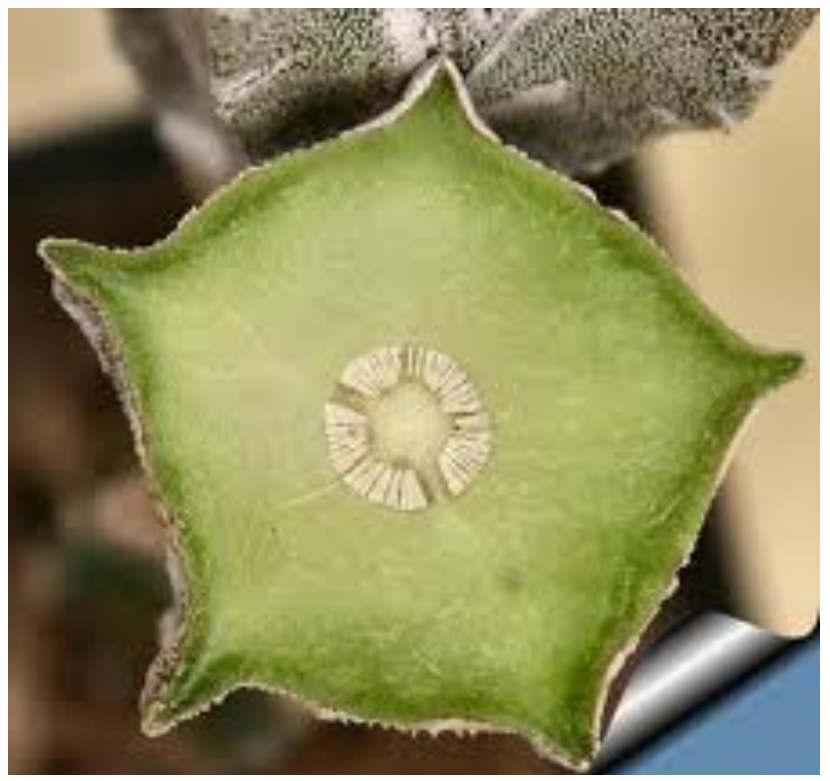

FIGURE 1.2.2.2: SKIN DEPTH OF THE BARREL CACTUS ${ }^{13}$ 


\subsubsection{Structure Adaptability}

\section{a. Cooling Ribs}

One of the most important evolutionary adaptations of the Barrel Cactus has to do with the structural adaptation of its ribbed shape. This ribbed shape structural adaptation is responsible for the "Cooling Ribs" ${ }^{14}$ concept. Having a folded structure or corrugated skin is not only a more stable structure to support the cactus in a hot dry climate but it also creates the potential for shade to be cast on portions of its surface which improves the ability of the Barrel Cactus to combat heat radiation and therefore cool down the skin. Having a corrugated skin allows the cactus to be partly in shade and partly exposed to the Sun during the day. Based on heat transfer by "convection" ${ }^{15}$, the surfaces exposed to direct solar radiation will increase in temperature faster than the shaded surfaces, and therefore the air near these surfaces with direct solar gain will heat up more quickly and begin to rise. As the hot air is forced to release its water and rise, the cooler heavier air (from the shaded surfaces) is drawn in to take its place. As this constant pattern of hot air rising and cool air being drawn in occurs throughout the day, a slight air current is produced within each of the "Cooling Ribs". This air current can be considered as a Selfventilating system that has evolved over time in the Barrel Cactus. This Self-ventilating system allows the cactus' surface to remain cooler during the day than that of a flat surface species; thus allowing it to preserve its vital water source within. Figure 1.2.3.1 shows the convection behavior on the surface of the Barrel Cactus created by the "Cooling Ribs" effect. 


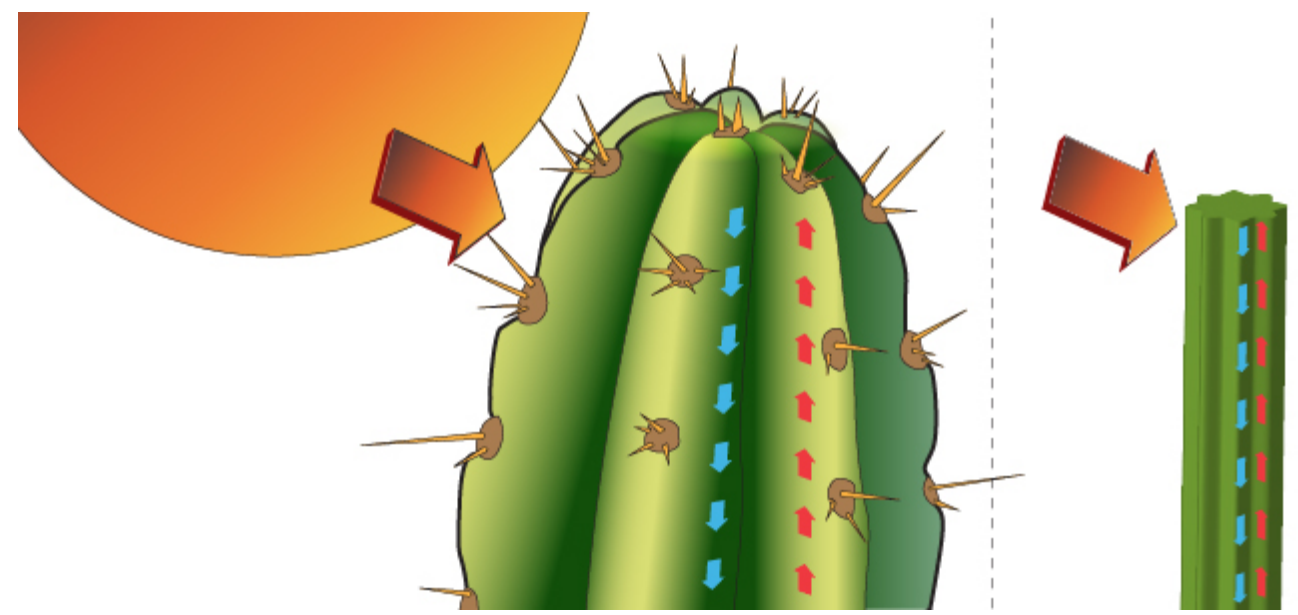

FIGURE 1.2.3.1: MECHANISMS FOR COOLING IN THE BARREL CACTUS ${ }^{16}$

\section{b. Spines}

Spines generally in cacti have many important responsibilities in regards to protecting cacti form water loss. Besides the fact that the spines help keep the cacti safe from predators, the densely spaced spines also create a loose semi-transparent skin which actually helps shade the skin of a cactus. Figure 1.2.3.2 shows how spines reflect and diffuse the direct incident solar radiation.

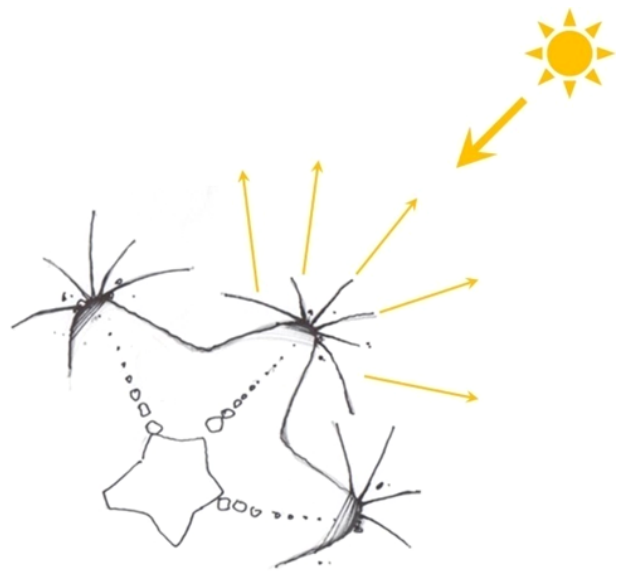

FIGURE 1.2.3.2: SPINES REFLECT THE DIRECT SOLAR RADIATION AND HELP TO SHADE THE SKIN OF A CACTUS 
The long needle shape of the spines also helps the cactus catch the rainwater and direct the water toward the shallow roots of the cactus. These spines are not only able to collect the rainwater, but are also able to collect any water vapor in the air. This is especially interesting considering the previously mentioned example of the "Cooling Ribs." As the hot air releases its water into the air to rise, the water vapor is collected by the spines and is drawn in towards the skin and the cactus' shallow roots; an effective way to bring a useable amount of water to the cactus, as this is a free source of water over the course of the day, all of this water vapor can add up to benefit the cactus in its waterless, desert environment. Figure 1.2.3.3 shows how spines catch the rainwater and water vapor and then direct the trapped water to the surface of the stem and at the end to the roots.

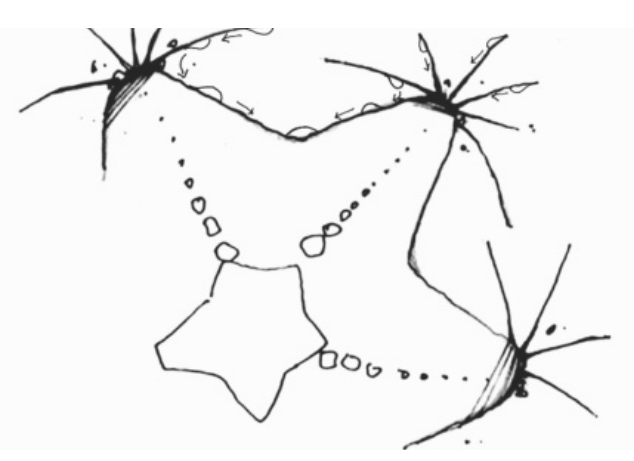

\section{FIGURE 1.2.3.3: SPINES CATCH THE RAINWATER AND EVAPORATION WATER}

The function of the spines catching the rainwater and water vapor adds extra moisture to the "Cooling Ribs" ventilation system in order to decrease the temperature inside the created microclimate area. Another benefit of spines is their ability to trap air and therefore add extra insulation to the skin thickness. 


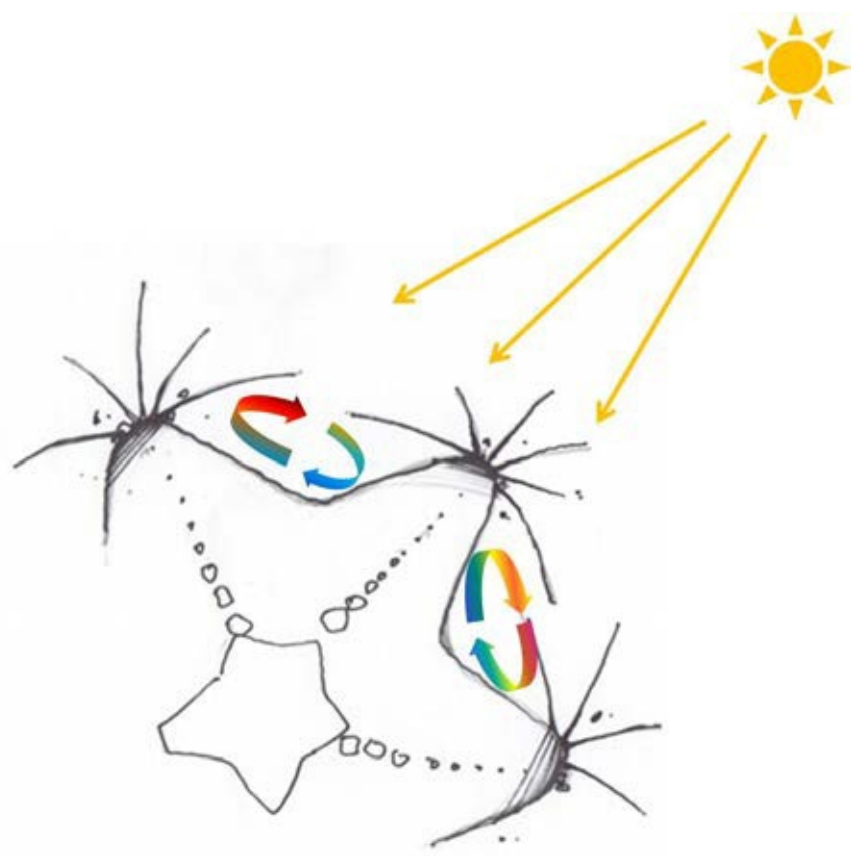

FIGURE 1.2.3.4: SPINES CRETAING A MICRO-CLIAMTE AREA

\subsubsection{Growth Adaptability}

\section{Self-shading Behavior of Barrel Cacti}

Many people mistakenly believe that the common sight of a tipped over Barrel

Cactus is due solely to the cactus falling over from water weight. ${ }^{17}$ Actually, Barrel Cacti appear to be leaning over because they grow based on the path of the Sun, just like any other plant. Water weight is just part of this occurrence. Unlike other plants, however, the Barrel Cactus usually grows towards the south to shade itself (to prevent sunburn), hence the nickname "compass cactus."18

Many plants tend to grow toward the Sun to maximize the collection of solar radiation for photosynthesis. When the Barrel Cactus is exposed directly to the Sun, it may lean toward the south (in the Northern Hemisphere) in order to cast a shadow over the major water storing stem portion of the cactus. By exposing the top part of the cactus toward the Sun, the cactus is able to take advantage of its globe shape, which minimizes 
the effect the solar radiation has on it when compared to a flat surface. This was explained in more detail in section 1.2.1, "Form Adaptability". Figure 1.2.4.1 shows how the Barrel Cactus grows toward the Sun (south in Northern Hemisphere) to shade the considerable surface area of its skin and prevent sunburn.

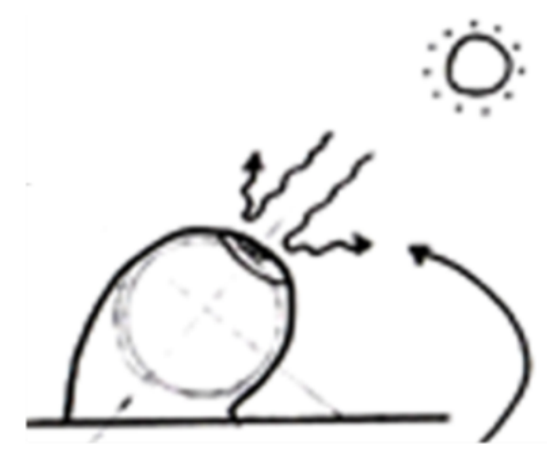

FIGURE 1.2.4.1: CONSISTENT GROWTH ADAPTABILITY OF BARREL CACTI FOR MILLIONS OF YEARS ${ }^{19}$

All species in all climates have evolved based on their surrounding for over millions of years to achieve adaptability with the environment to survive. Hot dry climates provide many stresses that make the survival of the species very hard when compared to the other climates. The major problem in hot dry climate is water preservation due to the lack of precipitation. Once a species such as Barrel Cactus catches and stores the water, it will apply many strategies to preserve it and prevent it from evaporating. These types of strategies can be categorized into two major groups. The first group is a type of adaptation that requires a dynamic mechanism to perform and the second type is the kind of firm adaptable behavior that has been formed over millions of years. The author has referred to the second group as evolutionary adaptation. Although the dynamic adaptation could be as a result of evolutionary adaptation as well, the type of mechanism that makes it happen is dynamic and therefore the period of time that 
dynamic adaptations develop is much less than the period of time that evolutionary adaptation are developed.

Dynamic Adaptation in Barrel Cactus was discussed through "CAM Metabolism". "CAM Metabolism" causes the stomata of the Barrel Cactus to open at night, unlike plants in temperate climates that are open throughout the day. When the stomata are open at night, they create a gas exchange part of the photosynthesis process. The Barrel Cactus performs the rest of the photosynthesis process during the day when the stomata are closed but the Sun is out.

The second type of adaptation is evolutionary adaptations. These adaptations were discussed through four sections: "Form Adaptability", "Material Adaptability", "Structure Adaptability" and "Growth Adaptability".

Form adaptability explains the numbers and the sizes of the Stomata compared to the typical plant having stomata all over their green tissues. Barrel Cacti have relatively few stomata formed with larger cells so there would be less possibility of water /water vapor to leak out. Another type of form adaptability is the Globe Configuration that causes Barrel Cactus skin to be partly exposed to the direct incident solar radiation and the rest of the skin is either in shade or exposed to the indirect solar radiation. Also the exposed surface of the globe form of the skin is consistently changing due to the changeable position of the Sun during the day.

Material adaptability is explained through "Waxy Coating" of the Barrel Cactus skin that increases the reflective factor of the material, and Barrel Cacti high skin thickness that improve the capability of storing water.

Structure adaptability is discussed through "Cooling Ribs" and spines. Both 
components create not only a Self-ventilation system by convection but a cooling system that decreases the temperature of the exterior surface of the Barrel Cactus and therefore minimizes the water loss.

"Growth Adaptability" causes Barrel Cacti to grow toward the Sun (south in Northern Hemisphere) to shade the noticeable surface area of the stem skin to prevent from sunburn. 


\section{CHAPTER 2:}

\section{Analysis of Passive Design Strategies in Yazd, Iran}

\section{Introduction}

There are many passive strategies that have been applied to architectural design for hundreds of years in Yazd, Iran. Yazd can be characterized as a hot dry climate and is considered one the hottest cities in Iran. The combination of the intense solar radiation, high temperature and hot winds have made the lives of the residents hard for years; therefore, to reduce the effects of the environment, local people have applied many strategies (mostly passive) in the design of the buildings. These types of passive strategies may be basic in planning and construction but have brought the residents of the city much more tolerable quality of spaces in terms of air temperature and air ventilation. Many of the builders of the buildings may have not been actual architects but local people who applied the adaptable solutions based on their experiences of living in such a climate. In this chapter, the most considerable passive design strategies of Yazd architecture will be analyzed and discussed in regards to the following three categories: form, material and structure; similar to the analysis categories of the first chapter. Figure 2.1 explains the chapter classification in the three groups of form, material and structural strategies. In the section regarding form, the shape of the exterior skin either on the façade or on the roof will be discussed. In the material section of the chapter the heat capacity and density of the material in terms of thermal mass will be analyzed. Finally, the effects of structural passive strategies in terms of ventilation and/or cooling systems such as "Windcatchers", central courtyard and "Qanat" ${ }^{20}$ System will be explained. 


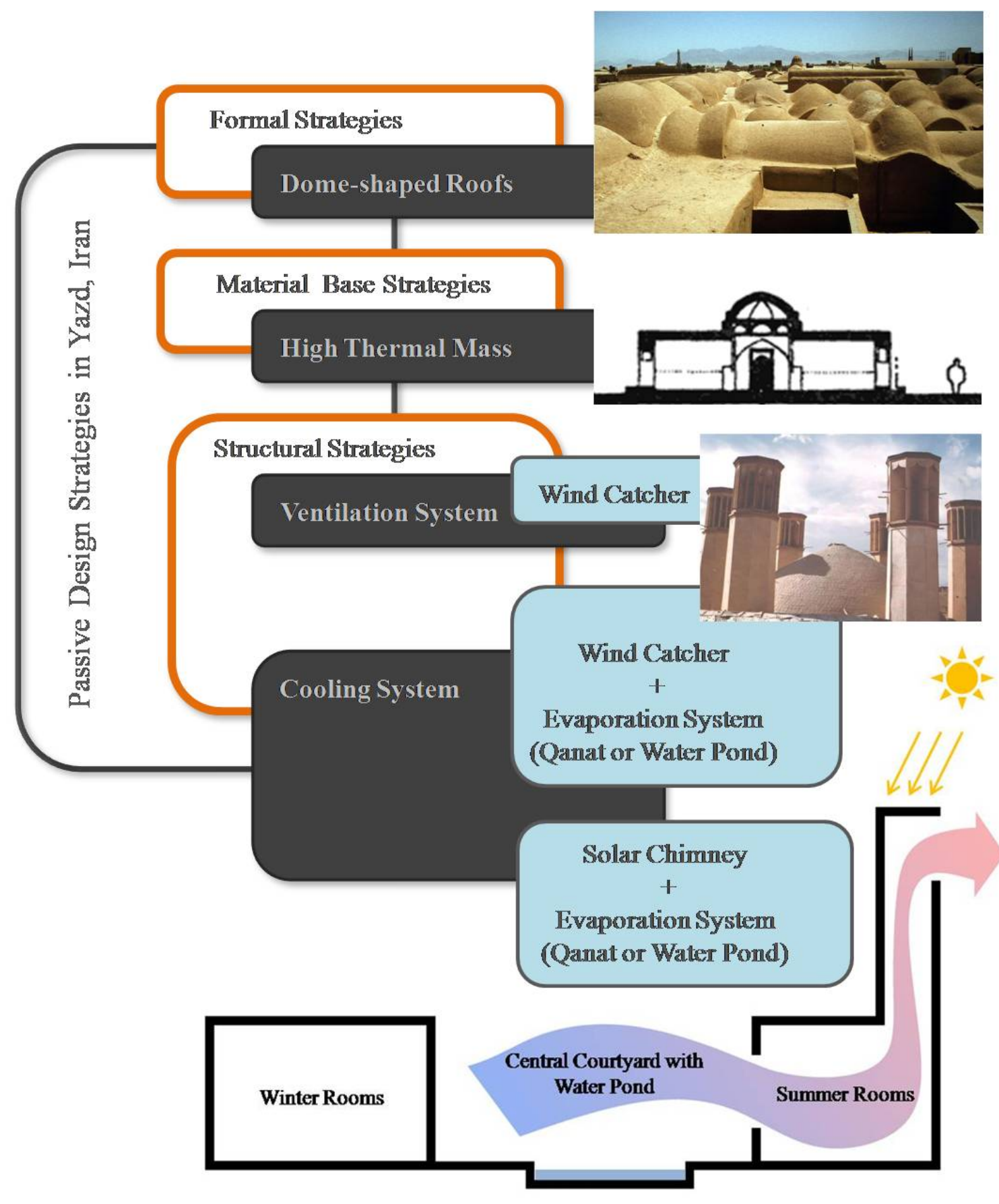

FIGURE 2.1: CHAPTER 2 ANALYSIS DIAGRAM

\section{Yazd, Iran}

Yazd is of foremost importance as a center of Persian architecture. ${ }^{21}$ Because of its climate, it has one of the largest networks of "Qanats". Qanats are water management 
systems used to provide a reliable supply of water for human settlements and irrigation in hot, arid and semi-arid climates ${ }^{22}$ around the world, and Yazdi Qanat makers are considered the most skilled in Iran.

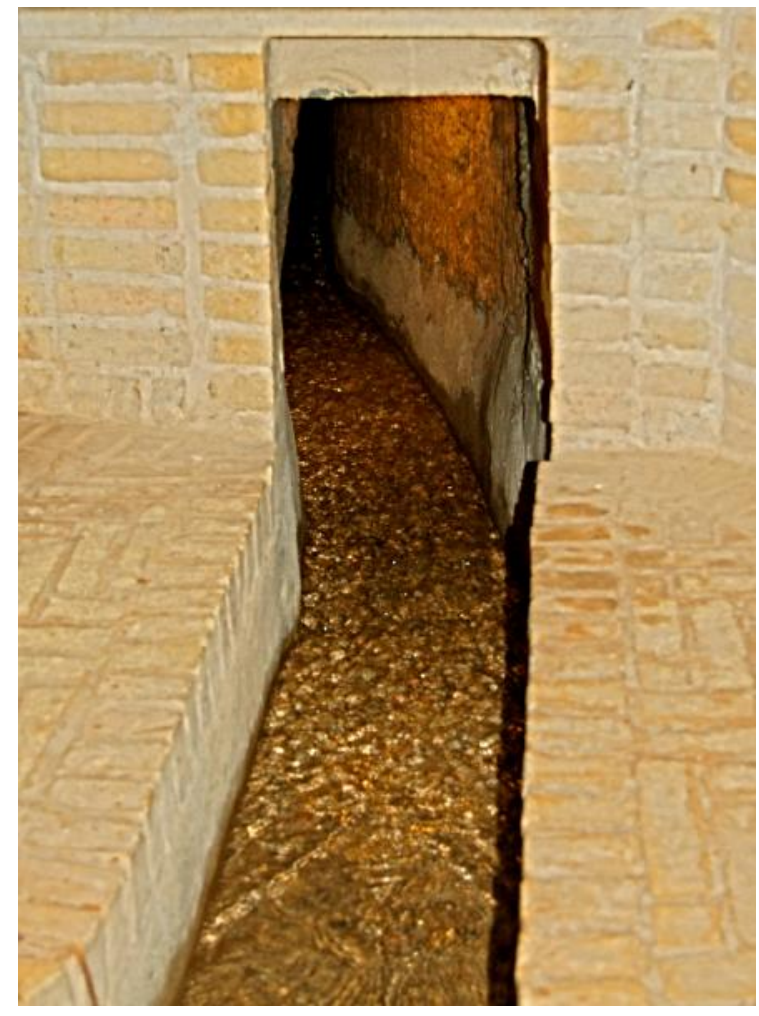

FIGURE 2.2: A "QANAT" CANAL ${ }^{23}$

To deal with the extremely hot summers, many old buildings in Yazd have magnificent "Windcatchers" and large underground areas. Figure 2.3 is a portion of the skyline of Yazd and shows the importance of using "Windcatchers" as part of their architecture.

Yazd is also one of the largest cities built almost entirely out of adobe. ${ }^{24}$ The city is also home to prime examples of "Yakhchal," 25 an ancient type of evaporative cooler above ground. The structure had a domed shape, but had a subterranean storage space; it 
was often used to store ice, but sometimes was used to store food as well. ${ }^{26}$ Figure 2.4 shows one of the old "Yakhchals" in Yazd, Iran.

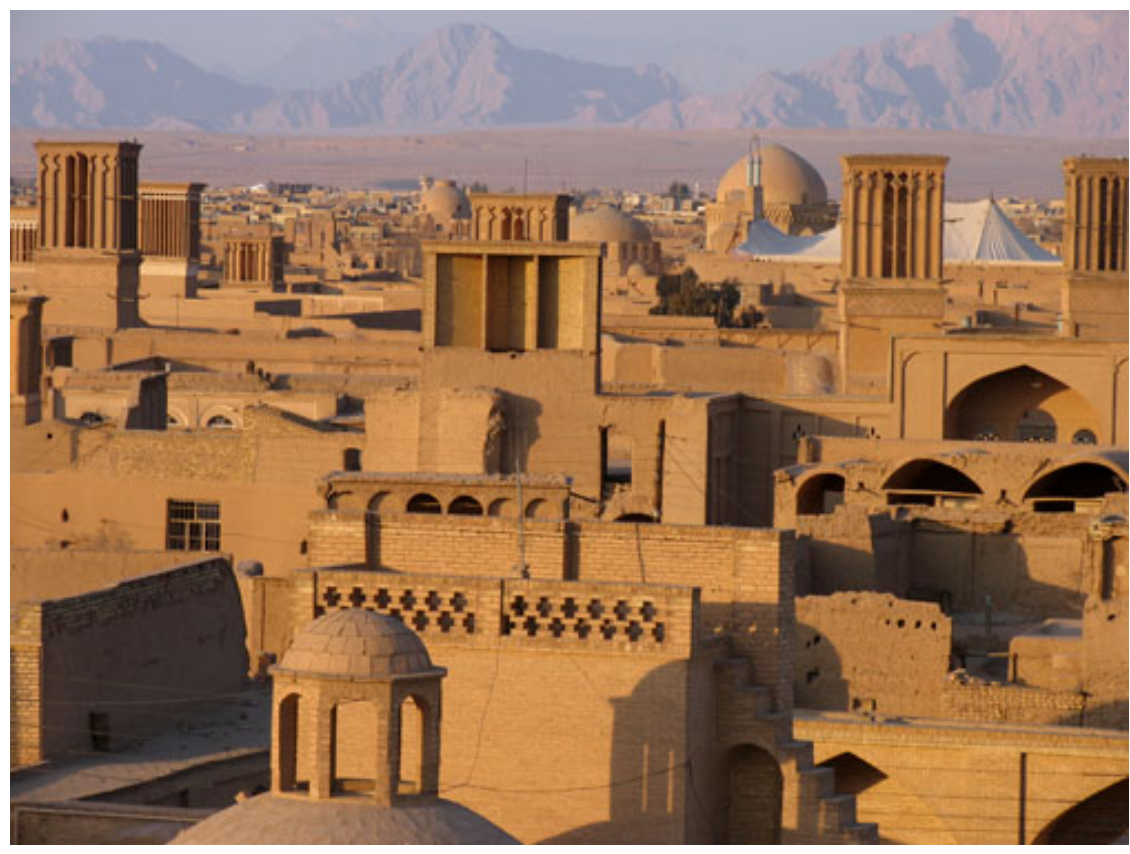

FIGURE 2.3: PORTION OF YAZD SKYLINE ${ }^{27}$

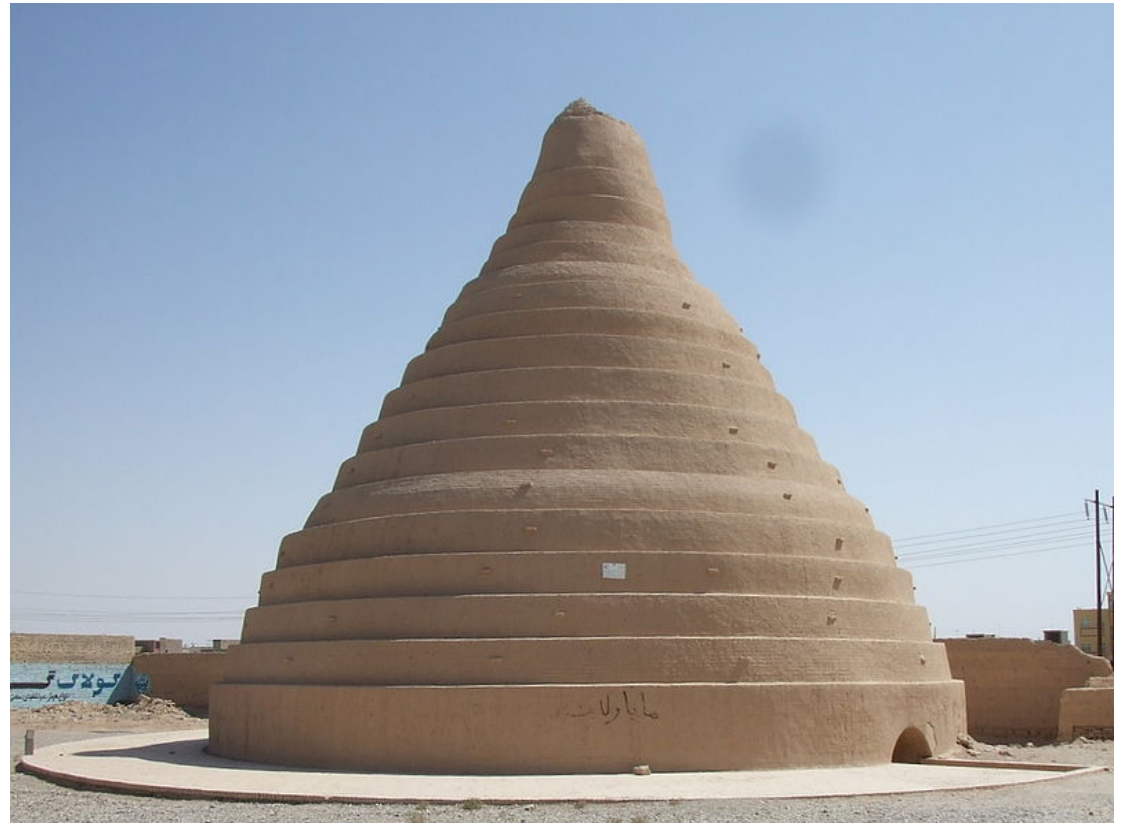

FIGURE 2.4: YAKHCHAL OF YAZD PROVINCE ${ }^{28}$ 


\section{Yazd Climatic Data}

Yazd is the driest major city in Iran, with an average annual rainfall of only 60 millimeters (2.4in). ${ }^{29}$ Summer temperatures in Yazd are very frequently above $40^{\circ} \mathrm{C}$ $\left(104^{\circ} \mathrm{F}\right)$ with intense sunshine with no humidity. Summer night temperatures are also uncomfortable. In the wintertime, during the day temperatures remain mild and even sometimes in the morning the low cloudiness causes very cold temperatures that can sometimes fall well below $0^{\circ} \mathrm{C}\left(32^{\circ} \mathrm{F}\right)$. Figure 2.5 shows the climatic data of Yazd, Iran.

\begin{tabular}{|c|c|c|c|c|c|c|c|c|c|c|c|c|c|}
\hline \multicolumn{14}{|c|}{ Climate data for Yazd } \\
\hline Month & Jan & Feb & Mar & Apr & May & Jun & Jul & Aug & Sep & Oct & Nov & Dec & Year \\
\hline Record high ${ }^{\circ} \mathrm{C}\left({ }^{\circ} \mathrm{F}\right)$ & $\begin{array}{l}27.0 \\
(80.8)\end{array}$ & $\begin{array}{l}28.0 \\
(82.4)\end{array}$ & $\begin{array}{l}32.0 \\
(89.8)\end{array}$ & $\begin{array}{l}37.0 \\
(98.8)\end{array}$ & $\begin{array}{c}41.0 \\
(105.8)\end{array}$ & $\begin{array}{c}44.0 \\
(111.2)\end{array}$ & $\begin{array}{l}45.0 \\
(113)\end{array}$ & $\begin{array}{c}45.6 \\
(114.1)\end{array}$ & $\begin{array}{c}42.0 \\
(107.6)\end{array}$ & $\begin{array}{l}38.0 \\
(98.8)\end{array}$ & $\begin{array}{l}30.0 \\
(86)\end{array}$ & $\begin{array}{l}27.4 \\
(81.3)\end{array}$ & $\begin{array}{c}45.6 \\
(114.1)\end{array}$ \\
\hline Average high ${ }^{\circ} \mathrm{C}\left({ }^{\circ} \mathrm{F}\right)$ & $\begin{array}{l}12.2 \\
(54)\end{array}$ & $\begin{array}{l}14.8 \\
(58.6)\end{array}$ & $\begin{array}{c}19.5 \\
(87.1)\end{array}$ & $\begin{array}{l}21.9 \\
(71.4)\end{array}$ & $\begin{array}{l}33.4 \\
(92.1)\end{array}$ & $\begin{array}{c}38.3 \\
(97.3)\end{array}$ & $\begin{array}{c}39.5 \\
(103.1)\end{array}$ & $\begin{array}{l}36.1 \\
(97)\end{array}$ & $\begin{array}{l}35.3 \\
(95.5)\end{array}$ & $\begin{array}{c}28.5 \\
(79.7)\end{array}$ & $\begin{array}{c}19.3 \\
(88.7)\end{array}$ & $\begin{array}{c}17.0 \\
(82.6)\end{array}$ & $\begin{array}{l}25.98 \\
(78.78)\end{array}$ \\
\hline Daily mean ${ }^{\circ} \mathrm{C}\left({ }^{\circ} \mathrm{F}\right)$ & $\begin{array}{c}5.1 \\
(41.2)\end{array}$ & $\begin{array}{c}8.0 \\
(48.4)\end{array}$ & $\begin{array}{l}13.5 \\
(58.3)\end{array}$ & $\begin{array}{l}19.5 \\
(87.1)\end{array}$ & $\begin{array}{l}25.4 \\
(77.7)\end{array}$ & $\begin{array}{l}30.8 \\
(87.4)\end{array}$ & $\begin{array}{c}32.4 \\
(90.3)\end{array}$ & $\begin{array}{l}30.4 \\
(88.7)\end{array}$ & $\begin{array}{l}28.1 \\
(79)\end{array}$ & $\begin{array}{c}19.5 \\
(87.1)\end{array}$ & $\begin{array}{l}12.1 \\
(53.8)\end{array}$ & $\begin{array}{c}8.8 \\
(44.2)\end{array}$ & $\begin{array}{l}19.13 \\
(88.43)\end{array}$ \\
\hline Average low ${ }^{\circ} \mathrm{C}\left({ }^{\circ} \mathrm{F}\right)$ & $\begin{array}{c}-0.8 \\
(30.6)\end{array}$ & $\begin{array}{c}0.1 \\
(32.2)\end{array}$ & $\begin{array}{c}5.3 \\
(41.5)\end{array}$ & $\begin{array}{c}9.5 \\
(49.1)\end{array}$ & $\begin{array}{l}17.7 \\
(83.9)\end{array}$ & $\begin{array}{l}20.0 \\
(88)\end{array}$ & $\begin{array}{c}23.3 \\
(73.9)\end{array}$ & $\begin{array}{c}19.9 \\
(87.8)\end{array}$ & $\begin{array}{c}18.7 \\
(85.7)\end{array}$ & $\begin{array}{c}8.8 \\
(47.5)\end{array}$ & $\begin{array}{c}2.3 \\
(36.1)\end{array}$ & $\begin{array}{c}-0.7 \\
(30.7)\end{array}$ & $\begin{array}{l}10.33 \\
(50.58)\end{array}$ \\
\hline Record low ${ }^{\circ} \mathrm{C}\left({ }^{\circ} \mathrm{F}\right)$ & $\begin{array}{c}-14 \\
(7)\end{array}$ & $\begin{array}{l}-10.0 \\
(14)\end{array}$ & $\begin{array}{l}-7 \\
(19)\end{array}$ & $\begin{array}{l}0.0 \\
(32)\end{array}$ & $\begin{array}{c}5.6 \\
(42.1)\end{array}$ & $\begin{array}{l}11.0 \\
(51.8)\end{array}$ & $\begin{array}{c}16.0 \\
(80.8)\end{array}$ & $\begin{array}{c}12.0 \\
(53.6)\end{array}$ & $\begin{array}{c}2.0 \\
(35.6)\end{array}$ & $\begin{array}{l}-3.0 \\
(28.6)\end{array}$ & $\begin{array}{l}-10 \\
(14)\end{array}$ & $\begin{array}{l}-16 \\
(3)\end{array}$ & $\begin{array}{l}-16 \\
(3)\end{array}$ \\
\hline Precipitation $\mathrm{mm}$ (inches) & $\begin{array}{c}7.0 \\
(0.278)\end{array}$ & $\begin{array}{c}0.8 \\
(0.031)\end{array}$ & $\begin{array}{c}11.0 \\
(0.433)\end{array}$ & $\begin{array}{c}21.9 \\
(0.862)\end{array}$ & $\begin{array}{c}0.6 \\
(0.024)\end{array}$ & $\begin{array}{c}2.0 \\
(0.079)\end{array}$ & $\begin{array}{l}0.0 \\
(0)\end{array}$ & $\begin{array}{l}0.0 \\
(0)\end{array}$ & $\begin{array}{c}3.0 \\
(0.118)\end{array}$ & $\begin{array}{l}0.0 \\
(0)\end{array}$ & $\begin{array}{c}2.0 \\
(0.079)\end{array}$ & $\begin{array}{l}0.0 \\
(0)\end{array}$ & $\begin{array}{c}48.3 \\
(1.902)\end{array}$ \\
\hline Avg. precipitation days & 1 & 3 & 2 & 11 & 1 & 1 & 1 & 0 & 1 & 0 & 2 & 0 & 23 \\
\hline$\%$ humidity & 53 & 46 & 37 & 33 & 25 & 18 & 17 & 18 & 19 & 27 & 38 & 47 & 31.5 \\
\hline Mean monthly sunshine hours & 181.8 & 203.0 & 207.5 & 230.9 & 293.9 & 334.1 & 340.7 & 335.0 & 313.1 & 278.1 & 217.8 & 193.4 & $3,129.1$ \\
\hline \multicolumn{14}{|c|}{ Source \#1: World Meteorological Organisation to } \\
\hline \multicolumn{14}{|c|}{ Source \#2: NOAA (extremes, mean, sun, humidity, 1961-1990) ${ }^{[3]}$} \\
\hline
\end{tabular}

\section{FIGURE 2.5: YAZD CLIMATIC DATA ${ }^{30}$}

Figure 2.6 shows a three dimensional weekly summary maximum temperature produced in an Autodesk software called Ecotect 2011. The weather data is TMY3 format used by Energy Plus (US government's energy simulation engine) and converted to EPW format on the US Department of Energy's Website. The figure shows that the maximum temperature is roughly bound between the twenty-fourth week and the thirtyeighth week; with the peak in temperature around the twenty-eighth week. The graph has two curves; one curve along the Weeks axis and another one along the Hours axis. The 
curve along the Weeks axis shows the seasonal changes in temperature changing from $10^{\circ} \mathrm{C}\left(50^{\circ} \mathrm{F}\right)$ during the daytime in winter to $+45^{\circ} \mathrm{C}\left(+113^{\circ} \mathrm{F}\right)$ in summer. The curve of the graph along the Hours axis visibly shows the huge daily diurnal changes in temperature, especially in the summertime. While it is $+45^{\circ} \mathrm{C}\left(+113^{\circ} \mathrm{F}\right)$ during the day, at night the temperature may fall down to 15 to $20^{\circ} \mathrm{C}\left(59\right.$ to $\left.68^{\circ} \mathrm{F}\right)$.

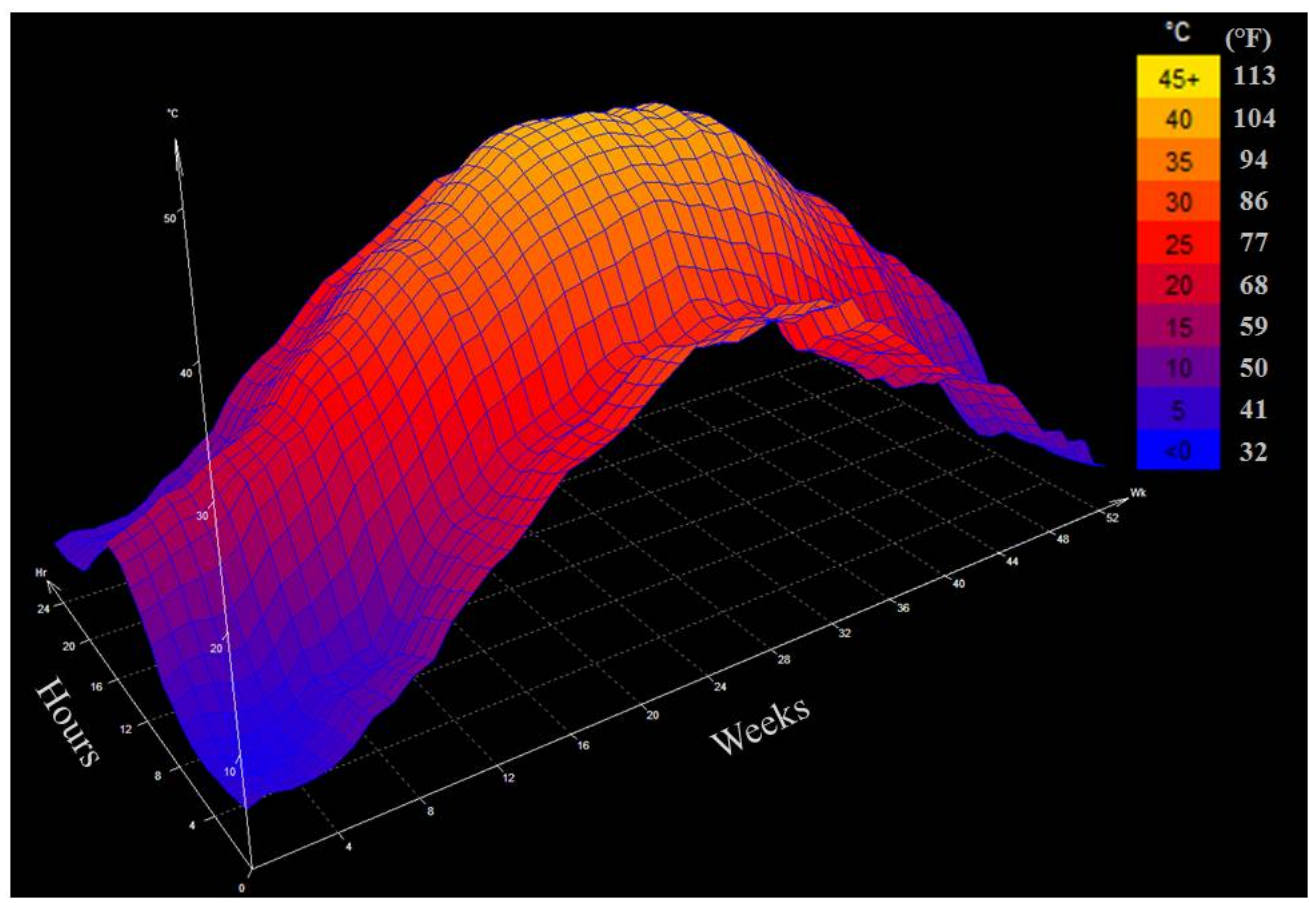

FIGURE 2.6: 3DIMENSIONAL WEEKLY SUMMARY MAXIMUM TEMPERATURE OF YAZD, IRAN AUTODESK ECOTECT 2011

Figure 2.7 shows a three dimensional weekly direct solar radiation graph also analyzed in Ecotect 2011. As shown in the graph, the maximum direct solar radiation begins to occur around the twenty-fourth week with the peak in direct solar radiation around the thirty-eighth week. When compared to Figure 2.6, it is interesting to see that these two figures are somewhat correlated, but the peak intensity occurs at different 
times. Therefore during the summer, not only is the high outdoor temperature a problem, but also when considering trying to collect natural daylight, heat gain and glare caused by intense direct solar radiation also presents itself as being an additional design challenge.

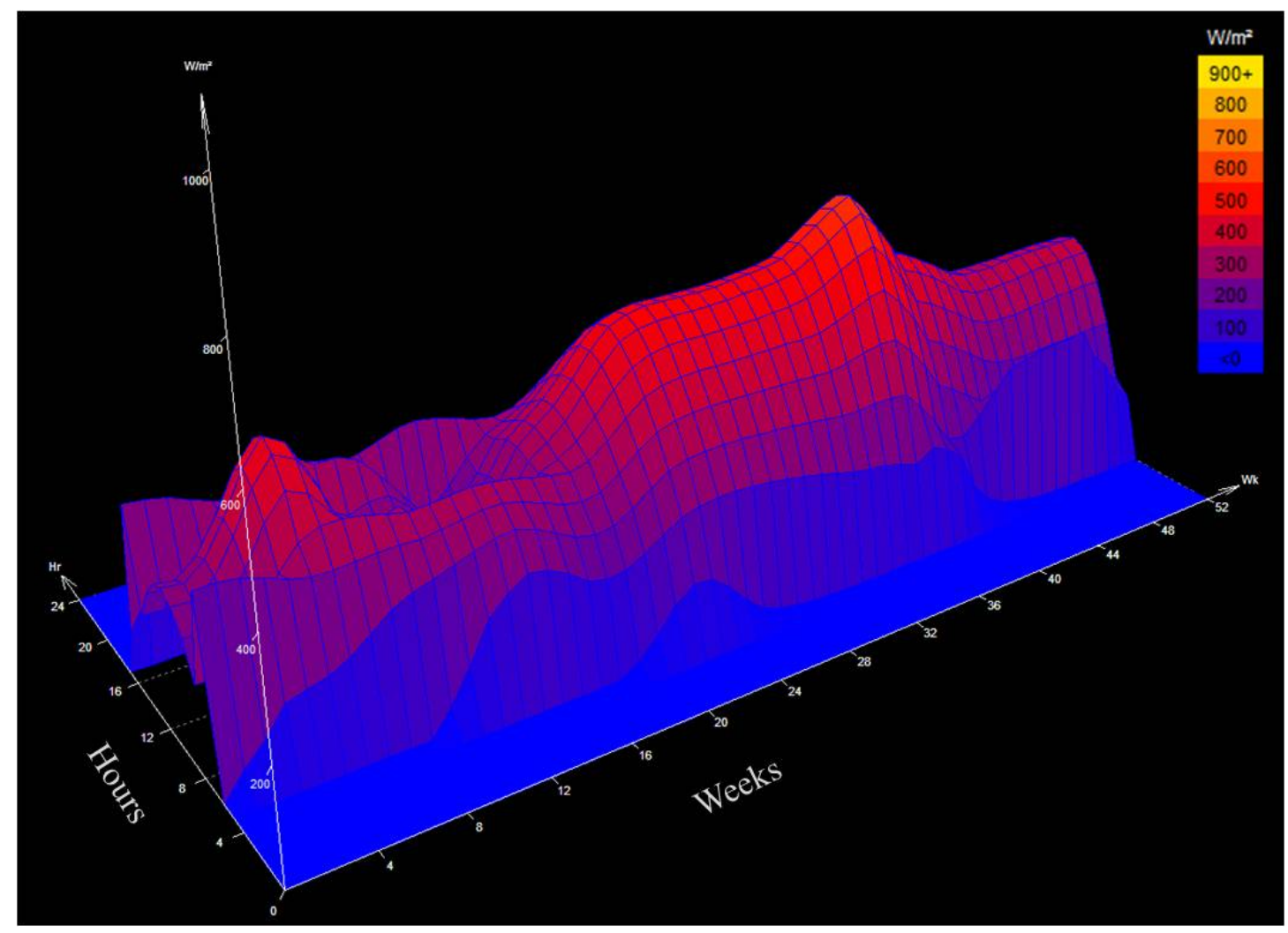

FIGURE 2.7: 3DIMENSIONAL WEEKLY DIRECT SOLAR RADIATION OF YAZD, IRAN AUTODESK ECOTECT 2011

Figure 2.8 shows the total average solar radiation during the year. Based on this analysis, it shows that the month of June has the highest average solar radiation, but when compared to Figure 2.7 which shows the non-averaged peak radiation, the peak appears to occur in August and/or September. Having said that, the plateau between weeks 24 to 30, appear to validate the data presented in Figure 2.8. 


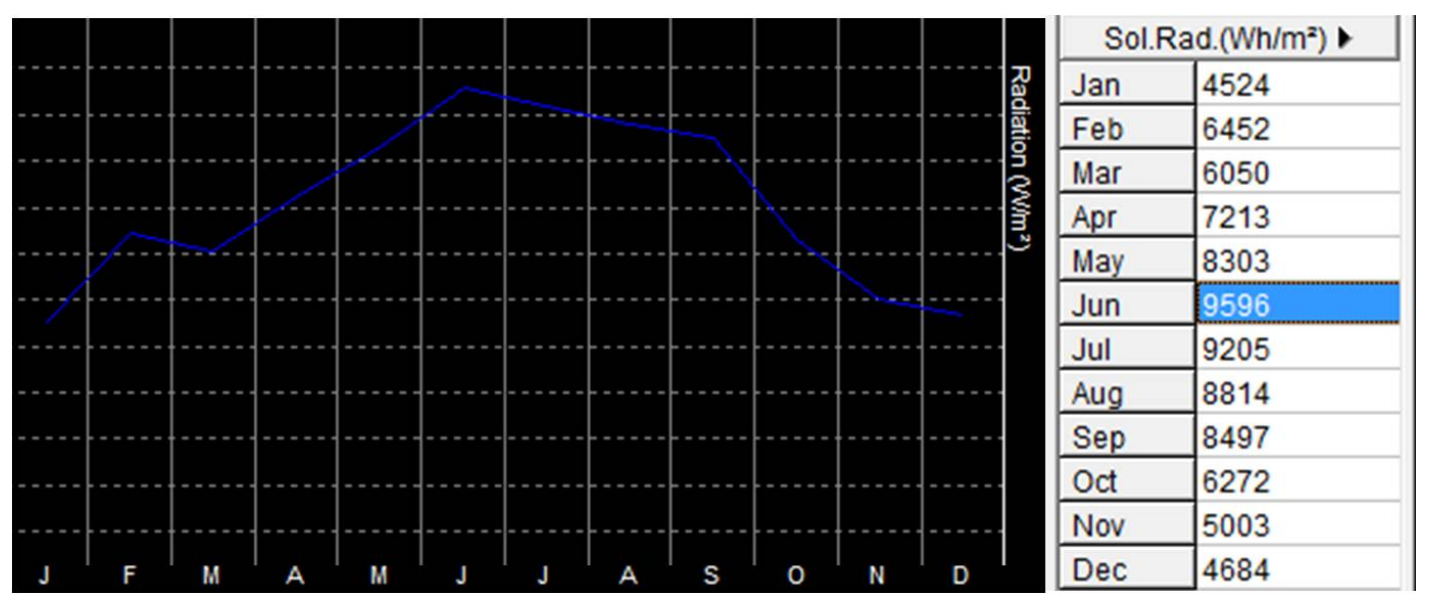

FIGURE 2.8: TOTAL AVERAGE SOLAR RADIATION OF YAZD, IRAN

AUTODESK ECOTECT 2011

\section{Passive Design Strategies in Yazd, Iran}

\subsection{Formal Strategies}

\section{Dome-Shaped Roofs}

There are many form based design strategies applied to the buildings throughout Yazd. In this section, the author will explain one of the most important formal strategies that effects the design of the building skins. From small-scale houses to the large-scale commercial buildings, people have used dome-shaped roofs to reduce the inside temperature. The dome-shaped roofs reduce the exposed surface area to the direct solar radiation especially during the summertime when compared to flat roofs; and therefore this can help to reduce the interior temperature of the building. Figure 2.1.1 is a photo of the roofs of a few buildings in Yazd, showing various scale buildings all utilizing domeshaped roof structures. The reason that domes are a more functional roof surface in hot dry climates rather than flat roofs is not only due to the reduction in surface area exposed to direct solar radiation during the day. Also, due to the fact that using a curved surface 
means that a portion of the roof is always in the shade as the position of the Sun moves throughout the day.

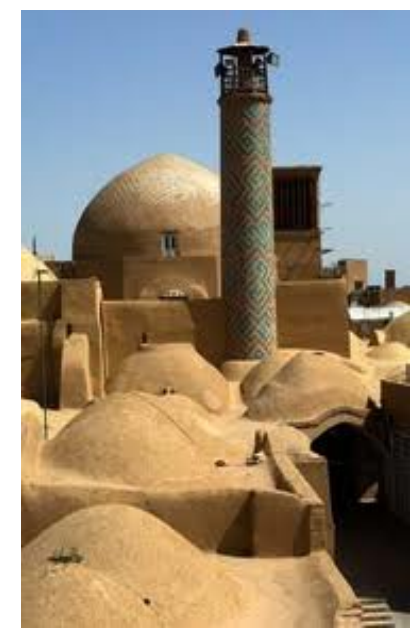

\section{FIGURE 2.1.1: DOME-SHAPED ROOFS YAZD, IRAN ${ }^{31}$}

Figure 2.1.2 is an incident solar radiation analysis of the simple sphere in Yazd, Iran. The analysis shows how spherical configurations are a better solution in order to dynamically decrease the exposed surface area to the solar radiation.

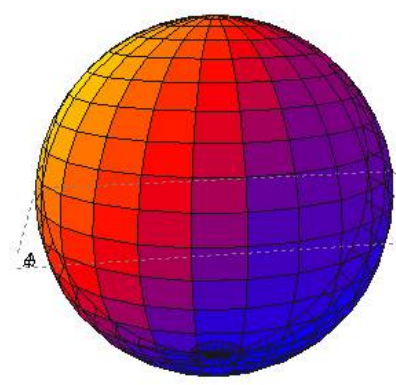

Incident Solar Radiation Analysis Summer Time Yazd, Iran 4:00 pm

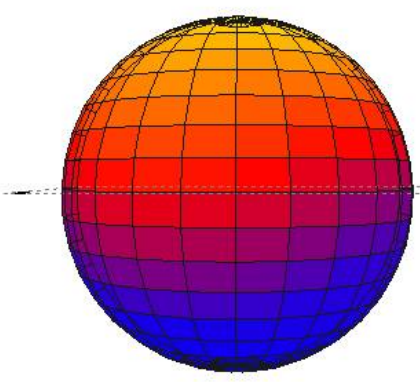

Incident Solar Radiation Analysis Summer Time Yazd, Iran $12: 00 \mathrm{pm}$

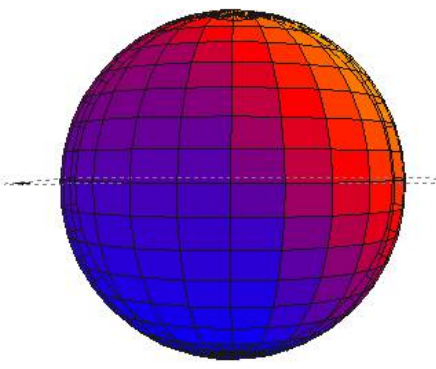

Incident Solar Radiation Analysis Summer Time Yazd, Iran 6:00 am

FIGURE 2.1.2: INCIDENT SOLAR RADIATION ANALYSIS ON A SPHERE YAZD, IRAN

AUTODESK ECOTECT 2011 
The figure shows how the exposed area is dynamically changing throughout the day. Based on this analysis, it is possible to come to the conclusion that the temperature of the dome-shaped roof surface should be much lower than that of a traditional flat or planer surface because there is less surface area exposed to direct incident solar radiation. This should have a positive impact to the internal temperature of the space as well. Curved forms, like arches, have also been applied on the facade system as vertical elements as well. Figure 2.1.3 is a photo of the "Amir Chakmak" ${ }^{32}$ facade system showing how arch-shaped facade elements cast shadows on the facade. The dynamic behavior of roof structures happen here as well which also reduces the temperature of the façade and interior spaces when compared to a flat facade.

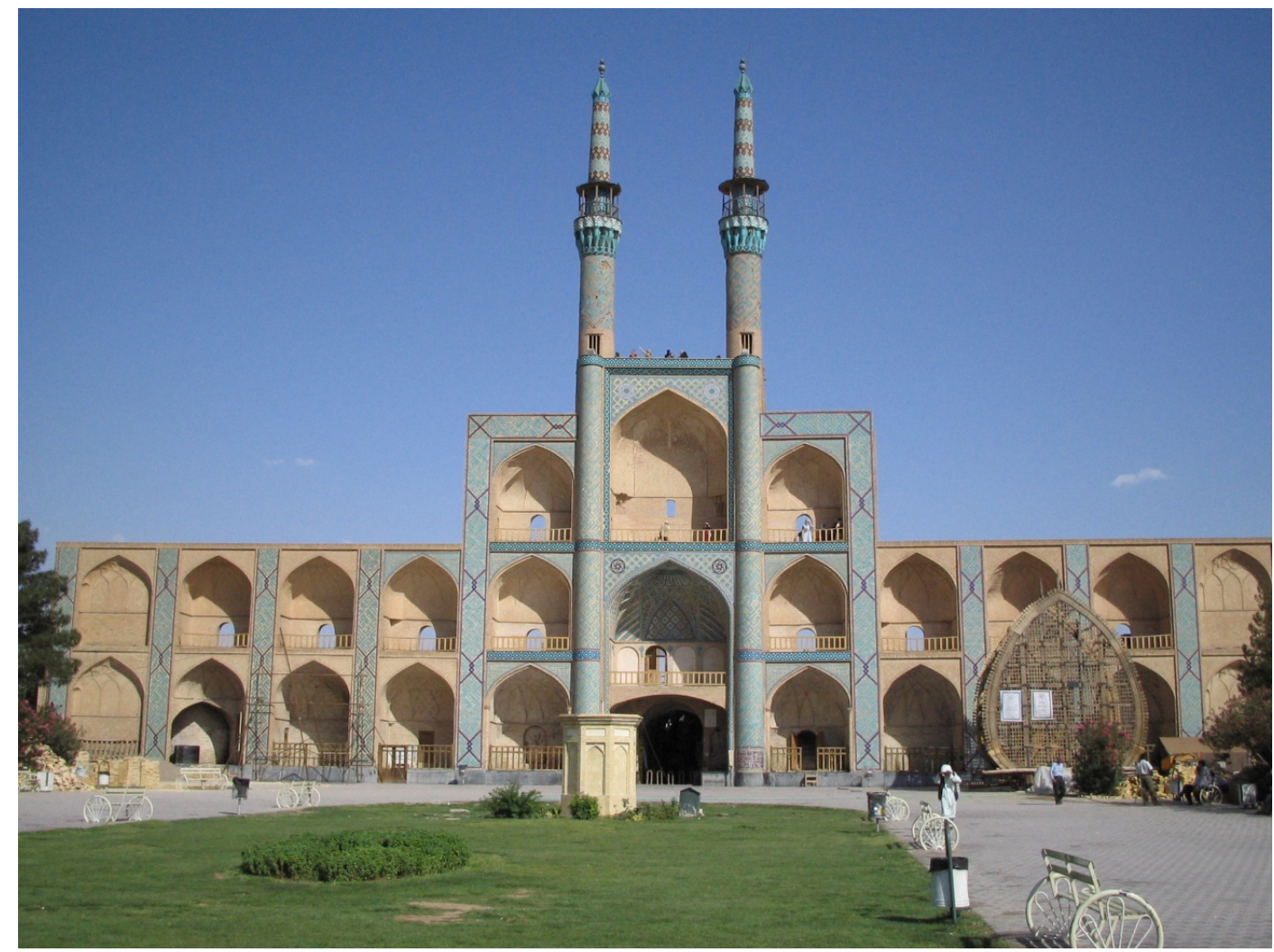

FIGURE 2.1.3: AMIR CHAKMAK MOSQUE FACADE SYSTEM ${ }^{33}$ 


\subsection{Material Base Strategies \\ High Thermal Mass}

One of the most successful material based strategies in the design of building skins in Yazd is the use of high thermal mass. Locally, homes and buildings in Yazd have been built with lots of exterior and interior masses. Heavy external walls help delay the heat transfer from the hot outside climate to the interior spaces; therefore, the rate at which interior air temperature increase is low. The consequence is a slow heating of the building in summer and the maximal inside temperature is reached only during the late hours when the outside air temperature is already low. ${ }^{34}$ Also during a shift in diurnal change, a high mass wall as passive design strategy is actually able to dissipate it's stored heat energy back out into the cool air and absorb the cool temperature and radiate this lower temperature into the interior space of the building. The user is able to further accelerate the night ventilation by opening the building up so the interior spaces are exposed to the cooler air. Thus allowing the high thermal mass to more easily absorb the cool air. By collecting this cool air and trapping it in the building, it helps to regulate the interior temperature during the day as the outside air temperature heats up. Therefore, the most important goal of the high thermal mass structure in hot dry climate is to store heat and release the heat when it is needed and the temperature is low.

Buildings that have a high percentage of insulation in their wall structure can actually have an adverse affect on the temperature of the interior space due to diurnal changes. Using insulation in the exterior and interior building skin may help bring the interior temperature close to the user thermal comfort zone during the hot time of the day; but it may cause an uncomfortable situation by keeping the heat (or cold) out during the 
cool (or hot) part of the day. Having insulation besides the mechanical equipment is an acceptable solution to help the high seasonal changes to provide a consistent temperature for inside the building during the year. Insulating walls with the help of mechanical equipment does help to some degree in regulating the internal temperature of a building, but it is just not as capable or adaptable to dealing with diurnal changes or passive design strategies for that matter like a high mass wall system is. Figure 2.2.1 shows an example of a building with high thermal mass.

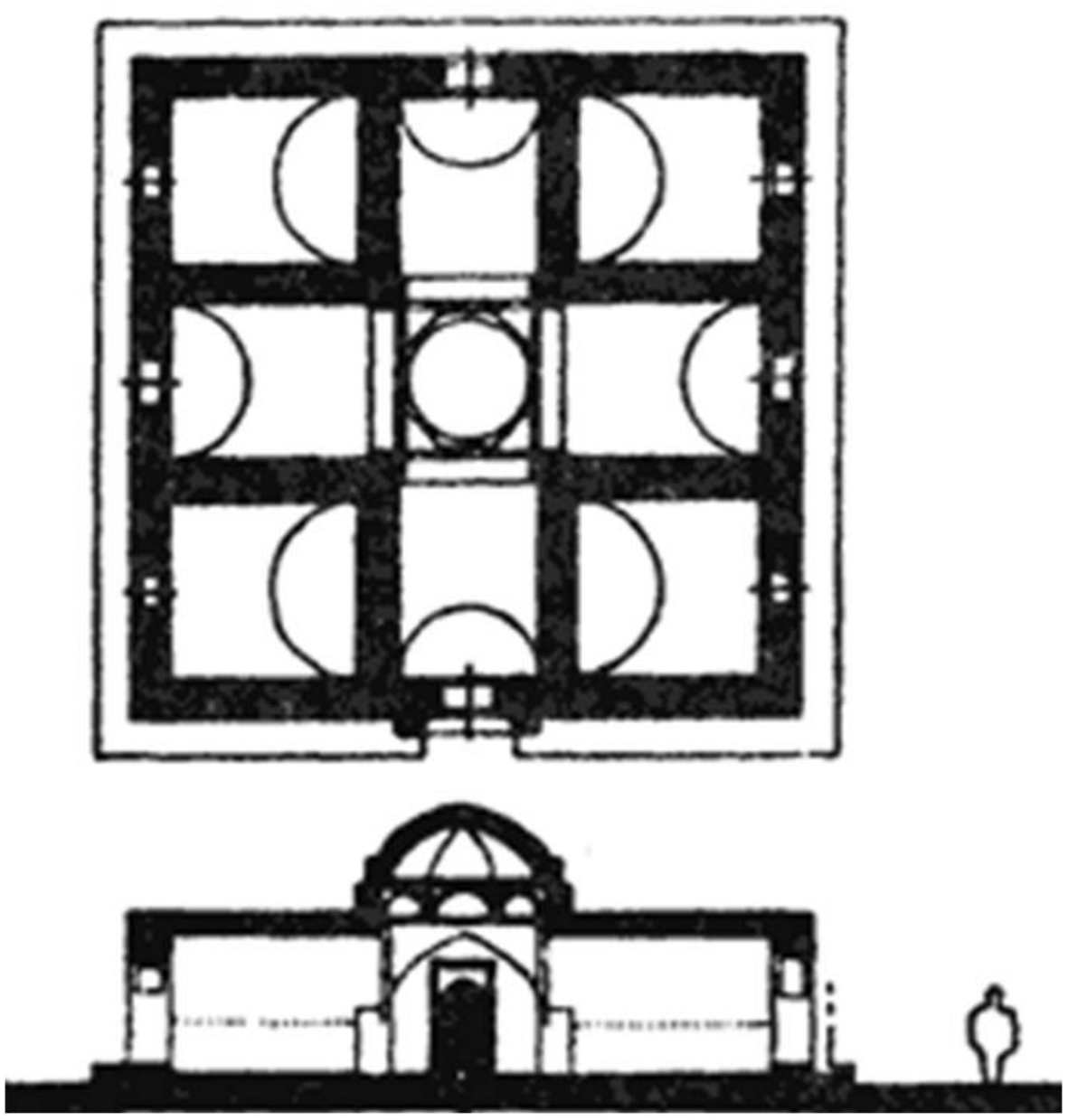

FIGURE 2.2.1: AN OLD BUILDING WITH HIGH THERMAL IN YAZD, IRAN ${ }^{35}$ 


\subsection{Structural Strategies}

\subsubsection{Ventilation System}

\section{"Windcatcher"}

Structural design strategies that have been applied to buildings in Yazd have mainly focused on the design of the ventilation system and/or cooling system that bring the occupants of a hot dry climate acceptable levels of comfort during the intolerable hot time of the day. A significant symbol of the dominant local ventilation system is the "Windcatcher"36.

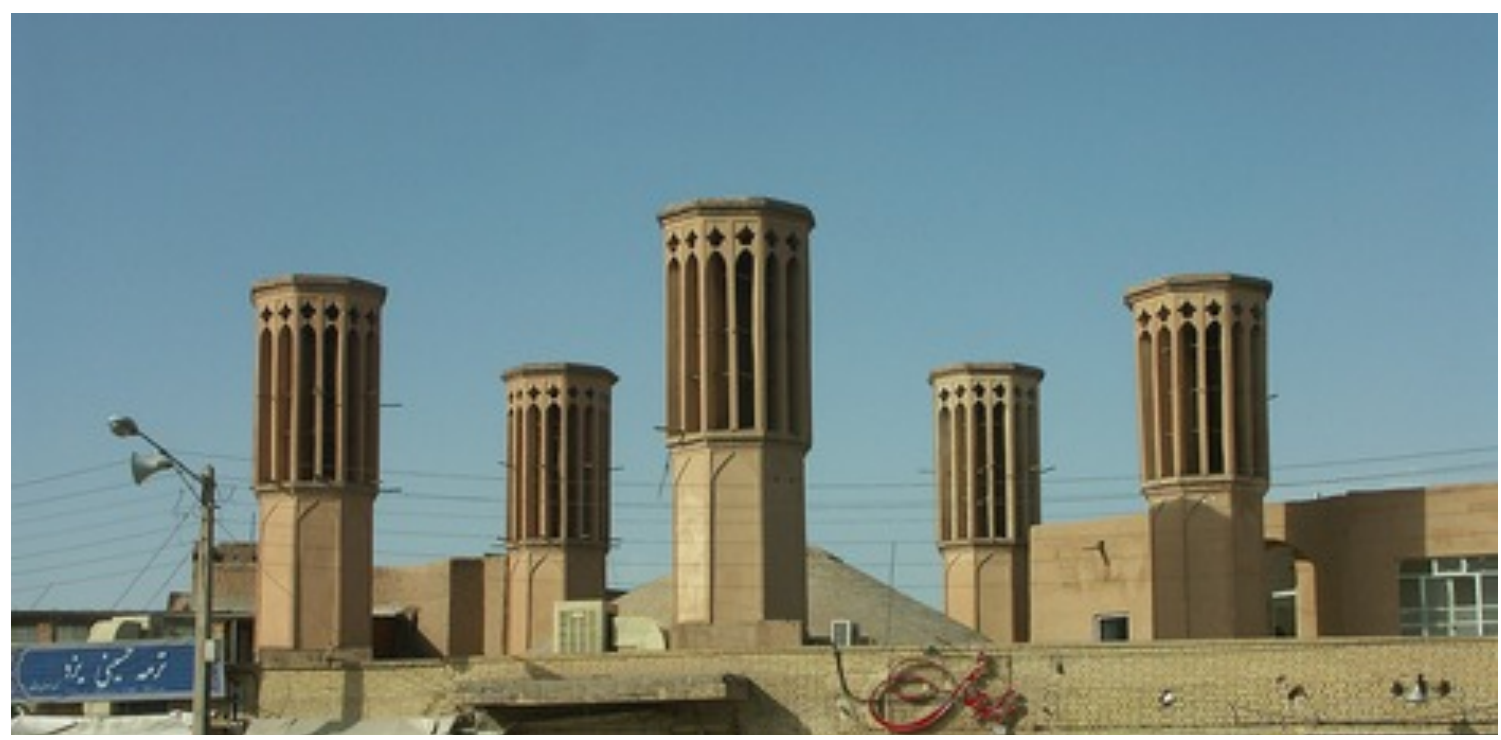

FIGURE 2.3.1.1: OLD "WINDCATCHERS" ("BADGIRS") IN YAZD, IRAN ${ }^{37}$

"Windcatcher is a traditional Persian architectural device used for many centuries to create natural ventilation in buildings ... Windcatchers come in various designs, such as the uni-directional, bi-directional, and multi-directional" ${ }^{38}$

Ventilation or air movement happens based on two reasons; first "pressure differential" ${ }^{39}$ and second "convection". 40 
Tavakolinia in her master thesis mentions that "When wind velocity varies it produces a pressure differential, which causes air movement from a higher air pressure zone to a lower pressure zone. This is based on the Bernoulli theory and it's called "Venturi action," which explains that when the velocity of a moving fluid increases the pressure decreases." ${ }^{41}$

The "Venturi Effect" ${ }^{42}$ is a common physical phenomenon as it is a basic principal of fluid dynamics. This principal of fluid dynamics (a sub-principal of fluid mechanics) accurately describes the behavior of a fluid like substance i.e. air. The basic interpretation of the principal is as follows: The velocity of a fluid increases as the cross sectional area decreases, in order for this to be true, there must also be a corresponding decrease in static pressure. As a fluid passes through a constriction, its velocity must increase to satisfy the "Principle of Continuity"43, while its pressure must decrease to satisfy the "Conservation of Mechanical Energy" principal. ${ }^{44}$

The pressure created when wind pushes against a building, is said to be "positive" air pressure. As the wind wraps around the building it forms pockets of sucking air, or "negative" air pressure, around the remaining sides (and top) of the building. This negative air pressure can be very useful if captured correctly, as it is capable of pulling large quantities of air through a space. To get a better conceptual understanding of the "Venturi Effect", please consider following along with figure 2.3.1.2:

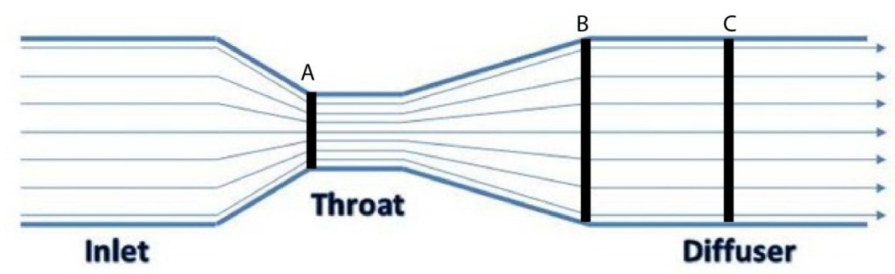

FIGURE 2.3.1.2: VENTURI EFFECT 
Imagine that at line $\mathrm{C}$ there is a plunger that is being drawn back (away from $\mathrm{B}$ in the direction of the arrows) creating a pulling force or negative pressure. The volume of air that exists between $\mathrm{B}$ and $\mathrm{C}$ will soon be removed from the region between $\mathrm{B}$ and $\mathrm{C}$ and due to the principle of continuity will need to be continuously replaced with the same volume that it is being removed. In order to do so, the air must pass from the inlet through the "Throat" ${ }^{45}$ to replenish the volume between B and C. Due to the fact that this larger volume needs to be replaced and that this large volume must pass through a constricted opening (Line A), the "Venturi Effect" implies that the velocity of the air will need to rapidly increase (accelerate) through the "Throat" (constriction) to replace the fleeing volume.

Now imagine that the Inlet is the outdoor environment, and Line A is a smaller opening/window to the building or ventilation duct. Line B is a larger opening or window on the opposite side of the building or ventilation duct. Line $\mathrm{C}$ is not a plunger, but is a pocket of negative air pressure that is formed on the leeward side of the building/ ventilation duct. The negative pressure draws the air through the "throat" at a rapid pace and accelerates the ventilation process by creating greater air flow and a better cooling effect overall.

A "Windcatcher" applies the same Venturi principal to create an airflow in the interior space. Figure 2.3.1.3 and 2.3.1.4 shows how the single-sided (uni-directional) and double-sided (bi-directional) "Windcatchers" are capable of creating an airflow inside the building based on the "Venturi Effect". This would also be true if the airflow was going in the opposite direction. 


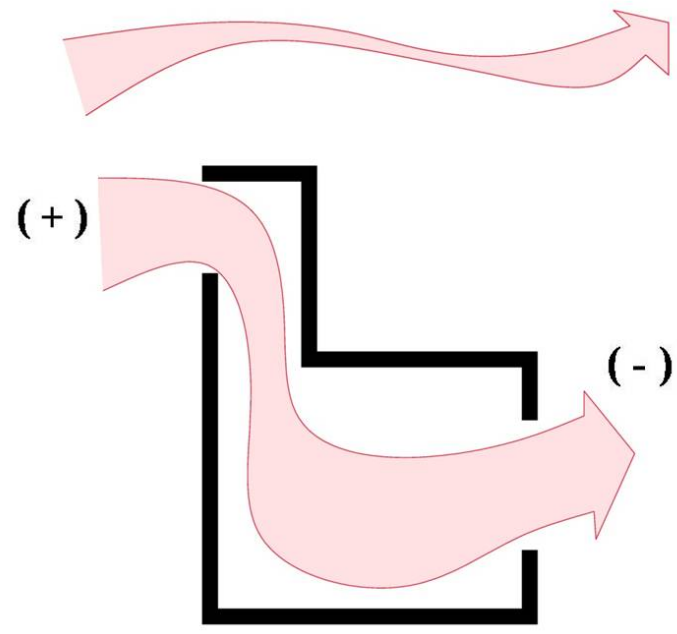

FIGURE 2.3.1.3: BUILDING SECTION SHOWING A UNI-DIRECTIONAL "WINDCATCHER" MECHANISM BASED ON THE VENTURI EFFECT

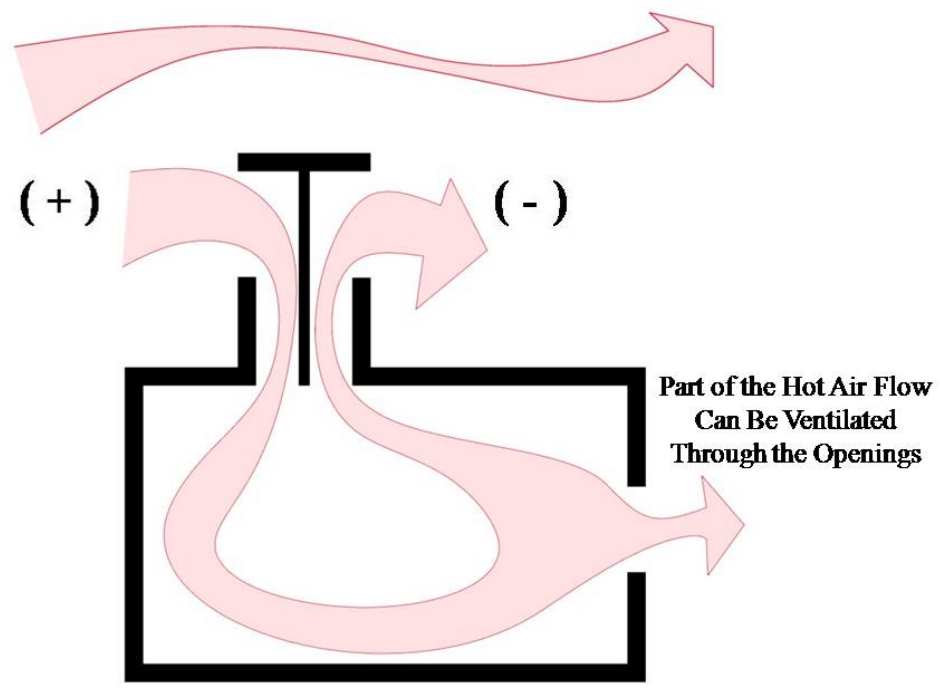

FIGURE 2.3.1.4: BUILDING SECTION SHOWING A BI-DIRECTIONAL "WINDCATCHER" MECHANISM BASED ON THE VENTURI EFFECT

\subsubsection{Cooling System}

\section{a. "Windcatcher" + Evaporation System ("Qanat" or Water Pond)}

In Yazd the wind is hot therefore included interior airflow that might help to ventilate the air trapped inside the building may create the hot airflow that may not lower 
the indoor temperature. Therefore, this type of the "Windcatchers" may only work for the hot humid climates while the airflow brought into the space already has moisture into it so the ventilation helps the space to cool down. In order to create a "Windcatcher" that is successful in a hot dry climate, people in Yazd have used architectural strategies such as "Qanat" (a water management system used to provide a reliable supply of water for human settlements and irrigation in hot, arid and semi-arid climates) and central courtyard as an evaporative system to not only ventilate the spaces with local wind but also cool the temperature down by adding moisture to the airflow. Figure 2.3.2.1 shows a single-sided (uni-directional) "Windcatcher" combined with the "Qanat" system creating a practical natural cooling system for the building.

As shown in the figure, the inlet of the airflow is further away from the building instead of being on one side of the "Windcatcher". That way, the hot air is drawn into the underground channel that is connected to the "Qanat" system with cold water and by passing the hot air over the cool water flow the converted cool air would be drawn into the building and pulled out by the "Venturi Effect" from the leeward side of the "Windcatcher". Figure 2.3.2.2 shows another possible "Venturi Effect" and "Qanat" cooling system. In this figure the "Windcatcher" is double-sided (bi-directional) and therefore the inlet and outlet of the air flow would both be designed on the sides of the "Windcatcher". 


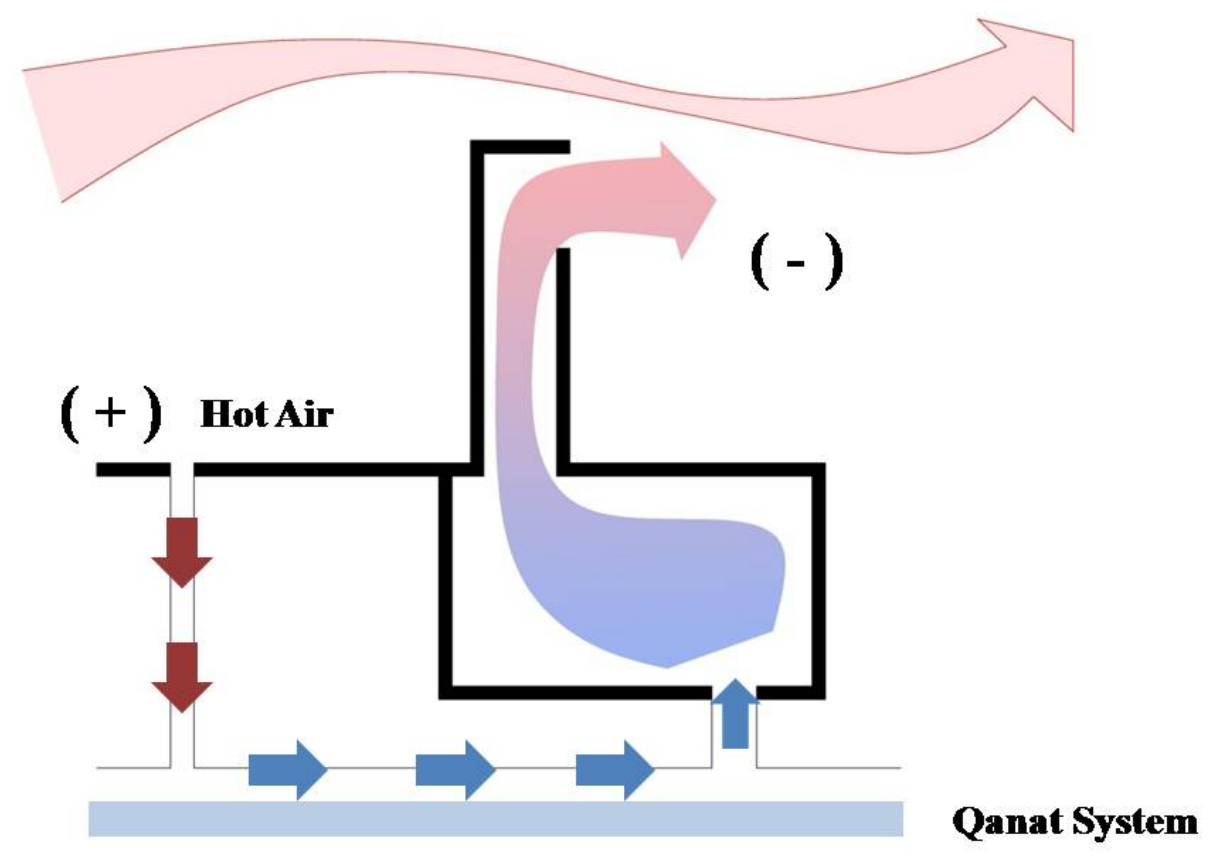

FIGURE 2.3.2.1: BUILDING SECTION SHOWING A UNI-DIRECTIONAL "WINDCATCHER" MECHANISM COMBINED WITH "QANAT COOLING SYSTEM"

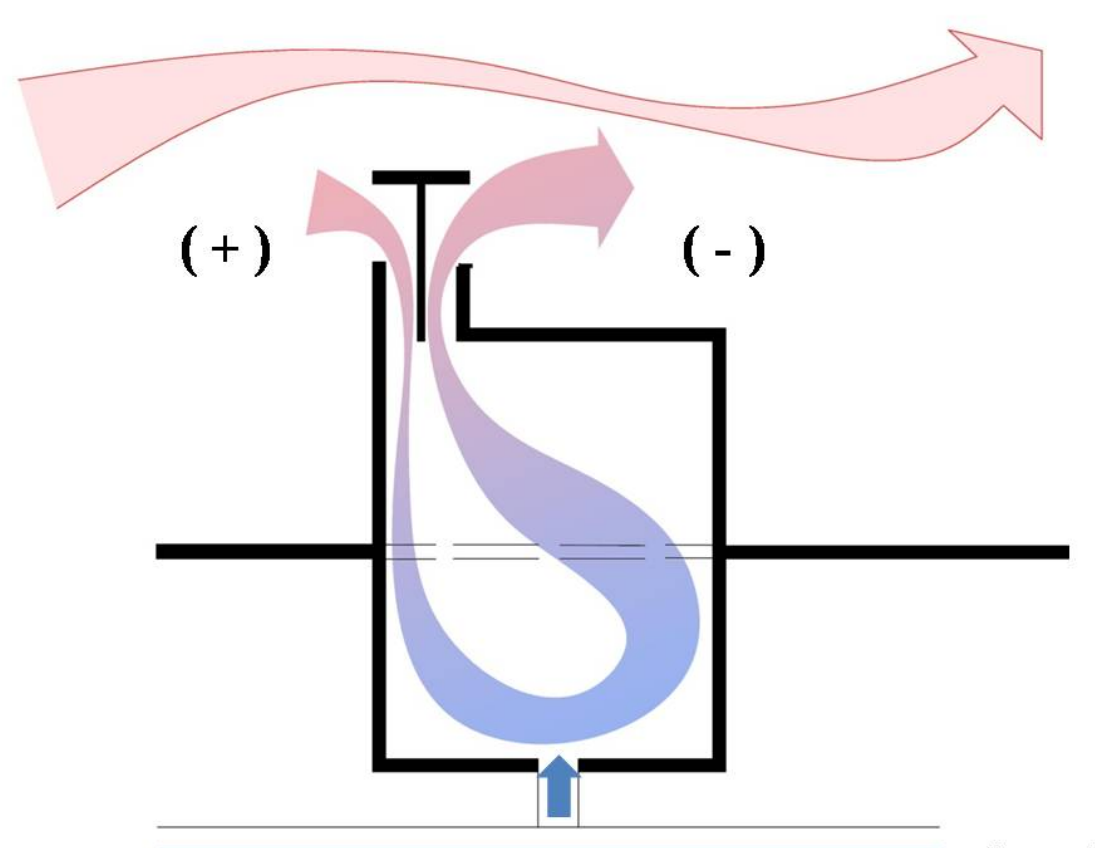

Qanat System

FIGURE 2.3.2.2: BUILDING SECTION SHOWING A BI-DIRECTIONAL "WINDCATCHER" MECHANISM COMBINED WITH "QANAT COOLING SYSTEM" 
As shown in the last figures the interior space that the airflow is created in is usually in an underground room. This underground room is typically used when the temperature outside is extremely hot and the above ground interior spaces have become uncomfortable due to the outside air temperature. Although occupants of Yazd city have created summer rooms and winter rooms based on direction of the solar radiation, the underground rooms are usually used during the hottest afternoons in summer when the temperature inside the summer rooms on the ground floor is too hot to tolerate. By creating a water reservoir or water pond connected to the "Qanat" system, the underground room will remain a more moderate temperature as the air is drawn over the water, which cools off the temperature of the air and releases moisture into the air as well. The microclimate created in the underground rooms can be shared with the above ground rooms if they are designed to receive the airflow as shown in Figures 2.3.2.1 and 2.3.2.2.

\section{b. "Solar Chimney" + Evaporation System ("Qanat" or Water Pond)}

The second type of air movement that will be studied is air movements by convection. Heat is transmitted by convection in fluids and gases, which creates air circulation. Warm air has a lower density when compared to cool air and therefore as the temperature of the air begins to heat up and lose its moisture content (density), the air begins to rise. As the hot air rises, cool air is drawn in to take its place. The rising of hot air and the drawing in of cool air creates an air movement that is called the Stack Effector "Chimney effect"46. "Windcatchers" work when there is a wind to create the "Venturi Effect". When there is no wind present, the "Windcatcher" structure can perform as a 
"Solar Chimney "47 ventilation system. The mechanism of "Solar Chimney " is shown in the figure 2.3.2.3 Sun hits the top part of the Solar Chimney, heats up the air causing it to rise and pull in the cool air. The cool air can be created by the evaporation system such as water pond. In Yazd the "Solar Chimney " system has been combined with the central courtyard strategy to create natural Stack ventilation in order to help cool down interior spaces.

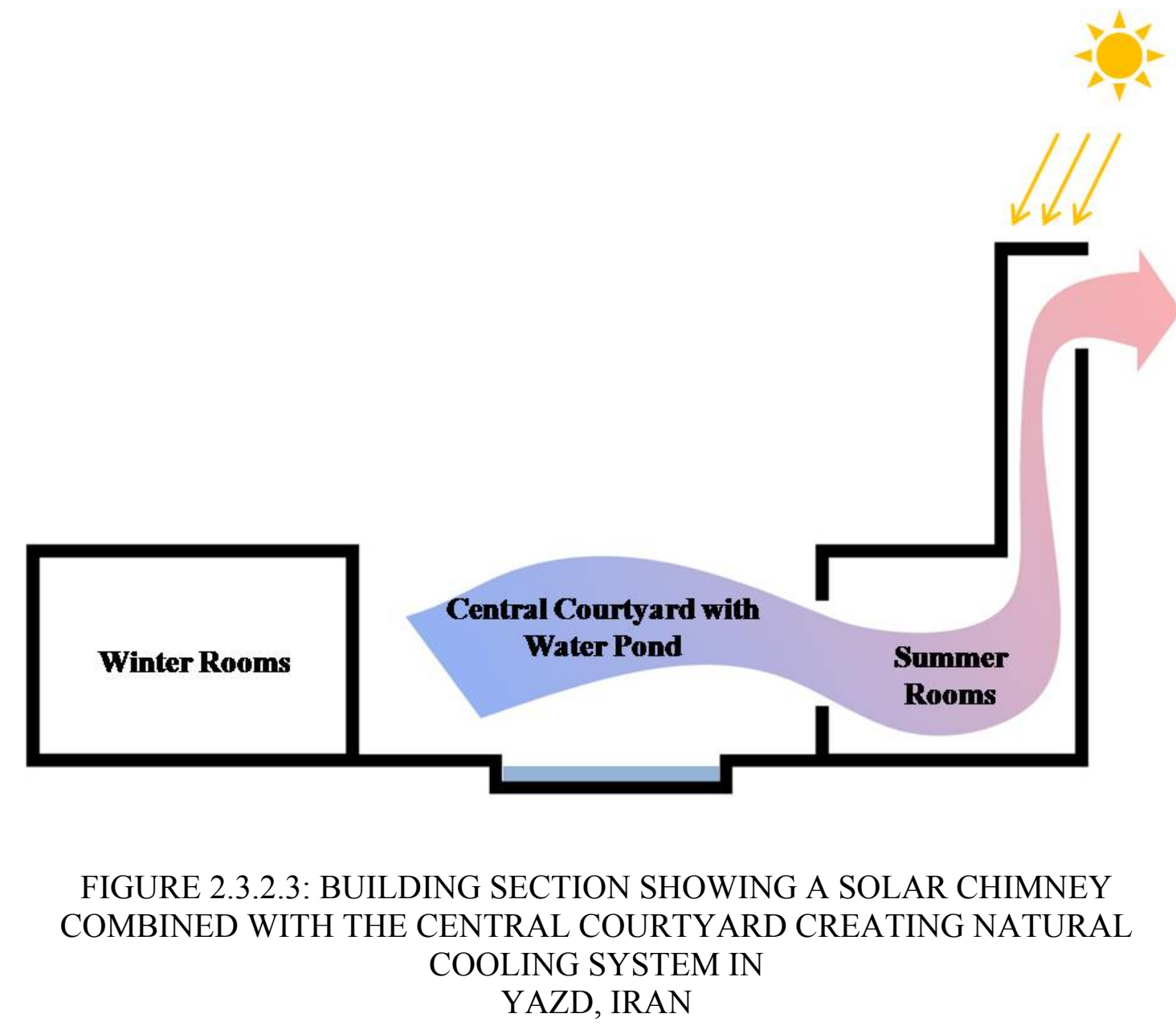

Both types of air movement mechanisms, pressure differential and convection, have been applied as structural passive strategies. They not only create a natural ventilation system, but also when combined with an evaporation system can create a 
natural cooling system as well. Although the core of the natural ventilation strategy in Yazd is the "Windcatcher" system, when combined with the "Qanat" system or a central courtyard pond, these two strategies create a useable airflow to help regulate the temperature of the interior spaces. "Windcatchers", "Qanat" cooling system and central courtyards combined with the other types of architectural passive strategies mentioned previously, such as: thermal mass and domed configuration of the building bring the possibility of design comfortable spaces in a climate that regularly achieves temperatures above $110^{\circ} \mathrm{F}$. In this chapter the author may not have gone into great lengths to explain all the details of the formal, material and structural strategies presented, but instead chose to cover the basics and allude to that fact that these strategies are complimentary and can be combined together. What is important is that these basic passive design strategies have been proven to work in providing the local building users with a level of thermal comfort necessary for everyday life without the need or help from major energy consuming mechanical systems or elaborate dynamic components. 


\section{CHAPTER 3:}

\section{Adaptation in Barrel Cactus vs. Architectural Design Strategies in Yazd, Iran Introduction}

Evolutionary adaptations in Barrel Cactus have more potential to be translated as passive design strategies rather than active strategies. Over millions of years natural species have adapted solutions to decrease the effects of environmental changes and stresses. These types of solutions are usually expressed in their form, structure or material of the species which have taken form over millions of years and are behaving as selfsupporting systems to overcome environmental stresses. Passive design strategies in architecture are also introducing self-supporting system in design as well. While active strategies need maintenance and advanced dynamic technology to be performed, passive strategies are self-supporting systems, which might not need any advanced technology to maintain their performance throughout the year but instead require a more thoughtful design from the architect and engineer. If a passive design strategy would be successful, either in form, structure or material-base strategies, then the architectural design would affect the building and its users rather than having to rely on active technological strategies to affect the building. Hence, self-supporting systems introduced in the form of evolutionary adaptation are capable of being translated into passive architectural strategies influenced by the environmental effects. Figure 3.1 begins to explain the relationship of how adaptations in nature can inspire design strategies in Architecture. 


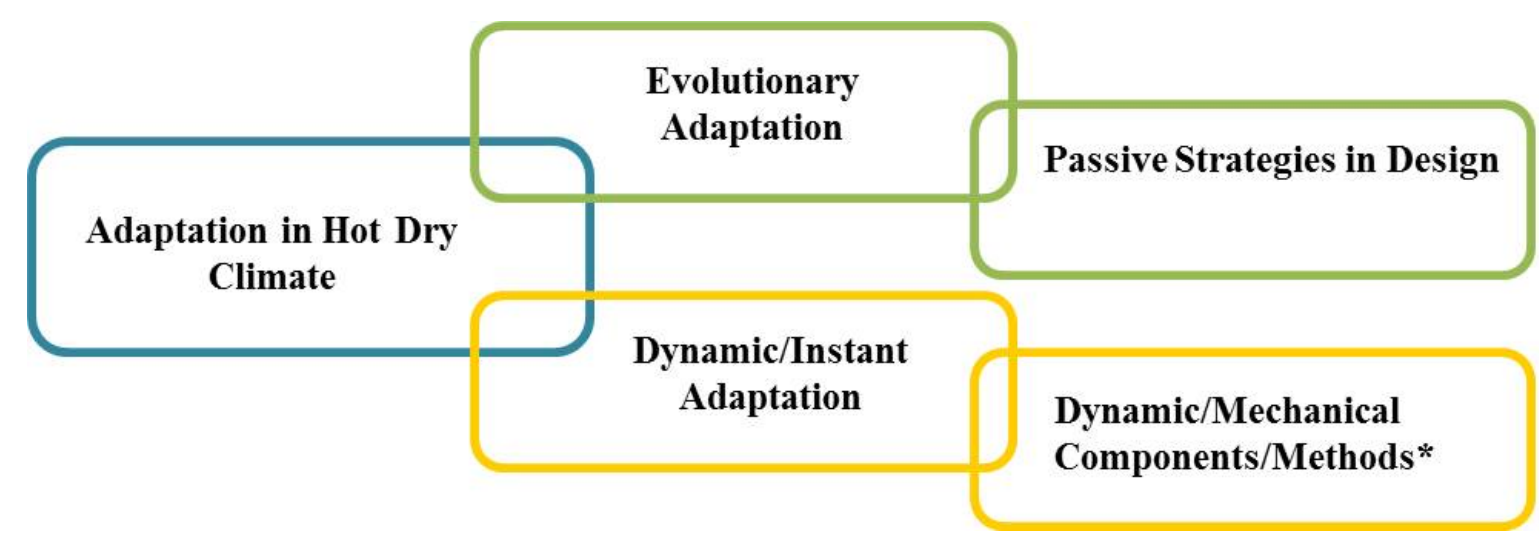

\section{FIGURE 3.1: THE RELATIONSHIP BETWEEN ADAPTATION IN NATURE AND DESIGN STRATEGIES IN ARCHITECTURE}

*Active Strategies from the author's point of view in this chapter are not necessarily harvesting solar energy or any other similar technology but rather, it refers to any strategy that requires dynamic action such as opening or closing of windows. For example, although a Windcatcher has an implied dynamic function due to its interactions with the wind; but because it's role in creating a non-mechanical ventilation/cooling system it is considered as a passive strategy. On the other hand, night ventilation which could be also a passive strategy is considered an active/dynamic strategy in this chapter because in order for it to work correctly, it requires a mechanism or dynamic action such as manual/automatic opening and closing of the windows.

Local people and architects in Yazd have applied many passive and active strategies to cool down their buildings during the hottest time of the year with the goal to bring thermal comfort to the occupants of hot dry climate. They might or might not have looked to nature for design inspiration but what is noticeable is that many of these architectural solutions are capable of being compared with long-term evolutionary solutions of the Barrel Cactus. In order to get some ideas about biomimicry the author 
compared and analyzed some architectural solutions in Yazd with adaptations in Barrel Cactus. That way we can have a better understanding of how it is possible to mimic the behavior of a natural species either through analyzing its form or structural design in order to enhance the user's comfort in terms of temperature, humidity, airflow and daylight.

\subsection{Dynamic Adaptability in Barrel Cacti vs. Dynamic Strategy in Traditional}

\section{Architecture of Yazd, Iran}

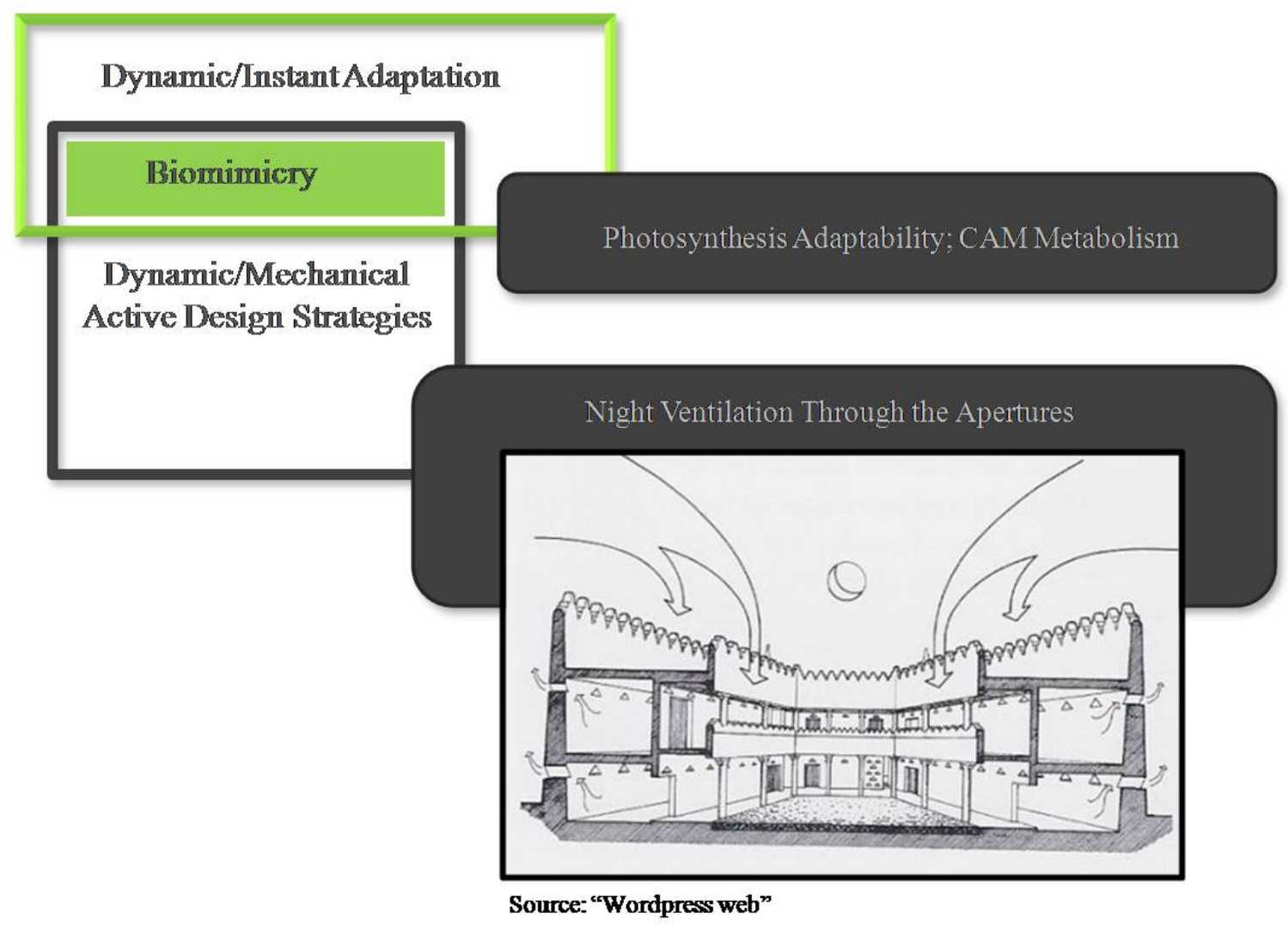

FIGURE 3.1.1: DYNAMIC ADAPTABILITY IN BARREL CACTI VS. DYNAMIC STRATEGY IN TRADITIONAL ARCHITECTURE OF YAZD, IRAN 
As mentioned before, cacti open their stomata at night to breath, storing the carbon dioxide for later use when daylight appears. Once daylight appears, the cactus closes its stomata and used the carbon dioxide stored as malic acid for use in photosynthesis. By only opening their stomata in the cool of night, far less water is lost.

Looking at the function of the buildings in Yazd, exterior openings are mainly closed during the daytime to reduce heat absorption. Examples can be found in figure 3.1.1. During the night, the courtyard and roofs pull the cool air in due to the difference in pressure between the courtyard and the surrounding environment. The heavy mass walls help absorb the heat during the day in order to try and keep the heat from penetrating the building interior. This retained heat in the walls can be removed during the evening and night with good ventilation strategies.

The function of the exterior openings of the buildings in Yazd is capable of being compared with the CAM Metabolism of the stomata on the surface of the Barrel Cactus. Both are opened during the cooler times of the day in order to perform the necessary air changes. In the case of the Barrel Cactus, the gas (air) exchange is for photosynthesis reasons while in the case of the building skin, the air changes help to remove any heat trapped within the building skin or in the building interior itself.

Because the action of opening the windows is dynamic and in contemporary architecture could be also automatic with the help of advanced technology, night ventilation can be considered as an active strategy rather than passive design strategy. As discussed before, from the author's point of view, in this thesis active and dynamic strategies are not necessarily mechanical equipment or clean energy generators but any 
strategy that requires dynamic mechanisms to be performed such as opening and closing the windows.

\subsection{Form Adaptability in Barrel Cacti vs. Passive Design Strategy in Traditional}

\section{Architecture of Yazd, Iran}

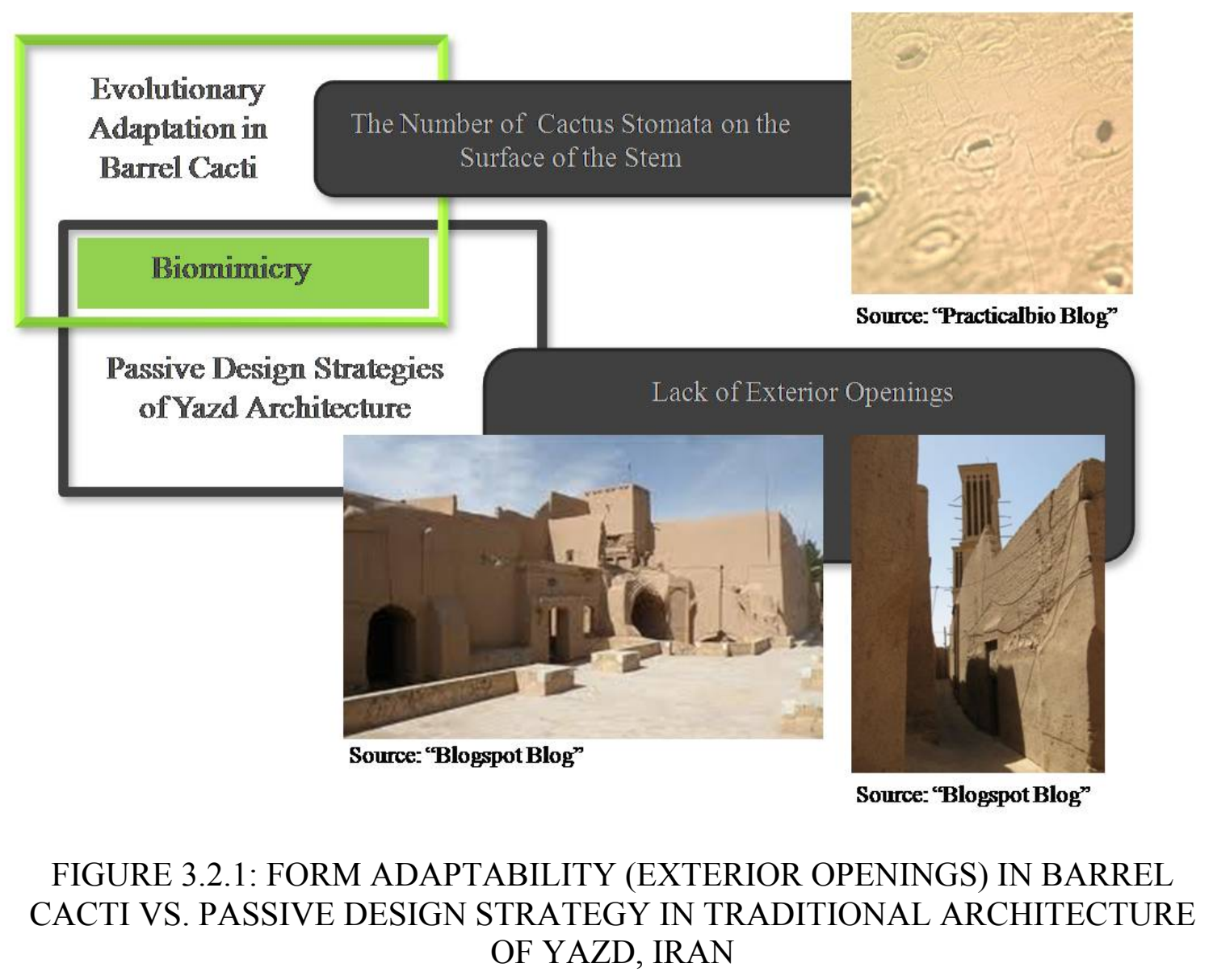

As mentioned in the first chapter, the quantity and size of the stomata on the exterior skin of the stem of the Barrel Cactus have been evolved to decrease the water/water vapor loss. Not only the numbers of the stomata on the surface area are less than the numbers of the stomata on the green tissues of the typical plants with broad 
leaves but also the sizes of the stomata cells are larger so during the hot time of the day the stomata would be firmly closed to prevent water vapor from leaking.

Looking at the number of openings on the exterior skin of most of the buildings of Yazd displayed in the figure 3.2.1 shows that there are fewer numbers of the openings on the exterior skin of the buildings when compared to that of typical buildings in a moderate climate. Therefore, there is a possibility of comparing the quantity of the Stomata on the exterior skin of Barrel Cactus with the openings on the exterior skin of the buildings in Yazd and looking at both of them as strategies that function the same; to prevent the interior space from experiencing extreme heat gain.

Another type of form adaptation as discussed previously in the first chapter and shown in the figure 3.2.2 is the Globe Configuration of the Barrel Cactus. The stems of the Barrel Cacti generally have evolved into a globular shape over millions of years. Not only because the globe form maximizes the volume while minimizes the surface area exposed to the solar radiation (this way part of the exterior skin is partly in the shade or indirectly exposed to the solar radiation) but also the exposed surface is consistently changing throughout the day as the earth rotates with respect to the Sun.

These same benefits of the globe form can be found in the roof shapes and facade elements of the buildings in Yazd as well. From small-scale houses to the large-scale urban buildings dome-shaped roofs have been built to minimize the exposed surface area of the exterior skin to the solar radiation to reduce the heat gain coming through the thermal mass of the roof of the building. Especially, during the summertime when horizontal surfaces in Yazd get almost as twice as much incident solar radiations when compared to the vertical surfaces. Therefore, dome-shaped roofs can be a great solution 
to decrease the surface area receiving direct solar radiation. Especially when you consider that the surface area receiving the solar radiation is also constantly changing due to the position of the Sun throughout the day and year.

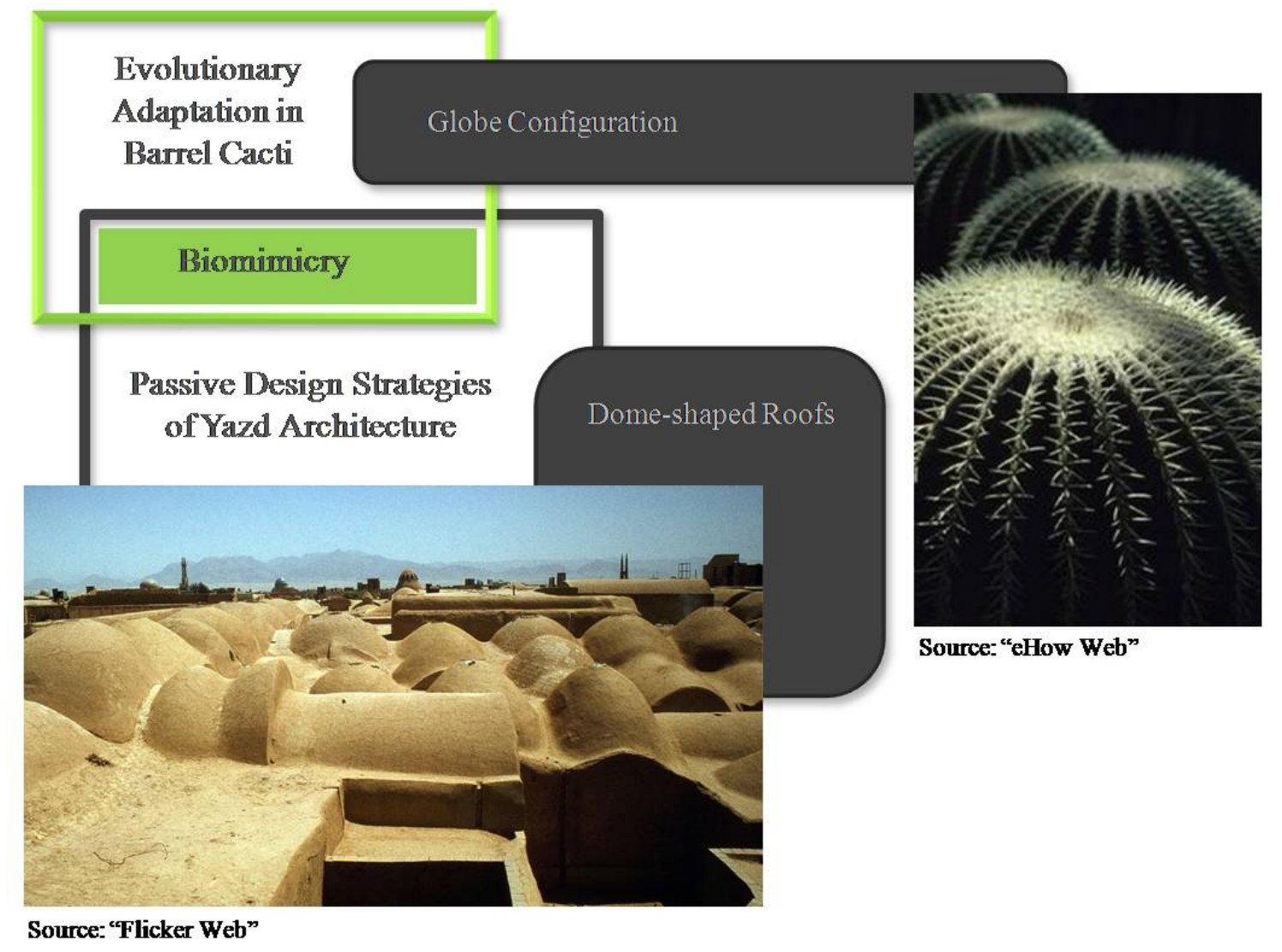

FIGURE 3.2.2: FORM ADAPTABILITY (GLOBE CONFIGURATION) IN BARREL CACTI VS. PASSIVE DESIGN STRATEGY IN TRADITIONAL ARCHITECTURE OF YAZD, IRAN

\subsection{Material Adaptability in Barrel Cacti vs. Passive Design Strategy in Traditional Architecture of Yazd, Iran}

As previously mentioned in the first chapter, not only is the main skin of the stem of Barrel Cactus covered by a thick waxy coating but also when the temperature gets too hot or the amount of solar radiation is excessive, the skin of Barrel Cactus produces an 
extra waxy cover coating which increases the solar radiation reflectance and therefore decreases the water loss by protecting it from evaporation.

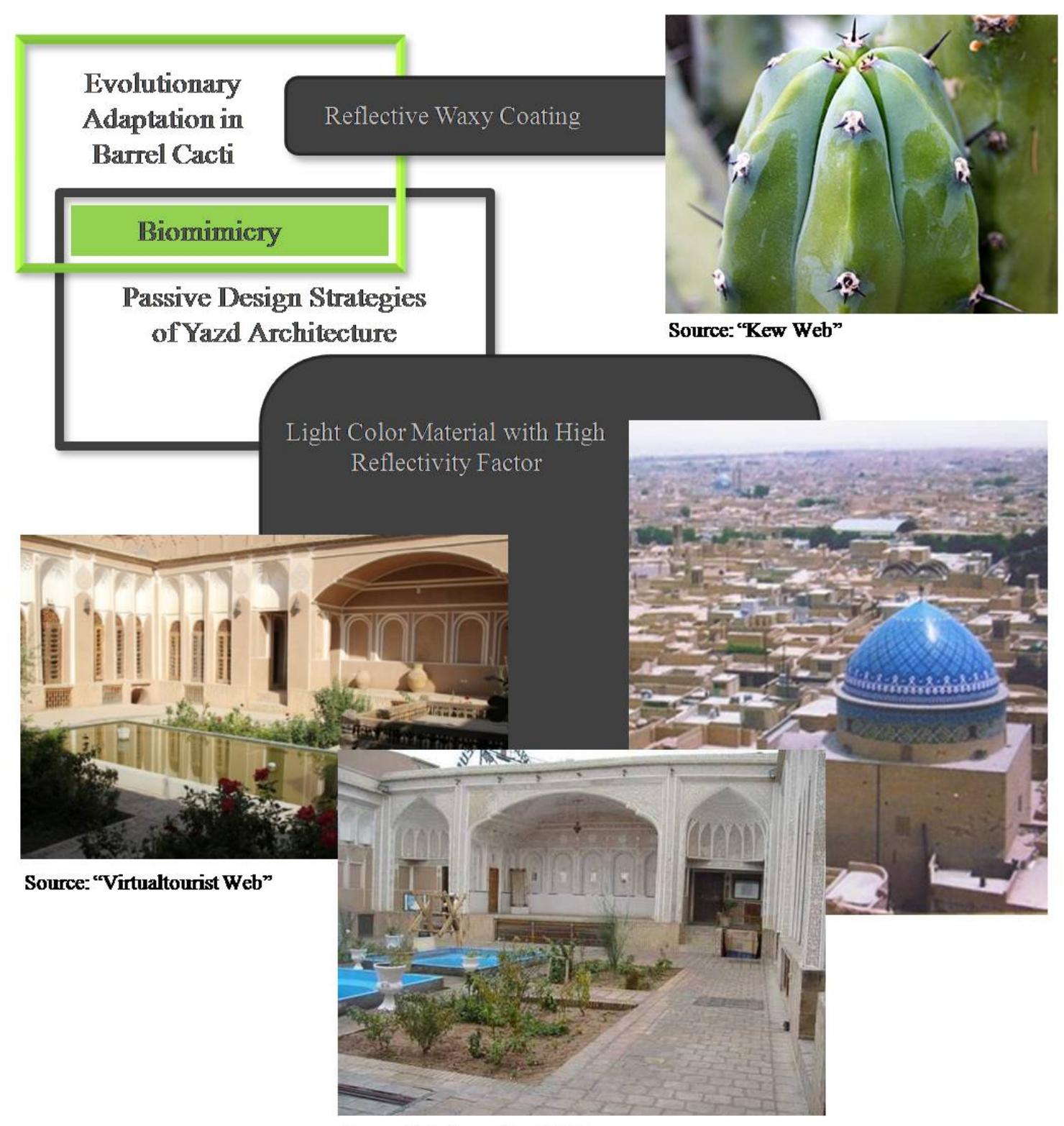

Source: "Farflungistan Web"

FIGURE 3.3.1: MATERIAL ADAPTABILITY (REFLECTANCE VALUE OF THE MATREIAL) IN BARREL CACTI VS. PASSIVE DESIGN STRATEGY IN TRADITIONAL ARCHITECTURE OF YAZD, IRAN 
Looking at the material of the building walls in Yazd shown in figure 3.5, most of the buildings are made of the plaster or light colored adobe to reflect the solar radiation or at least decrease the heat absorption rate. Also when looking at the surface area of the building roofs, (which are the most impacted by the incident solar radiation) they show that in the small scale, the roofs are made of adobe and plaster and in the larger scale they are made of materials such as tile which has a high reflectance value.

Considering that both types of adaptations are based on reflecting more of the solar radiation than absorbing it, Barrel Cactus material adaptability is capable of being mimicked by architectural design solutions. What is important though is one of the responsibilities of the Barrel Cactus skin and the building skins of the architecture in Yazd is that they are both attempting to prevent the interior spaces from experiencing extreme heat gain by decreasing the value of heat absorption by increasing reflectivity.

Another type of material adaptation in Barrel Cactus skin is the thickness and density of the skin. Which makes it very hard for any water or water vapor to leak out. Not only is the thickness of the skin useful in the fact that it can store water, (in the case of Barrel Cactus the absorbed water is changed to a liquid like jelly which further helps retain the water), but the thickness of the skin can also help delay heat transferring through the skin.

Thermal mass has been known as a successful traditional architectural solution for many years in Yazd, Iran. Many buildings have used massive construction methods for the design of the walls and roofs instead of using high percentages of traditional insulation in their wall assemblies. Thermal mass not only helps to delay the heat coming through the skin during the time of the day when it is undesired; but it can also radiate 
heat into the building when it is needed. As discussed in the second chapter the temperature of the environment during the evening and night decreases suddenly and therefore the heat that is retained in the wall is useful in helping to maintain a comfortable temperature within the building.

So high density material is another natural solution that is capable of being mimicked in architecture and the current architecture of Yazd has proven that it is working very successfully in this climate. Figure 3.3.2 shows that the thermal mass plays a very important role in the design of the building.

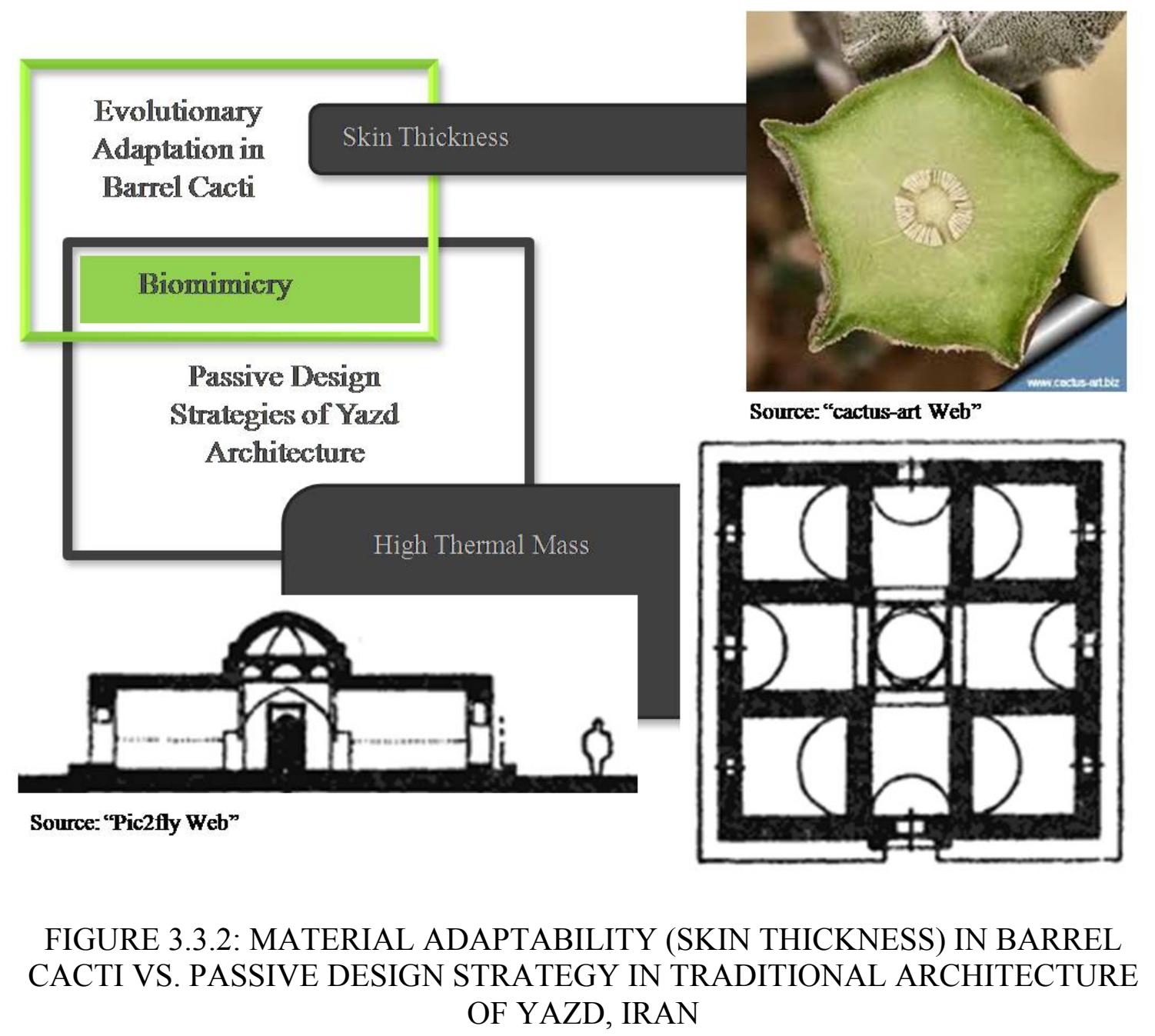


The thermal mass strategy throughout time has been very useful in balancing the daily and yearly changes in temperature of hot dry climates. It has been applied to some modern buildings that are trying to end their reliance on mechanical HVAC units to help regulate their temperature. Al Hamra tower in Kuwait City, Kuwait is an example of a modern building using thermal mass as a passive design strategy to help regulate the thermal comfort of the interior spaces.

\section{Case Studies}

\section{Al Hamra Tower}

\section{(Kuwait City, Kuwait)}

Al Hamra is the tallest stone clad structure on earth. Covered with 258,000 square meters of limestone, enough to tile NYC's Central Park. ${ }^{48}$ The stone clad wall is protecting the interior skin form the intense solar radiation in hot dry climate where the temperatures can get to top $55^{\circ} \mathrm{C}\left(131^{\circ} \mathrm{F}\right)$. The concrete wall is a high thermal mass and insulation for the interior spaces also it provides dramatic views for the users while controlling the amount solar radiation by the sculpted form.

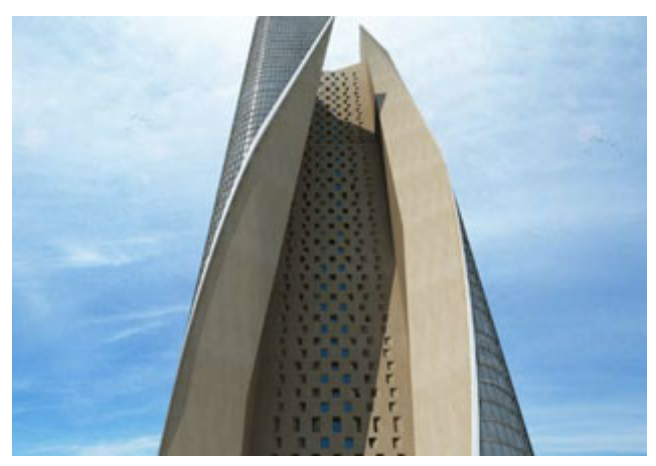

FIGURE 3.3.3: AL HAMRA BUILDING, KUWAIT CITY, KUWAIT. APPLYING THERMAL MASS AS PART OF THE PASSIVE DESIGN STRATEGY ${ }^{49}$ 


\subsection{Structure Adaptability in Barrel Cacti vs. Passive Design Strategy in Traditional Architecture of Yazd, Iran}

As discussed before in the first chapter, the structure adaptability of the Barrel Cactus' skin (cooling ribs and spines) main purpose is creating a microclimate not only to ventilate the cactus skin but also to cool the skin down by adding moisture to the air movement. The exterior ribs of the Barrel Cactus' skin create a ventilation system through convection. The corrugated skin exposes one side of the skin to the solar radiation and shade to the other side of the corrugation. Therefore hot air rises along the surface exposed the Sun and because of the convection it draws the cool air in from the shaded side, thus creating air movement and surface ventilation. These corrugated ribs of the Barrel Cactus are referred to as "Cooling Ribs" because of the ventilating system that they create. Figure 3.4.1 shows the mechanism of the cooling ribs. On the other hand, the spines growing on the surface of the "Cooling Ribs" create another cooling system as well. Not only do they shade the skin and help create a microclimate along the surface of the "Cooling Ribs", but they also can catch rainwater and the water evaporated by the convection cycle described earlier. As the air heats up and rises, it's forced to shed its water (as water vapor) which the spines are able to collect. The moisture that the spines collect eventually builds up on the spine and helps to cool down the heat infused rising air. Also as the water builds up on the spines, eventually the spines accumulate too much water and it falls off the spine and lands down at the base of the cactus where is can be absorbed again. Like the Barrel Cactus, the structural passive design strategies of the architecture in Yazd have mostly been focused on ventilation and cooling systems as well. The structure of the "Windcatcher" combined with the central courtyard and 
"Qanat" system help bring thermal comfort to the occupants of buildings in hot dry climates without the use of a high maintenance mechanical system. Figure 3.8 also shows the natural cooling system created by "Windcatcher" combined with "Qanat" cooling system to cool down a building in Yazd.

As explained in the second chapter, "Windcatchers" when combined with openings in the building skin (on opposite walls) create a ventilation system. Based on the climatic data, the type of the "Windcatcher" can differ; ranging from a one directional "Windcatcher" to a multi-directional "Windcatcher". In a hot dry climate though, a ventilation system like the one previously described, might not be successful on its own because of the temperature of the wind. You can imagine that if you are ventilating a building's interior with $55^{\circ} \mathrm{C}$ air, it doesn't matter how fast it is moving through the space; if it's hot it's not going to be comfortable. Therefore, to cool down the air entering the building, the function of the "Windcatchers" has been combined with a water reservoir in the central courtyard and/or "Qanat" system to help cool the air as it passes over the water.

Hence, what the author has learned from comparing these two types of structural strategies is that designing in such a climate definitely requires a ventilation and cooling system along with the other strategies that we have discussed: thermal mass, globe configuration and other types of adaptations would be more functional when they are combined with the passive ventilation/cooling system to move the hot air out and bring the cool air in. 


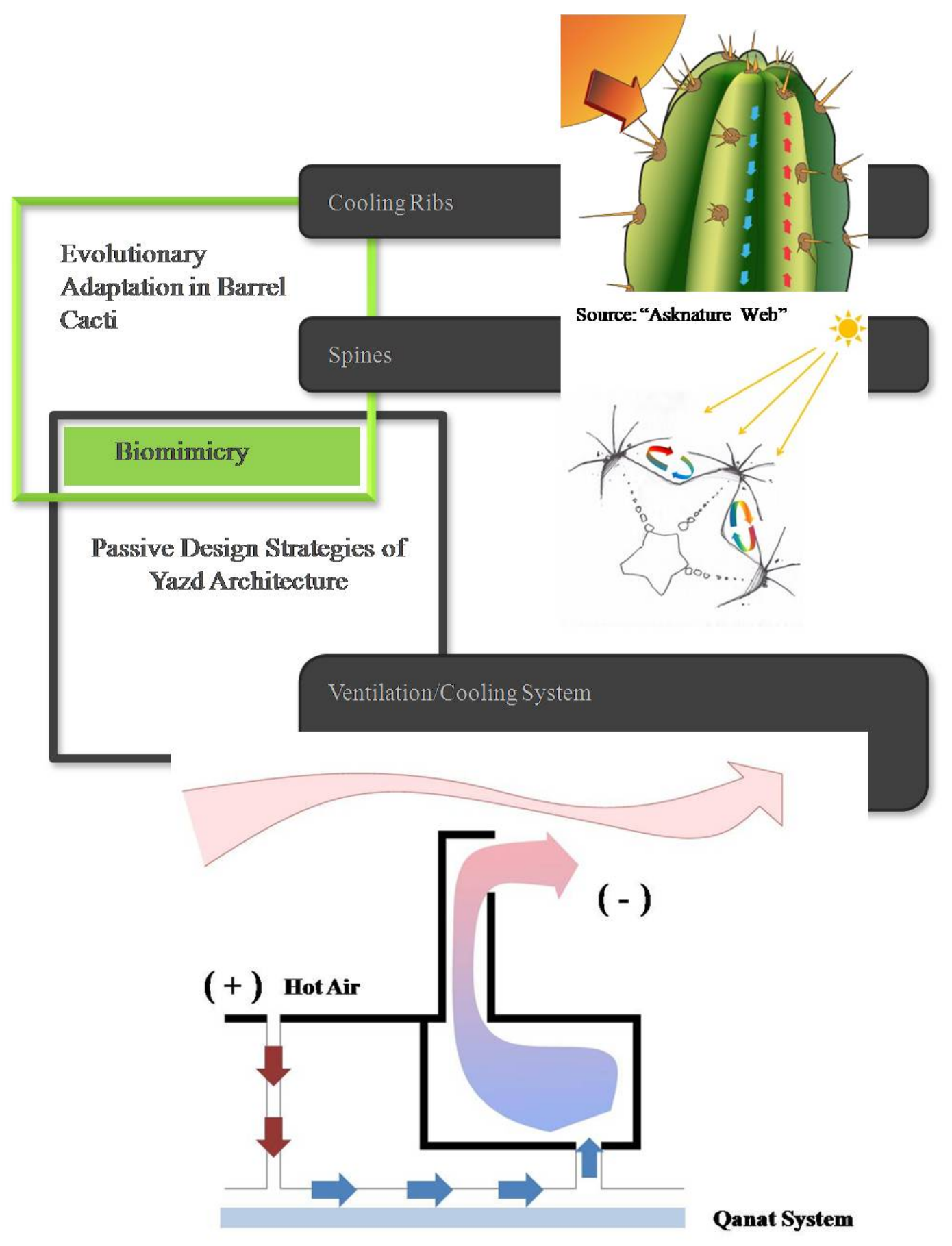

FIGURE 3.4.1: STRUCTURE ADAPTABILITY (VENTILATION/COOLING) IN BARREL CACTI VS. PASSIVE DESIGN STRATEGY IN TRADITIONAL ARCHITECTURE OF YAZD, IRAN 
After analyzing these adaptations in the Barrel Cactus' skin and comparing the results with the current architectural design strategies applied in Yazd, there is a better understanding of how we can utilize biomimicry by first analyzing the behavior of the natural species and looking for ways to mimic them in an architectural way. Below are some examples of biomimicry to show how students and architects in the past have looked to nature to help provide them with design inspiration not only from an aesthetic point of view, but a functional one as well.

\subsection{Biomimicry in Architecture \\ Case Studies}

\section{Eastgate Building, Harare, Zimbabwe}

\section{(Architect Mick Pearce collaborated with engineers at Arup Associates)}

"Termites have an amazing ability to maintain virtually constant temperature and humidity in their termite mounds in Africa despite outside temperatures that may vary from $3^{\circ} \mathrm{C}$ to $42^{\circ} \mathrm{C}\left(35^{\circ} \mathrm{F}\right.$ to $\left.104^{\circ} \mathrm{F}\right)$. Researchers initially scanned a termite mound and created 3-D images of the mound structure, which revealed construction that can influence human building design. The Eastgate Centre, a mid-rise office complex in Harare, Zimbabwe, uses a form of passive cooling similar to how the termite mound works and stays cool without air conditioning and uses only $10 \%$ of the energy of a conventional building its size." 50 

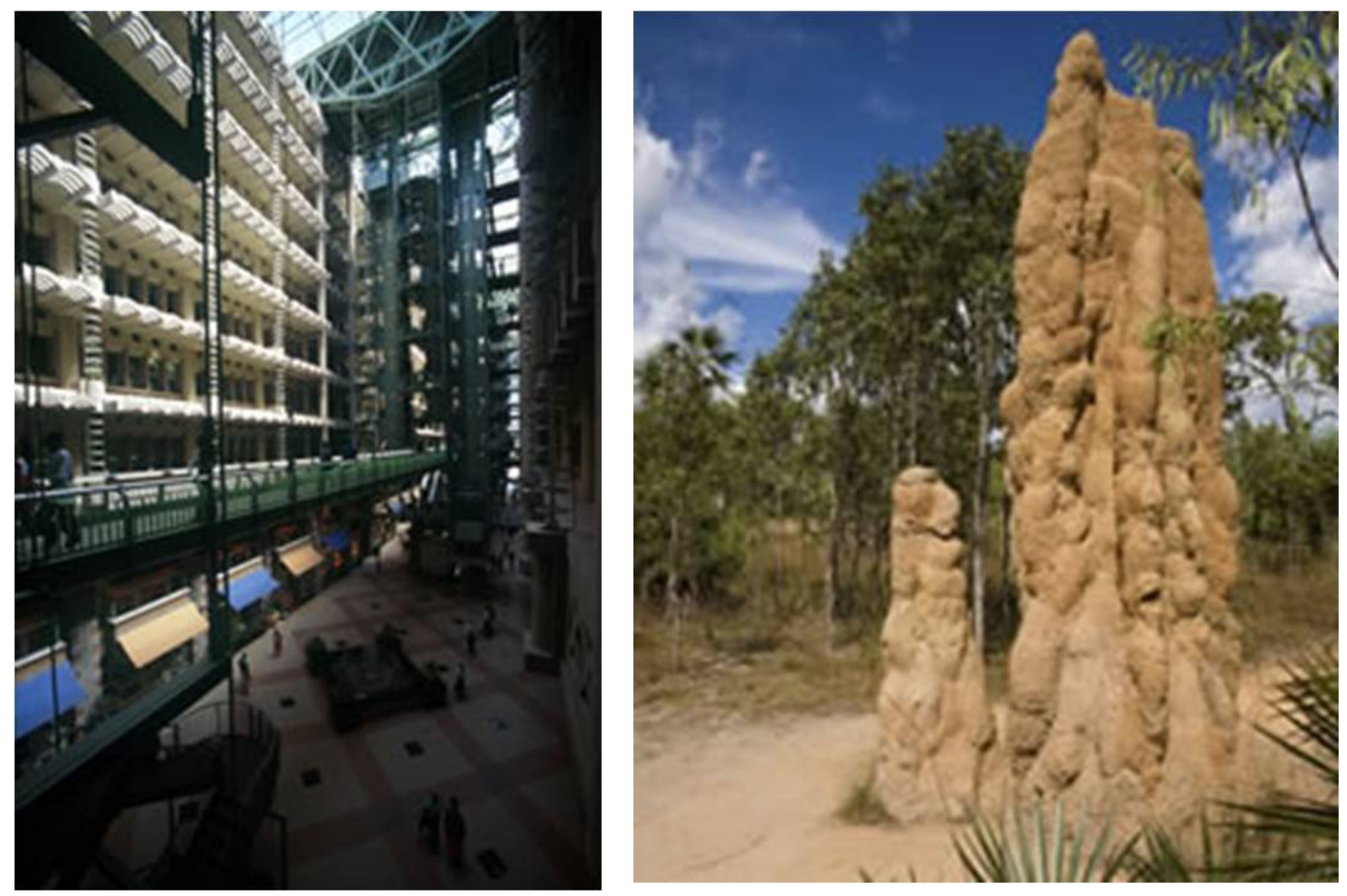

FIGURE 3.5.1: TERMITE-INSPIRED BUILDING, HARARE, ZIMBABWE ${ }^{51}$

BioArch Project, Yazd, Iran

\section{(Students at Art Institute of Isfahan in Iran)}

The snail's shell is capable of being architectural inspiration for dealing with the heat, and therefore a natural fit for inspiring passive building design ${ }^{52}$; the following elements of the shell are the inspiration keys of the design:

- $\quad$ Curved shape: Minimizes surface area exposing to the Sunlight

- Shell depth: Allows the snail to mount to the upper part of the shell to create a buffer zone between its body and the hot surface of the ground. Thus allowing the snail to escape the heat of the desert floor.

Figure 3.5.2 shows the design inspiration. Figure 3.5.3 explains the passive design strategies (natural Ventilation) inspired by snail. 

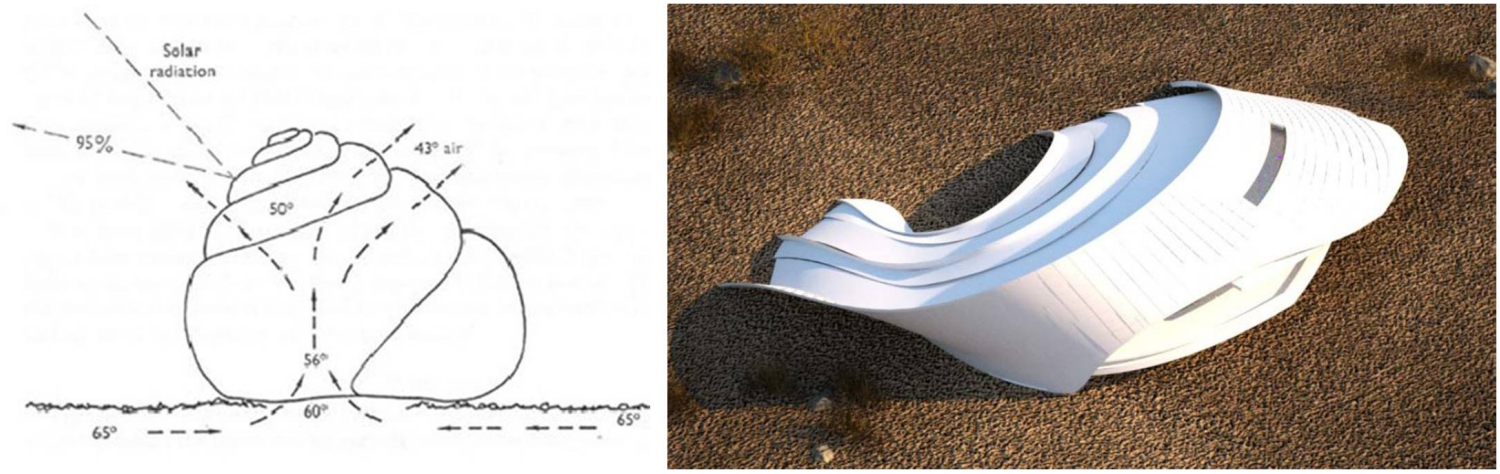

FIGURE 3.5.2: SNAIL-INSPIRED PROJECT, YAZD, IRAN ${ }^{53}$

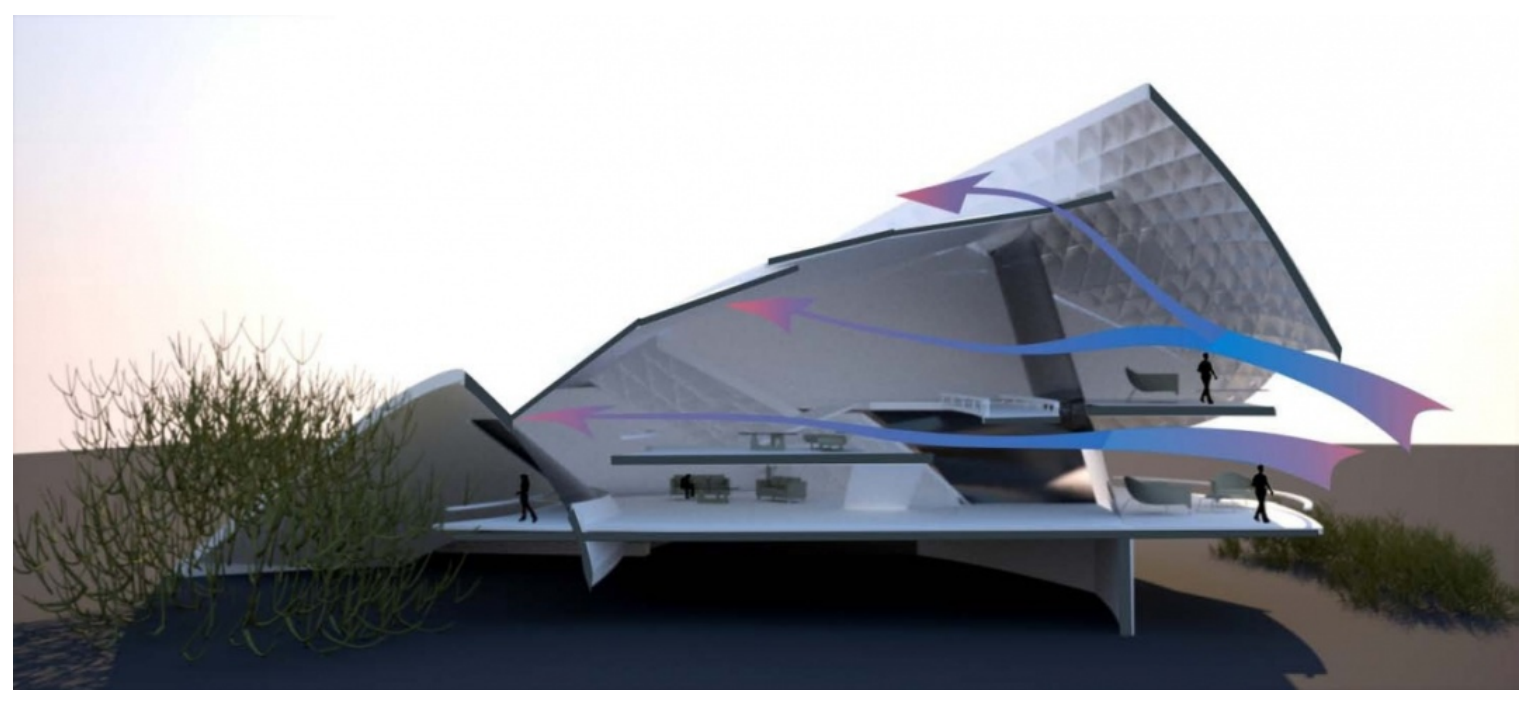

FIGURE 3.5.3: SNAIL-INSPIRED PROJECT, YAZD, IRAN ${ }^{54}$

All species in various climates throughout the world have evolved over the millions of years that they (or their ancestors) have been on this planet. They have evolved by achieving adaptable solutions to the environments in which the live in. The hot dry climate presents many stresses that make survival for the species that inhabit this 
climate very difficult especially when compared to the stresses of other more mild climates.

One of the major challenges in a hot dry climate is harvesting water due to the lack of precipitation naturally occurring throughout the climate. Once a species such as Barrel Cactus collects and stores the water, it will apply many adaptable strategies to preserve it and prevent it from evaporating. These types of strategies could be categorized into two major groups. The first group is a type of adaptation that requires a dynamic mechanism to perform an adaptable solution. While the second type is a kind of permanent adaptable solution that has been developed over millions of years. The dynamic adaptations are easily mimicked in building design through using advanced technology. On the other hand, when it comes to translating the second type of adaptations (evolutionary adaptations into the design), the designer must actively plan to bring the concept of utilizing a passive design strategy adaptation into the architectural design process early on rather than relying on technology to help solve the problems at the end of the design process. Although architecture today needs both the technology and the role of the designer to achieve adaptability in design, it is still the designer who makes the decision at the end to choose what behaviors in nature are capable of being translated into architecture.

From this author's point of view, in this chapter the adaptations of the Barrel Cactus which occurred over a relatively short period of time and referred to as instant/dynamic adaptations may have occurred for evolutionary reasons, but will not be labeled long-term evolutionary adaptations. An example of this type of trait in Barrel Cactus is "CAM Metabolism" which occurs during photosynthesis and causes the 
stomata to be closed during the hot time of the day and open during the cooler time of the day. "CAM Metabolism" is capable of being compared with the function of the exterior openings of the buildings in Yazd, Iran and how the building users operate them throughout the day.

The second category of adaptations in Barrel Cactus called evolutionary adaptations can be categorized into three groups: Form, Material and Structure. Form adaptations for example can be looked at as the number of the stomata on the stem skin of the Barrel Cactus and the Globe Configuration of Barrel Cactus. This can be compared with the number of the openings on the exterior skin of the buildings and the domeshaped roofs of the buildings in Yazd, Iran.

The second group of evolutionary adaptations are material adaptations. An example of this type of adaptation can be the reflective waxy coating of the Barrel Cactus skin. This can be compared with the light color, highly reflective material applied to the walls and roofs of the current buildings in Yazd. Also in the same section, is the skin thickness of Barrel Cactus, which stores the water and helps delay heat gain into the interior of the cactus. This can be compared with the high thermal mass of the building skins in Yazd.

The third group of evolutionary adaptations are structural adaptations. Structural adaptations of Barrel Cactus can be seen in the adaptations of the "cooling ribs" and spines. The cooling ribs create an exterior surface ventilation system that helps to create a microclimate and cool down the skin of the cactus. Creating a microclimate by forcing the hot air to release its water as it rises, which draws in the cooler air in from the shaded portion of the cooling rib thus helping to regulate the temperature of the exterior surface 
of the cactus. The spines then collect the water vapor that is released into the air by the hot rising air and collect this water to help further create the microclimate to the cooling ribs as well as collect that water for the cactus to absorb later. This natural ventilation system can be compared to the man made natural ventilation system referred to as the "Windcatcher", central courtyard and "Qanat" system. This man made system not only ventilates the building spaces and building skin but also creates a cooling system that reduces the temperature of the circulating air by adding moisture to it. Figure 3.5.4 is a diagrammatic conclusion to chapter 3 that helps compare adaptability in Barrel Cactus with passive design strategies used in the current architectural designs of Yazd, Iran. 




FIGURE 3.5.4: CHAPTER 3 ANALYSIS CHART: THE RELATIONSHIP BETWEEN ADAPTATION IN BARREL CACTI AND CURRENT DESIGN STRATEGIES IN ARCHITECTURE OF YAZD, IRAN 


\section{CHAPTER 4:}

\section{Design Analysis and Calculation}

\section{Introduction}

Design of an adaptable building skin for any climate and all types of users is seeking a balance between daylight and heat gain. While it is important to keep the heat caused by the solar radiation out during the hottest time of the day and year, it is essential to bring natural light into the building as much as possible. Balancing natural daylight and heat gain requires a passive ventilation design strategy in order to accommodate this balance. There is always unwanted heat created by the natural light and thermal heat gain transferred though the building skin; but there is also the heat radiated out into the interior of the building produced by the users and their equipment. So not only is it important to keep the solar heat out and bring it in when it is needed but also it is important to ventilate the heat created inside the building. In order to have less heat gain inside the building, the first step is to optimize the design of the exterior skin to absorb less solar radiation. Figure 4.1 explains the design process of the building skin step by step starting from the design of an exterior flat simple skin system, to a curved corrugated double façade building skin containing a high thermal mass and a Stack ventilation system. As shown in the figure 4.1 the exterior skin design and analysis process in reducing solar radiation starts with the analysis of a simple flat skinned building, typical of an open office area in a hot dry climate like Yazd, Iran. Next, the flat skinned building will be compared with a corrugated and curved corrugated skin. These two types of corrugated building skins are necessary in order to bring the "Cooling Ribs" and "Globe Configuration" effects into the design of the exterior skin and use their designs to 
compare with the flat skin building. The flat skin building serves as the control group for our design exploration.

The next step in order to minimize the heat gain and ventilate the absorbed heat is analyzing the air gap between the interior and exterior skin. Since the goal of the design is a building facade system along with the building roof system, double skin system is an assumed optimized solution. Therefore, the gap between the exterior and interior would be analyzed and designed in terms of "thermal mass" and "Stack ventilation" effect. These types of strategies have also been taken into consideration in the design of the flat and simple corrugated skin as it is shown in figure 4.1. They will not be part of the calculations in this chapter because the curved corrugated skin was determined to be a better option in the following calculation and analysis. The third design analysis belonged to the design of the interior skin of the building skin to bring natural light and ventilation into the office spaces so minimizing the artificial lighting and mechanical solution to ventilate and cool down the interior spaces. 


\section{Flat Skin System}

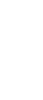

(1)

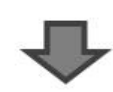

Corrugated Skin System

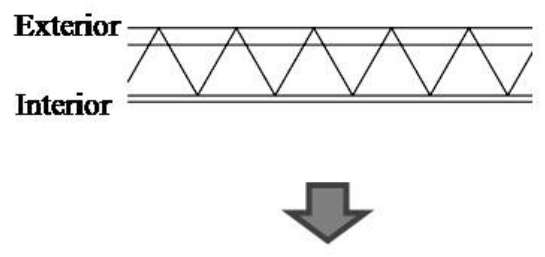

Curved Corrugated Skin System

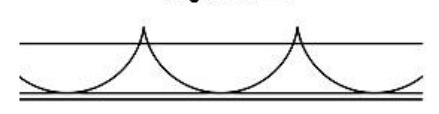

Exterior
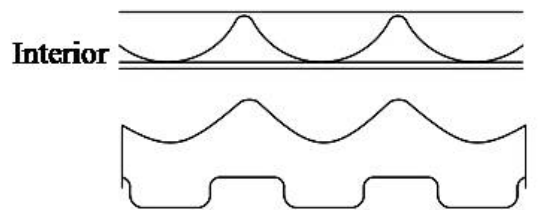

$\longrightarrow$
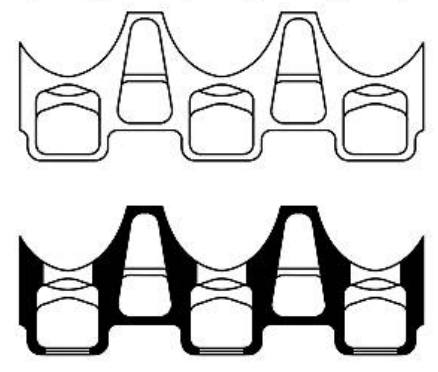

Design Process for a Flat Building Skin
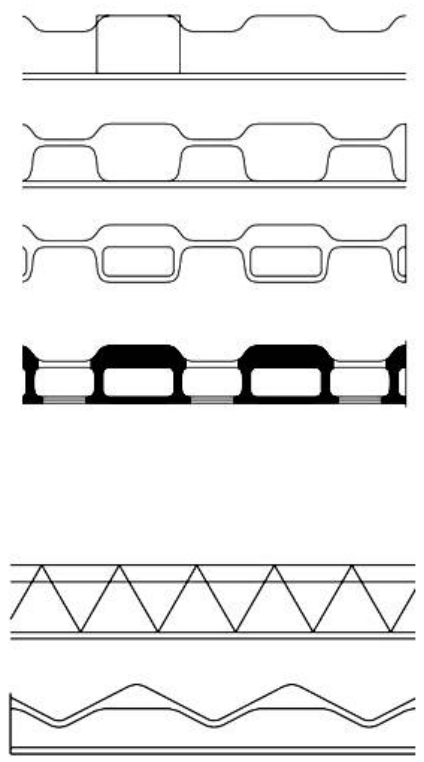

Design Process for a

Comugated Building

Skin
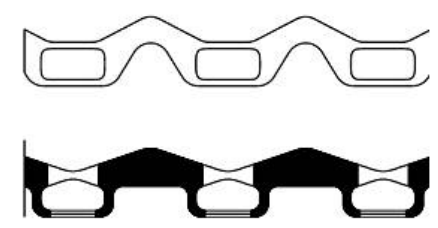

\section{Creating Curved Corrugated Skin System to Optimize the Cooling Ribs Effect and}

Globe Configuration Effect

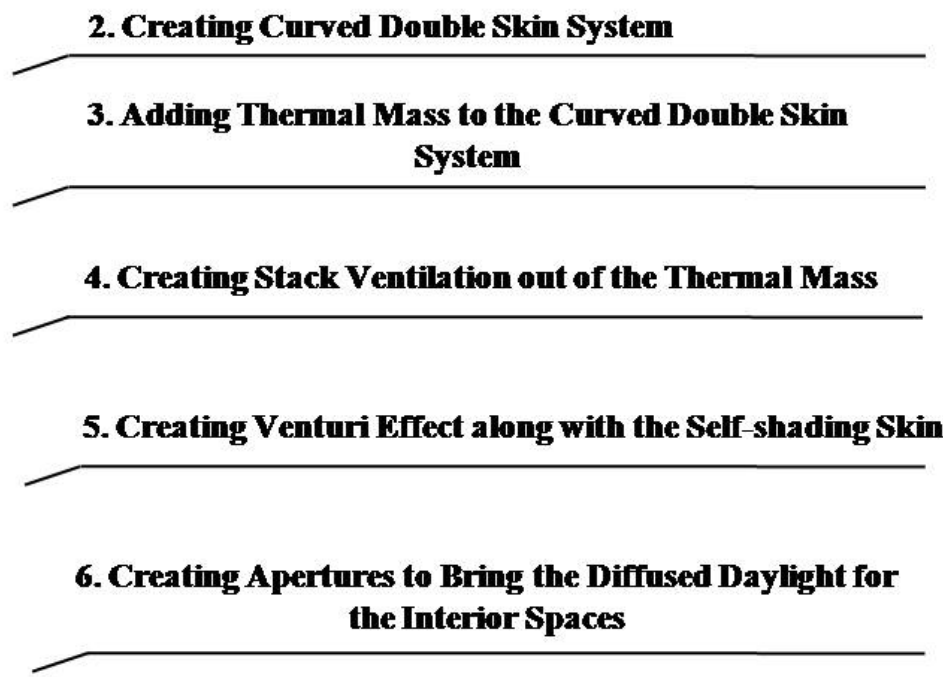

FIGURE 4.1: DESIGN PROCESS

SCALE: $1 / 64$ 
Based on the process explained in the figure 4.1, designing a building skin responsive to the heat gain, natural ventilation and daylight can be analyzed in the following three categories: exterior skin, interior skin and the air gap separating the two. Hence, this chapter is divided into three sections: "Exterior Skin Design Process", "Skin Gap Design Process" and "Interior Skin Design Process". Figure 4.2 and 4.3 explain the design elements in each section and layer that are taken either from the Barrel Cactus or traditional architecture of Yazd. As you can see in the figure 4.2 and 4.3, the exterior part of the building skin can be mostly mimicked form the Barrel Cactus skin while the skin gap and the interior skin should follow the responsive architecture that is currently applied in Yazd, Iran. The reason that exterior layer of the building skin is mimicking Barrel Cactus rather than traditional architecture of Yazd is that the exterior layer is directly dealing with the environmental effects such as diurnal and seasonal changes of this hot dry climate which is exactly the same conditions the Barrel Cactus' exterior skin has survived and evolved in so well. Therefore, as shown in figure 4.2 and 4.3, "Cooling Ribs", "Globe Configuration" and "Self-shading" characteristics of the Barrel Cactus skin can be applied as the chosen design factors of the exterior layer of the building skin. While the exterior layer of the Building skin is mostly mimicking the Barrel Cactus skin because of the direct response to the environmental effects, the interstitial layer (air gap) and the interior layer are directly dealing with more architectural concerns such as thermal comfort zones for users. Hence, responsive architectural solutions that have been explained widely in chapters 2 and 3 , are great design strategies to bring comfort for users. Among most of the strategies that have been presented in this paper, "Thermal Mass" and "Ventilation/Cooling System" have been the most successful in this climate 
and therefore will be design inspirations for the air gap layer and the interior layer of the building skin.

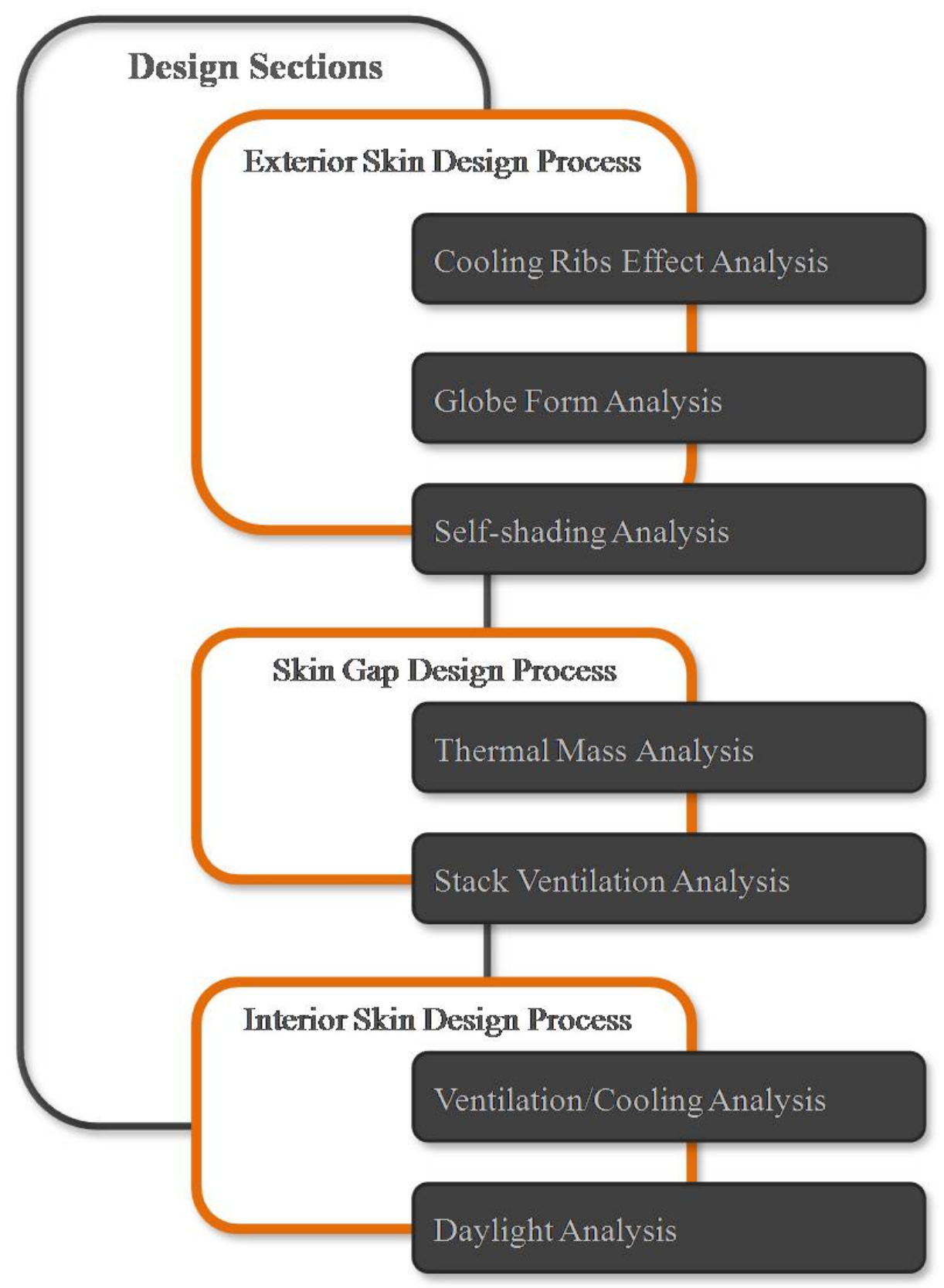

FIGURE 4.2: THE SECTIONS OF THE DESIGN PROCESS 


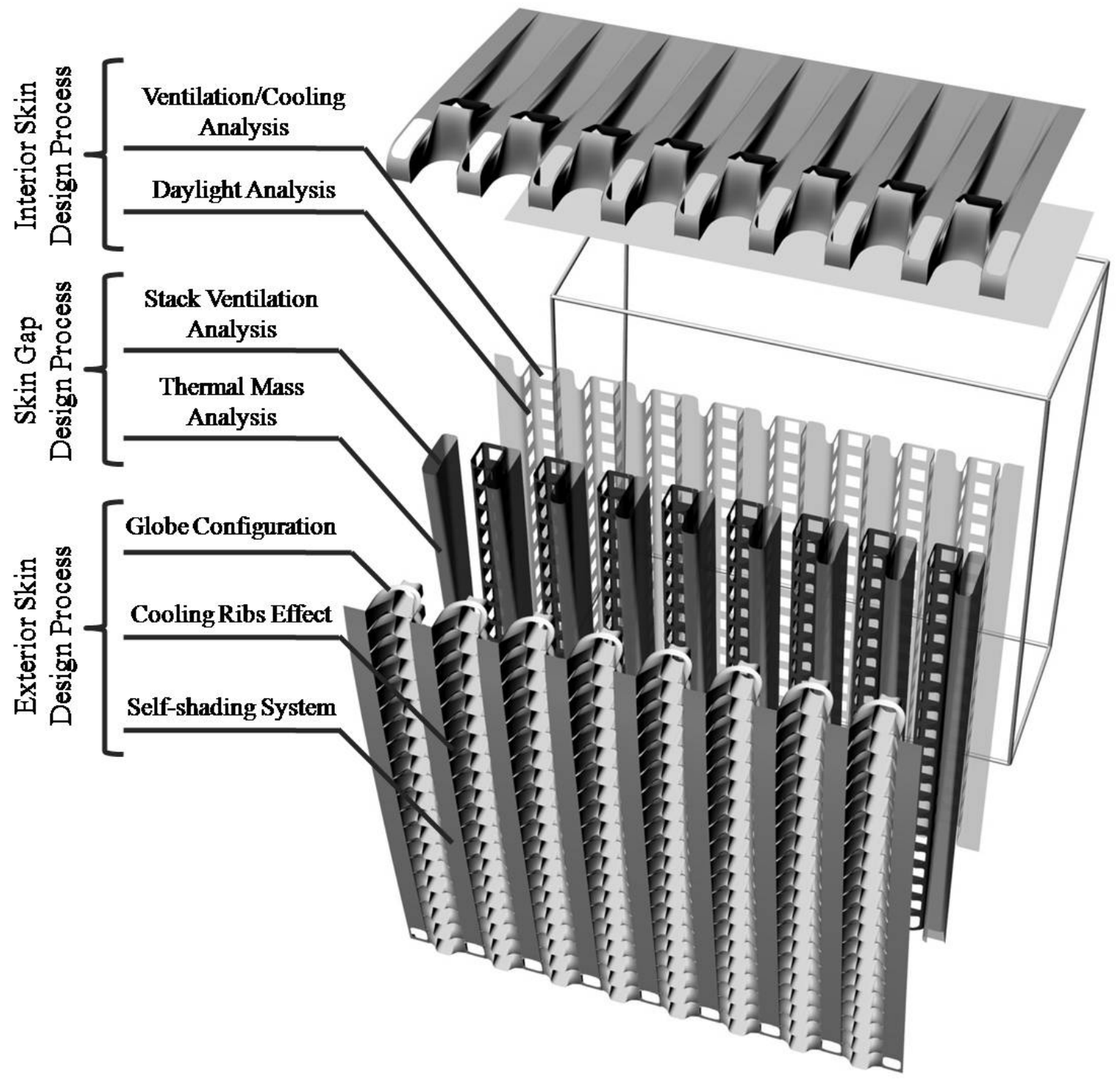

FIGURE 4.3: THREE LAYERS OF THE DESIGN PROCESS 


\subsection{Exterior Skin Design Process}

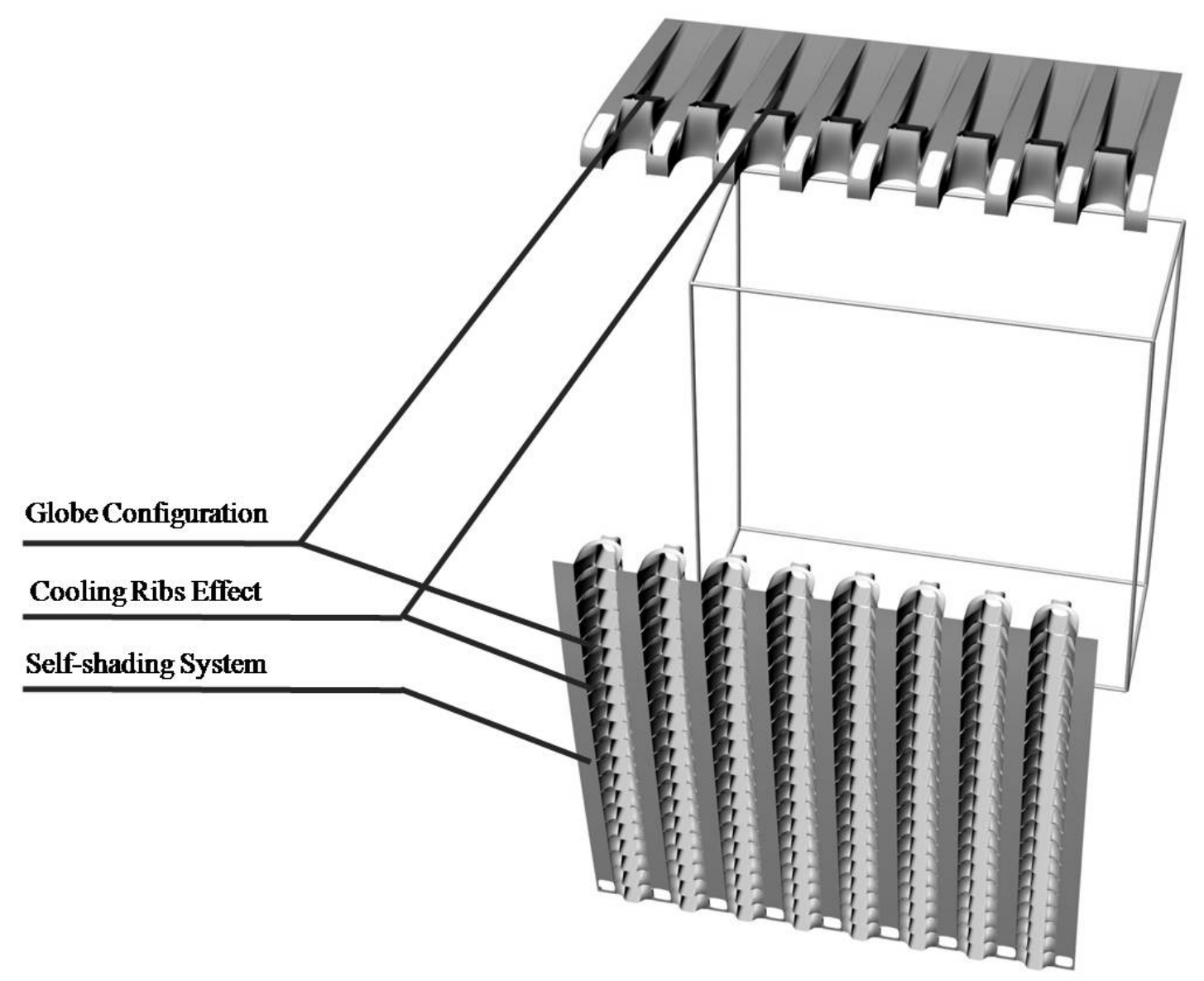

FIGURE 4.1.0: EXTERIOR SKIN DESIGN ANALYSIS FACTORS 


\section{Introduction}

Before starting the design analysis of the exterior skin, there are some design criteria/requirements that should be mentioned as they will inform the design process for this paper:

- The considered building skin system to be designed will be a south facing building façade system along with the roof system. As the south facing building façade system is the most important orientation of a building skin when considering designing an office building in a hot dry climate that needs to be operational during the hours of 8:00 am to 5:00 pm.

- Based on the climatic analysis in Chapter 2, the hottest time of the year including the highest amount of solar radiation is in June. Therefore, the heat gain and natural ventilation/cooling analysis and calculations to be performed will be for June 21 . Having said that, the design of the roof skin system is also an important part of a responsive building skin system for a hot dry climate due to the large amount of energy transferred through horizontal surfaces during the summer. So many of the design decisions that are taken into consideration for the south facade system might be taken for the roof system as well to reduce the amount of incident solar radiation on the roof during the summertime (June $21^{\text {st }}$ in this paper).

- Although heat gain and ventilation analysis are performed for June $21^{\text {st }}$, the daylight analysis is for June $21^{\text {st }}$, September $21^{\text {st }}$, March $21^{\text {st }}$ and Dec $21^{\text {st }}$ to make sure that there is enough natural daylight for users all throughout the year.

An analytical process was performed to design a better exterior skin based on the criteria explained previously. The process was performed and data obtained, from the 
combination of the Ecotect incident solar radiation analysis and hand calculations. These calculations were performed in order to find the temperature of the exterior skin and therefore the amount of heat gain by the surface, as well as try and determine if there were any heat losses on the surface due to temperature differences between the various surfaces of the exterior skin potentially causing air movements. Essentially, the author wanted to determine if the variations in the exterior skin could create a self-ventilated air movement. If so, try and determine the rate of the ventilation and if it had any impact on the thermal gain of the building surface. This process was performed for three kinds of building skins: flat, corrugated and curved corrugated skin. The design process steps explained below will be discussed fully during the analysis and calculation process of the three types of exterior skins.

1. Ecotect analysis to calculate the incident solar radiation $\left(\mathrm{Q}_{\text {sun }}\right)$

2. Calculate the amount of solar radiation absorbed by the concrete wall $\left(\mathrm{Q}_{\text {in }}\right)$

3. Calculate the temperature of the concrete wall based on the absorbed solar radiation.

4. Calculate the difference in air density due to the temperature difference of the surfaces.

5. Calculate the heat loss by convection due to the difference in air density. 6. Calculate of the Ventilation Rate based on the heat loss through convection. 


\subsubsection{Analysis of a Typical Flat Exterior Skin}

\subsubsection{Ecotect Analysis to Calculate the Incident Solar Radiation $\left(Q_{\text {sun }}\right)$}

The designed typical office building with a flat simple skin analyzed in Yazd, Iran is a 9 story office building made up of open office floor plans, with the facade system being composed of traditional framed and insulated walls having approximately $25 \%$ openings along the south facing façade. The material and the thickness of the structure applied to the design is shown in the figure 4.1.1.

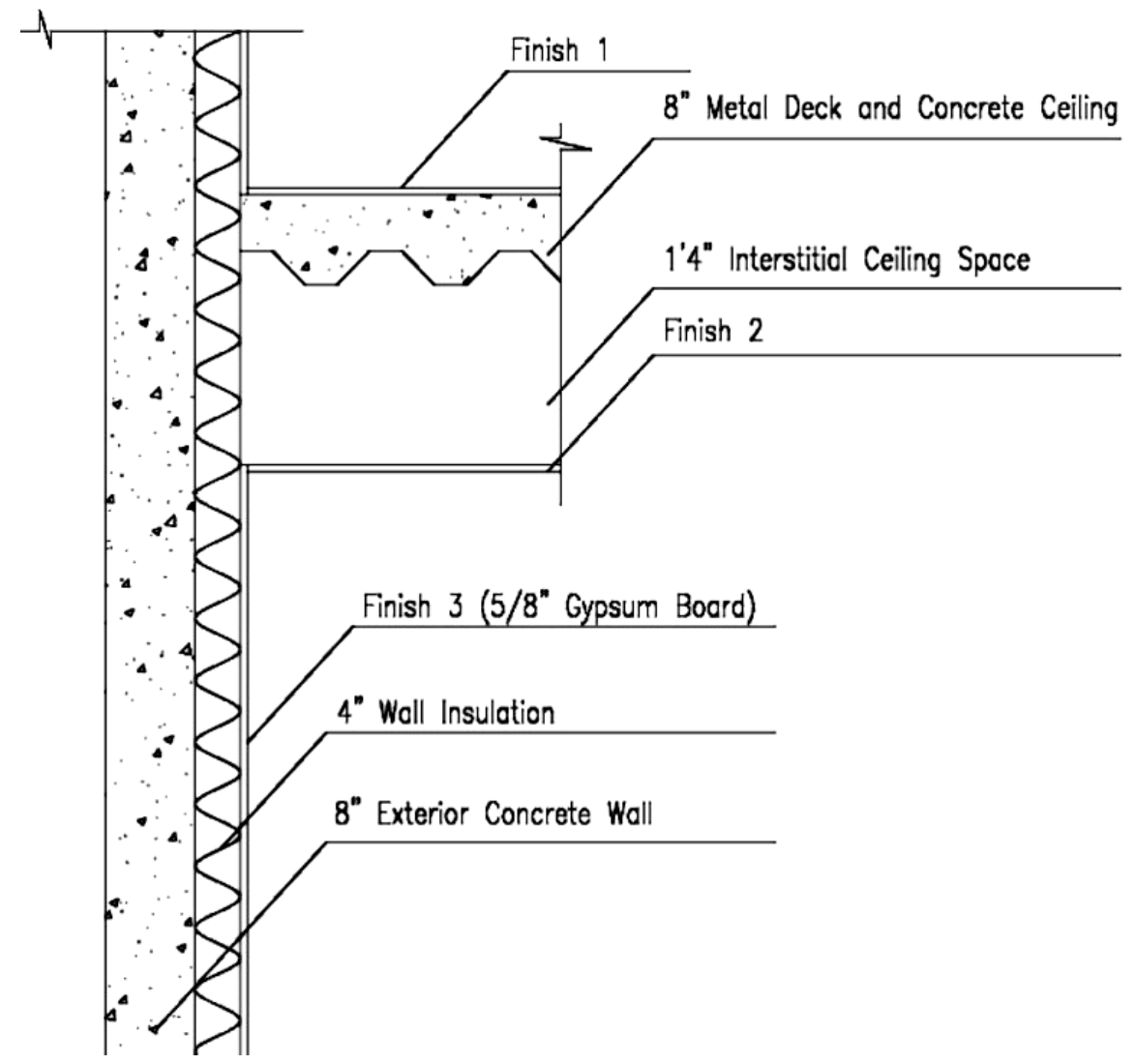

\section{FIGURE 4.1.1: TYPICAL BUILDING WALL AND FLOOR SECTION}

As shown in the figure 4.1.1, the structure and material of the exterior wall is the combination of the thermal mass and insulation to reduce the heat coming through the 
structure mass. The total wall thickness is 1 ' mass $+5 / 8$ " gypsum board. The ceiling drawn in the figure 4.1.1 is $8 "$ metal deck and concrete besides the space needed for the mechanical equipment. The total ceiling mass is $2^{\prime}$ thick.

As it is shown from Figure 4.1.2 to Figure 4.1.11, the first step of the analysis was to analyze the incident solar radiation of the flat exterior skin produced in the Ecotect 2011 software package. The analysis provided for the "typical design" is for two days of the year (June $21^{\text {st }}$ and December $21^{\text {st }}$ ) and five times of each day (8:00, 10:00, 12:00, 14:00 and 16:00).

The Ecotect analysis shown in figures 4.1.2 to 4.1.11 shows that while during the summer from 8:00 to $16: 00$ the south facing facade is receiving between $67 \mathrm{Wh} / \mathrm{m}^{2}$ to 363 $\mathrm{Wh} / \mathrm{m}^{2}$ of incident solar radiation, the roof is receiving between $363 \mathrm{Wh} / \mathrm{m}^{2}$ to 1000 $\mathrm{Wh} / \mathrm{m}^{2}$ of incident solar radiation. On the other hand, during the wintertime from 8:00 to 16:00 when south facing facade is receiving between $0 \mathrm{Wh} / \mathrm{m}^{2}$ to $416 \mathrm{Wh} / \mathrm{m}^{2}$ of incident solar radiation, the roof is receiving between $0 \mathrm{wh} / \mathrm{m}^{2}$ to $500 \mathrm{Wh} / \mathrm{m}^{2}$ of incident solar radiation. Generally, this calculation proves what was mentioned previously that the amount of incident solar radiation is much greater in June rather than Dec. and in terms of the roof skin it is almost twice the amount in the summertime when compared to the wintertime. 


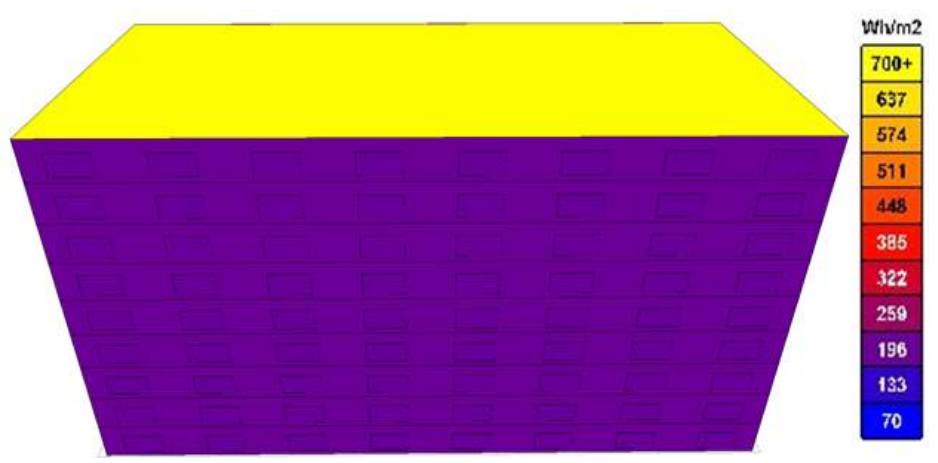

FIGURE 4.1.2: INCIDENT SOLAR RADIATION ANALYSIS OF THE FLAT BUILDING SKIN

JUNE $21^{\text {ST }} 8: 00$ - YAZD, IRAN

AUTODESK ECOTECT 2011

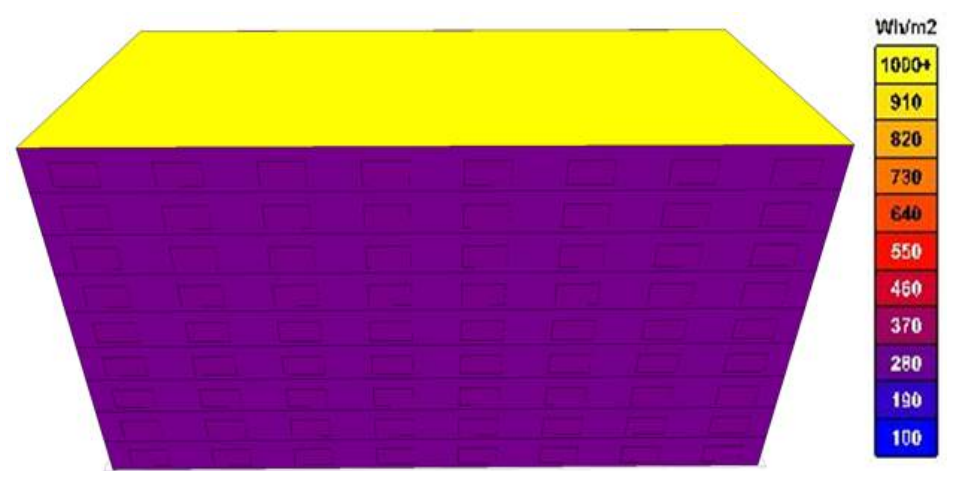

FIGURE 4.1.3: INCIDENT SOLAR RADIATION ANALYSIS OF THE FLAT BUILDING SKIN

JUNE $21^{\text {ST }}$ 10:00 - YAZD, IRAN

AUTODESK ECOTECT 2011

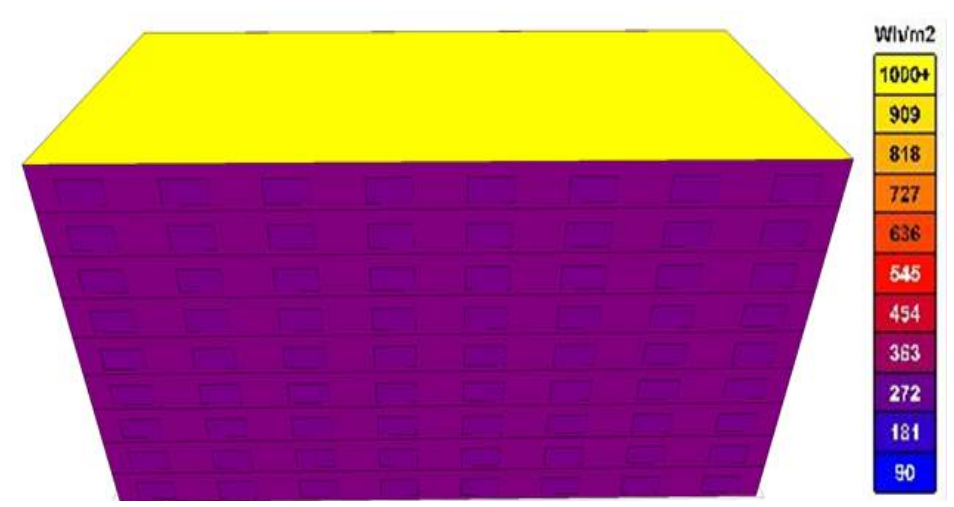

FIGURE 4.1.4: INCIDENT SOLAR RADIATION ANALYSIS OF THE FLAT BUILDING SKIN

JUNE $21^{\text {ST }}$ 12:00 - YAZD, IRAN

AUTODESK ECOTECT 2011 


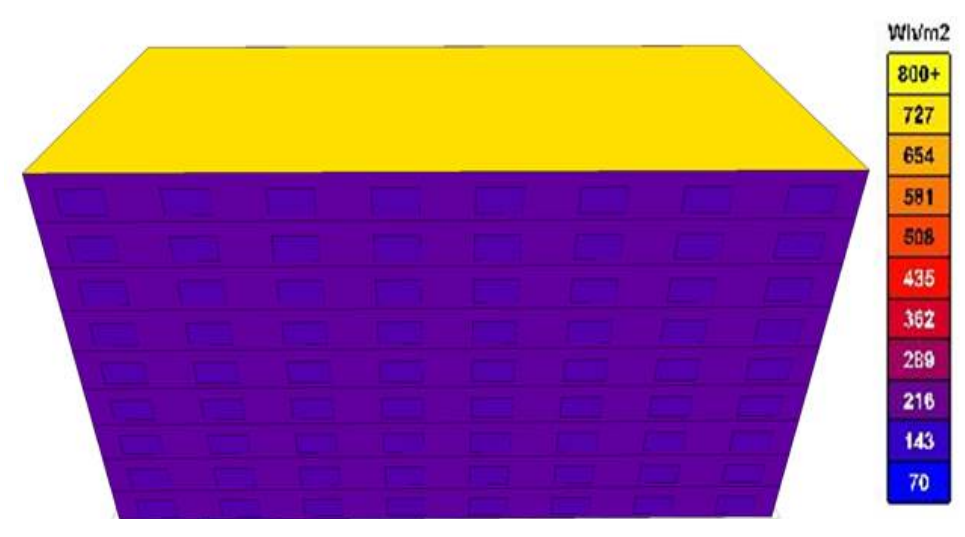

FIGURE 4.1.5: INCIDENT SOLAR RADIATION ANALYSIS OF THE FLAT BUILDING SKIN JUNE $21^{\text {ST }} 14: 00$ - YAZD, IRAN AUTODESK ECOTECT 2011

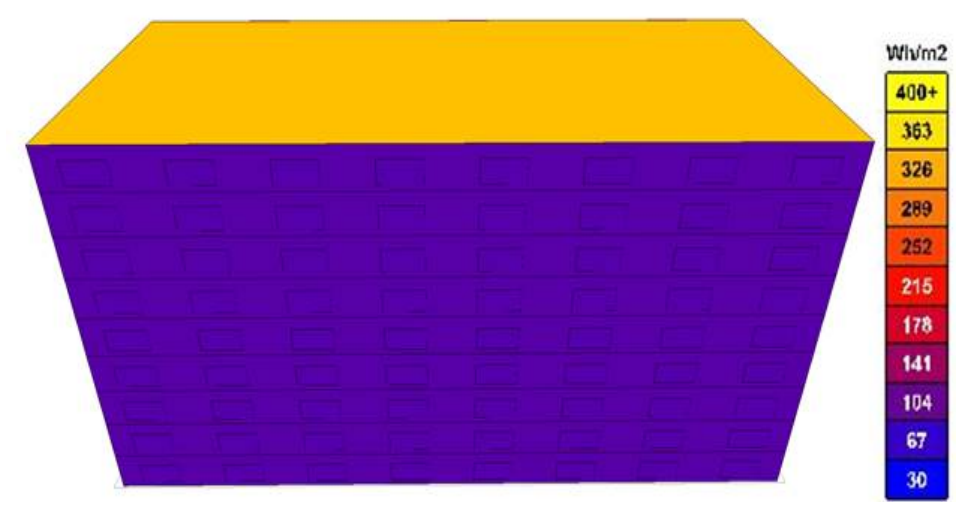

FIGURE 4.1.6: INCIDENT SOLAR RADIATION ANALYSIS OF THE FLAT BUILDING SKIN

JUNE $21^{\text {ST }} 16: 00$ - YAZD, IRAN

AUTODESK ECOTECT 2011

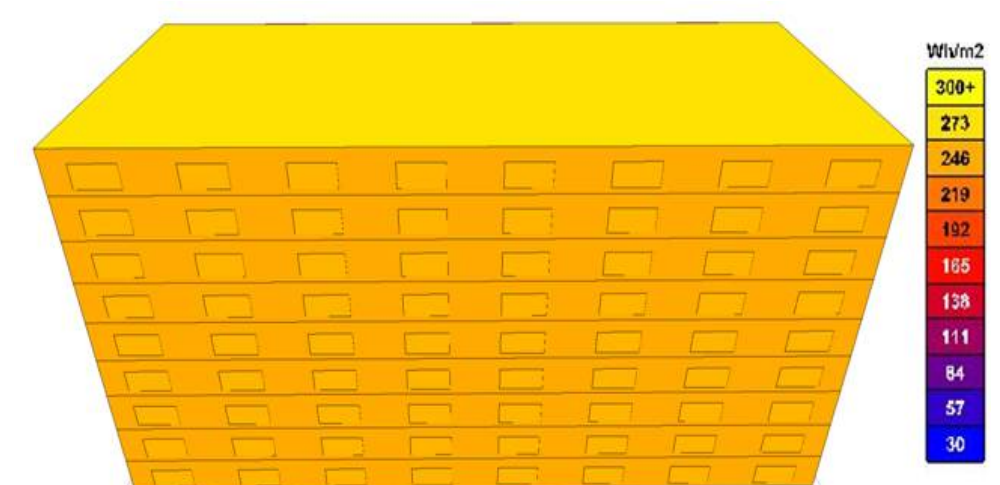

FIGURE 4.1.7: INCIDENT SOLAR RADIATION ANALYSIS OF THE FLAT BUILDING SKIN

DECEMBER $21^{\text {ST }}$ 8:00 - YAZD, IRAN

AUTODESK ECOTECT 2011 


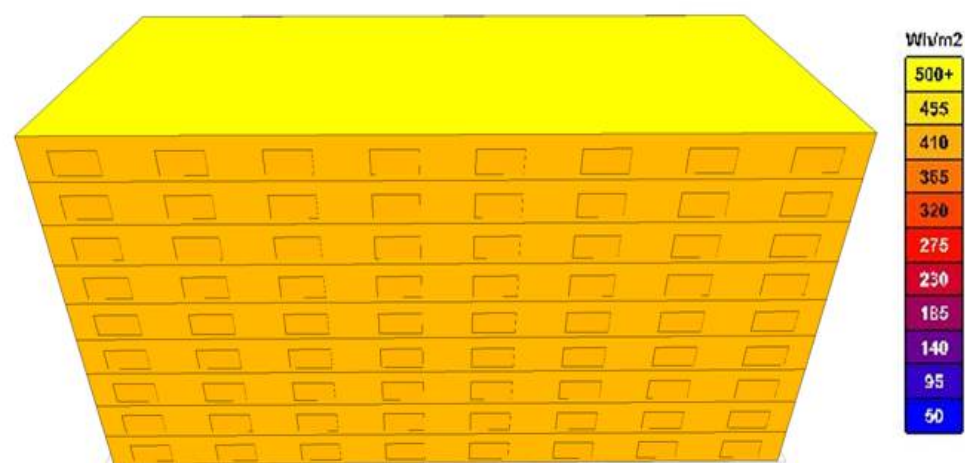

FIGURE 4.1.8: INCIDENT SOLAR RADIATION ANALYSIS OF THE FLAT BUILDING SKIN

DECEMBER $21^{\text {ST }}$ 10:00 - YAZD, IRAN

AUTODESK ECOTECT 2011

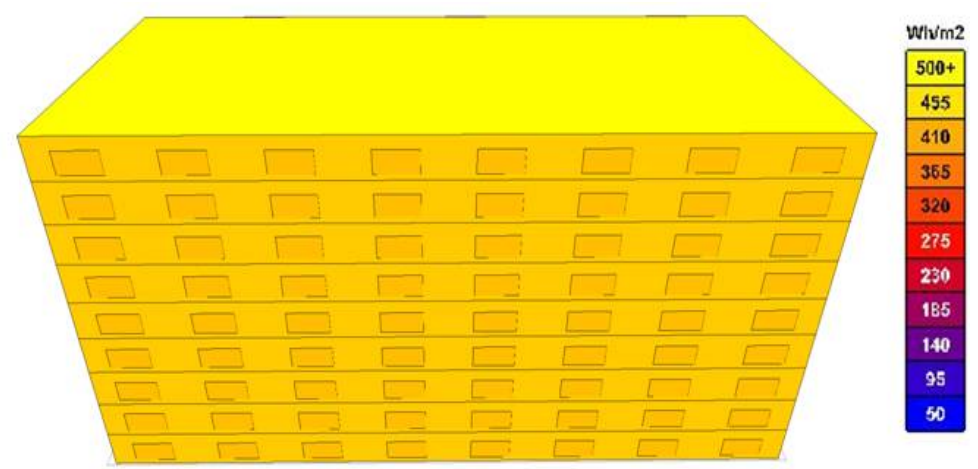

FIGURE 4.1.9: INCIDENT SOLAR RADIATION ANALYSIS OF THE FLAT BUILDING SKIN

DECEMBER $21^{\text {ST }}$ 12:00 - YAZD, IRAN

AUTODESK ECOTECT 2011

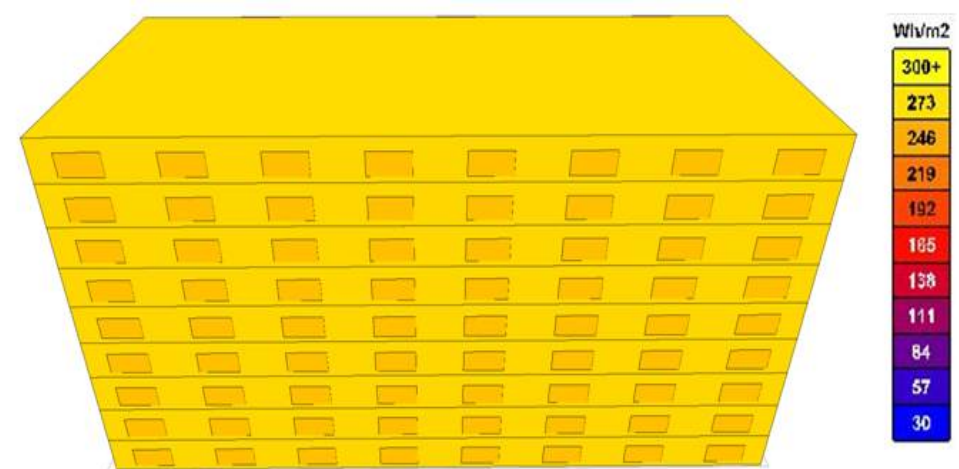

FIGURE 4.1.10: INCIDENT SOLAR RADIATION ANALYSIS OF THE FLAT BUILDING SKIN

DECEMBER $21^{\text {ST }} 14: 00$ - YAZD, IRAN

AUTODESK ECOTECT 2011 


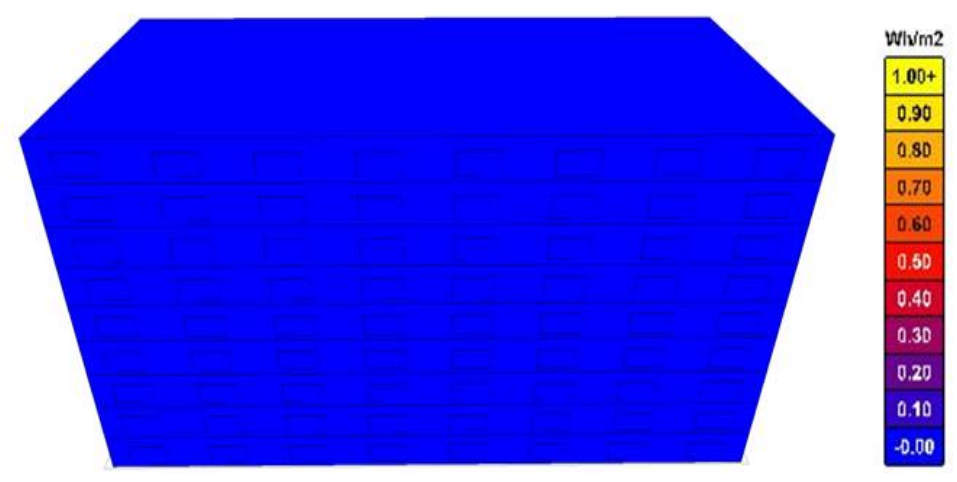

FIGURE 4.1.11: INCIDENT SOLAR RADIATION ANALYSIS OF THE FLAT BUILDING SKIN

\section{DECEMBER $21^{\text {ST }} 16: 00$ - YAZD, IRAN \\ AUTODESK ECOTECT 2011}

The incident solar radiation results shown in the figures 4.1.2-11 produced in Ecotect are in $\mathrm{Wh} / \mathrm{m}^{2}$ value and because the author is analyzing the building surface for one specific hour, the "h" value is equal to 1 and thus the results will be normalized for 1 hour and the "h" will be dropped. Therefore, we are left with $\mathrm{W} / \mathrm{m}^{2}$ as our incident solar radiation calculation units. This number in $\mathrm{W} / \mathrm{m}^{2}$ value is an incident solar radiation factor which could be also defined as $\mathrm{Q}_{\text {sun }}$ in the next equation.

\subsubsection{Calculate the Amount of Solar Radiation Absorbed by the Concrete Wall}

\section{$\left(Q_{\text {in }}\right)$}

Concrete has an solar radiation absorption factor $(\alpha)$ of $0.6^{55}$. Therefore, it stands to reason that in order to find the Q value absorbed by the simple exterior concrete wall $\left(Q_{\text {in }}\right), Q_{\text {sun }}$ should be multiplied by the absorption ratio of the concrete $(\alpha)$ to determine the heat capacity available for absorption based on the material properties of the wall. 


$$
\mathrm{Q}_{\text {in }}=\alpha \mathrm{Q}_{\text {sun }}
$$

$Q_{\text {in }}$ : Absorbed Solar Radiation

$\alpha$ : Absorption Ratio of the Material $(\alpha$ for concrete $=0.6$ )

$\mathrm{Q}_{\text {sun }}$ : Incident Solar Radiation

\section{EQUATION 4.1: ABSORBED SOLAR RADIATION}

Figure 4.1.12 shows the relationship between the $\mathrm{Q}_{\text {sun }}$ and $\mathrm{Q}_{\text {in }}$ and how it is possible to calculate the amount of heat absorbed by the material based on the amount of the incident solar radiation and the absorption ratio of the material.
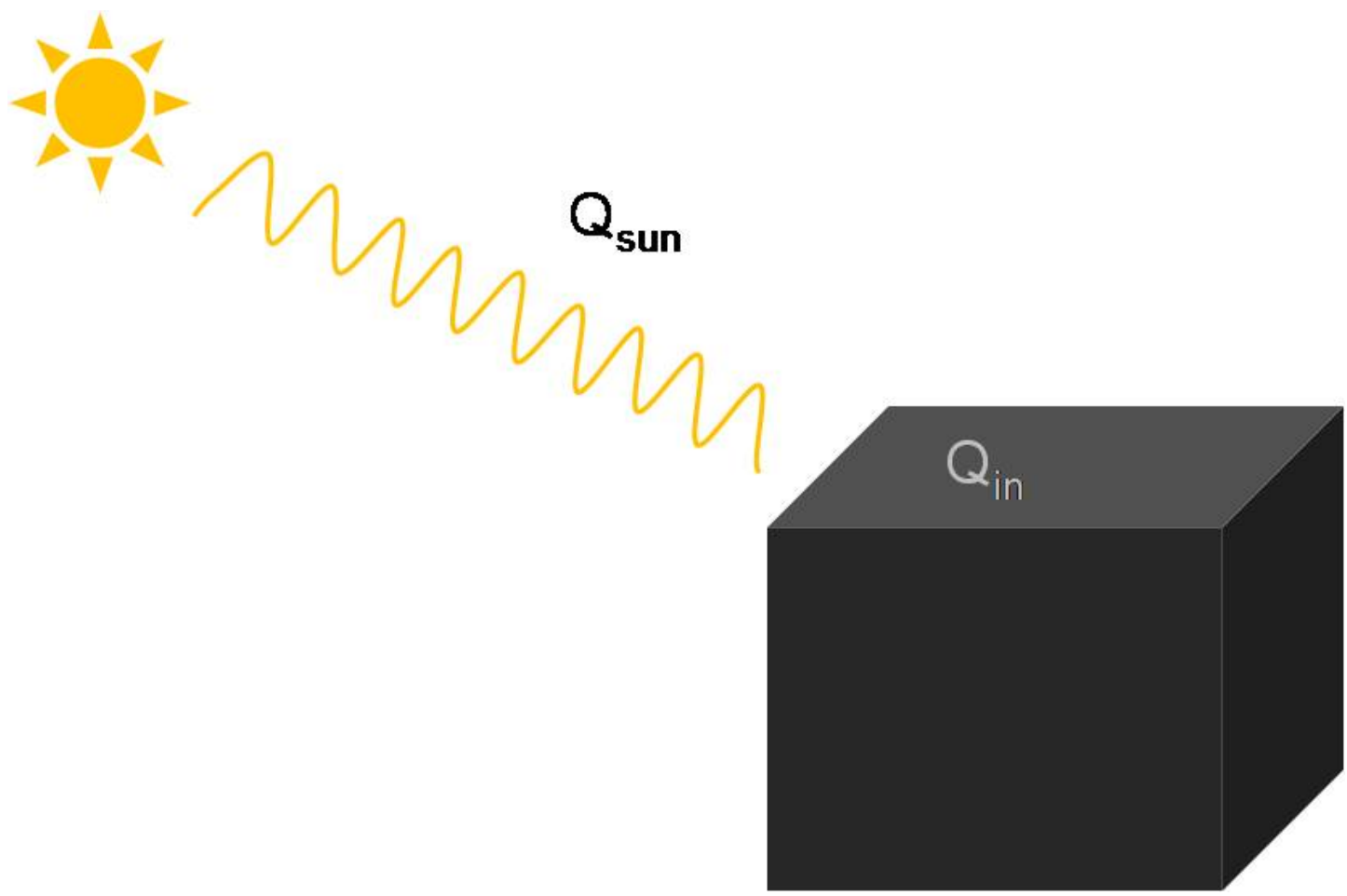

FIGURE 4.1.12: INCIDENT SOLAR RADIATION (QSUN)

Table 4.1.1 shows the calculated $\mathrm{Q}_{\text {in }}$ (equation 4.1) based on the amount of incident solar radiation analyzed by the Ecotect software (figures 4.1.2-11) and the 
absorption ratio of the exterior skin which is concrete; absorption ratio of the concrete is equal to 0.6 .

\begin{tabular}{|c|c|c|c|c|c|}
\hline & \multirow{2}{*}{ Time } & \multicolumn{2}{|c|}{ Vertical Flat Skin } & \multicolumn{2}{|c|}{ Horizontal Flat Skin } \\
\hline & & $\begin{array}{c}\mathrm{Q}_{\text {sun }} \\
\left(\mathrm{W} / \mathrm{m}^{2}\right)\end{array}$ & $\underset{\left(\mathrm{W} / \mathrm{m}^{2}\right)}{\mathrm{Q}_{\text {in }}}$ & $\begin{array}{c}\mathrm{Q}_{\text {sun }} \\
\left(\mathrm{W} / \mathrm{m}^{2}\right)\end{array}$ & $\begin{array}{c}\mathrm{Q}_{\mathrm{in}} \\
\left(\mathrm{W} / \mathrm{m}^{2}\right)\end{array}$ \\
\hline \multirow{5}{*}{$\begin{array}{l}\overline{\tilde{n}} \\
\stackrel{\sim}{N} \\
\stackrel{\Xi}{\Xi}\end{array}$} & $8: 00$ & 196 & 117.6 & 700 & 420 \\
\hline & $10: 00$ & 280 & 168 & 1000 & 600 \\
\hline & $12: 00$ & 363 & 217.8 & 1110 & 666 \\
\hline & $14: 00$ & 216 & 129.6 & 800 & 480 \\
\hline & $16: 00$ & 104 & 62.4 & 400 & 240 \\
\hline \multirow{5}{*}{ 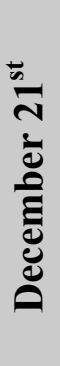 } & $8: 00$ & 246 & 147.6 & 300 & 180 \\
\hline & 10:00 & 410 & 246 & 500 & 300 \\
\hline & $12: 00$ & 410 & 246 & 550 & 330 \\
\hline & $14: 00$ & 273 & 163 & 273 & 163.8 \\
\hline & $16: 00$ & 0 & 0 & 0 & 0 \\
\hline
\end{tabular}

TABLE 4.1.1: HOURLY AND DAILY CALCULATION OF THE QIN BASED ON THE AMOUNT OF INCIDENT SOLAR RADIATION (Q $\left.{ }_{\text {SUN }}\right)$ AND ABSORPTION RATIO OF THE EXTERIOR SKIN $(\alpha)$

Table 4.1.1 shows that the maximum amount of absorbed radiation for the south facing vertical surface (shown in red color in the table) is at 10:00 and 12:00 on Dec. $21^{\text {st }}$. This result seems to be correct since the flat vertical surface is mostly exposed to the direct solar radiation during the wintertime especially at noon when the Sun is perpendicular to the south facing flat surface. Table 4.1.1 also shows that for the horizontal surfaces, the maximum amount of absorbed solar radiation (also shown in red color) is on June $21^{\text {st }}$ at noon. This result seems to be correct as well since the roof skin is 
receiving the maximum solar radiation during the summertime rather than wintertime especially at noon when the Sun is perpendicular to the horizontal surface.

This calculation though does not necessarily show that the temperature of the surface is maximum at the mentioned time since the skin temperature not only depends on the incident solar radiation but also depends on the outside temperature. Therefore, in the following section, the calculation for the exterior skin temperature, may show that although during the summertime the exterior skin of the south facing facade may receive a lesser amount of incident solar radiation than during the wintertime, due to the outside temperature, which is much higher during the summer rather than the winter, the exterior skin temperature will be higher during the summer months.

\subsubsection{Calculate the Temperature of the Concrete Wall Based on the Absorbed Solar Radiation} According to the next equation, it is possible to solve for the temperature of the exposed surface $\left(T_{s}\right)$ based on the amount of absorbed solar radiation $\left(\mathrm{Q}_{\text {in }}\right)$.

$$
\mathrm{Q}=\varepsilon \sigma\left(\mathrm{T}_{\mathrm{s}}{ }^{4}-\mathrm{T}_{\mathrm{o}}{ }^{4}\right)
$$

$\mathrm{Q}=\mathrm{Q}_{\text {in }}\left(\mathrm{W} / \mathrm{m}^{2}\right)$

$\varepsilon=$ Emissivity Ratio Based on Material Properties ( 0.88 for concrete)

$\sigma=$ Stefan-Boltzmann Constant $\left(5.67 * 10^{-8}\right)$

$\mathrm{T}_{0}=$ Outside Temperature $(\mathrm{K})$

$\mathrm{T}_{\mathrm{s}}=$ Surface Temperature $(\mathrm{K})$

EQUATION 4.2: EXTERIOR SURFACE TEMPRATURE ${ }^{56}$ 
Table 4.1.2 shows the results of the calculation process explained above for a flat simple skin on June $21^{\text {st }}$ and December $21^{\text {st }}$ for five times of the day in Yazd, Iran. The outside temperature is changing by the time of the day and so does the temperature of the surface.

\begin{tabular}{|c|c|c|c|c|c|}
\hline \multirow{2}{*}{$*$} & \multirow{2}{*}{ Time } & \multicolumn{2}{|c|}{ June 21 $^{\text {st }}$} & \multicolumn{2}{c|}{ December 21 $^{\text {st }}$} \\
\cline { 2 - 6 } & & Vertical & Horizontal & Vertical & Horizontal \\
\cline { 2 - 6 } & $8: 00$ & 120.63 & 188.97 & 98.34 & 107.90 \\
\cline { 2 - 6 } & $10: 00$ & 138.43 & 224.30 & 133.23 & 146.41 \\
\cline { 2 - 6 } & $12: 00$ & $\mathbf{1 5 4 . 7 8}$ & $\mathbf{2 3 7 . 9 4}$ & 135.91 & 155.80 \\
\cline { 2 - 6 } & $14: 00$ & 137.05 & 209.50 & 111.30 & 111.30 \\
\cline { 2 - 6 } & $16: 00$ & 122.41 & 164.90 & 48.00 & 48.00 \\
\hline
\end{tabular}

TABLE 4.1.2: HOURLY SURFACE TEMPERATURE $\left({ }^{\circ} \mathrm{F}\right)$ CALCULATION

Based on the analysis, the highest temprature of the facade and roof shown in red color occurs on June $21^{\text {st }}$ at noon. While the temprature outside is $98^{\circ} \mathrm{F}$, the temprature of the south facading facade is $154.78^{\circ} \mathrm{F}$ and the temperature of the roof is $237.94^{\circ} \mathrm{F}$. This conclusion proves what was mentioned earlier that although the maximum amount of incident and absorbed solar radiation is during the wintertime for the vertical south facing skin, becasue of the maximum outside temprature in summertime, the temprature of the exterior skin surface is higher in the summertime rather than the wintertime.

In conclusion, the first step of the calculation process to find the surface temperature is to determine the amount of solar radiation in the $\mathrm{W} / \mathrm{m}^{2}$ form. Therefore, we will utilize Ecotect to determine the amount of incident solar radiation in $\mathrm{W} / \mathrm{m}^{2}$ value for each specific time (figures 4.1.2-11). The second step is calculating the amount of 
solar radiation absorbed by the surface based on equation 4.1 (figure 4.1.12) and therefore finding the temperature of the exposed surface based on the amount of heat absorbed (equation 4.2 and table 4.1.2).

There are tables in the apendix section explaining the result for each specific dayand time based on the calculation process mentioned perviously.

While knowing the exterior skin temprature is important in order to make decisions for the design of the exterior skin to reduce the heat gain of the surfaces, the interior temprature also tells the designer if the design strategy for the exterior skin works for the interior spaces as well. Figure 4.1.13 and 4.1.14 are "Ecotect Hourly Temprature" results that show the outside temperature and the interior tempratue of the simple offce building with flat building skin in the two days of the year in Yazd. The hourly temperature figures show that on June $21^{\text {st }}$ the temperature of the inside of the building for some parts of the day is even higher than the temperature outside and it is close to 100F.

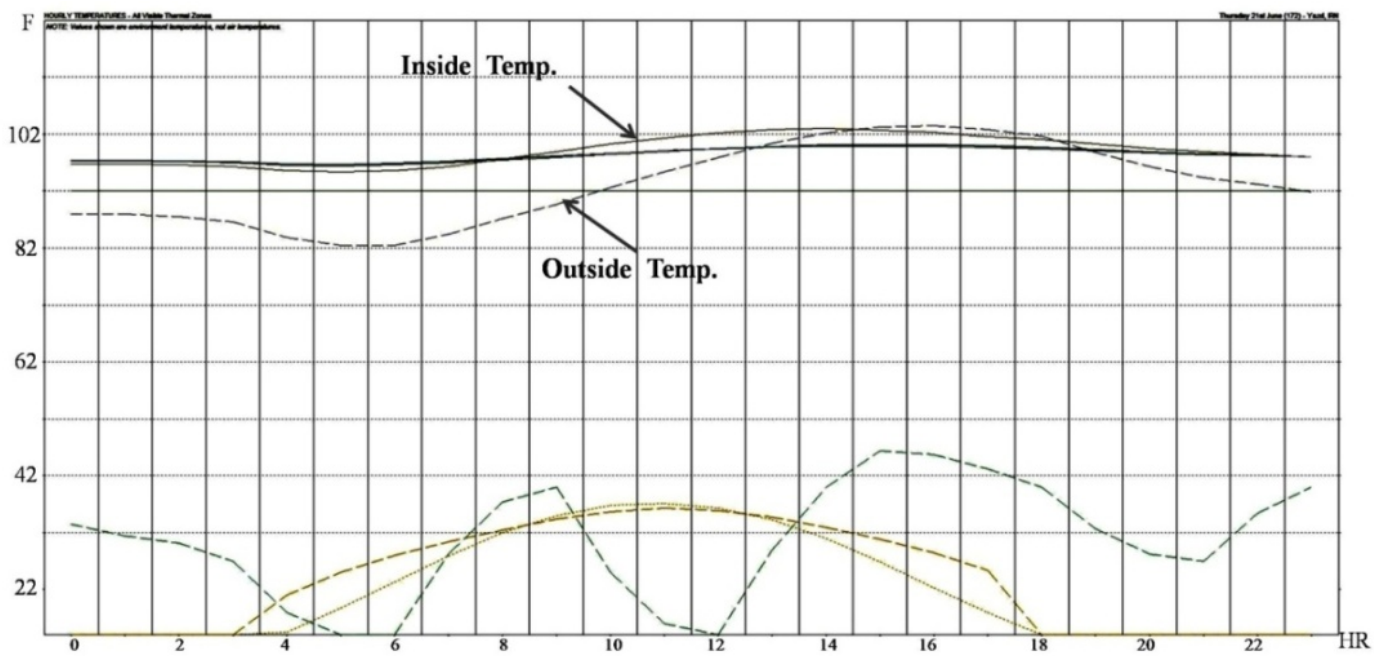

FIGURE 4.1.13: HOURLY TEMPERATURE ON JUNE $21^{\text {ST }}$ AUTODESK ECOTECT 2011 


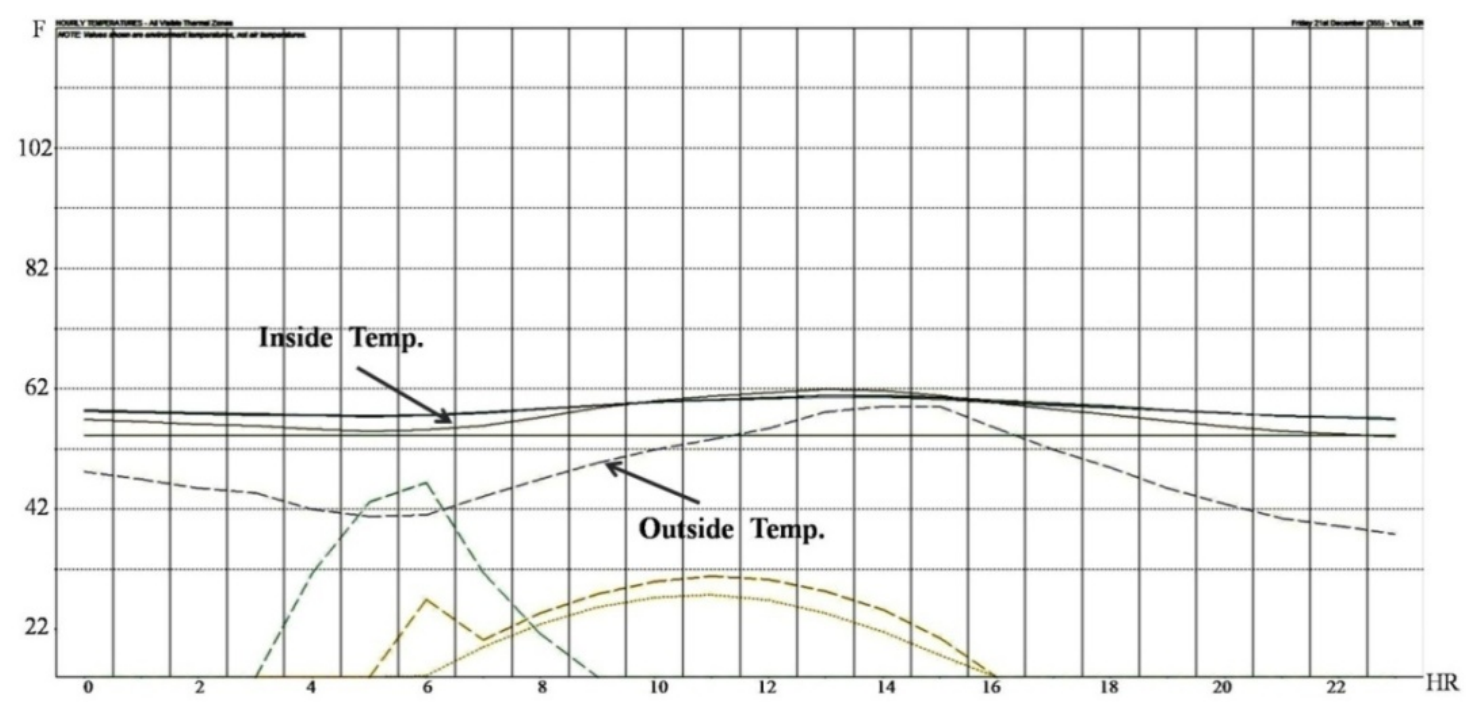

FIGURE 4.1.14: HOURLY TEMPERATURE ON DECEMBER $21^{\text {ST }}$ AUTODESK ECOTECT 2011

\subsubsection{Analysis of a Corrugated Building Skin;}

\section{Cooling Ribs Analysis}

After analyzing atypical flat facade office building located in Yazd and looking at the comfort zone it creates (or lack thereof) for the users (figures 4.1.13-14), it has been determined that the first step necessary to be taken in order to reduce the interior temperature and exterior skin temperature is to reduce the heat gain of the exterior skin. The less incident solar radiation the exterior skin receives, the less heat would be transferred through the building skin. Therefore, minimizing the surface area exposed to the solar radiation helps to minimize the heat gain for the entire facade system. Looking at the "Cooling Ribs" effect in the Barrel Cactus, the corrugated skin causes part of the skin to be in the shade and part of the skin to be exposed to the Sun; which minimizes the area that is directly exposed to the Sun to almost half.

Based on the solar radiation analysis and hourly temperature calculation for the flat typical exterior skin in the previous section, going forward will be only analysis 
proposing design solutions on June $21^{\text {st }}$ since this is the time of year that the inside and outside temperatures are at the most extreme in regards to heat gain. Since controlling heat gain and balancing daylight are the major concerns of this research paper, this seems appropriate.

Here is the summary of the process used to calculate the temperature of the surface exposed to the solar radiation based on the amount of the incident solar radiation:

- Ecotect analysis to calculate the incident solar radiation $\left(\mathrm{Q}_{\mathrm{sun}}\right)$

- Calculate the amount of solar radiation absorbed by the concrete wall $\left(Q_{\text {in }}\right)$

- Calculate the temperature of the concrete wall based on the absorbed solar radiation.

\subsubsection{Ecotect Analysis to Calculate the Incident Solar Radiation $\left(Q_{\text {sun }}\right)$}

Figures 4.1.15 to 4.1.19 show the Ecotect analyzed incident solar radiation for a south facing corrugated building skin with 9 floors on June $21^{\text {st }}$.

The materials of the exterior walls are the same as the pervious flat skin model so it would be easier to compare the two models.

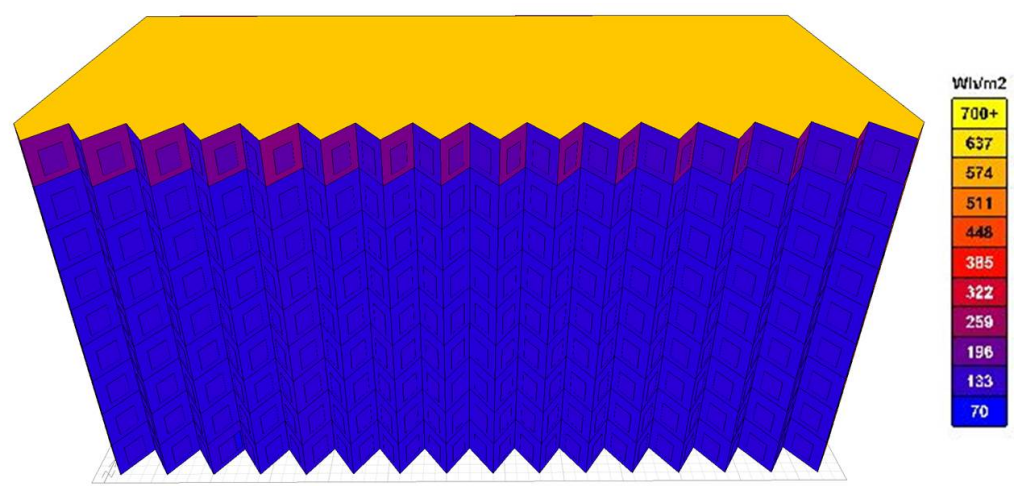

FIGURE 4.1.15: INCIDENT SOLAR RADIATION ANALYSIS OF CORRUGATE SKIN

JUNE $21^{\text {ST }} 8: 00$ - YAZD, IRAN

AUTODESK ECOTECT 2011 


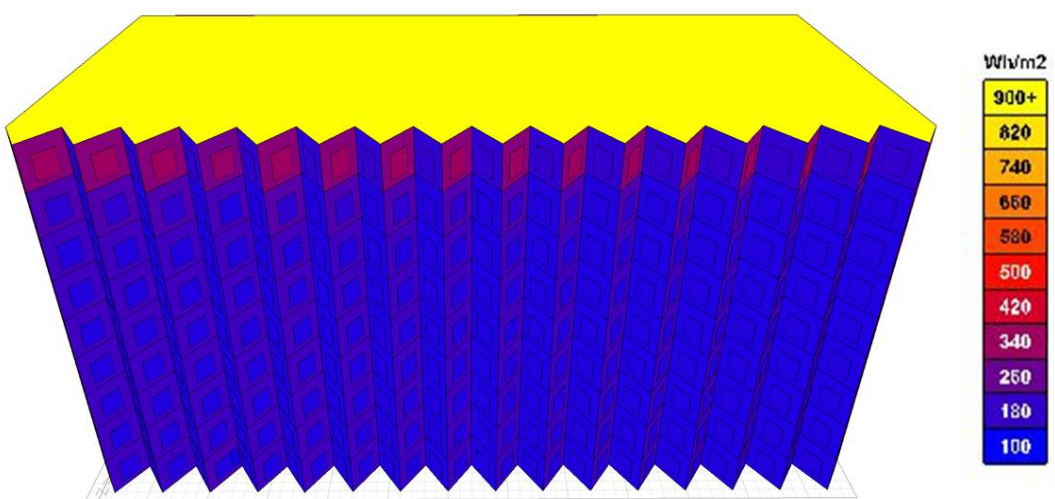

FIGURE 4.1.16: INCIDENT SOLAR RADIATION ANALYSIS OF CORRUGATE SKIN

JUNE $21^{\text {ST }}$ 10:00 - YAZD, IRAN

AUTODESK ECOTECT 2011

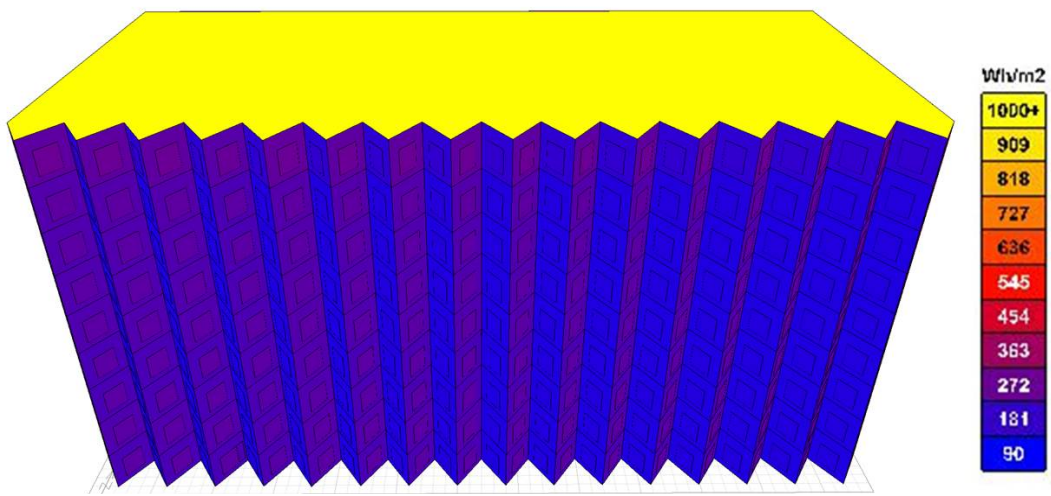

FIGURE 4.1.17: INCIDENT SOLAR RADIATION ANALYSIS OF CORRUGATE SKIN

JUNE $21^{\text {ST }}$ 12:00 - YAZD, IRAN

AUTODESK ECOTECT 2011

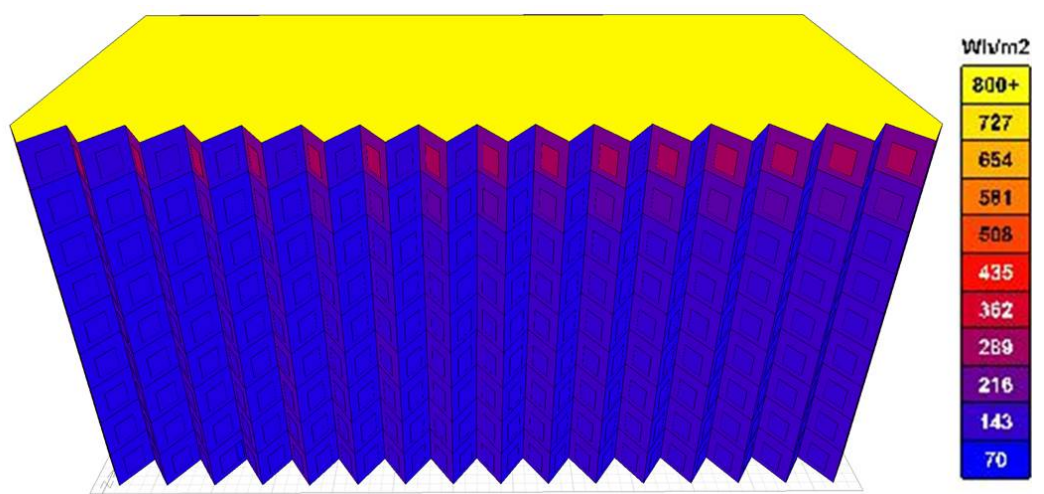

FIGURE 4.1.18: INCIDENT SOLAR RADIATION ANALYSIS OF CORRUGATE SKIN

JUNE $21^{\text {ST }}$ 14:00 - YAZD, IRAN

AUTODESK ECOTECT 2011 


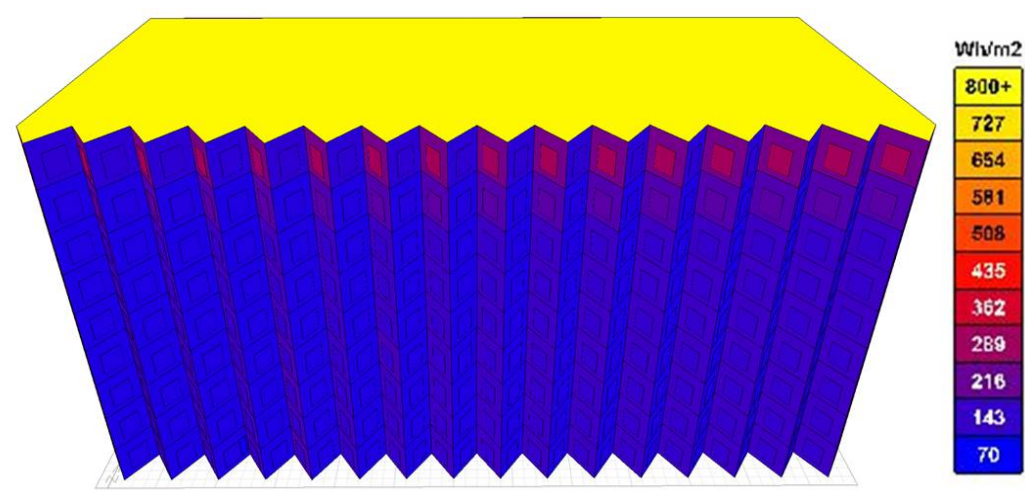

FIGURE 4.1.19: INCIDENT SOLAR RADIATION ANALYSIS OF CORRUGATE SKIN

JUNE $21^{\text {ST }}$ 16:00 - YAZD, IRAN

AUTODESK ECOTECT 2011

The Ecotect analysis shown in the figures 4.1.15-19 obviously show that at least half of the exterior vertical skin area is exposed to less solar radiation when compared to the flat vertical skin (figures 4.1.2-11) and therefore expecting less temperature for the skin. The portion that is exposed to the Sun, when compared to the flat skinned building, should receive a lower amount of solar radiation since it is not perpendicularly exposed to the Sun during the hottest time of the day, 12:00pm on June $21^{\text {st }}$. Also, since the portion of the building that is exposed to the Sun changes through out the day, the thermal mass of the wall should retain less heat and therefore less heat should radiate through the wall and into the interior of the building.

\subsubsection{Calculate the Amount of Solar Radiation Absorbed by the Concrete Wall}

$$
\left(Q_{\text {in }}\right)
$$

The next step is to calculate the $\mathrm{Q}_{\text {in }}$ of the corrugated skin based on the calculated $\mathrm{Q}_{\text {sun }}$ in the previous step and the absorption ratio of the building skin material (equation 
4.1). Table 4.1.3 shows the results of the calculation $\left(Q_{\text {in }}\right)$ for the east and west facing portions of the south facing wall of the exterior facade system on June 21.

\begin{tabular}{|c|c|c|c|c|c|}
\hline \multirow{2}{*}{\multicolumn{2}{|c|}{ Time }} & \multicolumn{2}{|c|}{ Vertical East Facing Skin } & \multicolumn{2}{|c|}{ Vertical West Facing Skin } \\
\hline & & \multirow{2}{*}{$\begin{array}{c}\begin{array}{c}\mathrm{Q}_{\text {sun }} \\
\left(\mathrm{W} / \mathrm{m}^{2}\right)\end{array} \\
133\end{array}$} & \multirow{2}{*}{$\frac{\begin{array}{c}\mathrm{Q}_{\text {in }} \\
\left(\mathrm{W} / \mathrm{m}^{2}\right)\end{array}}{79.8}$} & \multirow{2}{*}{$\frac{\begin{array}{c}\mathrm{Q}_{\text {sun }} \\
\left(\mathrm{W} / \mathrm{m}^{2}\right)\end{array}}{70}$} & \multirow{2}{*}{$\frac{\begin{array}{c}\mathrm{Q}_{\text {in }} \\
\left(\mathrm{W} / \mathrm{m}^{2}\right)\end{array}}{42}$} \\
\hline \multirow{5}{*}{ 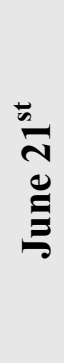 } & $8: 00$ & & & & \\
\hline & $10: 00$ & 250 & 150 & 70 & 42 \\
\hline & $12: 00$ & 272 & 163.2 & 90 & 54 \\
\hline & $14: 00$ & 70 & 42 & 170 & 102 \\
\hline & $16: 00$ & 70 & 42 & 170 & 102 \\
\hline
\end{tabular}

TABLE 4.1.3: HOURLY CALCULATION OF THE QIN BASED ON THE AMOUNT OF INCIDENT SOLAR RADIATION (Q $\left.{ }_{\text {SUN }}\right)$ AND ABSORPTION RATIO OF THE EXTERIOR SKIN $(\alpha)$

Table 4.1.3 shows that the greatest amount of incident solar radiation and absorbed solar radiation (shown in red in the table) for the vertical south facing corrugated skin is at noon on June 21. The following calculation process section shows the maximum temperature of the vertical exterior skin considering the outside temperature and absorbed solar radiation (equation 4.2).

\subsubsection{Calculate the Temperature of the Concrete Wall Based on the Absorbed Solar Radiation and Outside Temprature}

Table 4.1.4 is based on the amount of solar radiation that a corrugated vertical exterior skin surface receives and then absorbs because of the material properties of the exterior surface and the outside temperature (equation 4.2). Table 4.1.4 shows the 
difference in the temperature of the exterior skins of the flat and corrugated skin models. Table 4.1.4 proves that the temperature of the vertical exterior skin surface would be higher on a flat skin than a corrugated skin due to the consistent exposure to the solar radiation.

\begin{tabular}{|c|c|c|c|c|}
\hline \multirow{7}{*}{ 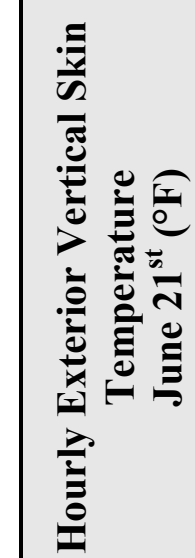 } & Time & $\begin{array}{c}\text { Vertical Flat } \\
\text { Skin }\end{array}$ & \multicolumn{2}{|c|}{ Vertical Corrugated Skin } \\
\hline & & & East Facing & West Facing \\
\hline & $8: 00$ & 120.63 & 110.18 & 99.12 \\
\hline & $10: 00$ & 138.43 & 133.96 & 104.71 \\
\hline & $12: 00$ & 154.78 & 142.01 & 113.70 \\
\hline & $14: 00$ & 137.05 & 114.07 & 130.10 \\
\hline & $16: 00$ & 122.41 & 116.90 & 132.70 \\
\hline
\end{tabular}

TABLE 4.1.4: HOURLY TEMPERATURE DIFFERENCES FOR THE VERTICAL FLAT EXTERIOR SKIN VS. THE CORRUGATED EXTERIOR SKIN

As shown in the table 4.1.4 the critical time of day for the flat surface temperature is at noon (shown in red color). When compared with the corrugated skin, the temperature is reduced by almost $12^{\circ} \mathrm{F}$ on the east facing surface and $41^{\circ} \mathrm{F}$ on the west facing surface.

Since the change in the form of the building skin (flat to the corrugated skin) was tested only on the vertical surfaces, the analytical results shown in the table 4.1.4 are only for the vertical surfaces (facade system) and not for the horizontal (roof system). The same result is assumed to happen for the corrugated roof when compared to a flat roof. 


\subsubsection{Calculate the Difference in Air Density Due to the Temperature Difference of the Surfaces}

Not only has it been proved that the exterior surface temperature of the corrugated skin is less than the exterior surface temperature of the flat skin for the same time of the day, but due to the difference in temperature of the west and east facing portions of the facade, an air movement (self-ventilated) is created which generates a heat loss due to convection as described in the second chapter. Convection occurs due to the difference in air density. The difference in temperature of the surface creates a difference in air density and therefore creates a self-ventilated air movement by convection. Equation 4.3 is used to calculate the difference in air density due to the difference in the surface temperature.

$$
\text { Air Density }=\frac{\text { Air Pressure } * 100}{\text { RT }}
$$

Air Pressure $=1,011 \mathrm{hpa}$

$\mathrm{R}=287.05 \mathrm{~J} / \mathrm{kg} . \mathrm{K}$ (Specific Gas Constant for Air)

$\mathrm{T}=$ Temperature of the Surface in $\mathrm{K}$

\section{EQUATION 4.3: AIR DENSITY DIFFERENCES DUE TO THE SURFACE TEMPERATURE DIFFERENCES ${ }^{57}$}

Base on the equation 4.3, results in the table 4.1.5 shows that the air density of the west facing and east facing vertical surfaces of the corrugated skin on June $21^{\text {st }}$ for 8:00, 10:00, 12:00, 14:00 and 16:00 are different. Therefore, there is the air movement by convection due to the calculated air density shown in the table 4.1.5. 


\begin{tabular}{|c|c|c|c|}
\hline \multirow{2}{*}{} & Time & East Facing & West Facing \\
\cline { 2 - 4 } & $8: 00$ & 1.11 & 1.13 \\
\cline { 2 - 4 } & $10: 00$ & 1.06 & 1.12 \\
\cline { 2 - 4 } & $12: 00$ & 1.05 & 1.10 \\
\cline { 2 - 4 } & $14: 00$ & 1.10 & 1.07 \\
\cline { 2 - 4 } & $16: 00$ & 1.09 & 1.07 \\
\hline
\end{tabular}

TABLE 4.1.5: AIR DENSITY CALCULATION DUE TO THE DIFFERENCE IN THE TEMPERATURE OF THE CORRUGATED SKIN JUNE $21^{\text {ST }}$

\subsubsection{Calculate the Heat Loss by Convection Due to the Difference in Air Density}

The next step after calculating the air density of each vertical surfaces of the corrugated skin (table 4.1.5) is to calculate the heat loss by convection that happens due to the differences in the air density. Figure 4.1.20 shows how convection happens on the corrugated skin due to the difference in the air density. Hot air on the hotter surfaces of the corrugated skin rises and it pulls in the cooler air from the colder side.

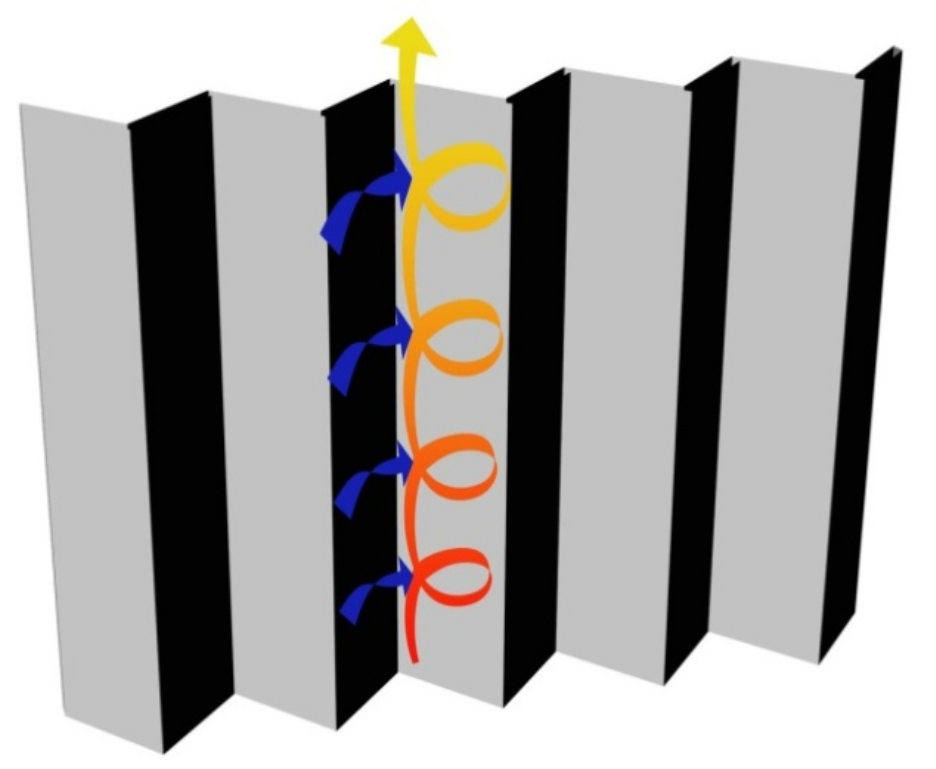

FIGURE 4.1.20: CONVECTION ON THE CORRUGATED SKIN DUE TO THE DIFFERENCE IN AIR DENSITY 
Air movement described due to convection creates a heat loss that we are able to calculate through the following equation:

$$
\mathrm{Q}=\mathrm{Sc}\left(\mathrm{T}_{1}-\mathrm{T}_{2}\right)^{5 / 4}
$$

$\mathrm{Q}=$ Heat loss through Convection on a Vertical Surface (BTU/HR)

$\mathrm{Sc}=\mathrm{A}$ constant Due to Orientation of the Surface $($ Vertical $=0.3)$

$\mathrm{T}_{1}=$ Surface Temperature $1\left({ }^{\circ} \mathrm{F}\right)$

$\mathrm{T}_{2}=$ Surface Temperature $2\left({ }^{\circ} \mathrm{F}\right)$

\section{EQUATION 4.4: HEAT LOSS CALCULATION DUE TO THE CONVECTION ${ }^{58}$}

Based on the equation 4.4, table 4.1.6 shows the heat loss due to convection on the corrugated vertical skin on June $21^{\text {st }}$ in five times of the day. As the time of the day changes, the position of the Sun changes too; this causes the skin exposed to the solar radiation to change throughout the day. This is another benefit to the corrugated skin; the building skin is directly exposed to the solar radiation for a less amount of time compared to the flat surface.

\begin{tabular}{|c|c|c|}
\hline \multirow{7}{*}{ 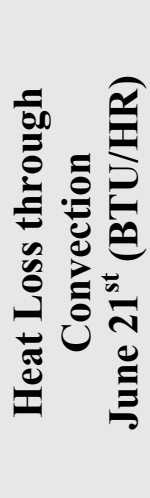 } & Time & Corrugated Skin \\
\hline & 8:00 & 6.05 \\
\hline & 10:00 & 20.40 \\
\hline & $12: 00$ & 19.58 \\
\hline & $14: 00$ & 9.61 \\
\hline & $16: 00$ & 9.45 \\
\hline & Total & 65.09 \\
\hline
\end{tabular}

TABLE 4.1.6: HEAT LOSS THROUGH CONVETION ON THE CORRUGATED SKIN

JUNE $21^{\text {ST }}$ 
In conclusion, table 4.1 .6 proves that there is the heat loss due to convection based on the geometry of the building skin; just by changing a flat facade system to the simple flat corrugated facade there is a possibility of creating a "Cooling Ribs" effect to self-ventilate the skin. Not only by changing the geometry and form of the skin, the temperature of the exterior skin decreases (table 4.1.4), but also air movement is created by the difference of the surface temperature on the corrugated surfaces. By selfventilating the surface consistently through out the day, it will help regulate the interior climate of the building by creating a heat loss on the exterior surface of the building. The amount of ventilation rate due to convection is then the next step to be calculated. This step however is not completed for the simple flat corrugated skin, but instead was completed for the final design of the building; a curved corrugated skin. The final step for the simple, flat corrugated skin is proving that folding the skin creates heat loss due to convection. The amount of heat loss based on the convection (table 4.1.6) might not be that much, but just proves that the Self-ventilating system has been created by the form of the facade system. Also by having the consistent air movement on the skin, the temperature is decreasing to the less of what has been calculated in table 4.1.4. Because of the lack of knowledge and information in terms of the ventilation and air movement, calculation of the reduction in temperature based on the air movement of the Selfventilation system would not be that exact and possible by the hand calculation although, the reduction of the temperature by consistent convection is possible to be calculated by advanced programs. All the tables regarding the hourly vertical surface temperature, difference in air density and heat loss by convection for the vertical corrugated skin has been provided for each specific time in the appendix section of the paper. 
The final results as explained before are for the vertical surfaces and therefore for the facade system. Since the numbers of the calculation showed that changing the flat vertical exterior skin to the corrugated skin creates the self-ventilating skin(ventilation rate has not been calculated for the flat corrugated skin yet but for the curved corrugated skin), heat loss by convection (table 4.1.6), the same type of design has been assumed successful for the roof system. Although the roof system is a horizontal skin and the amount of heat loss may not be as much as the vertical surface, corrugated skin for the roof system obviously creating different orientations of the exposed surfaces to the solar radiation and so different surface temperatures, different air density on each surface and hence heat loss by convection.

\subsubsection{Analysis of a Curved Corrugated Building Skin; \\ Globe Configuration Effect}

The next step in optimization of the design of the exterior skin is changing the corrugated skin to the curved corrugated skin (figure 4.1.21) based on the information discussed in chapters 1, 2 and 3 about the benefits of the Globe Configuration; curved skin or globe form of the exterior skin not only minimizes the amount of the exposed area to the solar radiation but also the exposed area to the solar radiation is consistently changing due to the changes in the time of day. In this section, not only the corrugated skin was converted to the curved corrugated skin but also the flat roof system changed to a curved corrugated skin as well. The design presented here is the final design based on the entirety of the information discovered during the research process. The final design will not only be a double skin facade system, but will have a curved corrugated exterior 
skin that is Self-shading and will utilizes heat stacking and the "Venturi Effect" in the air gap between the double skin to help ventilate the heat energy (figure 4.1.21). Due to the complexity of the entire exterior skin geometry, there have been some issues regarding the incident solar radiation analysis performed in Ecotect. Therefore, only the exterior skin will be included in the computer generated analysis (using Geco, see below) and calculations while the rest of the calculations will be performed by hand.

Although the flat skin analysis and corrugated skin analysis was completed for a 9 floor building, the final curved corrugated exterior skin is a part of a 20 floor building. This increase in floors was to further increase the challenge of trying to design a tall office building in a hot dry climate like Yazd, Iran. Also, the idea of having the Stack ventilation system integrated with the skin should be greatly amplified with this increase in building height.

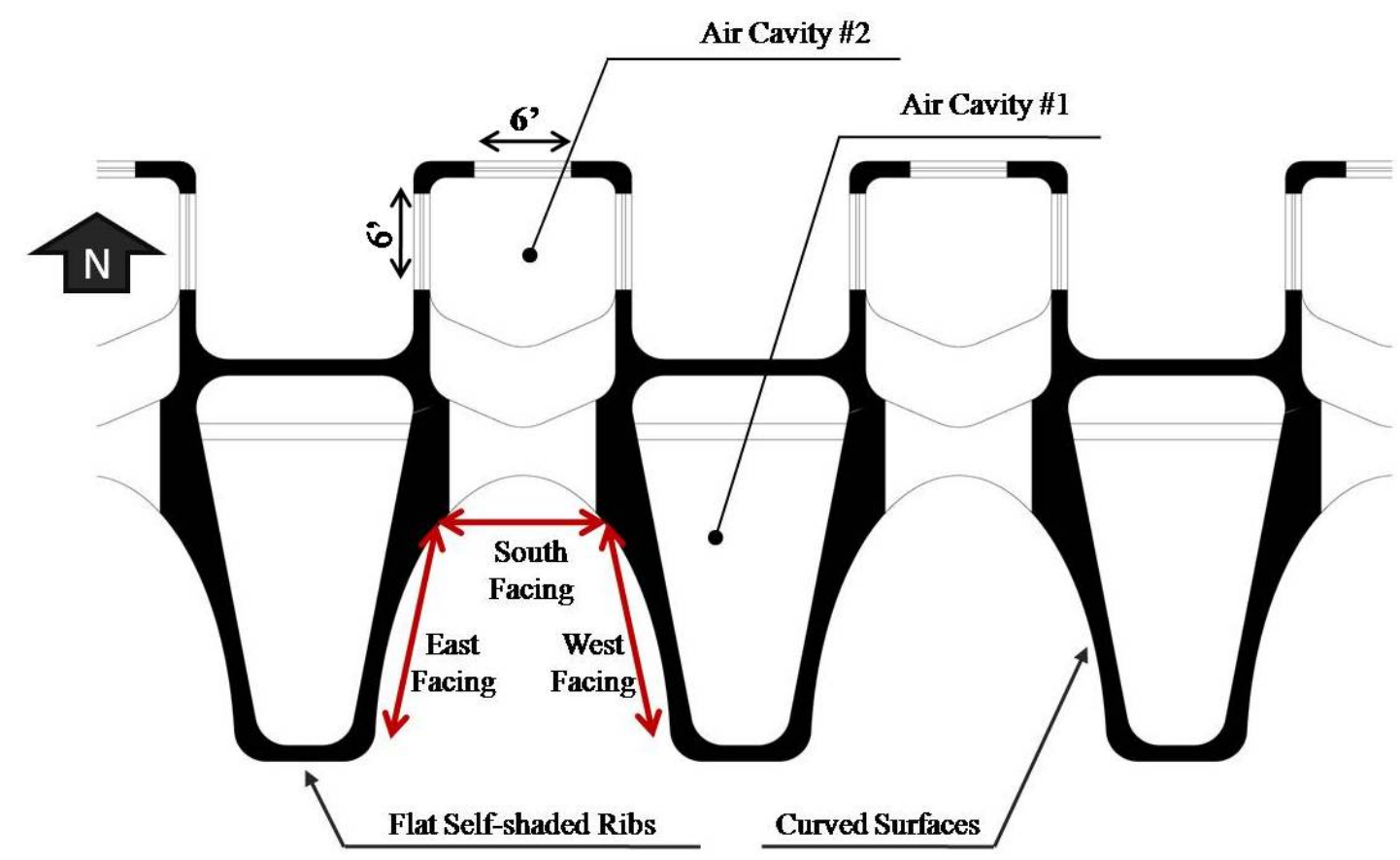

FIGURE 4.1.21: $20^{\mathrm{TH}}$ LEVEL OF CURVED CORRUGATED PLAN SECTION 
Before starting the analysis and calculation process for the curved corrugated skin, here is the summary to review the process of exterior skin temperature and selfventilating behavior:

- Ecotect analysis to calculate the incident solar radiation $\left(\mathrm{Q}_{\text {sun }}\right)$

- Calculate the amount of solar radiation absorbed by the concrete wall $\left(\mathrm{Q}_{\text {in }}\right)$

- Calculate the temperature of the concrete wall based on the absorbed solar radiation.

- Calculate the difference in air density due to the temperature difference of the surfaces.

- Calculate the heat loss by convection due to the difference in air density.

\subsubsection{Ecotect Analysis to Calculate the Incident Solar Radiation $\left(Q_{\text {sun }}\right)$}

Figures 4.1.22 to 4.1.26 show the Incident solar radiation of the exterior skin in Geco (Grasshopper plug-in that connects the Rhino files to Ecotect to analyze). Figures 4.1.22-26 show that part of the analyzed curved surfaces in certain times of the day are blue in color signifying that there is little to no direct incident solar radiation on that portion of the curved surface. It is interesting to compare the values/colors with the flat exterior skin and the simple corrugated skin. Figures 4.1.22-26 also show that the amount of directly exposed surfaces to the solar radiation are consistently changing. The highest surface temperature based on the Geco analysis will be explained in the following sections. The Geco analysis also provide us with the incident solar radiation analysis for the "Flat Self-Shaded Ribs" of the curved corrugated skin (figure 4.1.21) for which the color of the skin is nearly consistent for the entire length of the surface. The reason this is 
possible has to do with the Self-shading behavior of the flat portion of the exterior skin. Author will explain this in further detail as the paper progresses.

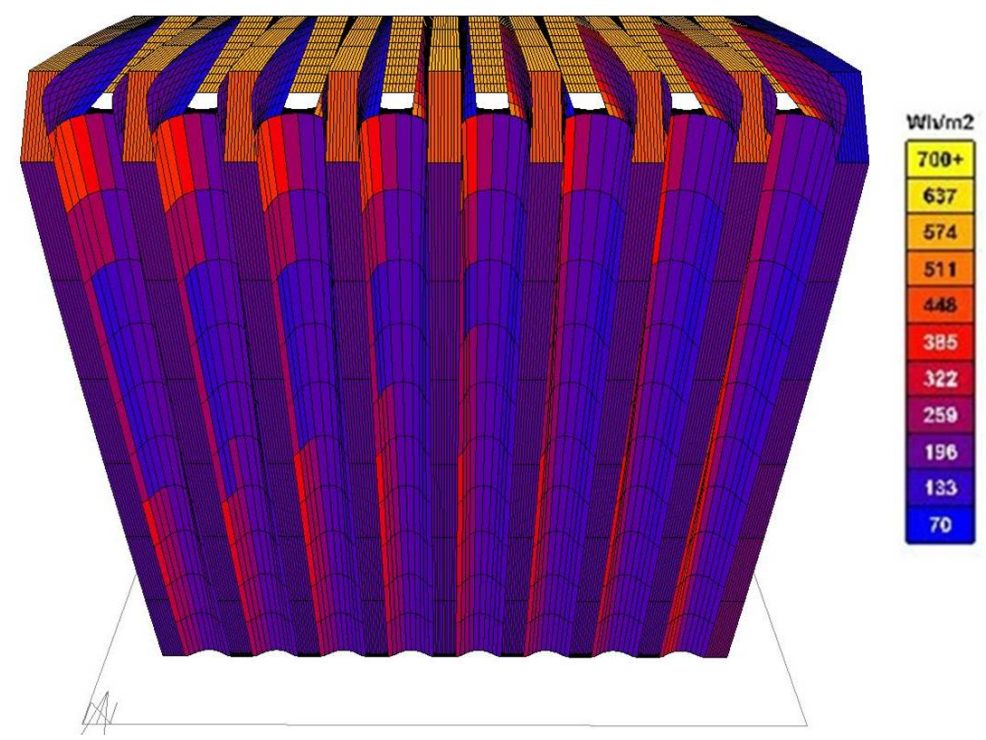

FIGURE 4.1.22: INCIDENT SOLAR RADIATION ANALYSIS JUNE $21^{\mathrm{ST}} 8: 00$ - YAZD, IRAN GECO ANALYSIS

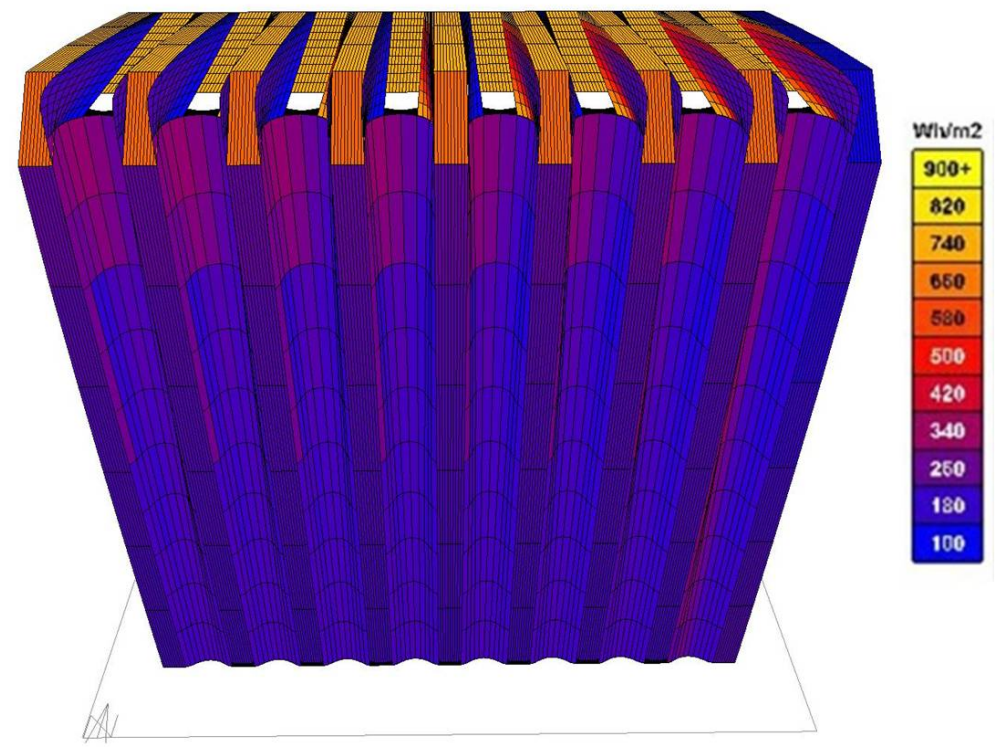

FIGURE 4.1.23: INCIDENT SOLAR RADIATION ANALYSIS JUNE $21^{\text {ST }}$ 10:00 - YAZD, IRAN GECO ANALYSIS 


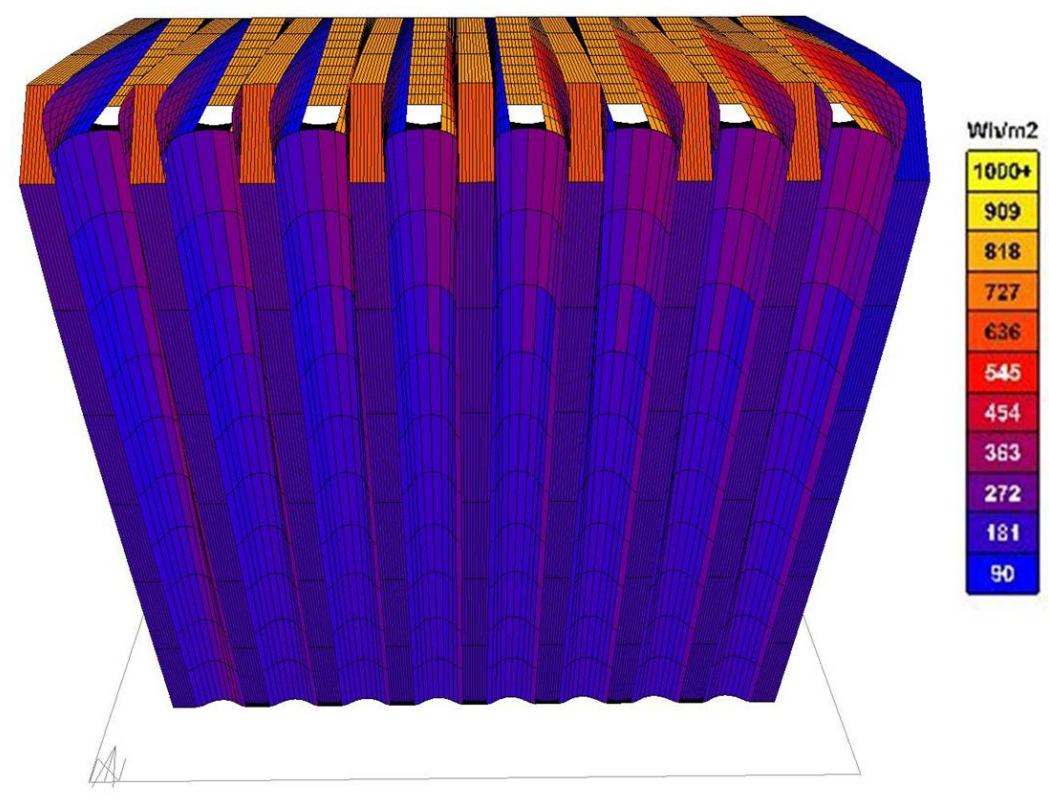

FIGURE 4.1.24: INCIDENT SOLAR RADIATION ANALYSIS JUNE $21^{\text {ST }}$ 12:00 - YAZD, IRAN GECO ANALYSIS

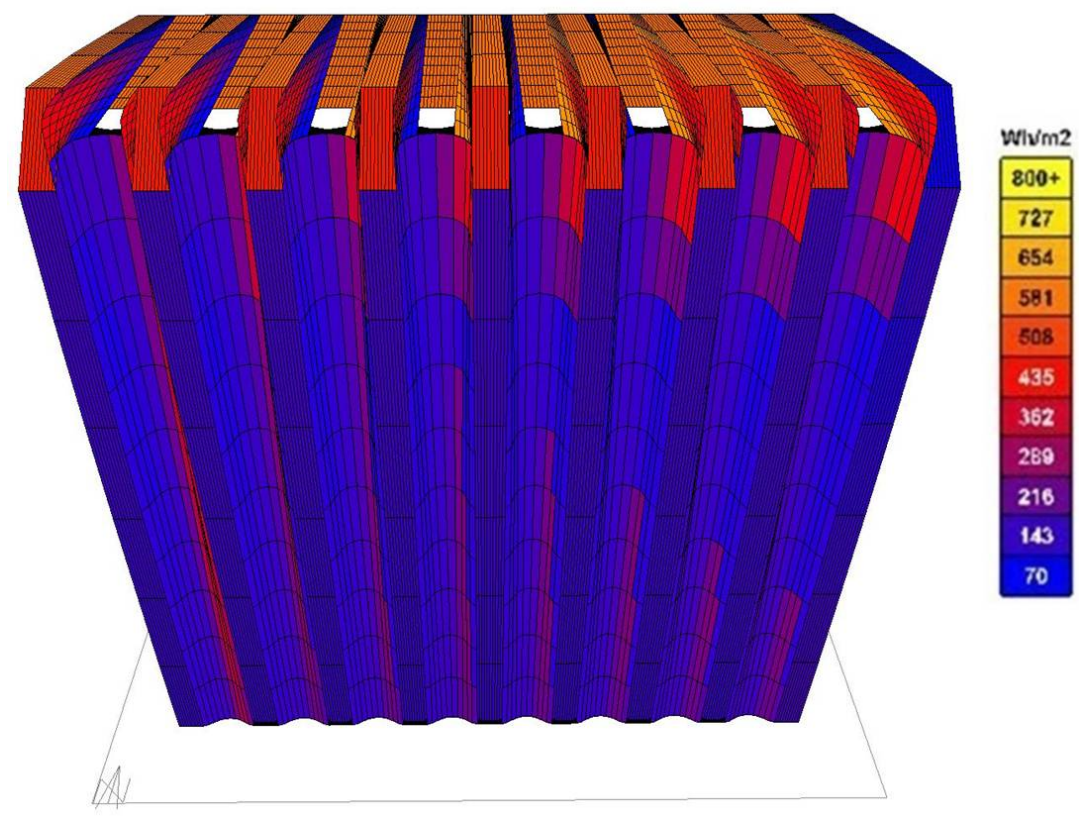

FIGURE 4.1.25: INCIDENT SOLAR RADIATION ANALYSIS JUNE $21^{\text {ST }} 14: 00$ - YAZD, IRAN

GECO ANALYSIS 


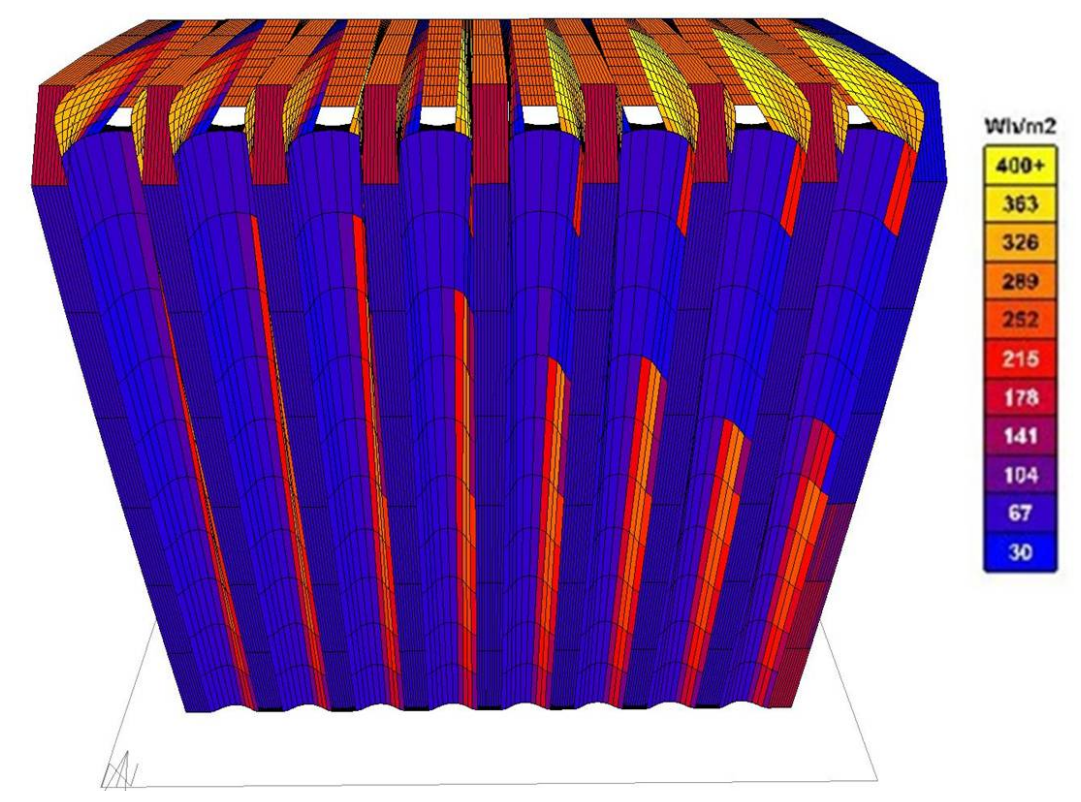

FIGURE 4.1.26: INCIDENT SOLAR RADIATION ANALYSIS JUNE $21^{\text {ST }} 16: 00$ - YAZD, IRAN

GECO ANALYSIS

\subsubsection{Calculate the Amount of Solar Radiation Absorbed by the Concrete Wall}

$\left(Q_{\text {in }}\right)$

While there are only two kinds of surfaces exposed to the solar radiation in the simple corrugated skin, a curved surface has as infinite numbers of surfaces each having differrnt tempratures based on the equation 4.2. Therefore, the author divided the curved surface skin into three sections: east facing, south facing and west facing (figure 4.1.21) in order to simplify the calculations and the presentation of the data.The calculation of the $\mathrm{Q}_{\text {in }}$ is for each surface based on the amount of incident solar radiation and absorption ratio of the exterir skin (concrete walls) on the sepcific time. The table (4.1.7) shows the calculated amount of $\mathrm{Q}_{\text {in }}$ based on equation 4.1. The table shows that the maximum absorbed solar radiation is for the west facing skin at 14:00. Also the east facing skin at 8:00 in the morning has a close calculated absorbed solar radiation to maximum. This 
table does not show the maximum temperature of the surface though since the outside temprature is another factor effecting the exterior skin temprature. The next step will be the calculation of the surface temprature based on the amount of absorbed solar radiation and outdoor temprature (equation 4.2).

\begin{tabular}{|c|c|c|c|c|c|c|c|}
\hline & \multirow{2}{*}{ Time } & \multicolumn{2}{|c|}{$\begin{array}{c}\text { Vertical East } \\
\text { Facing Skin 1/3 }\end{array}$} & \multicolumn{2}{|c|}{$\begin{array}{l}\text { Vertical South } \\
\text { Facing Skin 1/3 }\end{array}$} & \multicolumn{2}{|c|}{$\begin{array}{l}\text { Vertical West } \\
\text { Facing Skin } 1 / 3\end{array}$} \\
\hline & & $\begin{array}{c}\mathrm{Q}_{\text {sun }} \\
\left(\mathrm{W} / \mathrm{m}^{2}\right)\end{array}$ & $\begin{array}{c}\mathrm{Q}_{\text {in }} \\
\left(\mathrm{W} / \mathrm{m}^{2}\right)\end{array}$ & $\begin{array}{c}\mathrm{Q}_{\text {sun }} \\
\left(\mathrm{W} / \mathrm{m}^{2}\right)\end{array}$ & $\begin{array}{c}\mathrm{Q}_{\text {in }} \\
\left(\mathrm{W} / \mathrm{m}^{2}\right)\end{array}$ & $\begin{array}{c}\mathrm{Q}_{\text {sun }} \\
\left(\mathrm{W} / \mathrm{m}^{2}\right)\end{array}$ & $\begin{array}{c}\mathrm{Q}_{\text {in }} \\
\left(\mathrm{W} / \mathrm{m}^{2}\right)\end{array}$ \\
\hline \multirow{5}{*}{ 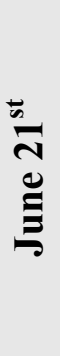 } & $8: 00$ & 221 & 132.6 & 133 & 79.8 & 70 & 42 \\
\hline & $10: 00$ & 201 & 120.6 & 100 & 60 & 115 & 69 \\
\hline & $12: 00$ & 90 & 54 & 145 & 87 & 181 & 108.6 \\
\hline & $14: 00$ & 70 & 42 & 143 & 85.8 & 224 & 134.4 \\
\hline & $16: 00$ & 30 & 18 & 50 & 30 & 160 & 96 \\
\hline
\end{tabular}

TABLE 4.1.7: HOURLY CALCULATION OF THE QIN BASED ON THE AMOUNT OF INCIDENT SOLAR RADIATION (Q SUN $)$ AND ABSORPTION RATIO OF THE EXTERIOR SKIN $(\alpha)$

\subsubsection{Calculate the Temperature of the Concrete Wall Based on the Absorbed Solar Radiation}

Table 4.1.8 is the result of the calculation for the temperature of the exposed surface area for each section of the curved corrugated skin (figure 4.1.21) based on equation 4.2 .

Since the surface temperature is different for each level of the skin because of the Self-shading behavior of the final surface design, the surface temperature calculation in table 4.1.8 was completed only for the $10^{\text {th }}$ floor of the curved exterior surface, so the calculated result could be considered near the average for the entire curved surface as the 
$10^{\text {th }}$ floor is the most middle floor. It is worth noting, the steps described to determine the values for the $10^{\text {th }}$ floor could be repeated for the remaining floors. Table (4.1.8) shows that because of the globe shape, the temperature of the curved corrugated skin during the hottest time of the day is less than the simple corrugated skin. Table 4.1 .8 compares the surface temperature results for the flat, corrugated and curved corrugated skin based on equation 4.2. Looking at the table, it shows that during the critical time of the day, June $21^{\text {st }}$ at noon, the maximum temperature of the exposed surface areas (shown in red color) is lower on the curved corrugated skin when compared to the values for the flat corrugated skin by $14^{\circ} \mathrm{F}$ and is less than the maximum surface temperature of the flat skin by $26^{\circ} \mathrm{F}$. The curved skin on the $10^{\text {th }}$ floor, compared to the simple flat corrugated skin has either the same temperature, lower temperature or sometimes higher temperature for the exposed surface area. What is important though is the maximum temperature of the surface exposed to the solar radiation during the critical time of the day (at noon) is lower on the curved corrugated skin compared to the flat corrugated one.

Not to mention that even the exposed surfaces to the solar radiation in the curved skin vs. the flat corrugated skin that have higher surface temperature are consistently changing due to the globe effect. Therefore, the real surface temperature is even less than what is calculated in the table 4.1.8 here since it is not possible to do the hand calculation for reduction in the surface temperature due to the consistent changing of the position of the Sun. 


\begin{tabular}{|c|c|c|c|c|c|c|c|}
\hline \multirow{7}{*}{ 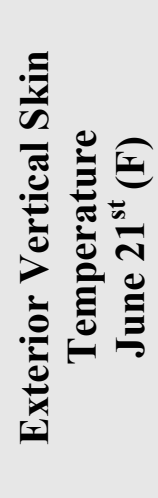 } & \multirow[t]{2}{*}{ Time } & \multirow[t]{2}{*}{$\begin{array}{l}\text { Flat } \\
\text { Skin }\end{array}$} & \multicolumn{2}{|c|}{ Corrugated Skin } & \multicolumn{3}{|c|}{$\begin{array}{l}\text { Curved Corrugated Skin } \\
\left(\mathbf{1 0}^{\text {th }} \text { Floor }\right)\end{array}$} \\
\hline & & & $\begin{array}{c}\text { East } \\
\text { Facing } \\
\end{array}$ & $\begin{array}{c}\text { West } \\
\text { Facing }\end{array}$ & $\begin{array}{c}\text { East } \\
\text { Facing } \\
\end{array}$ & $\begin{array}{l}\text { South } \\
\text { Facing }\end{array}$ & $\begin{array}{r}\text { West } \\
\text { Facing }\end{array}$ \\
\hline & 8.00 & 120.63 & 110.18 & 99.12 & 124.63 & 110.18 & 99.12 \\
\hline & 10.00 & 138.43 & 133.96 & 104.71 & 126.42 & 109.91 & 112.45 \\
\hline & 12.00 & 154.78 & 142.01 & 113.70 & 113.70 & 122.70 & 128.36 \\
\hline & 14.00 & 137.05 & 114.07 & 130.10 & 114.07 & 125.90 & 138.24 \\
\hline & 16.00 & 122.41 & 116.90 & 132.70 & 110.19 & 113.57 & 131.18 \\
\hline
\end{tabular}

TABLE 4.1.8: HOURLY SURFACE TEMPERATURES

As mentioned before, the results here are for the vertical surfaces. The results however show that because of the Globe Configuration, the maximum surface temperature of the curved skin is lower than the maximum surface temperature of the flat corrugated skin. The same conclusion is assumed to be true for the curved corrugated horizontal roof surface; as seen by the colors in Figures 4.1.22-26 since the reason of the lower surface temperature is having fewer surfaces exposed directly to the solar radiation, a curved corrugated horizontal skin minimizes the amount of surface area exposed directly to the solar radiation as well. Therefore there are more surfaces in shade or indirectly exposed to the solar radiation with the lower surface temperatures. This concept also was explained in the second chapter as one of the passive design strategies has been taken to consideration for years in Yazd; dome-shaped roofs.

\subsubsection{Calculate the Difference in Air Density Due to the Temperature Difference of the Surfaces}

The next step is to find out if there are any changes in the air density of the exposed vertical surfaces due to the difference in temperature of the east facing, south 
facing and west facing surfaces (equation 4.3) and so any heat loss by convection (equation 4.4). The same steady state formula for the air density, equation 4.3, explained before in the corrugated skin section, applied here to calculate the air density based on the temperature differences for the curved corrugated vertical surfaces. Table 4.1.9 shows the air density on each side of the curved section in the five times of the day. Table 4.1.9 shows that convection happen due to the difference in the air density of each sides of the curved skin. Although the difference in the air density might not be much, it is possible to calculate the heat loss through the convection because of the differences in the air density based on the equation 4.4 .

\begin{tabular}{|c|c|c|c|c|c|c|}
\hline \multirow{2}{*}{ Time } & \multicolumn{2}{|c|}{ Corrugated Skin } & \multicolumn{2}{c|}{ Curved Corrugated Skin } \\
\cline { 2 - 7 } & $\begin{array}{c}\text { East } \\
\text { Facing }\end{array}$ & $\begin{array}{c}\text { West } \\
\text { Facing }\end{array}$ & $\begin{array}{c}\text { East } \\
\text { Facing }\end{array}$ & $\begin{array}{c}\text { South } \\
\text { Facing }\end{array}$ & $\begin{array}{c}\text { West } \\
\text { Facing }\end{array}$ \\
\cline { 2 - 7 } & $8: 00$ & 1.11 & 1.13 & 1.085 & 1.11 & 1.13 \\
\cline { 2 - 7 } & $10: 00$ & 1.06 & 1.12 & 1.08 & 1.11 & 1.10 \\
\cline { 2 - 7 } & $12: 00$ & 1.05 & 1.10 & 1.10 & 1.08 & 1.07 \\
\cline { 2 - 7 } & $14: 00$ & 1.10 & 1.07 & 1.10 & 1.08 & 1.06 \\
\cline { 2 - 7 } & $16: 00$ & 1.09 & 1.07 & 1.11 & 1.10 & 1.07 \\
\hline
\end{tabular}

TABLE 4.1.9: AIR DENSITY CALCULATION DUE TO THE TEMPERATURE DIFFRENECE JUNE $21^{\text {ST }}$

\subsubsection{Calculate the Heat Loss by Convection Due to the Difference in Air Density}

The results in table 4.1.10 are based on equation 4.4; heat loss calculation due to difference in the air density. Table 4.1.10 shows the total heat loss that happens between the east facing and south facing surfaces, and this also happens between the south facing and west facing surfaces due to the convection. 


\begin{tabular}{|c|c|c|c|}
\hline \multirow{7}{*}{ 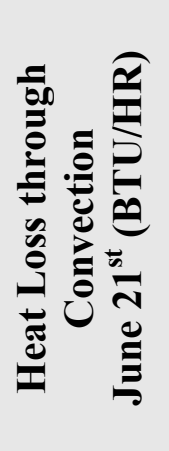 } & Time & Corrugated Skin & Curved Corrugated Skin \\
\hline & 8.00 & 6.05 & 14.50 \\
\hline & 10.00 & 20.40 & 10.95 \\
\hline & 12.00 & 19.58 & 7.29 \\
\hline & 14.00 & 9.61 & 13.51 \\
\hline & 16.00 & 9.45 & 12.19 \\
\hline & Total & 65.09 & 58.44 \\
\hline
\end{tabular}

TABLE 4.1.10: HEAT LOSS THROUGH THE CONVETION ON THE CORRUGATED SKIN VS. CURVED CORRUGATED SKIN

Table 4.1.10 also compares the heat loss of the flat corrugated skin vs. curved corrugated skin. Based on the table 4.1.10 results, the total heat loss due to the convection occurs between the east facing and west facing surfaces for the corrugated skin is more than the total heat loss happens between the east facing, south facing and west facing of the curved corrugated skin. This conclusion seems to be accurate since the difference in the temperature of the two folded flat surfaces is more than the temperature difference of the three surfaces of the curved skin. Although the curved corrugated skin Geco analysis (Figures 4.1.22-26) shows less exposed surfaces to the solar radiation because the surfaces are mostly in shade compared to the Ecotect analysis of the flat corrugated skin (figures 4.1.15-19), the heat loss of the curved skin is close to the corrugated skin (table 4.1.10). Which concludes that the surface temperature of the curved skin even less in reality. It is difficult to calculate how much heat loss is actually occurring and the temperature of the surfaces reduced based on self-ventilating air movement. Due to the existence of the heat loss (table 4.1.10), the author assumes that there is a reduction in the surface temperature due to heat loss by convection. 


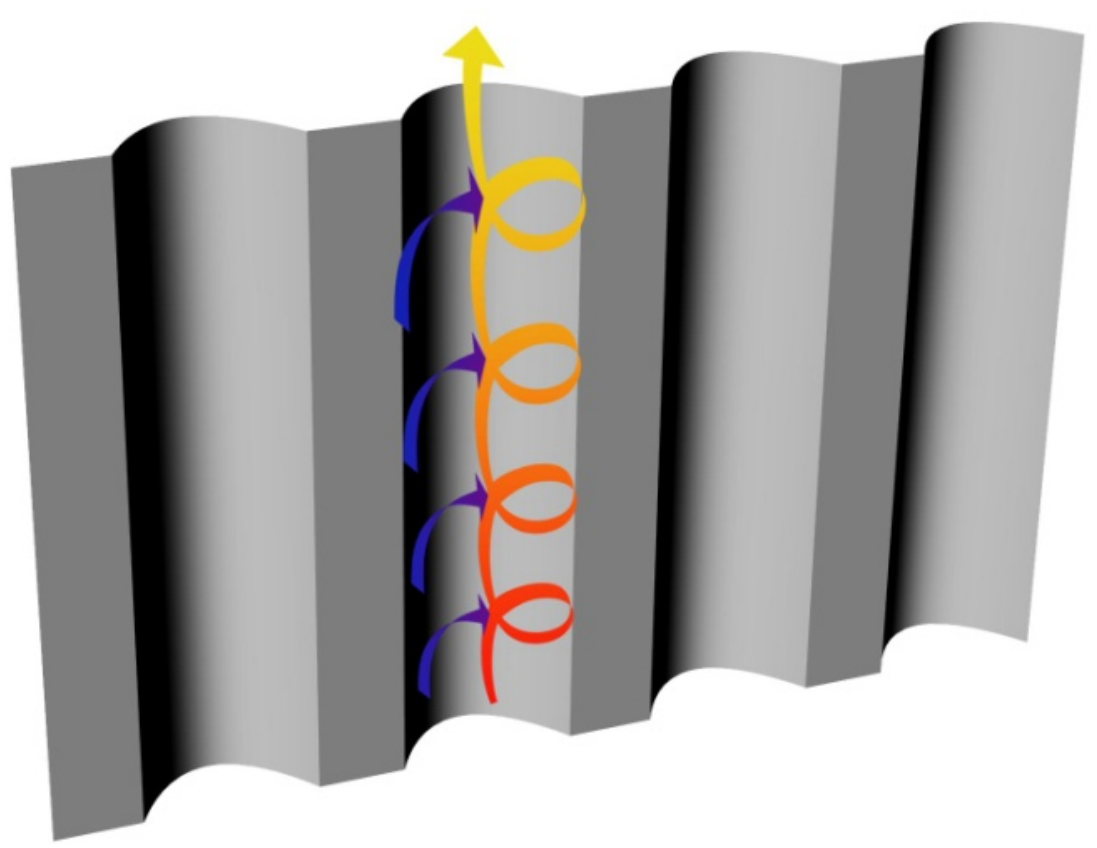

\section{FIGURE 4.1.27: CONVECTION ON THE CORRUGATED SKIN DUE TO DIFFERENCE IN AIR DENSITY}

Figure 4.1.27 displays the heat loss by convection on the curved corrugated skin. Hot air rises on the surface area with the higher surface temperature and it pulls in the cool air on the cooler surface that is in the shade or indirectly exposed to the solar radiation. This process may happen on the east facing, south facing or west facing surface area based on the time of the day.

The curved corrugated skin may not have higher heat loss when compared to the flat corrugated skin but there are three reasons that made the author decide to choose this type of the skin rather than the simple corrugated skin going forward. First, the 20 floors Geco analysis of the curved skin (Figures 4.1.22-26) is clearly showing that, there is less surface area exposed to the direct solar radiation for the most part of the day when compared to the 9 floor Ecotect analysis of the flat corrugated skin. So generally, the curved corrugated skin has lower surface temperature for the entire skin and so lower 
interior temperature for the building envelope. Second, the critical surface temperature (at noon on June $21^{\text {st }}$ ) of the vertical curved corrugated skin is less than the flat corrugated skin by $14^{\circ} \mathrm{F}$ and less than flat typical building skin by $26^{\circ} \mathrm{F}$. Third, in reality, the exterior surface temperature results for the curved corrugated skin are even less compared to the flat corrugated skin due to the fact that, the surface area of the curved corrugated skin exposed to the solar radiation is consistently changing during the day while the flat corrugated skin is being exposed to the radiation for a longer time during the day. So considering these three reasons, the author decided to go forward with using a curved corrugated skin as the design solution for the exterior building skin, both vertical and horizontal.

The next calculation step (the last step to prove the Self-ventilation behavior of the curved corrugated exterior skin), is calculating the ventilation rate due to the temperature differences of the surfaces and heat loss through convection. As convection creates air movement due to the temperature differences of the surfaces and differences in the air density, a ventilation rate should be calculable.

\subsubsection{Calculate of the Ventilation Rate Based on the Difference in the Surface Temperature}

The next equation shows that it is possible to calculate the amount of ventilation in CFM (Cubic Feet per Minute) due to the temperature differences of the surfaces of the curved corrugated skin and heat loss by convection. 


$$
\mathrm{V}=\frac{\mathrm{Q}}{\mathrm{PS}(\Delta \mathrm{T})}
$$

$\mathrm{V}=$ Ventilation Rate Based on the Difference in Temperature

$\mathrm{Q}=$ Heat Loss through Convection on a Vertical Surface

$\mathrm{S}=$ Specific Heat of Air

$\mathrm{P}=$ Average Density of the Air

$\Delta \mathrm{T}=$ Temperature Difference of the Surfaces

\section{EQUATION 4.5: VENTILATION RATE DUE TO THE TEMPERATURE DIFFERENCES OF THE SURFACES ${ }^{59}$}

Table 4.1.11 shows the ventilation rate values in CFM for the curved corrugated skin that occurs between the east facing and south facing and also occurs between the west facing and south facing skins. The ventilation rate is currently only calculated for the changes in temperature on the $10^{\text {th }}$ floor. It is in the opinion of the author, that the ventilation rate would actually be higher due to the air movement rising from floor to floor and combining together as the hot air rises. Table 4.1.11 shows us that the highest ventilation rates occur during the morning and afternoon when the Sun is at greater angles when compared to the building skin and as such there is more shade and a larger difference in the temperatures of the exterior surface and the actual amount of heat loss. This can also be seen in table 4.1 .10 as well.

Although the amount of the ventilation is not much, it proves the concept of the self-ventilating skin. Ventilation happens because of the differences in the temperature of the curved corrugated skin surfaces, which is based on the design solution; changing the flat skin to the curved corrugated skin. The same type of result (self-ventilating behavior) with different numbers may happen for the flat corrugated skin since there is a temperature difference between the exposed surfaces based on the configuration of the skin. 


\begin{tabular}{|c|c|c|c|}
\hline \multirow{6}{*}{ 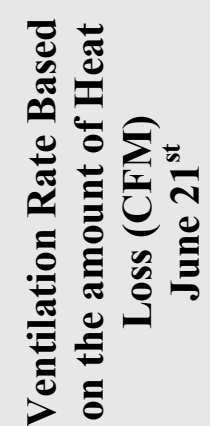 } & Time & East to South & West to South \\
\hline & 8:00 & 0.591 & 0.553 \\
\hline & $10: 00$ & 0.611 & 0.383 \\
\hline & $12: 00$ & 0.525 & 0.468 \\
\hline & $14: 00$ & 0.562 & 0.568 \\
\hline & $16: 00$ & 0.411 & 0.621 \\
\hline
\end{tabular}

\section{TABLE 4.1.11: VENTILATION RATE DUE TO THE CONVETION ON THE CURVED CORRUGATED SKIN}

As mentioned before, all these calculations and design decisions are made based on their effects on the vertical surface and not for the horizontal surfaces. Since the results of these analysis and calculations are based on some steady state formulas and concepts of thermodynamics, the assumption has been made that these concepts if applied to the horizontal surface would be beneficial as well. Therefore, the final building skin, facade system along with the roof skin is a curved corrugated skin on which the self-ventilating behavior happens.

\section{Self-shading Behavior of the Ribs}

While the curved part of the curved corrugated skin (figure 4.1.21) has the corrugated Globe Configuration that creates self-ventilating behavior causing heat loss, the flat part (ribs in the figure 4.1.21) of the final designed building skin mimics the Selfshading behavior of the Barrel Cactus. The flat ribs are tilted toward south by $5^{\circ}$, so the higher levels shade the lower levels at noon on June $21^{\text {st }}$ as the Sun approaches its highest position. Figure 4.1.28 shows a section of the designed building showing that the flat part 
of the south facing exterior skin is tilted $5^{\circ}$ to create the Self-shading behavior and therefore reduces the temperature of the exterior surfaces for the lower levels.

Although the altitude of the Sun on June $21^{\text {st }}$ at noon is almost $74^{\circ}$ (Ecotect solar tool analysis) and so the ideal Self-shading degree is around $26^{\circ}$ to self-shade the entire exterior flat ribs, figures 4.1.22-26 show that the incident solar radiation analysis on the flat ribs are less for the lower levels when compared to the higher levels because of the Self-shading behavior of the ribs even with only $5^{\circ}$ tilting. The incident solar radiation analysis results (figures 4.1.22-26) convinced the author to consider $5^{\circ}$ tilting as an effective design solution since any self-shaded degree higher than $5^{\circ}$ was considered to be a waste of space and material.

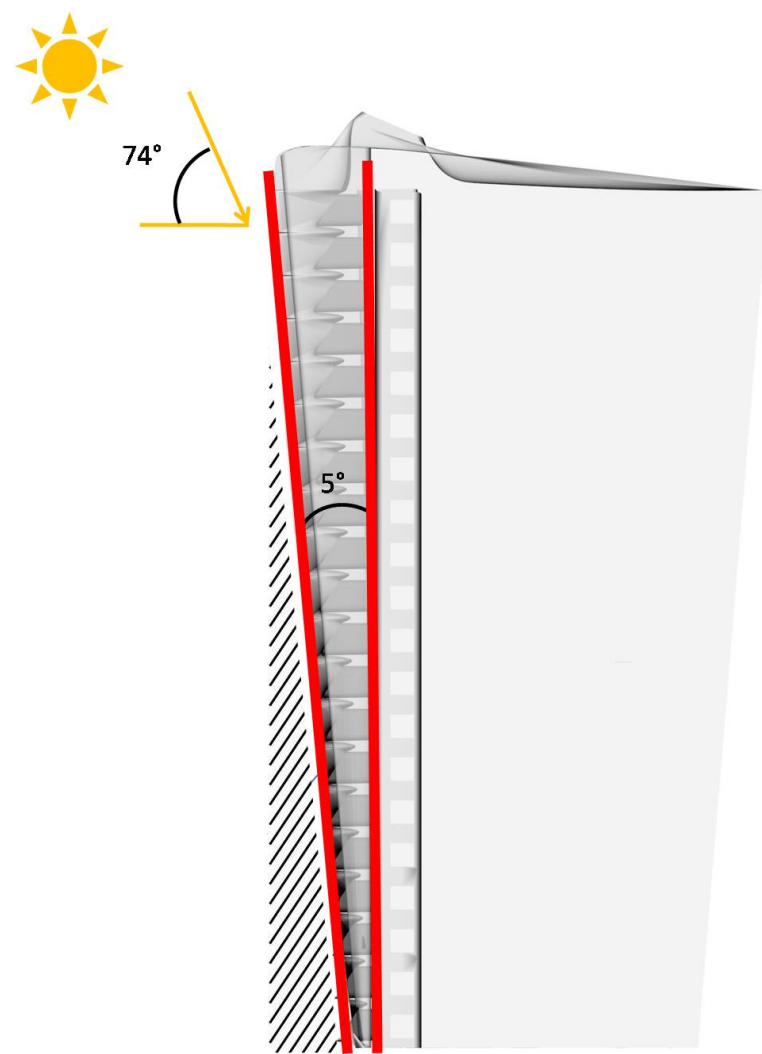

FIGURE 4.1.28: DESIGNED BUILDING SECTION; $5^{\circ}$ TILTED FLAT RIBS OF THE EXTERIOR CURVED CORRUGATED SKIN CREATING SELF-SHADING BEHAVIOR TO SHADE THE LOWER FLOORS

JUNE $21^{\mathrm{ST}}$ 
Since the flat ribs are the exterior skin of the air cavity $\# 1$ in figure 4.1.21, the lower temperature of the exterior skin causes less absorbed heat through the thermal mass and into the air cavity. Therefore, there would be less heat gain for the interior spaces as well; this conclusion will be discussed in more details in the following section.

Meanwhile, table 4.1.12 compares the temperature of the typical flat building skin (table 4.1.2) with the self-shaded flat ribs of the curved corrugated skin to prove that $5^{\circ}$ tilted south vertical skin causes lower surface temperature on the shaded surfaces when compared to the typical flat exposed surfaces based on the equation 4.2.

\begin{tabular}{|c|c|c|c|}
\hline \multirow{6}{*}{ 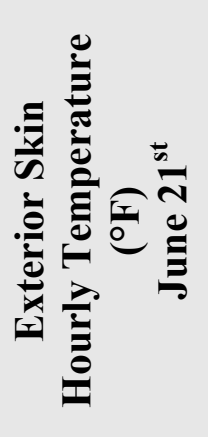 } & Time & Flat Skin & Self-shading5 $5^{\circ}$ Tilted Flat Ribs \\
\hline & 8:00 & 120.63 & 120.63 \\
\hline & $10: 00$ & 138.43 & 129.38 \\
\hline & $12: 00$ & 154.78 & 134.33 \\
\hline & 14:00 & 137.05 & 125.90 \\
\hline & $16: 00$ & 122.41 & 116.40 \\
\hline
\end{tabular}

TABLE 4.1.12: HOURLY SURFACE TEMPERATURE OF THE FLAT VERTICAL SKIN VS. $5^{\circ}$ TILTED (SELF-SHADED) FLAT SKIN

Table 4.1.12 proves that only $5^{\circ}$ tilting the flat skin reduces the surface temperature by $20^{\circ} \mathrm{F}$ on the most critical time of the day, at noon on June $21^{\text {st }}$. During the other time of the day, the temperature of the shaded surfaces is either equal to the temperature of the typical vertical flat skin or lower. The results of the table 4.1.12 are based on calculation process explained through the equation 4.1 and 4.2.

In conclusion, the designed exterior skin includes two parts; the curved part and the flat ribs (figure 4.1.21). The curved part of the exterior skin is designed based on the 
Globe Configuration and Cooling Ribs effect. Mimicking the Globe Configuration effect of the Barrel Cactus skin, the curved part of the exterior skin creates less exposed surfaces to the solar radiation (Geco analysis figures 4.1.22-26) and therefore less surface temperature during the hottest time of the day, June $21^{\text {st }}$ at noon (table 4.1.8). Not to mention that the actual temperature of the curved surfaces is less than what is calculated in the table 4.1.8 since the exposed surfaces to the solar radiation are consistently changing during the day. Beside the Globe Configuration adaptation, the curved part of the exterior skin creates the Cooling Ribs effect; Curved design of the exterior skin creates multiple surfaces with multiple surface temperatures. Differences in the surface temperature cause convection and therefore natural ventilation, which has been called a Self-ventilating system. Although the amount of natural ventilation rate of the Selfventilating system is not as much as it was hoped to be (table 4.1.11), the goal of this paper is to prove mimicking the natural evolutionary adaptations of the Barrel Cactus such as Cooling Ribs (with the self-ventilating behavior) can have a positive impact on the energy consumption of a building and user experience.

While Globe Configuration and Cooling Ribs effect are mimicked, analyzed and calculated in the design of the curved part of the exterior skin, mimicking the thermal mass and Self-shading behaviors has been taken into the consideration in the design of the flat ribs (figure 4.1.21). The $5^{\circ}$ tilted flat ribs are creating the same behavior discussed in the first chapter; higher levels of the skin casting shadows on the lower levels of the south facing facade system and so creating lower surface temperatures for the lower levels. Table 4.1.12 and figures 4.1.22-26 clearly show the surface temperature difference between the flat surface and the self-shaded flat surface (rib). Besides the 
mimicked Self-shading behavior of the flat ribs, the self-shaded ribs also have the Selfventilating system of the cooling ribs as well since the surface temperature and so the air density of the flat surfaces are different from the adjacent curved surfaces (west and east surfaces on the figure 4.1.21). Because of the complexity of the Self-ventilating system calculation process, the Cooling Ribs effect was analyzed and calculated for the curved surfaces and only assumed to exist on the flat ribs because of the differences in the surface temperatures. In the design of the flat ribs there are designed air cavities (air cavity \#1 in the figure 4.2.1) in the skin gap layer of the building skin (to be discussed in the next section) which create a thermal mass with high heat capacity characteristics which can delay the heat coming through the building skin. This behavior is discussed in the second chapter as one of the most important architectural passive design strategies in Yazd, Iran and will be expanded upon in more detail in the following section. 


\subsection{Skin Gap Design Process}

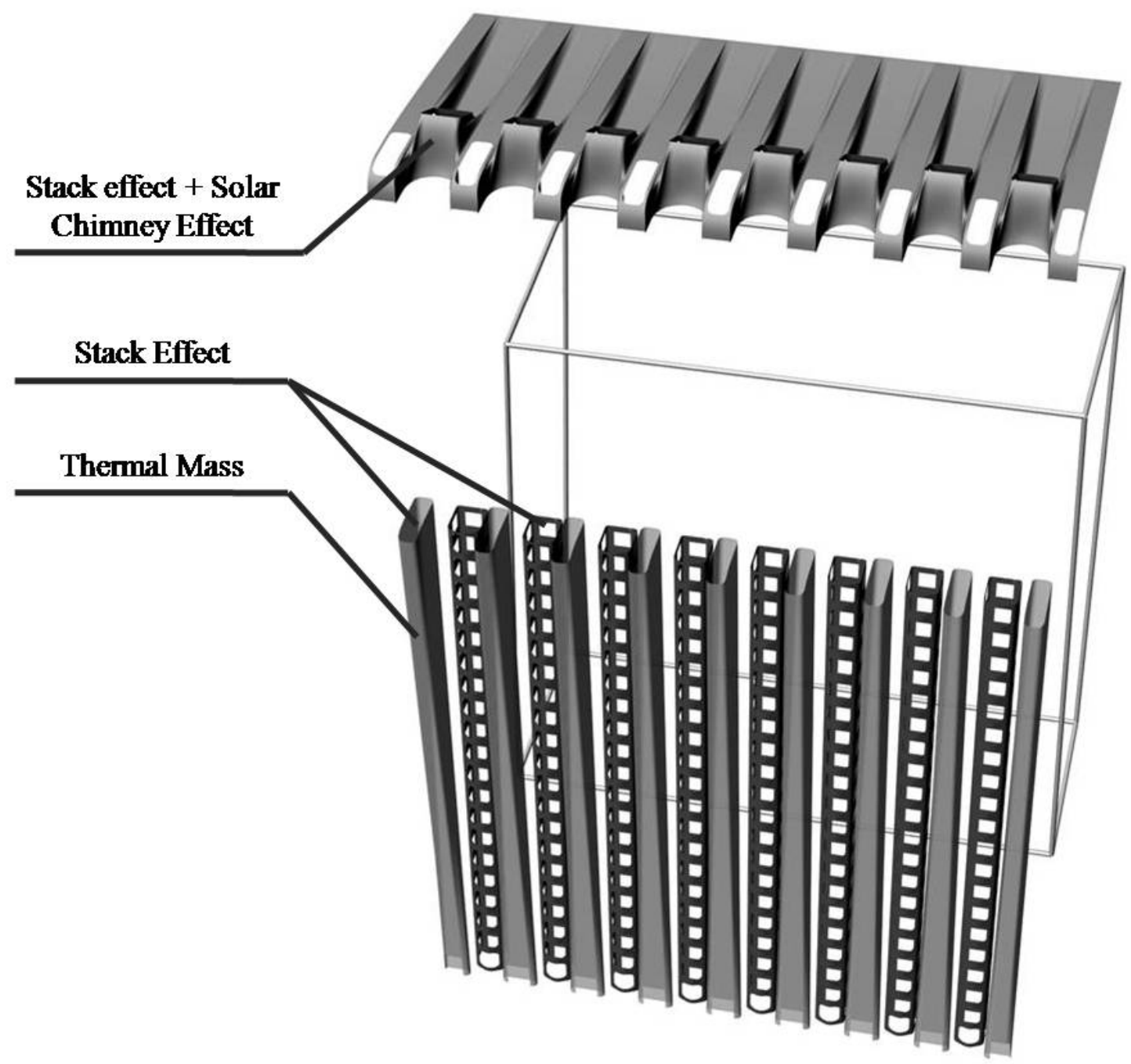

FIGURE 4.2.0: SKIN GAP DESIGN ANALYSIS FACTORS 


\section{Introduction}

In the previous section of this chapter, we analyzed the exterior skin design process based on: the Cooling Ribs effect, Globe Configuration effect and Self-shading behavior of the Barrel Cactus exterior skin. The next two sections of this chapter, will deal with design process of the gap between the exterior and interior skin, and design process of the interior skin. Both of these design processes will be based on passive architectural design principals. In order to achieve the comfort zone required for the users of an office building, the following three goals should be considered in the design of the gap between the interior and exterior skin and the design of the interior skin:

First, ventilating the heat absorbed by the exterior skin and the thermal mass.

Second, ventilating the heat gain that has penetrated itself into the interior of the building as well as the heat generated by the users and their equipment.

Third, providing enough natural daylight for the interior spaces so that the users are not fully dependent upon artificial light sources to provide the required light levels necessary to perform their tasks.

Since the second and third goals are integrated (functionally) with the interior skin, they will be discussed in the last part of the chapter, in the section titled "Interior Skin Design Process". Therefore, the first mentioned goal is the responsibility of the skin gap and will be discussed in this section of the chapter.

As there are many iterations and design steps between the first steps of the design process described in figure 4.1, and the final design solution which includes the curved corrugated skin with two kinds of air cavities (figure 4.2.1), author continually analyzes the final step to see if the design process chosen for the design steps solves it's intended 
problem; and if it fits in with the overall design and responds to the goals discussed above.

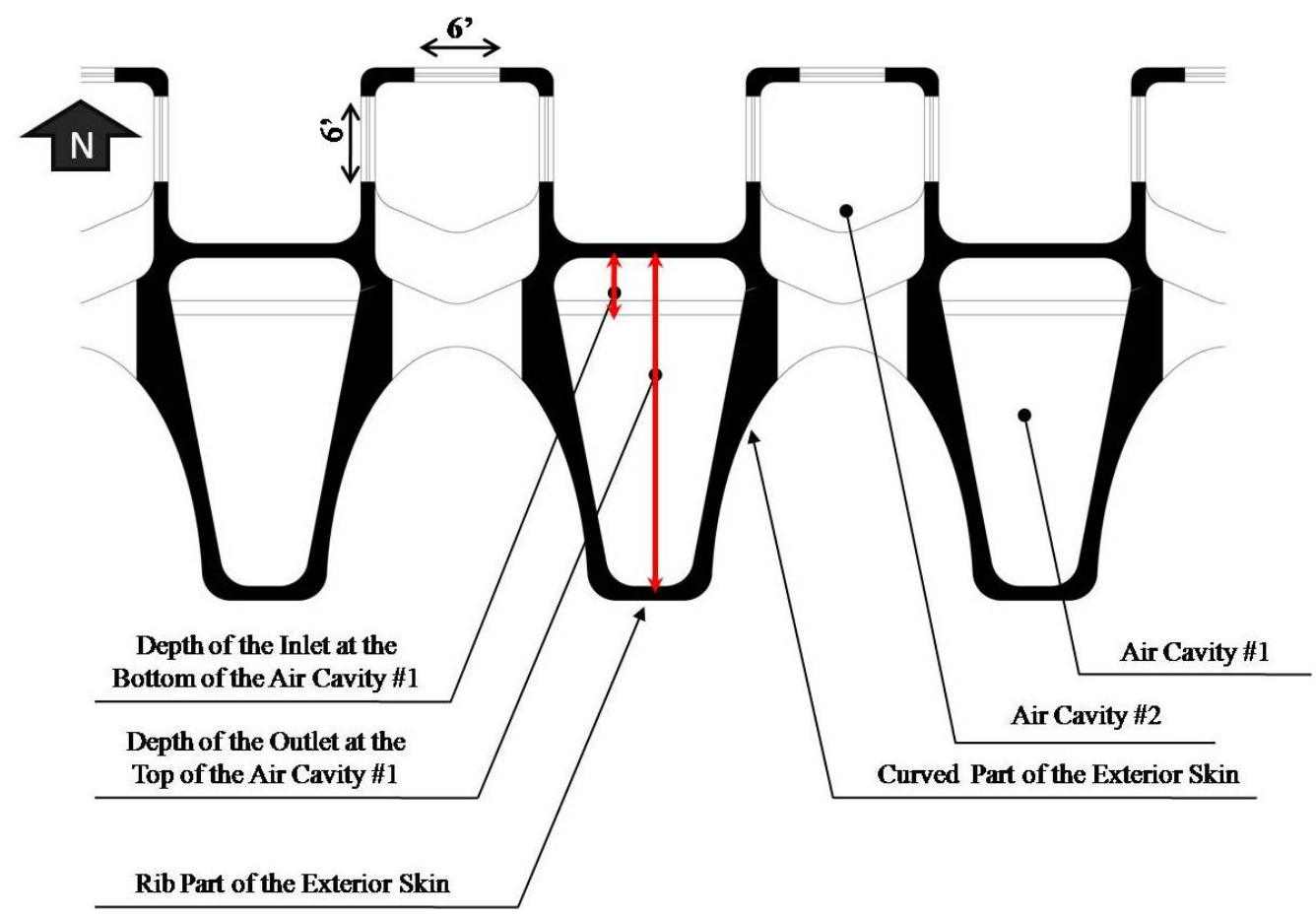

\section{FIGURE 4.2.1: PLAN SECTION OF THE $20^{\mathrm{TH}}$ LEVEL OF THE DESIGNED BUILDING SKIN}

Shown in the Figure 4.2.1, the plan section of the south facade skin includes two kinds of air cavities. While the "flat ribs exterior skin" contains air cavity \#1 of which intended function is to act as a thermal mass and stack ventilate the air cavity to help mitigate any heat gain by the façade system, the "curved part of the exterior skin" contains air cavity \#2 which provides natural daylight and ventilation for the interior spaces. Since the responsibilities of air cavity \#2 are integrated with the design of the interior skin, air cavity \#2 will be explained in the last section, "Interior Skin Design Process". Therefore, in this section, "Skin Gap Design Process", only the analysis and 
calculations relating to the ventilation system of air cavity\#1will be discussed. As previously mentioned, the goal of air cavity \#1 is to ventilate the heat absorbed by the thermal mass of the "flat ribs exterior skin." Since the exterior skin thermal mass of the air cavity $\# 1$ is the rib part of the curved corrugated skin (figures 4.2.1 and 4.2.2), whenever the author is talking about the exterior skin of air cavity \#1, it means the vertical rib area of the exterior skin (Figures 4.2.1-2).

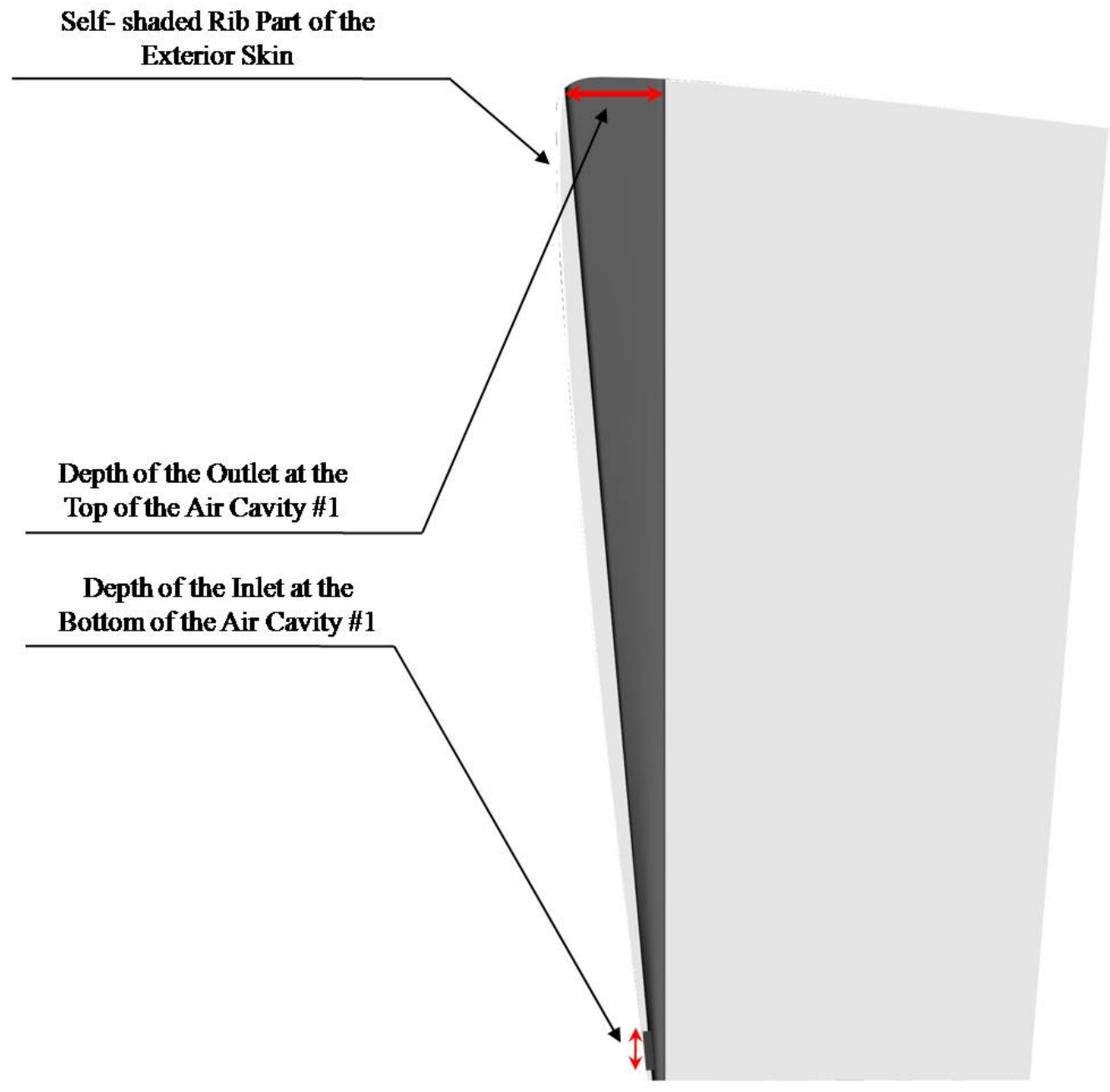

FIGURE 4.2.2: SECTION OF THE AIR CAVITY \#1 SHOWING THE INLET/OUTLET RATIO 
Figure 4.2.2 shows the section of the air cavity \#1 and the proportion of the inlet/outlet that causes Venturi Effect. The main focus of the calculation portion of the "Skin Gap Design Process" is to find out the role of the skin gap in dissipating the heat gain absorbed by the thermal mass of air cavity \#1. In this section author will calculate the ability of the "Stack Effect," the "Venturi Effect" that causes by the inlet/outlet proportion (figures 4.2.1-2 ) and the "Summer Wind Effect" to dissipate the heat gain. These calculations are based on the dimensions of the ventilation portion of air cavity \#1 (figure 4.2.2).

Below is a summary of the steps necessary to calculate the outcome of the "effects" described above:

1. Calculate $\mathrm{Q}_{\text {in }}$ for the Rib Section (Figure 4.2.1) per $\mathrm{M}^{2}$ based on the Ecotect Analysis on the $1^{\text {st }}$ Floor, $10^{\text {th }}$ Floor and $18^{\text {th }}$ Floor.

2. Convert the unit of the $\mathrm{Q}_{\text {in }}(\mathrm{W} / \mathrm{M} 2)$ to $\mathrm{BTU} / \mathrm{H}^{*} \mathrm{ft}^{2}$ for $\mathrm{US}$ standards.

3. Calculate the $Q_{\text {in }}$ over the vertical square feet of a single flat rib portion of the exterior skin to eliminate the $\mathrm{ft}^{2}$ unit. Complete this for the $1^{\text {st }}$ floor, $10^{\text {th }}$ floor and $18^{\text {th }}$ floor to determine the heat gain entering the air cavity at each floor.

4. Using Interpolation to Calculate the Heat Gain for the Remaining Floors and Finding the Total Heat Gain at the Center of the air cavity \#1 based on the values determined in Step 3.

5. Find the temperature at the center of the air cavity based on the $Q_{\text {in }}$ for each individual floor mentioned in Step 3. 
6. Based on the values derived in step 5, use Interpolation to calculate for the average temperature at the center of the air cavity in order to calculate the heat loss due to the ventilation rate in the air cavity $\# 1$.

7. Calculate the ventilation rate due to the Stack Effect and Venturi Effect.

8. Calculate the amount of heat energy dissipated due to heat Stacking Effect and Venturi Effect as a result of step 7 and determine the amount of heat gain remaining in air cavity \#1.

9. Calculate the ventilation rate due to the Summer Wind Effect combined with the Venturi Effect.

10. Calculate the amount of heat energy dissipated due to the combined effect of the summer winds, Stack Effect and the Venturi Effect.

In performing these calculations, it is important to make sure that we are using the same vertical rib for the $1^{\text {st }}, 10^{\text {th }}$, and $18^{\text {th }}$ floors, as we are trying to create a "building section" like heat gain profile; Table 4.2.2 should help to illustrate the "building section" concept. The main purpose for performing these 10steps is to try and calculate if the natural ventilation system (air cavity \#1) created by the Stack and Venturi Effect is able to ventilate the heat absorbed by the thermal mass of the exterior skin (the ribs). The author also wanted to see how the summer winds when combined with the Venturi Effect and Stack Effect would work together to help dissipate the heat gain contained in air cavity \#1 as there are strong seasonal winds that the author feels if captured correctly could have a beneficial impact on ventilating the heat trapped in air cavity \#1.

Based on the calculation process in the previous section of this chapter, the critical time for our analysis is June $21^{\text {st }}$ due to the constantly higher temperatures and 
intense solar radiation. Therefore, the final design solution, curved corrugated skin will be analyzed on this specific time and date in terms of the "Skin Gap design process".

\subsubsection{Calculate $Q_{\text {in }}$ for the Rib Section (Figure 4.2.1) per $\mathbf{M}^{2}$ based on the Ecotect Analysis on the $1^{\text {st }}$ Floor, $10^{\text {th }}$ Floor and $18^{\text {th }}$ Floor}

This step has been explained for the curved part of the designed exterior skin (curved portion of the exterior skin shown in the figure 4.2.1) at the $10^{\text {th }}$ floor in the previous section; "Exterior Skin Design Process". In this section, the calculation process was completed for the flat part of the exterior skin, (ribs of the exterior skin shown in the figure 4.2.1) not only for the $10^{\text {th }}$ floor but also for the $1^{\text {st }}$ and $18^{\text {th }}$ floors in order to calculate the entire heat gain in the air cavity \#1. The calculation process is based on the equation 4.1 and Ecotect analysis in the 4.1.3.1 section and the final results for $\mathrm{Q}_{\text {in }}$ are in $\mathrm{W} / \mathrm{M}^{2}$.

The reason that author chose the $18^{\text {th }}$ level as the highest floor in the calculation instead of the $20^{\text {th }}$ level (the actual highest level of the design) is that the temperature at the center of the air cavity for the $20^{\text {th }}$ level might not be calculated realistically since the last level is touching the outside temperature. Therefore, the highest level considered in the calculation is the $18^{\text {th }}$ floor. Table 4.2.1 shows the $\mathrm{Q}_{\text {in }}$ in $\mathrm{W} / \mathrm{M}^{2}$ for the three mentioned floors. Because of the Self-shading effect of the flat part of the exterior skin discussed in the previous section (4.1.c), the $\mathrm{Q}_{\text {in }}$ is quite minimal on the $1^{\text {st }}$ floor when compared to the value obtained for the $18^{\text {th }}$ floor. Figures 4.1.24-28, are images of the Ecotect incident solar radiation analysis and show that the incident solar radiation and 
hence the $\mathrm{Q}_{\text {sun }}$ varies along the face of the façade due to the Self-shading behavior of the ribs.

\subsubsection{Convert the Unit of the $Q_{\text {in }}(\mathrm{W} / \mathrm{M} 2)$ to $B T U / H^{*} \mathrm{ft}^{2}$ for $\mathrm{US}$ Standards}

In order to Find the final results, the total energy absorbed by the rib part of the exterior skin (air cavity \#1) in the US standards, $Q_{\text {in }}$ calculated in the previous step in $\mathrm{W} / \mathrm{m}^{2}$ should be converted to BTU/H.ft ${ }^{2}$ in the table 4.2.1. Since the $\mathrm{Q}_{\text {in }}$ is for one hour as explained before the $\mathrm{H}$ value is equal to 1 and therefore the final result for $\mathrm{Q}_{\text {in }}$ is in $\mathrm{BTU} / \mathrm{ft}^{2}$ in US standards. Author used a conversion calculator to achieve the results shown in the table 4.2.1.

\subsubsection{Calculate the $Q_{\text {in }}$ over the Vertical Square Feet of a Single Flat Rib Portion of the Exterior Skin to Eliminate the $\mathrm{ft}^{2}$ Unit}

The amount of $\mathrm{Q}_{\text {in }}$ calculated for the rib section in the previous step is in BTU/ $\mathrm{ft}^{2}$.

To find the total amount of heat gain of the rib section, it is required to removal the $\mathrm{ft}^{2}$ unit. In this step, the $\mathrm{Q}_{\text {in }}$ is multiplied by 1 floor vertical area of the rib part of the exterior skin (figure 4.2.1) to reach the final number in BTU as the author is only interested in the specific amount of heat energy that is available within air cavity \#1. The height of each floor on the exterior skin is $11 \mathrm{ft}$ and width of the same portion of exterior skin is $8.8 \mathrm{ft}$ therefore, totaling $96.80 \mathrm{ft}^{2}$. The final results for steps $1-3$ for the $1^{\text {st }}, 10^{\text {th }}$ and $18^{\text {th }}$ floors are shown in the table 4.2.1. The $\mathrm{Q}_{\text {in }}$ in BTU value explains the amount of total energy absorbed by the vertical area for the specific floor. As shown in the table 4.2.1, the highest number for the $\mathrm{Q}_{\text {in }}(5009.47 \mathrm{BTU})$ belongs to the highest floor, $18^{\text {th }}$, 
and the lowest absorbed heat $\left(\mathrm{Q}_{\text {in }}\right)$ belongs to the first floor. It is in the opinion of this author that the large difference in $\mathrm{Q}_{\text {in }}$ and BTUs between the $1^{\text {st }}, 10^{\text {th }}$, and $18^{\text {th }}$ floor is due to the effectiveness the Self-shading behavior of the ribs as designed in the previous sections.

\begin{tabular}{|c|c|c|c|c|c|}
\hline ?ํ. & Floor & $Q_{\text {in }}\left(W / M^{2}\right)$ & $Q_{\text {in }}\left(B T U / f^{2}\right)$ & $\mathbf{A}$ & $Q_{\text {in }}(B T U)$ \\
\hline$\vec{n}$ & $1^{\text {st }}$ Floor & 108.6 & 34.44 & 96.80 & 3333.51 \\
\hline$\underset{0}{\bar{v}}$ & $10^{\text {th }}$ Floor & 132.0 & 41.86 & 96.80 & 4051.78 \\
\hline$\Xi$ & $18^{\text {th }}$ Floor & 163.2 & 51.75 & 96.80 & 5009.47 \\
\hline
\end{tabular}

TABLE 4.2.1: QIN CALCULATION FOR 1 FLOOR VERTICAL AREA PER RIB

\subsubsection{Using Interpolation to Calculate the Heat Gain for the Remaining Floors and Finding the Total Heat Gain at the Center of the Air cavity \#1 based on the Values Determined in Step 3}

The amount of $\mathrm{Q}_{\text {in }}$ calculated for the three floors shown in Table 4.2.1 are assumed to be the amount of heat gain at the center of the air cavity \#1 for these three floors. These values were calculated by using Equation 4.1 and the R-value based on the structural properties of the exterior wall; $1 \mathrm{ft}$ thick reinforced concrete. The depth of the air in the air gap is different depending on what floor you are on. There is also a difference in the amount of direct solar radiation $\left(\mathrm{Q}_{\text {sun }}\right)$ on the exterior surface of the façade due to the Self-shading design of the exterior ribs. It is because of these two characteristics of the exterior ribs that the total heat gain at the center of air cavity \#1 for each floor is different. When you take the previously mentioned characteristics and combine them with the fact that as you move to a higher and higher floor; the hot air rises 
then you can begin to see that how this "Stack Effect" can to impact the temperature/heat gain of the air cavity per floor.

In order to determine the total heat gain for air cavity \#1, it is required to calculate the amount of the heat gain for all 20 floors. Therefore, interpolation was used to determine the heat gain in air cavity \#1for the remaining floors. Using the data collected for floors 1,10 and 18 and then using interpolation to determine the remaining floors proved to be a much more efficient way of completing these calculations instead of performing the required calculations for each floor.

Table 4.2.2 shows the total heat gain available based on our interpolation. The final number is in BTU/H and since the air cavity calculations are only for one hour intervals, for this example specifically at noon, then we can eliminate the $\mathrm{H}$ unit as it is equal to 1 . Therefore, the total heat gain of the air cavity in the table 4.2 .2 is $84,028.33$ BTU.

As mentioned in the introduction part of this section, the goal of the calculations for this section is to understand the total amount of heat gain in air cavity \#1 at noon. In order to understand the efficiency of the skin gap design in reducing the amount of heat that can potentially penetrate its way into the interior of the building by collecting the heat gain and utilizing natural ventilation to help remove it. Table 4.2.2 gives us the final number of the total heat gain of air cavity \#1. Once we determine the heat loss through natural ventilation, we will be able to reduce the total shown in Table 4.2 .2 by this newly calculated heat loss and see how effective the skin gap design is. The heat loss calculations will be performed at a later point in this paper. 


\begin{tabular}{|c|c|c|}
\hline Floor & $\begin{array}{l}\text { Heat Energy Av } \\
\text { Section per Floo } \\
\text { Noc }\end{array}$ & $\begin{array}{l}\text { ailable per Rib } \\
r \text { due to Qin at } \\
\text { on }\end{array}$ \\
\hline 20 & $5,248.89$ & BTU/HR \\
\hline 19 & $5,129.18$ & BTU/HR \\
\hline 18 & $5,009.47$ & BTU/HR \\
\hline 17 & $4,889.76$ & BTU/HR \\
\hline 16 & $4,770.05$ & BTU/HR \\
\hline 15 & $4,650.33$ & BTU/HR \\
\hline 14 & $4,530.62$ & BTU/HR \\
\hline 13 & $4,410.91$ & BTU/HR \\
\hline 12 & $4,291.20$ & BTU/HR \\
\hline 11 & $4,171.49$ & BTU/HR \\
\hline 10 & $4,051.78$ & BTU/HR \\
\hline 9 & $3,971.97$ & BTU/HR \\
\hline 8 & $3,892.16$ & BTU/HR \\
\hline 7 & $3,812.35$ & BTU/HR \\
\hline 6 & $3,732.55$ & BTU/HR \\
\hline 5 & $3,652.74$ & BTU/HR \\
\hline 4 & $3,572.93$ & BTU/HR \\
\hline 3 & $3,493.12$ & BTU/HR \\
\hline 2 & $3,413.32$ & BTU/HR \\
\hline 1 & $3,333.51$ & BTU/HR \\
\hline *Total Energy Available & \multicolumn{2}{|c|}{$84,028.33 \mathrm{BTU} / \mathrm{HR}$} \\
\hline
\end{tabular}

TABLE 4.2.2: TOTAL HEAT GAIN AVAILABLE AT CENTER OF THE AIR CAVITY \#1

\subsubsection{Find the Temperature at the Center of the Air cavity based on the $Q_{\text {in }}$ for Each Individual Floor Mentioned in Step 3}

Heat absorbed by the exterior concrete ribs (table 4.2.1) increases the temperature of the exterior side of the concrete wall (explained in the section 4.1.1.3) and also the temperature at the center of the air cavity. Based on equation 4.6 and the calculated $Q_{\text {in }}$ 
for each floor in the table 4.2.1, it is possible to calculate the temperature at the center of the air cavity for each of the three mentioned floors.

$\mathrm{T}_{\text {in air cavity }}$ is part of the $\Delta \mathrm{T}$ in the equation 4.6 and to solve for the $\mathrm{T}_{\text {outside exterior skin }}$ as the other factor of the $\Delta \mathrm{T}$, please refer to the calculation process in the section 4.1.1.3.

$$
\mathrm{Q}=\left(\left(\left(\mathrm{A} * \mathrm{D}_{\text {conc }} * \mathrm{~W}_{\text {conc }}\right) * \mathrm{~S}_{\text {conc }}\right)+\left(\left(\mathrm{A} * \mathrm{D}_{\text {air }} * \mathrm{~W}_{\text {air }}\right) * \mathrm{~S}_{\text {air }}\right)\right) *(\Delta \mathrm{T})
$$

$\mathrm{Q}=\mathrm{Q}_{\text {in }}(\mathrm{BTU})$ solved for 1 floor in the 4.2 .3 section

$A=$ Area of the Vertical Surface of the Air cavity for 1 Floor

$\mathrm{D}_{\text {conc }}=$ Depth of the Concrete

$\mathrm{W}_{\text {conc }}=$ Weight of the Concrete

$\mathrm{S}_{\text {conc }}=$ Specific Heat of the Concrete

$\Delta \mathrm{T}=\mathrm{T}_{\text {outside exterior skin }}-\mathrm{T}_{\text {in air cavity }}$

EQUATION 4.6: THE AMOUNT OF ABSORBED HEAT FOR 1 FLOOR ELEVATION AREA OF THE CONCRETE WALL (RIBS) ${ }^{60}$

\begin{tabular}{|c|c|c|c|}
\hline \multicolumn{4}{|c|}{ Temperature $\begin{array}{r}{ }^{\circ} \text { F)at the Center of Air cavity } \\
\text { June } \mathbf{2}^{\text {st }} \\
\mathbf{1 2 : 0 0} \mathbf{~ p m}\end{array}$} \\
\hline Floor & $1^{\text {st }}$ Floor & $10^{\text {th }}$ Floor & $18^{\text {th }}$ Floor \\
\hline T Outside Exterior Skin $_{\text {Sir cavity }}$ & 128.36 & 134.33 & 142.01 \\
\hline $\mathbf{T}_{\text {in Air }}$ & 127.81 & 133.65 & 141.17 \\
\hline
\end{tabular}

TABLE 4.2.3: CALCULATE FOR THE TEMPERATURE AT THE CENTER OF THE AIR CAVITY BASED ON THE ABSORBED HEAT BY 1 FLOOR ELEVATION AREA OF THE CONCRETE WALL AND THE TEMPERATURE OF THE EXTERIOR SIDE OF THE CONCRETE WALL

Table 4.2.3 shows that the temperature at the center of the air cavity ( $\left.\mathrm{T}_{\text {in air cavity }}\right)$ is about $1^{\circ} \mathrm{F}$ less than the temperature of the exterior skin of the air cavity ( $\left.\mathrm{T}_{\text {outside exterior skin }}\right)$. Although the depth of the plan area of the bottom of the air cavity is almost $1 / 4$ of the 
depth of the plan area at the top part of the air cavity, the difference between the temperature of exterior skin and inside the air cavity $(\Delta \mathrm{T})$ is about the same for all three floors. This means that the depth of the air cavity has almost no effect on reducing the temperature at the center of the air cavity. The heat capacity of air is very low therefore, increasing the depth of the air cavity has almost no effect on reducing the temperature at the center of the air cavity. What makes a difference in the temperature of the center of the air cavity is the thickness of the exterior concrete wall as a thermal mass and the natural ventilation that occurs through the air cavity due to the Stack Effect and Venturi Effect which can dissipate some amount of absorbed heat.

\subsubsection{Based on the Values Derived in Step 5, Use Interpolation to Calculate for the Average Temperature at the Center of the Air cavity in order to Calculate the Heat Loss due to the Ventilation Rate in the Air cavity \#1}

This step is like the step 4.2.4 when the author calculated the amount of total heat gain of the air cavity based on the heat gain of the $1^{\text {st }}, 10^{\text {th }}$ and $18^{\text {th }}$ floors. However at this step, instead of adding up the temperatures like step 4.2.4 we need to find the average temperature of the air cavity to help us solve for the ventilation rate and the heat loss in the following steps. Table 4.2.4 shows the interpolation and the average temperature at the center of the air cavity. These values will be used with equation 4.7 to determine the ventilation rate due to the Stack Effect. 


\begin{tabular}{|c|r|r|}
\hline \multicolumn{2}{|c|}{ Floor } & Temperature in Air Cavity \\
\hline 20 & 142.00 & $\mathrm{~F}$ \\
19 & 141.17 & $\mathrm{~F}$ \\
18 & 140.33 & $\mathrm{~F}$ \\
17 & 139.50 & $\mathrm{~F}$ \\
16 & 138.66 & $\mathrm{~F}$ \\
15 & 137.83 & $\mathrm{~F}$ \\
14 & 136.99 & $\mathrm{~F}$ \\
13 & 136.15 & $\mathrm{~F}$ \\
12 & 135.32 & $\mathrm{~F}$ \\
11 & 134.48 & $\mathrm{~F}$ \\
10 & 133.65 & $\mathrm{~F}$ \\
9 & 133.00 & $\mathrm{~F}$ \\
8 & 132.35 & $\mathrm{~F}$ \\
7 & 131.70 & $\mathrm{~F}$ \\
6 & 131.05 & $\mathrm{~F}$ \\
5 & 130.40 & $\mathrm{~F}$ \\
4 & 129.75 & $\mathrm{~F}$ \\
3 & 129.10 & $\mathrm{~F}$ \\
2 & 128.46 & $\mathrm{~F}$ \\
1 & 127.81 & $\mathrm{~F}$ \\
\hline
\end{tabular}

TABLE 4.2.4: TEMPERATURE AT THE CENTER OF THE AIR CAVITY FOR ALL FLOORS AND THE AVERAGE TEMPERATURE OF THE AIR CAVITY

\subsubsection{Calculate the Ventilation Rate due to the Heat Stacking Effect and Venturi Effect}

Based on the equation 4.7, it is possible to solve for the ventilation rate by having the dimensions of the air cavity, outside temperature and the temperature at the center of the air cavity (Average Temp. in the table 4.2.4). Since the temperature at the center of the air cavity is different for each floor (table 4.2.4), therefore the calculated average temperature in the section 4.2.6 (table 4.2.4) is applied in this equation. 


$$
\mathrm{V}=\mathrm{C} * \mathrm{~K} * \mathrm{~A} * \sqrt{ }\left(\mathrm{h} *\left[\left(\mathrm{t}_{\mathrm{i}}-\mathrm{t}_{\mathrm{o}}\right) / \mathrm{t}_{\mathrm{i}}\right]\right)
$$

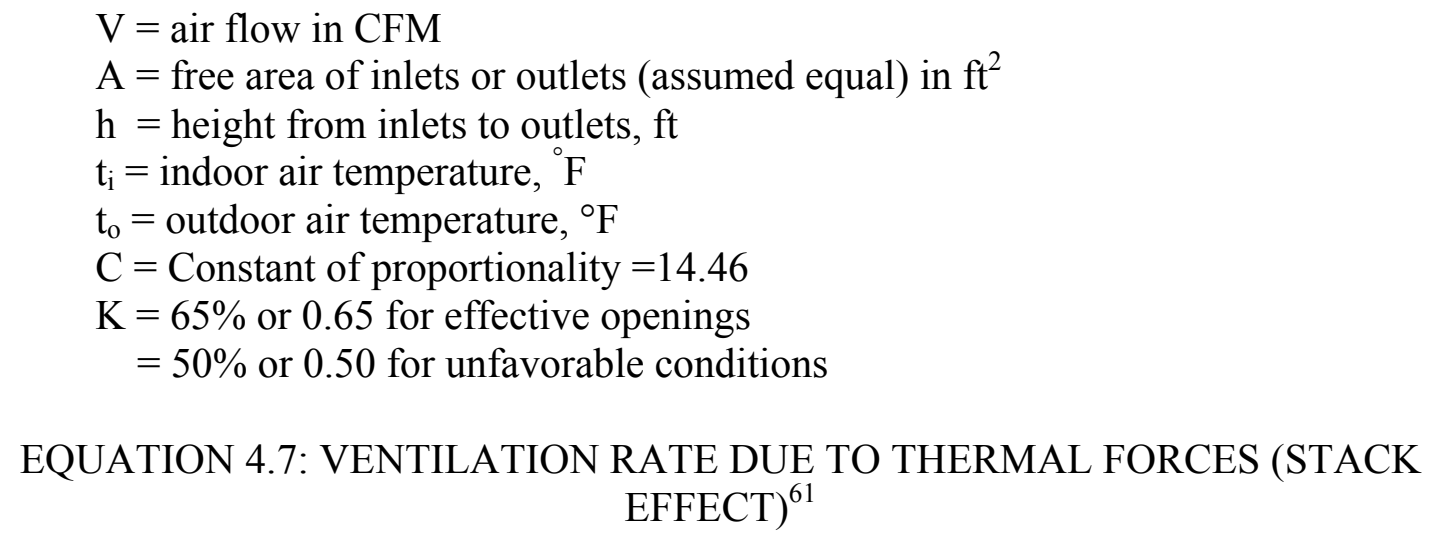

\section{EQUATION 4.7: VENTILATION RATE DUE TO THERMAL FORCES (STACK EFFECT $)^{61}$}

Equation 4.7 assumes that the inlet and outlet sizes are equal during the calculation. For the design of air cavity \#1 though, the sizes of the inlet and outlet are not the same (figure 4.2.2), as they were purposely designed based on the information in section 2.3.1 of this paper regarding the Venturi Effect; as the author wanted to maximize the efficiency of the ventilation rate. Figure 4.2.3 shows the increase in the airflow rate because of the differences in the sizes of the openings. The horizontal axis in the diagram listed values representing the ratio of the openings and the vertical axis shows the percentage of increase in the airflow due to the opening ratio. The increase in the percentage of the airflow should be added to the airflow calculated from equation 4.7 to get the actual value of the ventilation rate. In the final design as shown in the plan and section (Figures 4.2.1-2) the inlet/outlet area ratio is 1 to 4 so based on the following diagram the ventilation rate should increase by roughly $37 \%$ of the calculated airflow from equation 4.7 when the openings were assumed to be equal. 


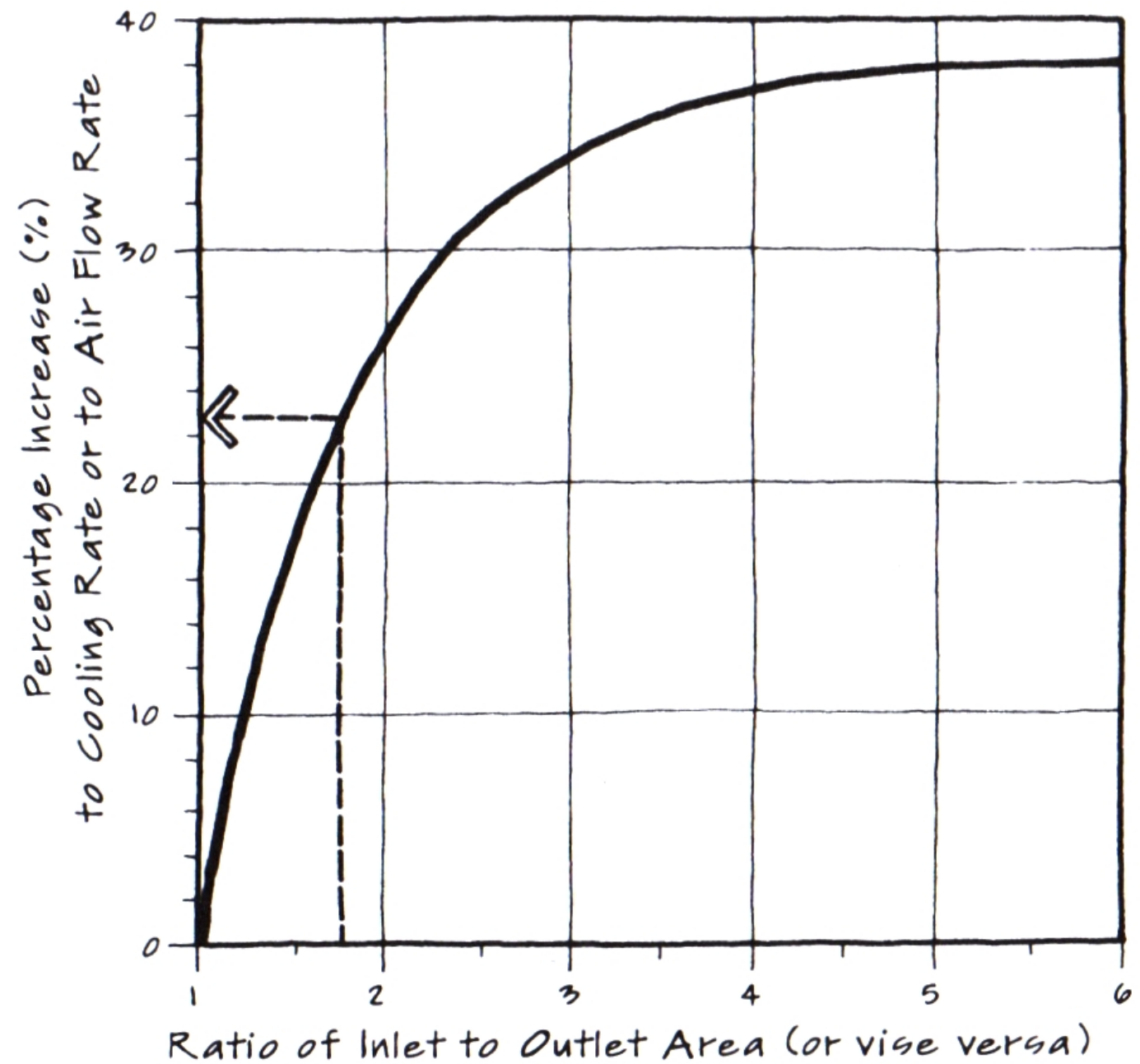

FIGURE 4.2.3: INCREASE IN THE VENTILATION RATE DUE TO DIFFERENTIAL OPENING SIZES ${ }^{62}$

Table 4.2.5 shows the final result for the ventilation rate due to the heat stacking effect (effects of the height of the air cavity and indoor/outdoor temperature) and Venturi Effect (Inlet/outlet ratio effect). Table 4.2.5 proves that there is a $1.10 \mathrm{MPH}$ (or 7,154.36 Cubic Feet per Minute) ventilation rate in air cavity \#1 due to the stack effect. 


\begin{tabular}{|lc|}
\hline \multicolumn{2}{|c|}{$\begin{array}{c}\text { Ventilation Rate Due to Heat Stacking Effect \& } \\
\text { Venturi Effect }\end{array}$} \\
\hline A & $72.00 \mathrm{sqft}$ \\
$\mathrm{C}$ & 14.46 \\
$\mathrm{~K}$ & 0.65 \\
$\mathrm{H}$ & $219.50 \mathrm{ft}$ \\
Tin air cavity & $134.49 \mathrm{~F}$ \\
Toutside air & $98.00 \mathrm{~F}$ \\
& \\
V & $5,222.16 \mathrm{CFM}$ \\
Eventuri & $37.00 \%$ \\
V & $7,154.36 \mathrm{CFM}$ \\
\cline { 2 - 2 } Vbased on A & \\
\cline { 2 - 2 } & \\
\cline { 2 - 2 } & \\
\end{tabular}

TABLE 4.2.5: VENTILATION RATE (V) DUE TO HEAT STACK EFFECT AND VENTURI EFFECT

\subsubsection{Calculate the Amount of Heat Energy Dissipated due to Heat Stacking Effect and Venturi Effect as a Result of Step 7 and Determine the Amount of Heat Gain \\ Remaining in Air cavity \#1}

By calculating the airflow and natural ventilation in air cavity $\# 1$ from the previous step (table 4.2.5) caused by the Venturi Effect and Stack Effect it is now possible to solve for the heat loss due to the natural ventilation using equation 4.8. This equation is the same equation applied to calculate the ventilation rate of the Cooling Ribs effect in the section 4.1.3.6. This equation helps us solve for the heat dissipated due to the ventilation rate and airflow occurring in air cavity \#1. 


$$
\mathrm{V}=\frac{\mathrm{Q}}{\mathrm{PS}(\Delta \mathrm{T})}
$$

$\mathrm{V}=$ Ventilation Rate based on the difference in temperature

$\mathrm{Q}=$ Heat loss through Convection on a vertical surface

$\mathrm{S}=$ Specific Heat of Air

$\mathrm{P}=$ Density of the Air

$\Delta \mathrm{T}=\mathrm{T}_{\text {outside }} \mathrm{T}_{\text {in air cavity }}$

EQUATION 4.8: CALCULATE FOR THE HEAT LOSS DUE TO THE

VENTILATION RATEOF THE AIR CAVITY \#1

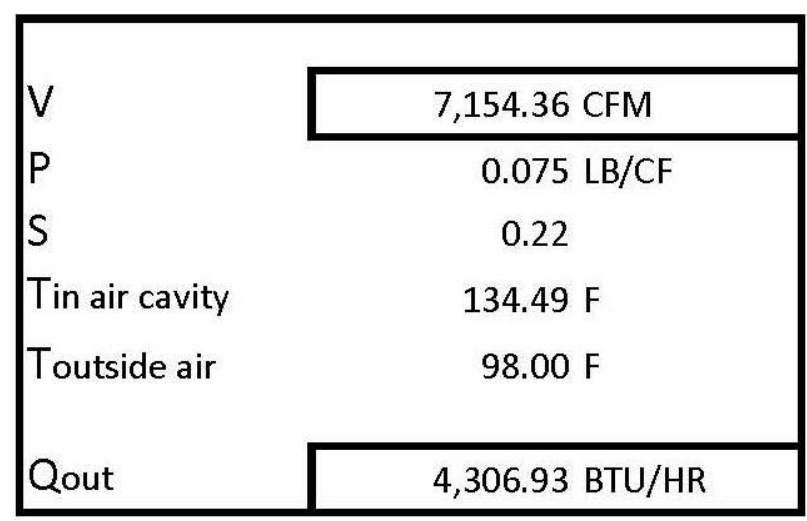

TABLE 4.2.6: THE AMOUNT OF HEAT ENERGY DISSIPATED DUE TO HEAT STACKING EFFECT AND VENTURI EFFECT

Table 4.2.6 shows the amount of heat dissipated due to airflow caused by the heat stacking effect and Venturi Effect in the air cavity \#1. Total heat dissipated is 4,306 BTU during the noon hour on June $21^{\text {st }}$ per rib or per air cavity.

In the section 4.2.4, the total heat gain for the air cavity is calculated at noon and so based on the results in this section, the Stack ventilation combined with the Venturi Effect are capable of removing a portion (5\%) of the total heat gain per air cavity. Table 4.2.7 shows the total calculated heat gain of $84,028.33$ BTUs and a dissipated heat gain of $4,306.93$ BTUs, which is about $5 \%$ of the total heat gain. 
The numbers and results achieved in this section may not be as successful as the author had originally hoped for at the beginning of the design process, but the results do prove that passive design strategies such as Stack ventilation and the Venturi Effect when incorporated into the design of the air cavity within the double facade system is capable of helping the façade system remove a portion of the heat gained through the exterior skin. Further design studies may want to further improve upon this sort of Stack ventilation and Venturi Effect technique in order to increase the amount of heat loss.

\begin{tabular}{|c|c|}
\hline Qout & 4,306.93 BTU/HR \\
\hline Eavailable $1 \mathrm{hr}$ & 84,028.33 BTU/HR \\
\hline Qdelta & 79,721.40 BTU/HR \\
\hline
\end{tabular}

TABLE 4.2.7: TOTAL HEAT GAIN AND DISSIPATED HEAT OF AIR CAVITY \#1

So based on the calculation process described at the beginning of this section, the first step in calculating the heat loss of air cavity \#1was to calculate the amount of absorbed heat $\left(\mathrm{Q}_{\text {in }}\right)$ per concrete rib for the $1^{\text {st }}, 10^{\text {th }}$ and $18^{\text {th }}$ floors. Next, the author calculated the heat gain and the temperature at the center of the air cavity based on the amount of heat absorbed by the vertical surface area of the concrete rib for one floor. Based on the average temperature at the center of the air cavity, the author was able to calculate the airflow/ventilation rate due to the Venturi Effect and heat stacking effect. At the end, author calculated the amount of heat that was dissipated due to the calculated airflow; the amount of dissipated heat is only $5 \%$ of the total heat gain at the center of the air cavity. The heat Stack Effect and Venturi Effect are passive deign strategies that have 
been applied and used through the design of the air gap between the interior and exterior skin. Another factor that may improve the natural airflow in air cavity \#1 by enhancing the heat Stack Effect and Venturi Effect are the local summer wind patterns. These patterns and their impact on improving the natural ventilation rate in air cavity \#1 will be discussed in more detail in the following section.

\subsubsection{Calculate the Ventilation Rate due to the Summer Wind Effect Combined with the Venturi Effect}

Figure 4.2.4 is an Ecotect wind analysis for Yazd for the month June. Based on

the data from the Ecotect Analysis, the directions of the local summer winds are mostly east and north directions. Therefore, the airflow in the designed air cavity \#1is directed out toward the south and west directions to allow for passing wind to draw the air out of the air cavity through the negative air pressure and help accelerate the ventilation rate for air cavity \#1. Figure 4.2.5 shows the airflow directed out from the air cavity because of the local Summer Wind Effect. Figure 4.2.5 shows that when the major winds blow to the building envelope form the north and east directions, it creates negative pressure areas around the south side of the building, which causes the airflow in the air cavity to be pulled out toward the south and west. Now that we know how the local winds effect the direction of the airflow pulled out of the air cavity, based on the equation 4.9 , it is possible to calculate for the ventilation rate and the velocity of the airflow in the air cavity \#1 in MPH and CFM values due to Summer Wind Effect. 


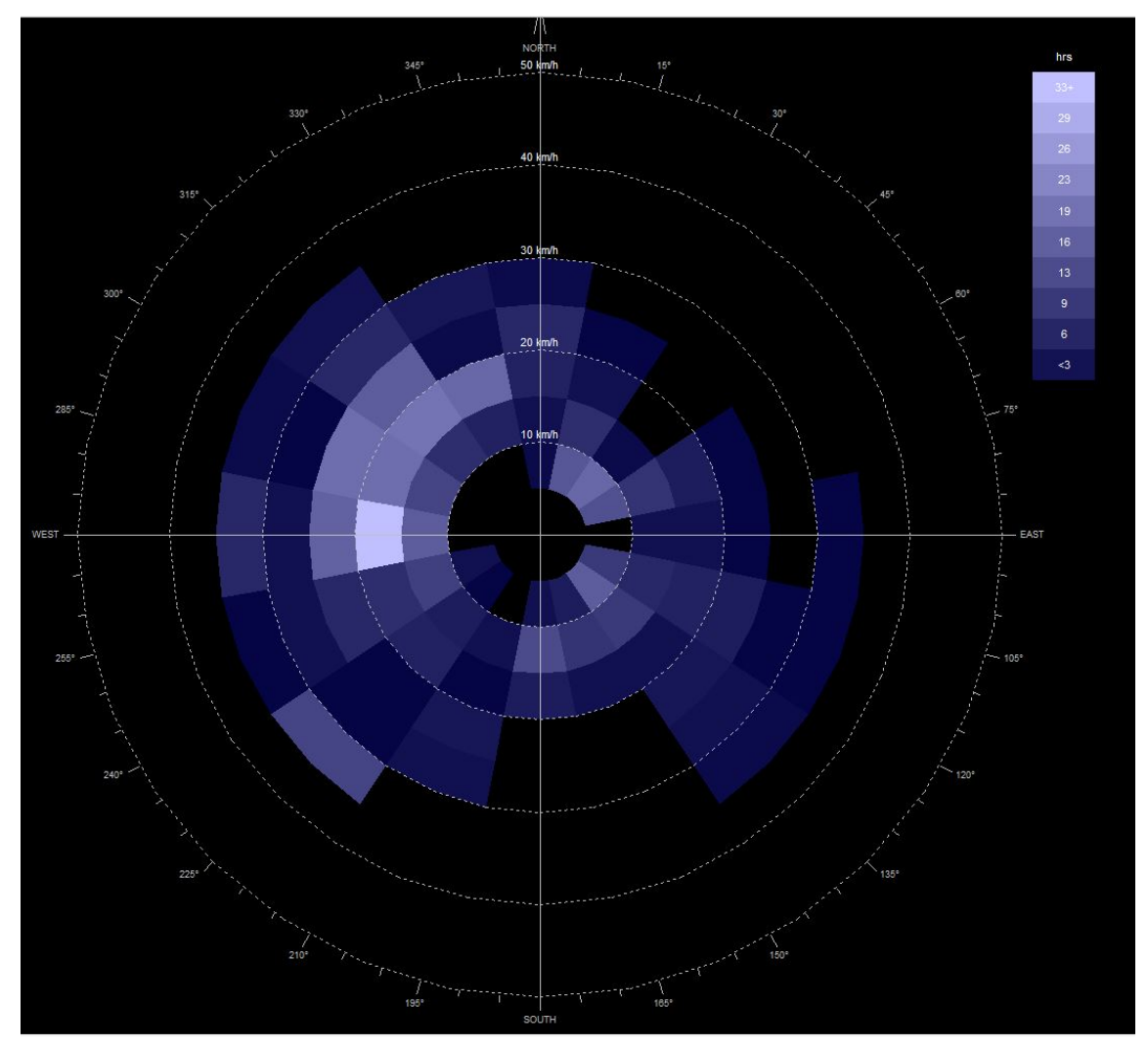

FIGURE 4.2.4: AUTODESK ECOTECT WIND ANALYSIS JUNE YAZD, IRAN

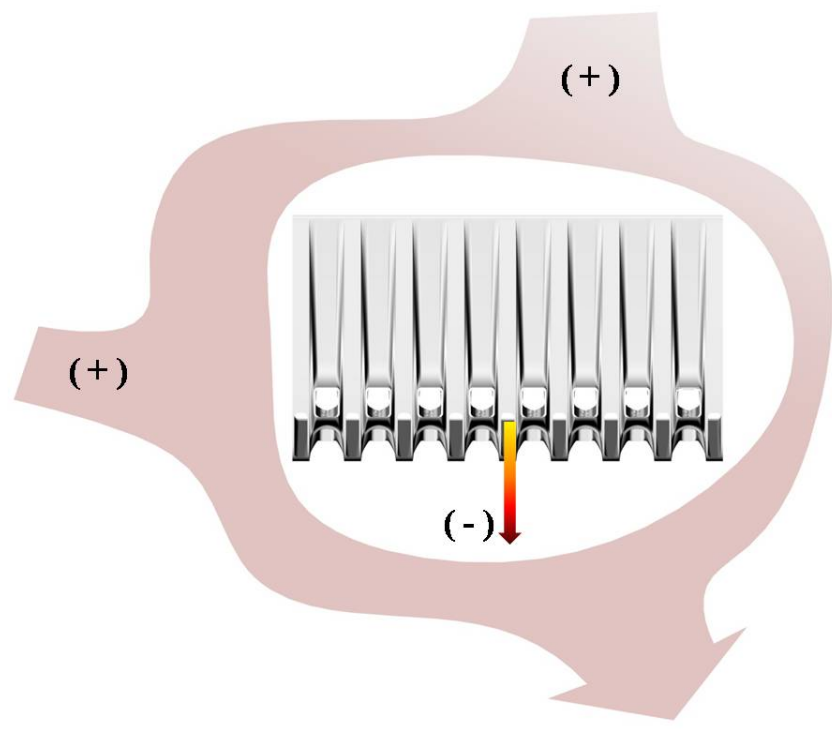

FIGURE 4.2.5: LOCAL SUMMER WINDS CREATING NEGATIVE PRESSURES ON THE SOUTH SIDE OF THE BUILDING PULLING THE AIRFLOW OUT OF THE AIR CAVITY 
Equation 4.9 can be applied to calculate the ventilation rate due to the summer

winds:

$$
\mathrm{V}=\mathrm{EAV}_{\text {Wind }}
$$

$\mathrm{V}=$ airflow in $\mathrm{ft}^{3} / \mathrm{min}$

$\mathrm{A}=$ free area of inlet openings in $\mathrm{ft}^{2}$

$\mathrm{V}_{\text {Wind }}=$ wind velocity in $\mathrm{ft} / \mathrm{min}$

$\mathrm{E}=$ effectiveness of openings

$=0.5-0.6$ perpendicular winds

$=0.25-0.35$ diagonal winds

$\mathrm{V}_{\text {Wind }}$ for design practice $=1 / 2 *$ seasonal average

\section{EQUATION 4.9: VENTILATION RATE DUE TO WIND EFFECT ${ }^{63}$}

Table 4.2.8 shows the results of the calculations performed with equation 4.9.

Since the Venturi Effect, discussed in the section 4.2.7, also effects the airflow due to the Summer Wind Effect, the 37\% efficiency of the Venturi Effect has been applied to the calculation as well.

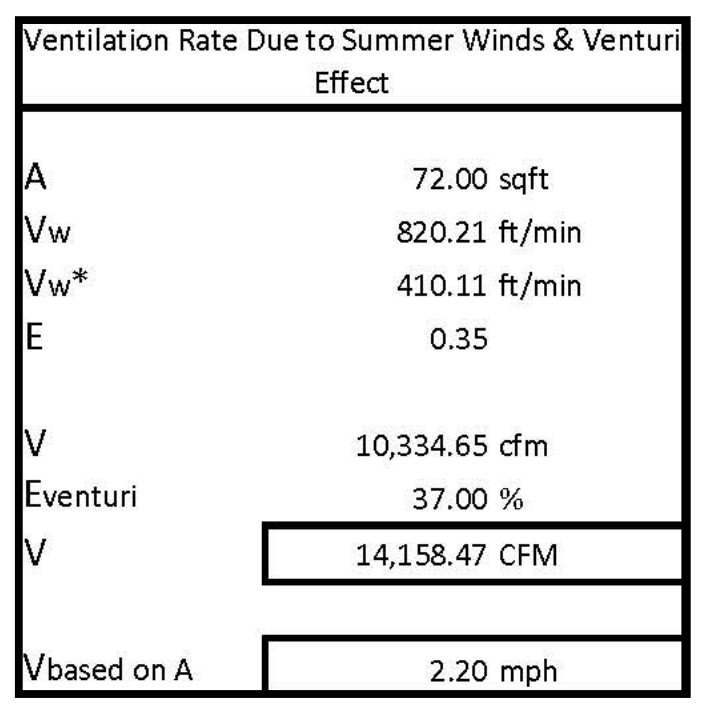

TABLE 4.2.8: THE VENTILATION RATE DUE TO SUMMER WIND AND VENTURI EFFECT 
Based on the results in the table 4.2.8, the velocity of the airflow in the air cavity \#1 is 2.2 MPH (Miles per Hour) and the direction of the airflow pulled out is mostly toward southwest in the month June in Yazd.

The calculations performed to determine the airflow/ventilation rate for air cavity \#1 in this section was completed separately for the Stack Effect and Summer Wind Effect. Each of these factors were combined individually with the Venturi Effect to create the airflow in air cavity \#1; the airflow calculated due to the Stack Effect was assumed to happen when there was no wind. Since both of these effects (Stack and Summer Winds) were calculated separately to show that they both worked on their own without the other being present, what would the result be if both conditions were present at the same time? The next step explains and calculates the airflow and the dissipated heat due to the Stack ventilation and Summer Wind Effect combined in air cavity \#1.

\subsubsection{Calculate the Amount of Heat Energy Dissipated due to the Combined Effect of the Summer Winds, Stack Effect and the Venturi Effect}

The author was not able to find a single equation or solution to calculate the amount of heat energy dissipated due to the Summer Wind combined with the Stack Effect and Venturi Effect. The resource the author used for the previous equation (equation 4.9) says that "When the two flows are equal, actual flow is about $30 \%$ greater than the flow caused by either force." ${ }^{64}$ Assuming that when the flows are equal, the maximum airflow is happening; so when the flows are not equal, the actual flow is $1 \%$ to $30 \%$ of the smaller flow added to the value of the larger flow. In this calculation, the airflow due to the wind effect is $2.2 \mathrm{MPH}$ and the airflow due to the Stack ventilation 
effect is $1.1 \mathrm{MPH}$, which is half as the flow due to wind effect based on the calculation. Therefore, the author assumes that $10 \%$ of the Stack ventilation airflow would be an appropriate percentage to be added to the flow due to the wind effect to find the final airflow in the air cavity when these two effects are combined together. The decision to use the $10 \%$ was a conservative assumption based on the information discovered by the author during the research leading up to this paper. Table 4.2.9 shows the result of this assumption; the final ventilation rate in MPH and CFM values for the airflow due to the combination of Stack Effect and the wind effect is 2.5 MPH, 0.3 MPH more than the air flow due to the wind effect and 1.4 MPH more than the airflow due to the stack effect. The Venturi Effect was previously included in the calculation and is already included in the results listed below.

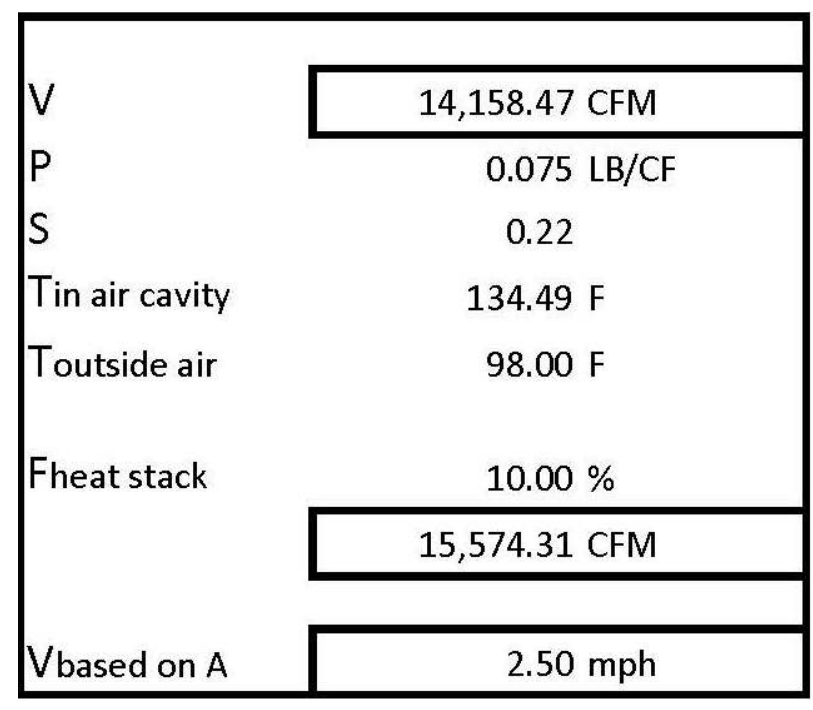

\section{TABLE 4.2.9: THE VENTILATION RATE DUE TO SUMMER WIND EFFECT AND HEAT STACKING EFFECT}

Now based on the final results, the final ventilation rate is marginally greater then the ventilation rate due to the Summer Wind Effect, which causes some amount of heat 
dissipated. The following table (Table 4.2.10) shows the amount of the heat dissipated due two both Stack ventilation effect and Summer Wind Effect. The equation to calculate the amount of heat dissipated is equation 4.8 explained previously in the section 4.2.8.

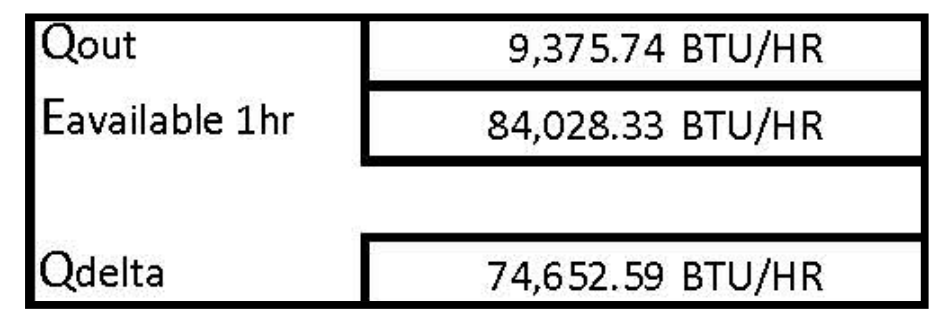

\section{TABLE 4.2.10: THE AMOUNT OF HEAT DISSIPATED DUE TO SUMMER WIND EFFECT AND HEAT STACKING EFFECT}

Based on the results in the table 4.2.10, the amount of heat dissipated due to the Stack ventilation and Summer Wind Effect combined with the Venturi Effect is 11\% of the total heat gain along with south facade at 12:00 pm on June $21^{\text {st }}$. Although the final numbers are not as efficient as assumed, the calculation process shows the possibility of losing heat absorbed by the exterior building skin due to the Stack ventilation and Summer Wind Effect combined with the Venturi Effect caused by the passive design strategies taken into consideration during the design of the air gap between the interior and exterior skin. Therefore, this calculation process and the results mathematically prove the effects of the stack effect, Summer Wind Effect and Venturi Effect on the design of the building skin to reduce the heat gain and increase the natural ventilation of the building skin. Further design solutions such as increasing the thickness of the exterior skin and/or changing the proportion of the inlet and outlet of the air cavity can be applied to improve the results shown in the table 4.2.10 in order to increase the percentage of the dissipated heat due to the Stack ventilation, Summer Wind and Venturi Effects. Unlike 
the first section of this chapter, "Exterior Skin Design Process" where most of the solutions were translated from the natural behavior of the Barrel Cactus skin (such as Globe Configuration, Cooling ribs and Self-shading, this section), the "Skin Gap Design Process" section focused mostly on the passive architectural design solutions. While the exterior skin is mostly dealing with the environment and is capable of being mimicked from natural species, the air gap between the exterior and interior is mostly capable of being designed based on the passive rules such as natural ventilation due to the Stack ventilation and Venturi Effect. These types of solutions in terms of natural ventilation/cooling have been applied for years in the architecture of Yazd, which helped the author to have a better understanding of the design of the air gap. An example of these passive strategies found in Yazd, are wind catchers. Wind catchers were previously discussed in the second chapter of this paper. The function of which is capable of being compared with the function of air cavity \#1 regarding dissipating heat and creating an airflow in the cavity. Figure 4.2.6 is graphically showing the results of the passive design solutions (Stack ventilation, Summer Wind and Venturi Effect) applied to the design of air cavity \#1 in order to create an airflow and reduce the heat gain. 
Local Wind Helps the Portion of the Heat

Gain Trapped in the Air Cavity Dissipated

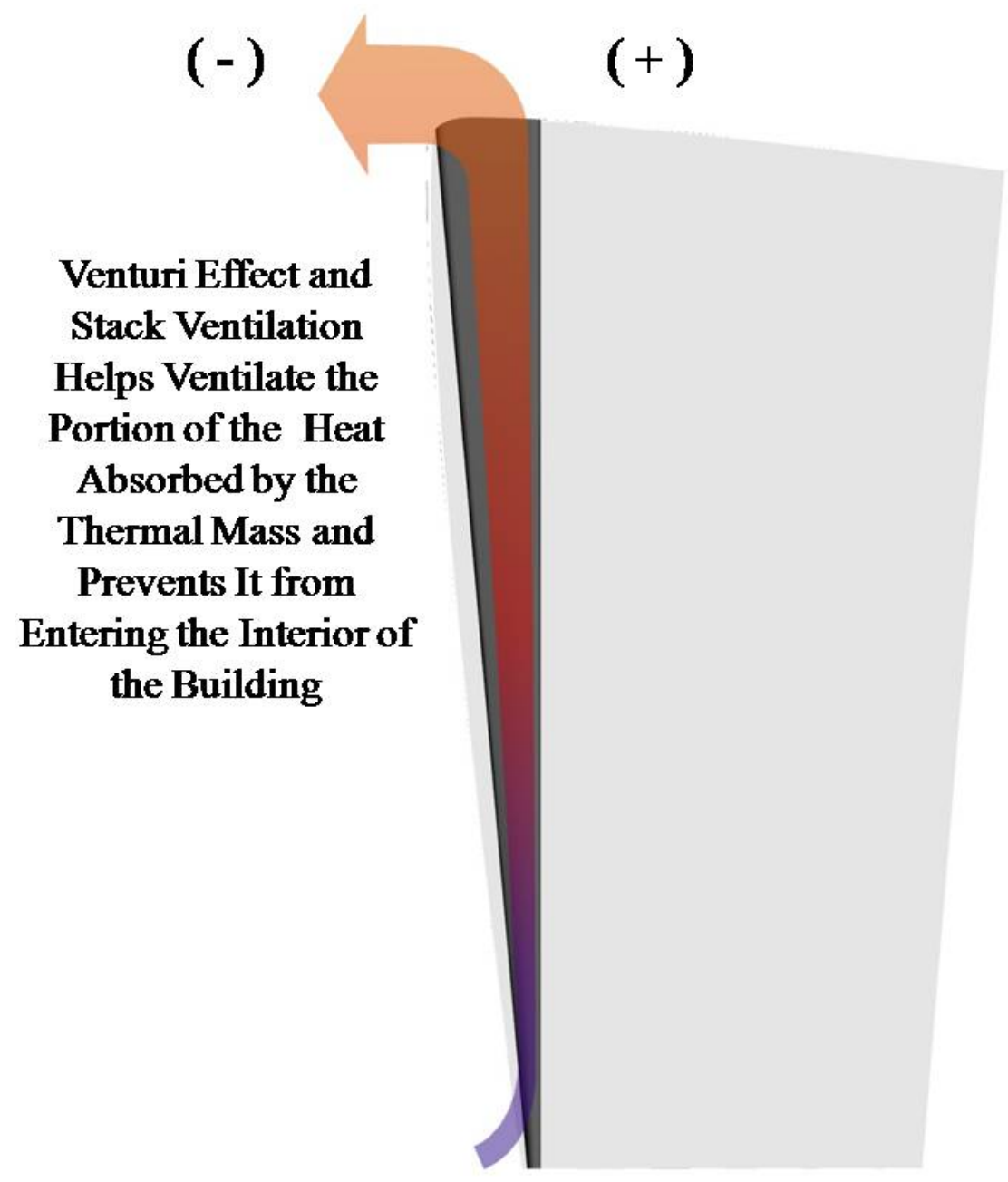

FIGURE 4.2.6: A PORTION OF THE HEAT GAIN ABSORBED BY THE THERMAL MASS OF THE EXTERIOR SKIN DISSIPATED DUE TO THE STACK EFFECT, SUMMER WIND AND VENTURI EFFECT 


\subsection{Interior Skin Design Process}

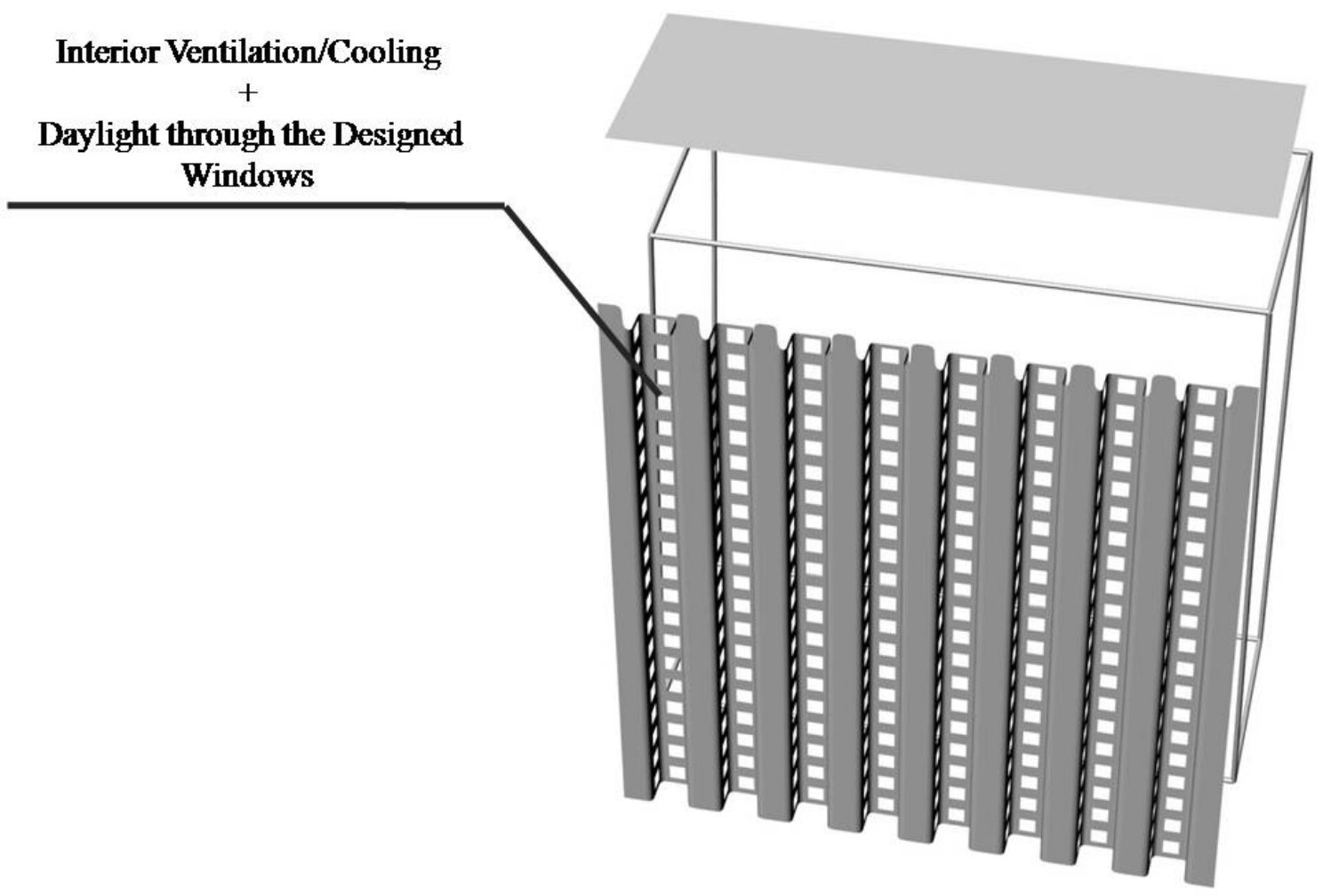

FIGURE 4.3.0: INTERIOR SKIN DESIGN ANALYSIS FACTORS 


\section{Introduction}

As mentioned before, while the exterior skin design solutions are mostly Biomimicry solutions mimicked form the natural evolutionary adaptation of the Barrel Cactus exterior skin, the skin gap design solutions (section 4.2) are mostly lessons taken from the passive architecture of Yazd, Iran. The last section, "Interior Skin Design Process" is mostly focusing on the comfort zone of the users of an office building in such a climate. Therefore, the solutions proposed at the end of this section are based on the comfort level in the open office spaces.

The comfort zone for the users of an office building can be defined based on three factors: heat gain, natural ventilation and sufficient daylighting. The first two factors, heat gain and natural ventilation are explained in section 4.3.1; the total heat gain of the designed building skin is compared with the heat gain of the typical building skin to which shows that there is less heat gain in the proposed designed building skin when compared to the typical building skin. The third factor, natural daylighting, is explained in section 4.3.2 which includes the analysis and calculations for the natural daylighting solution applied in the design of the interior skin.

In the first part of the "Interior Skin Design Process" section, the total amount of heat gain passing through the building skin is calculated and compared with the total heat gain passing through the typical building skin. The total heat gain of the proposed building skin at first must be subtracted from the amount of heat loss due to the selfventilating behavior of the designed Cooling Ribs (section 4.1.3.5) and the amount of heat dissipated due to the Stack Effect, Summer Wind and Venturi Effect(section 4.2.10). The second step is calculating the ventilation rate based on the amount heat loss as 
described above. The author will propose a solution in order to achieve the calculated ventilation rate to remove the total heat gain and achieve the desired comfort zone.

Since this paper is discussing the effect of passive design strategies on the building skin design process and not the building envelope, the proposed solutions for the interior space comfort zone are only in the conceptual level of design rather than being calculated and analyzed. These proposed ideas could be further studied, analyzed and calculated in the future research. Here is the summery of process of the first part of this section of chapter 4 , interior heat gain and ventilation rate:

1. Calculating the Total $Q$ value coming inside the building for the $10^{\text {th }}$ floor on June $21^{\text {st }}$ at $12: 00 \mathrm{pm}$.

2. Calculating the ventilation rate based on the amount of heat gain and comfort temperature.

3. Proposing the design solutions to solve for the ventilation rate.

The second part of the section will propose and analyze the natural daylighting for the interior spaces. This section proposes a solution for the natural daylight on the interior skin to achieve the required daylight illumination for an office building. Unlike the first part of this section, the daylight calculation is for 4 days of the year, June $21^{\text {st }}$, September $21^{\text {st }}$, December $21^{\text {st }}$ and March $21^{\text {st }}$ to understand what would be the provided daylight illumination all around the year. Here is the summary of the process of calculating the provided daylight by the interior skin:

1. Calculate the Outdoor daylight Illumination

2. Calculate the Daylight Illumination in air cavity \#2 $\left(\mathrm{P}_{1}\right)$

3. Calculate the Daylight Factor in the air cavity \#2 $\left(\mathrm{P}_{1}\right)$ 
4. Interior Daylight Illumination based on Illumination in air cavity \#2 and Daylight Factors at $\mathrm{P}_{2}$ and $\mathrm{P}_{3}$

\subsubsection{Interior Heat Gain and Ventilation Rate}

\subsubsection{Calculating the Total $Q$ value Coming Inside the Building for the $10^{\text {th }}$ Floor on June $21^{\text {st }}$ at 12:00}

As mentioned previously in the introduction of this section, the first part of this section talks about heat gain and natural ventilation and their impact on the interior skin. Table 4.3.1 shows the results for the calculation of the amount of heat coming through both air cavities. The final amount of heat energy coming inside the building is determined by: subtracting the amount of heat loss due to the Self-ventilation behavior of the Cooling Ribs and the heat loss due to the Stack ventilation, Summer Wind and Venturi Effect from the total heat gain absorbed by the thermal mass of the building. Based on figure 4.3.1, the plan section of the designed south building skin, air cavity \#1 is connected to the outdoor air only by the apertures at the bottom of the exterior building surface which helps to create a natural airflow to remove a portion of the heat gain from the exterior thermal mass. Air cavity \#2 (figure 4.3.1) provides natural daylight and ventilation for the interior spaces by having three apertures designed into the building skin, one on each side of the air cavity. While the major heat transfer occurring through the building skin from air cavity \#1 is mostly due to the thermal mass heat gain, for air cavity \#2 the major heat gain is transferred through the glazing area which has been increased by $50 \%$ when compared to the typical building skin to improve the natural daylight levels (figure 4.3.1). 


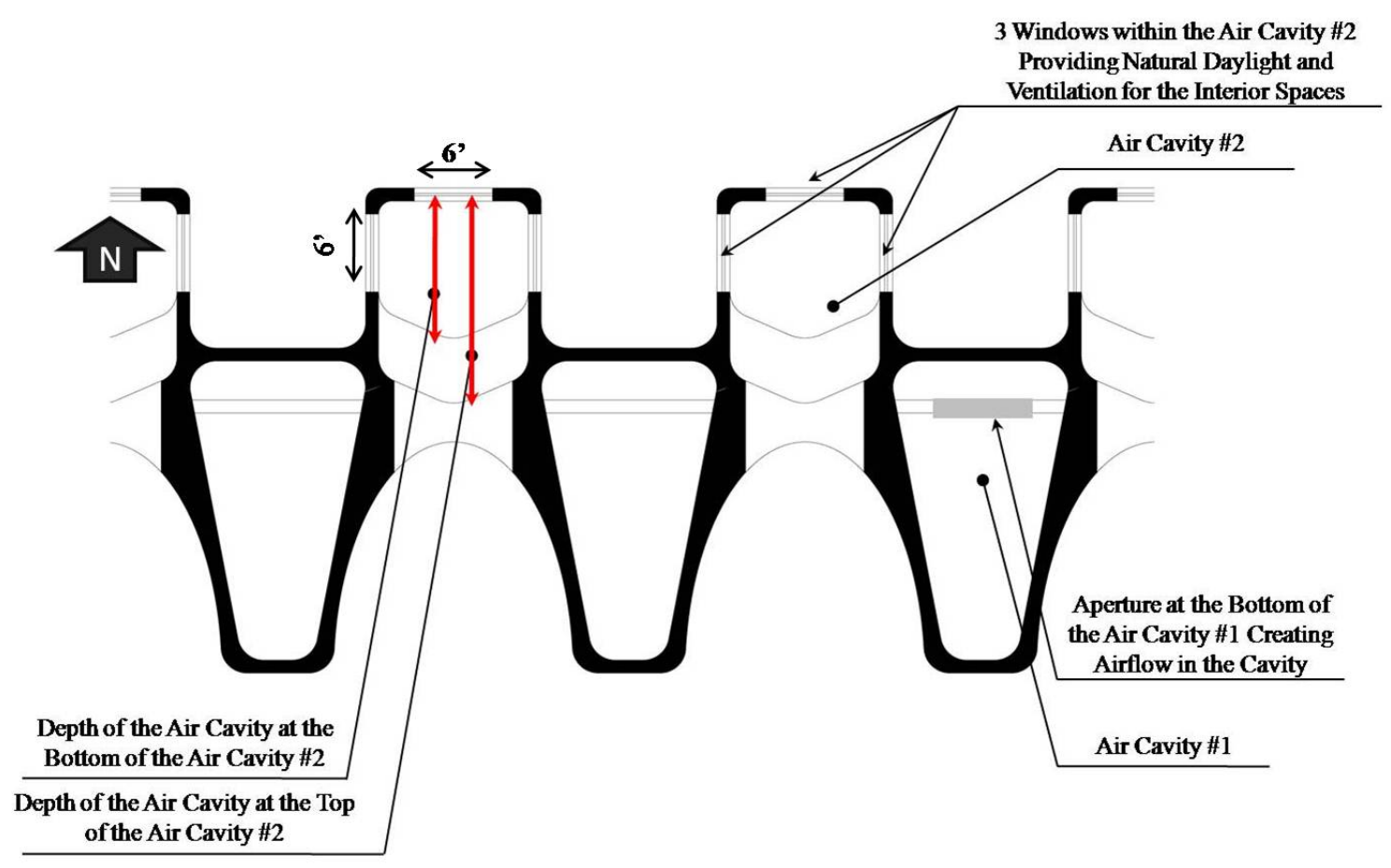

\section{FIGURE 4.3.1: PLAN SECTION OF THE $20^{\mathrm{TH}}$ LEVEL OF THE DESIGNED BUILDING SKIN}

The type of the calculation that ends up with the results in the table 4.3.1 have been explained before in the section 4.2.5. Based on equation 4.10, which is similar to the equation 4.6, the total heat gain for the entire south facade system is 29,238.95 BTU/HR and since this calculation is only at noon on June $21^{\text {st }}$ for the $10^{\text {th }}$ floor, the total heat gain is $29,238.95$ BTUs.

As it is clear in the table 4.3.1, the heat loss due to Heat Stacking Effect and heat loss due to the Cooling Ribs effect (shown in red color in the table 4.3.1) are subtracted from the total heat gain of the curved corrugated skin. While table 4.3.1 shows the total heat gain of 1 floor $\left(10^{\text {th }}\right.$ floor $)$ south facade area, table 4.3.2 shows the heat gain of 1 floor $\left(5^{\text {th }}\right.$ floor $)$ south facade area of a typical building skin as described in the section 4.1; the total heat gain for the typical building skin is $32,411.86$ BTUs. Although the total 
heat gain of the final design is a little less than the typical building skin, reasons below explain why the final design is even a better solution in terms of total heat gain for 1 floor facade area.

- $\quad$ The typical building skin is a flat facade system which has more of its surface area exposed to direct sunlight when compared to the corrugated interior skin of the final solution. Although the surface area of the interior skin is greater than that of the flat skin, the total heat gain of the corrugated interior skin is less than that of the typical flat skin. See table 4.3.1 and 4.3.2. The additional surface area of the corrugated interior skin is necessary for the Cooling Ribs effect, natural daylight and thermal mass purposes.

- The greater amount of surface area of the final design solution when compared to the typical building skin allows for a greater amount of glazing area to be installed. The glazing area in the final solution is 1.5 times greater than the glazing area in the typical building skin. The reason is to provide more daylight for the office users, which is now possible despite the hot and intense solar radiation during the daytime.

- $\quad$ In section 4.1 and 4.2 , the outside temperature was determined to be $98^{\circ} \mathrm{F}$ at noon on June $21^{\text {st }}$. This temperature was used as $T_{2}$ for the typical flat building skin. For equation $4.10, \mathrm{~T}_{2}$ for air cavity $\# 2$ is assumed to be $93^{\circ} \mathrm{F}$ as it is in the shade. An additional benefit of the corrugated building skin is that shade is always present which helps to cool off the air temperature and limit the exposure to direct solar gain. The author assumed for calculation purposes that the temperature at the center of the air cavity $\# 2$ would be $5^{\circ} \mathrm{F}$ less than the outdoor air temperature due to the shade factor.

Comparing the table 4.3.1 to 4.3.2 shows that the amount of heat gain transferring through the building skin component based on the equation 4.10 for the typical building 
skin is more than the amount of heat gain transferring through the building skin component for the final design building skin solution by almost 3,000 BTUs. While the thickness of the exterior walls are the same, the passive design strategies in the final design solution creates a designed air gap (section 4.2) and a designed corrugated interior skin (section 4.3) which reduces the heat gain due to the Cooling Ribs effect, Stack Ventilation and Venturi Effect. This reduction in heat gain is achievable even though the final designed solution contains 50\% more glazing when compared to the typical building skin design.

$$
\mathrm{Q}=\mathrm{UA}\left[\mathrm{T}_{1}-\mathrm{T}_{2}\right]
$$

$\mathrm{Q}=$ The Rate of the Heat Transfer Through a Construction Component (BTU/HR) $\mathrm{U}=$ Thermal Transmittance of Envelope $\left(\mathrm{U}=1 / \mathrm{R}_{\mathrm{T}}\right)$ : the $\mathrm{U}$ Value of a Composite Building Element is the Inverse of the Sum of the Thermal Resistances (R) of each Material Layer, Cavity (if any), and the External and Internal Surfaces. $A=$ Area of Surface (Portion of Envelope under Consideration) $\mathrm{T}_{1}=$ Indoor Air Temperature $\mathrm{T}_{2}=$ Outdoor Air Temperature

EQUATION 4.10: CALCULATION FOR THE RATE OF THE HEAT TRANSFER THROUGH A CONSTRUCTION COMPONENT ${ }^{65}$ 


\begin{tabular}{|c|c|}
\hline \multicolumn{2}{|c|}{ 10th Floor on June 21st @ 12:00 } \\
\hline \multicolumn{2}{|c|}{ South Wall } \\
\hline \multicolumn{2}{|c|}{ Air Cavity \#1 } \\
\hline $\mathrm{RT}$ & 3.99 \\
\hline$U$ & $0.25 \mathrm{BTU} / \mathrm{h} * \mathrm{sf} * \mathrm{~F}$ \\
\hline$A$ & $1,089.00$ sqft. \\
\hline Tindoor & $75.00 \mathrm{~F}$ \\
\hline Toutdoor (surface temp) & $134.33 \mathrm{~F}$ \\
\hline Qair cavity & $16,192.10 \mathrm{BTU} / \mathrm{HR}$ \\
\hline $\begin{array}{l}\text { Qheat loss due to Wind, } \\
\text { Heat Stacking (Entire Floor) }\end{array}$ & $-4,161.76$ BTU/HR \\
\hline Qdelta & $12,030.34 \mathrm{BTU} / \mathrm{HR}$ \\
\hline
\end{tabular}

\begin{tabular}{lc|}
\hline \multicolumn{2}{|c|}{ Air Cavity \#2 Glass Portion } \\
RTG & 2.51 \\
UG & $0.40 \mathrm{BTU} / \mathrm{h}^{*} \mathrm{sf}^{*} \mathrm{~F}$ \\
$\mathrm{AG}$ & $864.00 \mathrm{sqft}$. \\
Tindoor & $75.00 \mathrm{~F}$ \\
Toutdoor & $93.00 \mathrm{~F}$ \\
& \\
Qair duct (Glass) & $6,196.02 \mathrm{BTU} / \mathrm{HR}$ \\
\hline & \\
\hline & Air Cavity \#2 Concrete Portion \\
RTC & 1.86 \\
UC & $0.54 \mathrm{BTU} / \mathrm{h}^{*} \mathrm{sf*} F$ \\
AC & $1,144.00 \mathrm{sqft}$. \\
Tindoor & $75.00 \mathrm{~F}$ \\
Toutdoor & $93.00 \mathrm{~F}$ \\
& \\
Qair duct (Concrete) & $11,070.97 \mathrm{BTU} / \mathrm{HR}$ \\
\hline
\end{tabular}

Qheat loss due to
convection on exterior
surface due to Cooling Rib
Effect (Entire Floor)
Qsouth wall total

TABLE 4.3.1: TOTAL HEAT GAIN FOR THE $10^{\mathrm{TH}}$ FLOOR SOUTH FACING FACADE SYSTEM OF THE FINAL DESIGNED SOLUTION 


\begin{tabular}{|c|c|}
\hline \multicolumn{2}{|c|}{ 5th Floor on June 21st @ 12:00 } \\
\hline \multicolumn{2}{|c|}{ South Wall } \\
\hline Rtotal glass & 1.79 \\
\hline Uwall glass & $0.56 \mathrm{BTU} / \mathrm{h} * \mathrm{sf} * \mathrm{~F}$ \\
\hline Aglass ( $25 \%$ of total) & $605.00 \mathrm{sqft}$. \\
\hline Tindoor & $75.00 \mathrm{~F}$ \\
\hline Toutdoor (surface temp) & $154.78 \mathrm{~F}$ \\
\hline Qsouth wall glass & $26,964.23 \mathrm{BTU} / \mathrm{hr}$ \\
\hline Rtotal wall solid & 26.58 \\
\hline Uwall solid & $0.04 \mathrm{BTU} / \mathrm{h} * \mathrm{sf} * \mathrm{~F}$ \\
\hline Awall solid ( $75 \%$ of total) & $1,815.00 \mathrm{sqft}$. \\
\hline Tindoor & $75.00 \mathrm{~F}$ \\
\hline Toutdoor (surface temp) & $154.78 \mathrm{~F}$ \\
\hline Qsouth wall solid & $5,447.63 \mathrm{BTU} / \mathrm{hr}$ \\
\hline Qsouth wall total 5th floor & 32,411.86 BTU/hr \\
\hline
\end{tabular}

\section{TABLE 4.3.2: TOTAL HEAT GAIN FOR THE $5^{\mathrm{TH}}$ FLOOR SOUTH FACING FACADE SYSTEM OF THE TYPICAL BUILDING SKIN}

\subsubsection{Calculating the Ventilation Rate based on the Amount of Heat Gain and Comfort Temperature}

Now that we have the total amount of heat gain for the entire south facing building skin for the $10^{\text {th }}$ floor, it is possible to solve for the ventilation rate required to remove the heat gain based on equation 4.11, which is similar to the equations 4.5 and 4.8 discussed in the section 4.2. Table 4.3.3 shows the ventilation rate that is required to provide the comfort indoor temperature $\left(75^{\circ} \mathrm{F}\right)$ for an office building in Yazd at noon on June $21^{\text {st }}$. 


$$
\mathrm{V}=\frac{\mathrm{Q}}{\mathrm{PS}\left(\mathrm{T}_{1}-\mathrm{T}_{2}\right)}
$$

$\mathrm{V}=$ Ventilation Rate required to remove a heat load(Q)

$\mathrm{Q}=$ Heat Load

$\mathrm{S}=$ Specific Heat of Air $(0.24 \mathrm{BTU} / \mathrm{LB} / \mathrm{F})$

$\mathrm{P}=$ Average Air Density (approx. $0.075 \mathrm{LB} / \mathrm{CF}$ at an indoor temperature of $70 \mathrm{~F}$ )

$\mathrm{T}_{1}=$ Indoor temperature $(\mathrm{F})$

$\mathrm{T}_{2}=$ Outdoor temperature $(\mathrm{F})$

EQUATION 4.11: CALCULATION FOR THE VENTILATION RATE (V) REQUIRED

TO REMOVE THE HEAT LOAD (Q)

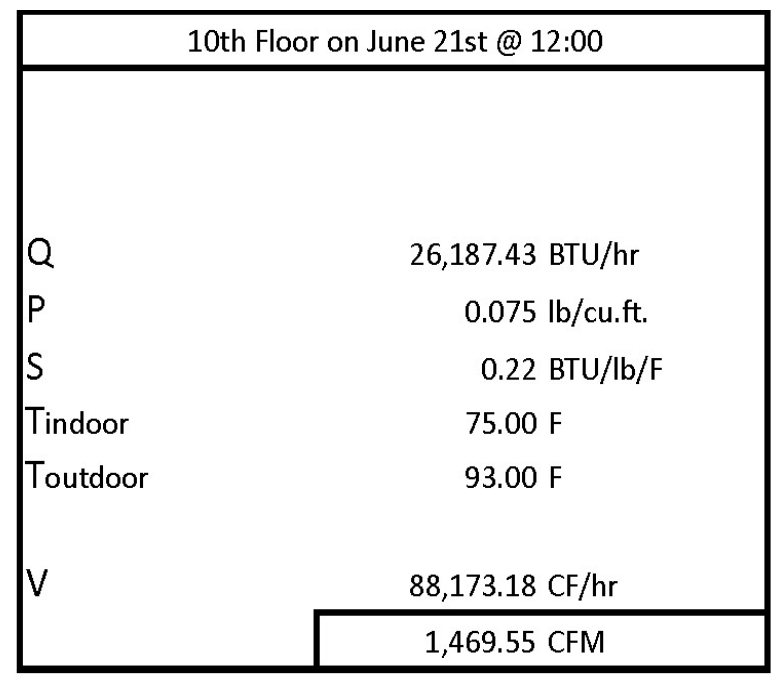

TABLE 4.3.3: CALCULATING THE VENTILATION RATE BASED ON THE AMOUNT OF HEAT GAIN AND INDOOR/OUTDOOR TEMPERATURE $10^{\mathrm{TH}}$ FLOOR

JUNE $21^{\text {ST }}$ 12:00 - YAZD, IRAN

Based on the calculation in the table 4.3.3, the required ventilation rate in order to provide $75^{\circ} \mathrm{F}$ as the comfort indoor temperature for the interior office is $1,469.55 \mathrm{CFM}$ or 1.4 MPH through the window vents from the interior of the building into air cavity $\# 2$. So, in order to achieve the interior ventilation rate and the desired indoor comfort temperature, the author proposes two passive design strategies for an office building 
envelope. Since the design of the building skin is the goal of the paper and not the design of the entire building envelope, the proposed solutions regarding design solutions for the building envelope will only be presented at a conceptual level without additional calculations. The solutions applied in order to achieve the required interior ventilation rate are:

- Solar Chimney on top of the air cavity \#2 on the roof

- Evaporation system on the north side of the building envelope

\subsubsection{Propose the Design Solutions to Solve for the Interior Ventilation Rate a. Solar Chimney}

On top of the outlet of the Air cavity \#2 (figure 4.3.1), is a designed Solar Chimney which improves the effect of the natural ventilation and airflow of the interior spaces. Solar Chimney effect was explained in the second chapter as one of the efficient passive design strategies in Yazd that creates natural ventilation inside the building when there is no wind outside. Figure 4.3.2 is a section through air cavity $\# 2$ showing the main surface of the Solar Chimney outlet is facing to the south and therefore will receive more direct solar radiation. Therefore, the south facing part of the designed Solar Chimney will become extremely hot and create a pressure differences between the air in the air cavity and the air inside the building, thus creating an outflow from the interior of the building out through air cavity \#2. Here, figure 4.3.3 shows that the designed Solar Chimney on the roof is connected to the air cavity \#2 and is able to pull the hot air inside the air cavity and the building spaces out because of the pressure differences explained in the second chapter. 


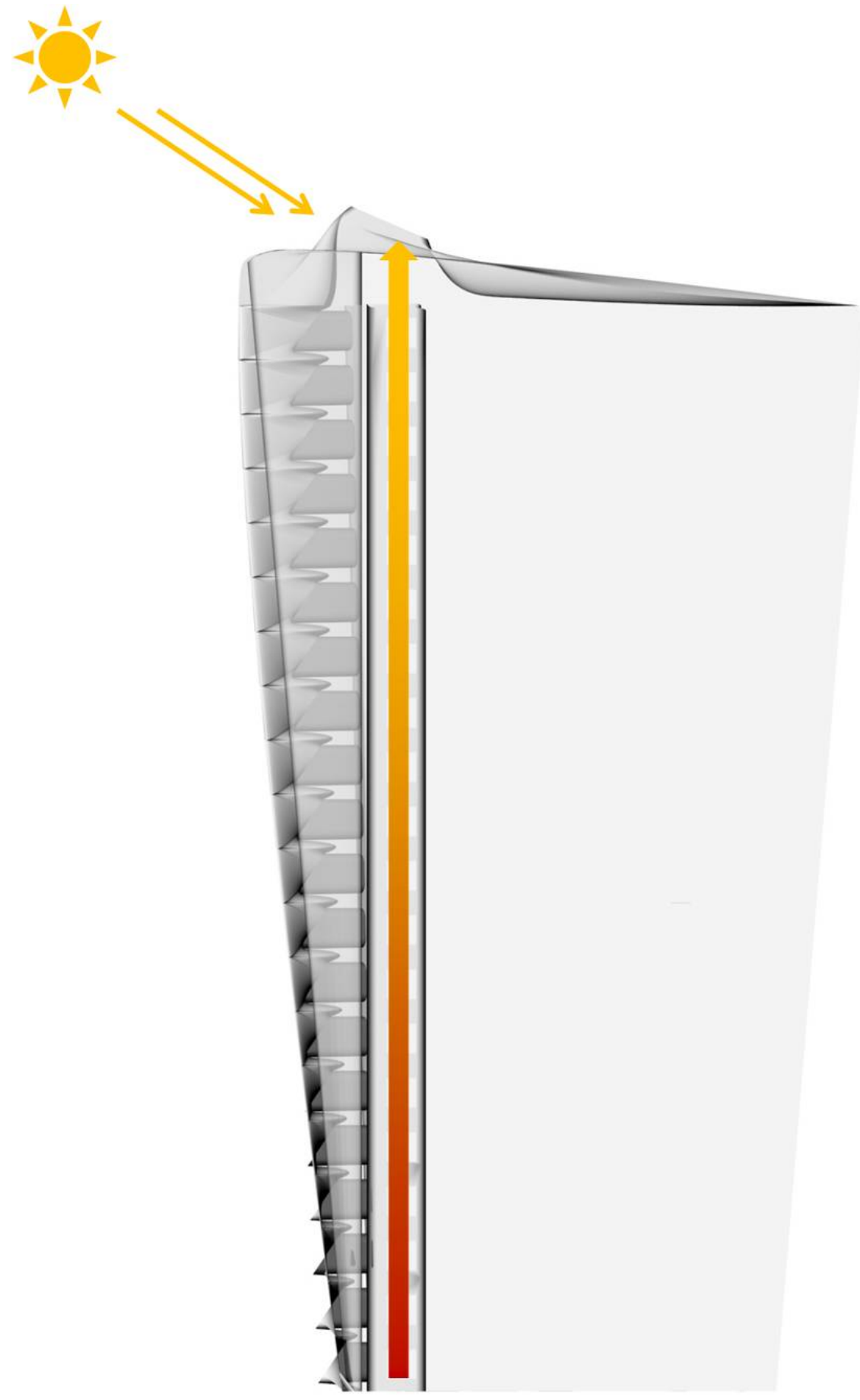

FIGURE 4.3.2: AIR CAVITY \#2 SECTION SHOWING THE SOLAR CHIMENY EFFECT 


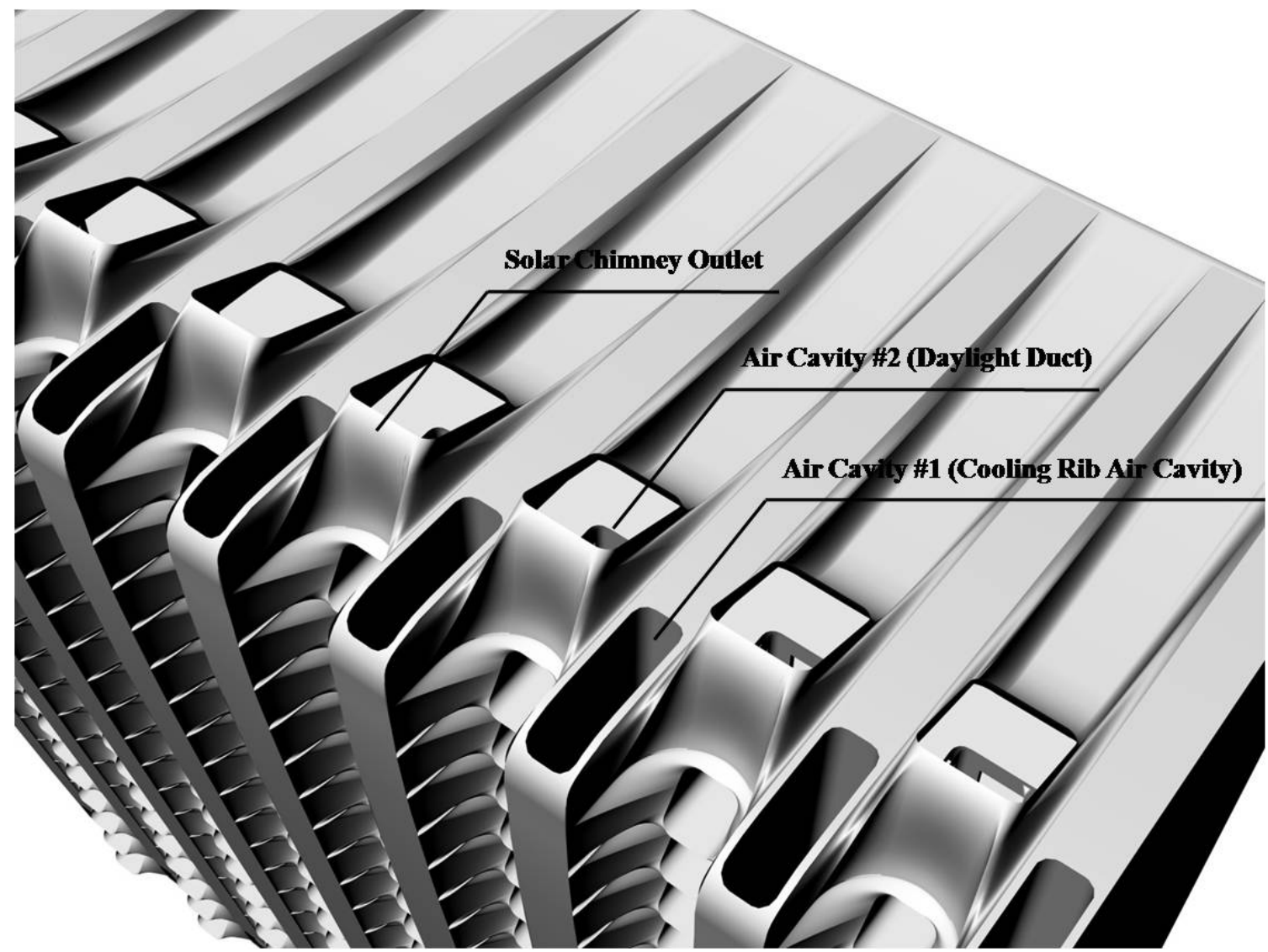

FIGURE 4.3.3: SOLAR CHIMNEY AS A VENTILATION SOLUTION ON THE ROOF SYSTEM

\section{b. Evaporation System}

Besides the Solar Chimney solution, there is also another passive design solution helping to create greater pressure differences in the air cavity \#2 and inside the building to improve the natural ventilation. Here the author proposes an evaporation system which could be designed as small pools on the north sides of the building. Since the summer local winds are from the north and the west, having openings on the north façade of the building skin brings the cooler shaded air inside the building, passing it over the evaporation system. Although the shaded air is cooler than the Sun exposed air, it is still quite warm as far as human comfort is concerned. Therefore, this warm air as it passes 
over the evaporation ponds will cause the air to cool as the water evaporates thus helping to maintain a comfortable temperature of the interior of the building. The water vapor in the air will help to further create an imbalance of air pressure between the building interior and air cavity \#2 which will help to accelerate the ventilation rate. On the south side of the building, the heat gain absorbed by the building skin combined with the heat generated by the users and their machines begins to create a natural ventilation within the building interior due to the air pressure and temperature differences between the northern and southern microclimates within the building. This natural ventilation could be improved by the Solar Chimney designed on the roof (previous section).

Figure 4.3.4 shows that local wind not only creates pressure differences on the two sides of the building (section 4.2.9), but also with the help of evaporation system on the north side of the building and Solar Chimney on the south side of the building, it is possible to create a greater pressure difference to improve the natural ventilation and possibly reach the ventilation rate required in the table 4.3.3.

Both strategies are related to air cavity \#2 since this air cavity is connected to the interior spaces as it brings natural daylight and ventilation to the building. As described in Chapter 2, the Qanat evaporation system combined with Windcatchers and Solar Chimney s are passive design strategies in the architecture of Yazd to create natural ventilation. Therefore, the passive strategies that have been proposed here are examples of lessons taken from the traditional architecture of Yazd. 


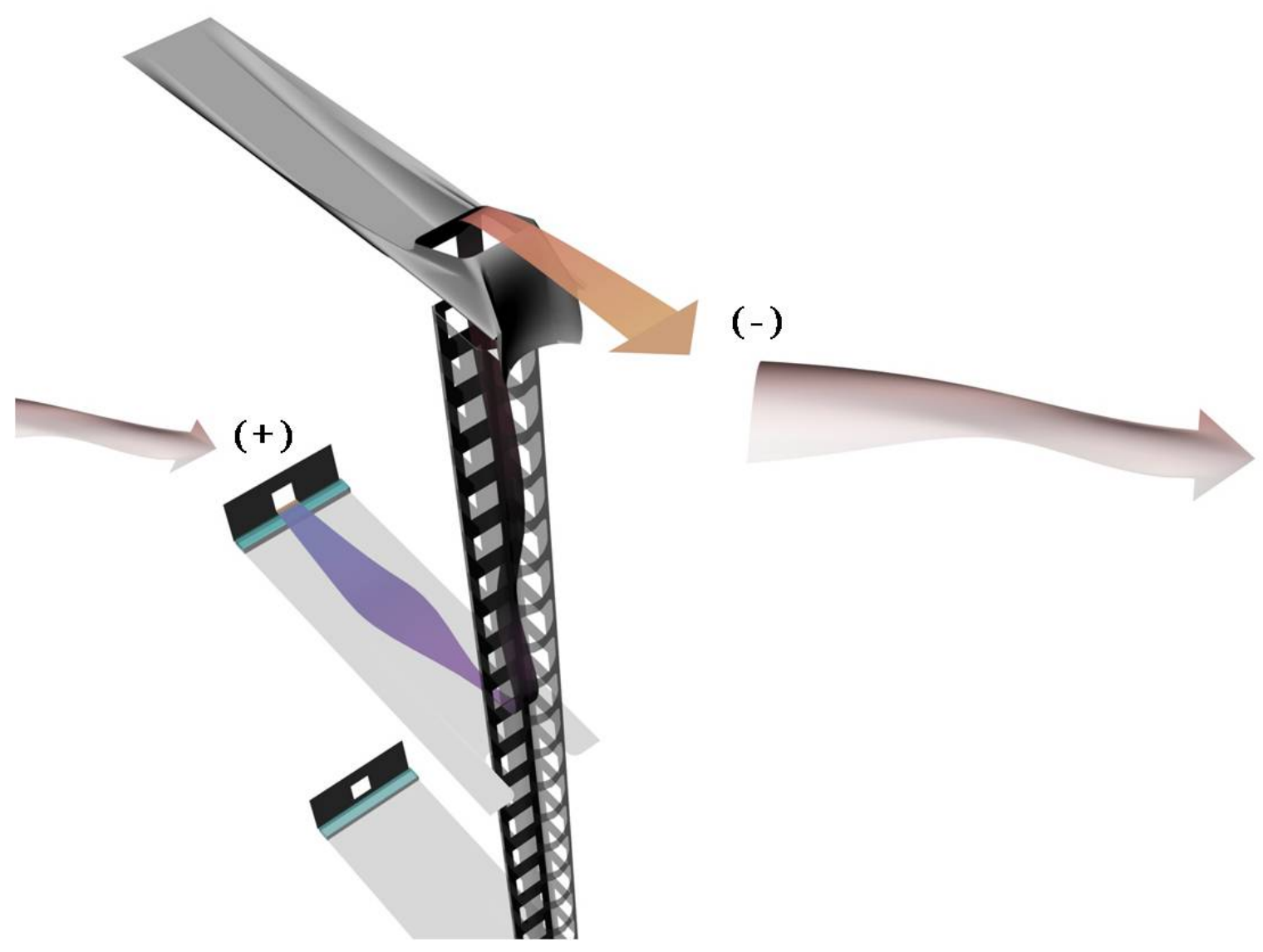

FIGURE 4.3.4: LOCAL SUMMER WINDS WITH THE HELP OF EVAPORATION SYSTEM AND SOLAR CHIMNEY CREATES PRESSURE DIFFERENCES THAT IMPROVES THE NATURAL VENTILATION INSIDE THE DAYLIGHT DUCT AND INSIDE THE BUILDING SPACES

Figure 4.3.5 shows the section of air cavity \#2 and explains the two types of passive design strategies (evaporation system combined with the Solar Chimney ) combined with the local Summer Wind creating natural ventilation inside the building and inside air cavity \#2. All the graphical examples are for the $10^{\text {th }}$ floor of the building since all the calculations in this section are for this floor. 


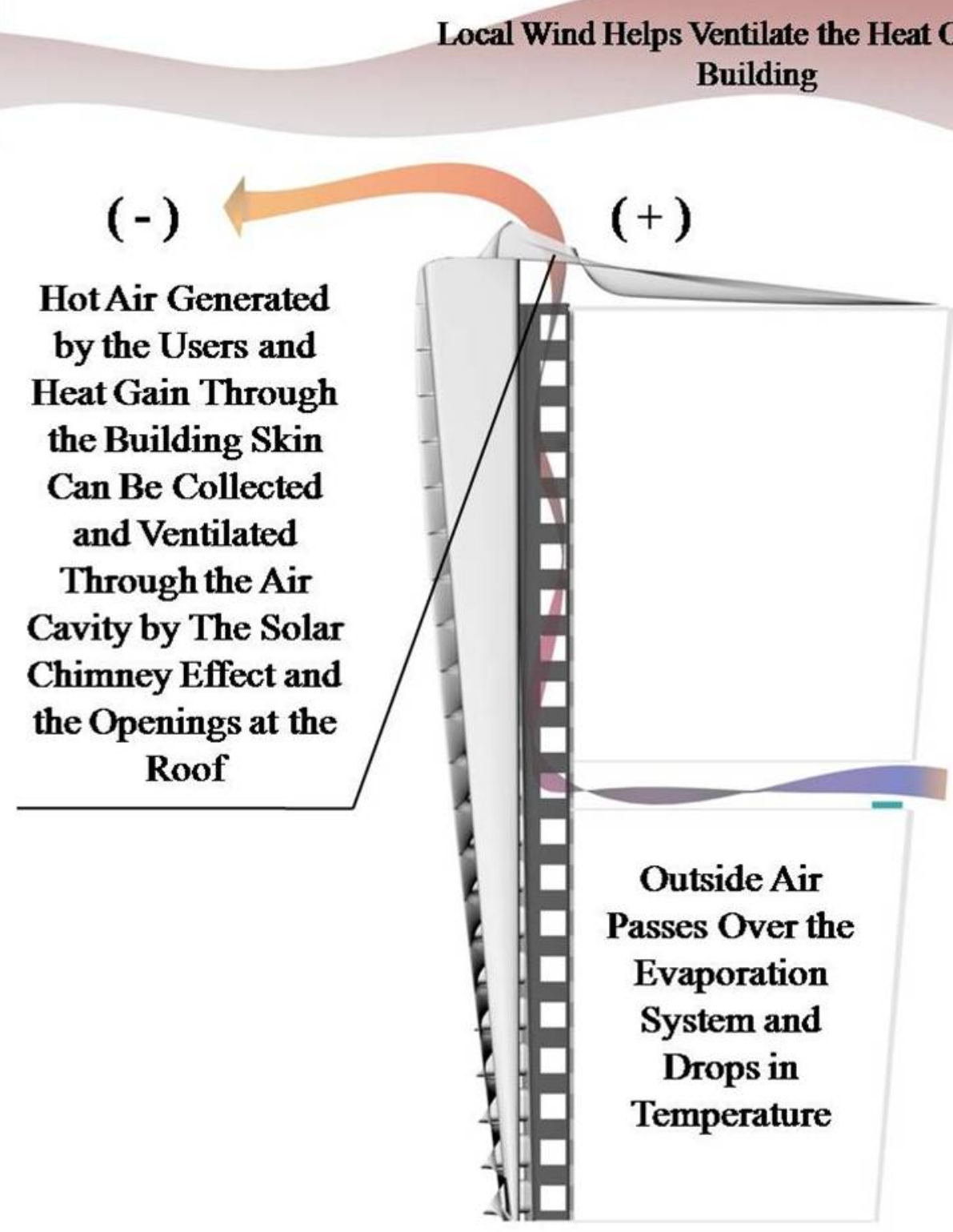

FIGURE 4.3.5: LOCAL SUMMER WINDS WITH THE HELP OF EVAPORATION SYSTEM AND SOLAR CHIMNEY CREATE PRESSURE DIFFERENCES THAT IMPROVE THE NATURAL VENTILATION INSIDE AIR CAVITY \#2 AND INSIDE THE BUILDING SPACES

As mentioned before, the combination of an evaporation system combined with Windcatcher/Solar Chimney is an efficient passive architectural strategy applied in the architecture of Yazd, Iran. These types of solutions are still applicable to modern 
architectural design in hot dry climates today. These solutions are required to provide comfortable temperatures for the interior of the building.

Beside heat gain and natural ventilation of the building envelope, natural daylight is another considerable comfort factor in the design of the building skin. The following sections will describe how the design of the interior building skin is based on providing adequate natural daylight.

\subsubsection{Daylight Design Consideration}

As explained in the second chapter, one of the passive design strategies of the architecture in Yazd is to have most of the openings (windows and doors) on the interior facing facade of the building usually opening up toward the central courtyard. The exterior facade of the building though has only the minimum amount of openings (main entrance) when compared to exterior facades of building in other climates. The same type of adaptation has been applied to the exterior skin of the Barrel Cactus. As the Barrel Cactus has only the minimum required Stomata when compared to plants in other climates (section 1.2.1).

The final design solution also follows a similar design strategy. While the exterior facade of the building is mostly solid which helps to regulate the amount of solar radiation passing through the air cavity and into the interior of the building, the interior layer of the building skin is designed to allow natural daylight to enter the building through three large windows. Figure 4.3.6 shows a plan section of the corrugated interior layer having three windows on each side of the interior walls. The three designed windows surrounding the air cavity \#2 bring diffused daylight into the open office space. 
These windows surrounding air cavity\#2 are like the openings of the buildings in Yazd that surround the courtyard. The function of the windows therefore is not only bringing natural light but also ventilating/cooling to the interior spaces as mentioned previously in this chapter.

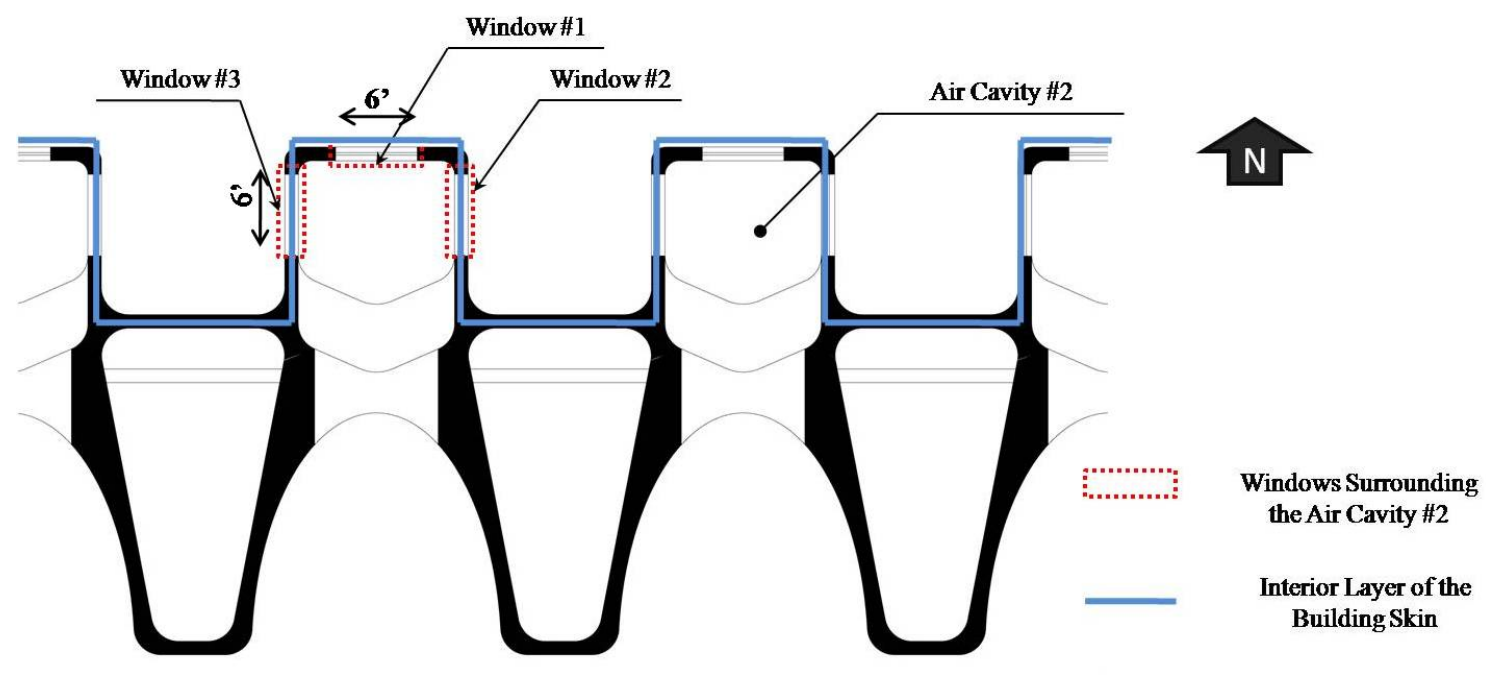

FIGURE 4.3.6: THREE DESIGNED WINDOWS LOCATED AROUND THE AIR CAVITY \#2

Before explaining the daylight design solution of the interior layer of the building skin, the first step is to find out the sufficient required daylight illumination for an open office area. Figure 4.3.7 shows the required daylight illumination for different tasks calculated by the Ecotect daylight analysis tool.

Considering 10.76lux is almost equal to $1 \mathrm{fc}$, the required amount of daylight illumination for an office desk is about40fc or 400lux. 


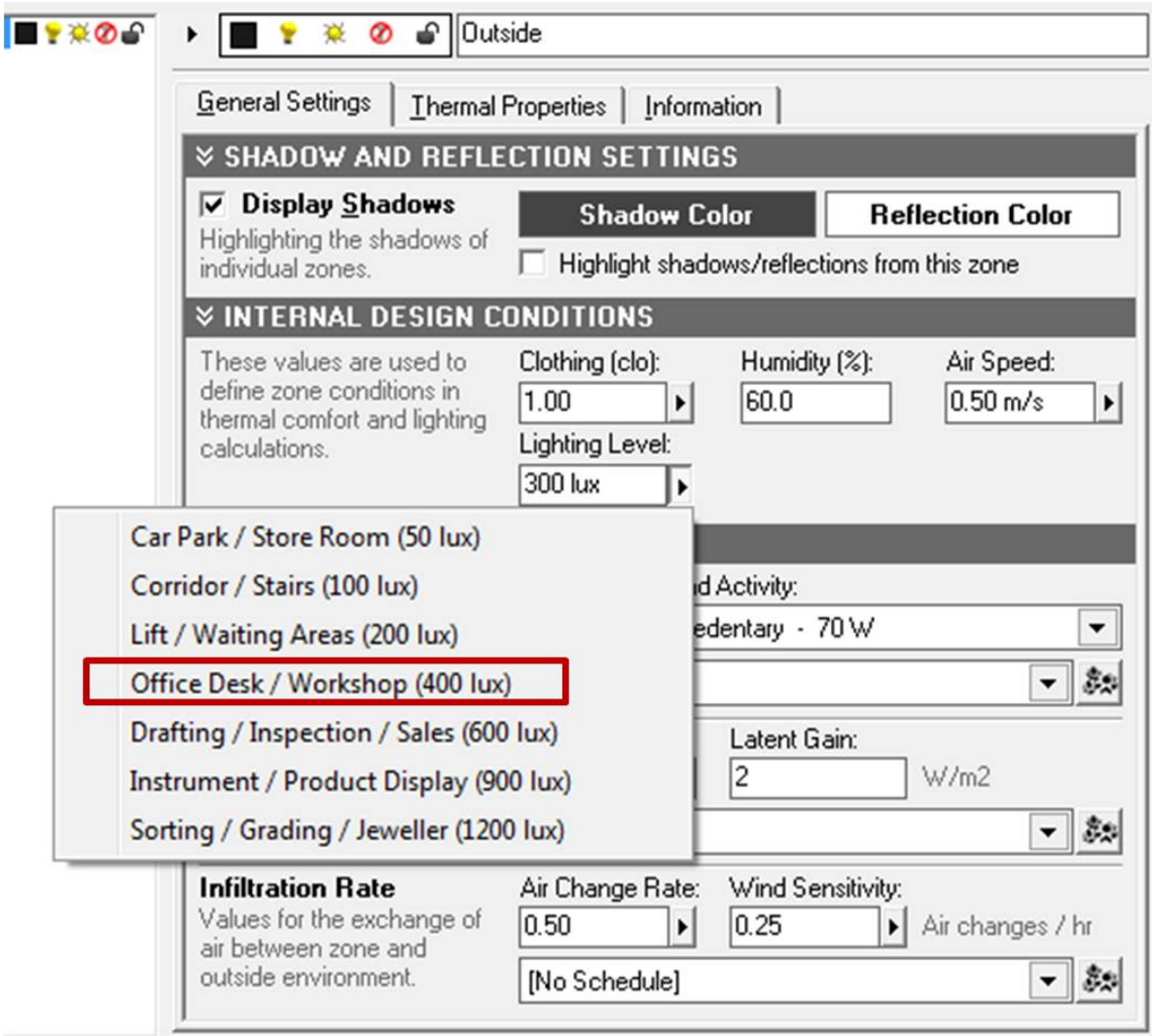

\section{FIGURE 4.3.7: REQUIRED ILLUMINATION FOR DIFFERENT TASKS PROVIDED BY ECOTECT}

Following equation solves for the interior daylight illumination.

Indoor Daylight Illumination $(\mathrm{fc})=$ Outdoor Daylight Illumination(fc) * Daylight Factor(\%)

\section{EQUATION 4.12: INDOOR DAYLIGHT ILLUMINATION CALCULATION}

Based on equation 4.12, the amount of daylight illumination provided inside the building by the corrugated interior layer (figure 4.3.6) is the percentage of the outdoor daylight illumination multiplied by the "Daylight Factor" ${ }^{66}$. Therefore, it is required to calculate the outdoor daylight illumination as the first step to solving this calculation. The 
next step is then to calculate the "Daylight Factor" which is the multiplication of "Sky Component (SC)"67, the "Internally Reflected Component (IRC)"68 and the "Externally Reflected Component (ERC)" ${ }^{\prime 69}$.

Here is a summary of the Calculation steps necessary to solve the interior daylight illumination:

- Calculate the total outdoor daylight illumination

- $\quad$ Calculate the daylight illumination in air cavity \#2 $\left(\mathrm{P}_{1}\right)$

- $\quad$ Calculate the daylight factor in the air cavity \#2 $\left(\mathrm{P}_{1}\right)$

- Interior daylight illumination based on illumination in air cavity \#2 and the daylight factors at $\mathrm{P}_{2}$ and $\mathrm{P}_{3}$

Before starting the calculation, please remember that:

- In order to understand how the interior light levels might vary over the course of a year, this calculation process was completed for 4 times of the year; March $21^{\text {st }}$, June $21^{\text {st }}$, September $21^{\text {st }}$ and December $21^{\text {st }}$.

- In order to understand how the interior light levels might vary over the course of a day, this calculation process was completed 5 times for each of the above mentioned days; 8:00, 10:00, 12:00, 14:00 and 16:00.

- The entire calculation process occurs on the $10^{\text {th }}$ floor of the final designed building.

\subsubsection{Calculate the Total Outdoor Daylight Illumination}

Since Yazd has a hot dry climate, it is appropriate to use the "Uniform Brightness $\mathrm{Sky}{ }^{70}$ method for determining the total Outdoor Daylight Illumination. The following 
equation solves for the outdoor daylight illumination based on the position of the Sun and the anticipated cloud cover in Yazd for the day in question. The Sun altitude data required for equation 4.13 is provided in the table 4.3 .4 for each specific date. This data was collected through the Ecotect Analysis 2011 software package using the Solar Tool.

$$
I_{H}=A\left[1750 *\left(\sin a^{0.5}\right)\right]+B\left[13200 * \sin a * 10^{-0.1 m}\right]
$$

$\mathrm{I}_{\mathrm{H}}=$ Illumination on a Horizontal Surface

$\mathrm{A}=0.89$ and $\mathrm{B}=0.35$ of Thin Film of Clouds

$\mathrm{A}=0.54$ and B 0.26 for Cloudy Sky

$\mathrm{A}=1.02$ and $\mathrm{B}=0.08$ for Light White Clouds and Clear Sun

$\mathrm{a}=$ Altitude of the Sun

$\mathrm{m}=$ Air Mass (or csc a)

$10^{-0.1 \mathrm{~m}}=$ Transmission Factor of Atmosphere

EQUATION 4.13: OUTDOOR DAYLIGHT ILLUMINATION CALCULATION ${ }^{71}$

\begin{tabular}{|c|c|c|c|c|c|}
\hline \multirow{6}{*}{ 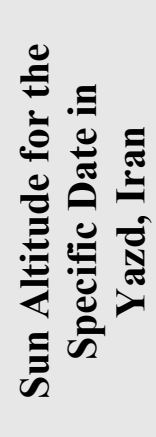 } & Date & March 21 ${ }^{\text {st }}$ & June $21^{\text {st }}$ & September $21^{\text {st }}$ & December $21^{\text {st }}$ \\
\hline & 8:00 & $12.3^{\circ}$ & $25.4^{\circ}$ & $16^{\circ}$ & $0.9^{\circ}$ \\
\hline & $10: 00$ & $36.4^{\circ}$ & $50.6^{\circ}$ & 39.9 & $20.9^{\circ}$ \\
\hline & $12: 00$ & $54.5^{\circ}$ & $75^{\circ}$ & 56.9 & $33^{\circ}$ \\
\hline & $14: 00$ & $54.7^{\circ}$ & $73.2^{\circ}$ & 54.3 & $32^{\circ}$ \\
\hline & $16: 00$ & $36.7^{\circ}$ & $48.5^{\circ}$ & $34.9^{\circ}$ & $18.4^{\circ}$ \\
\hline
\end{tabular}

TABLE 4.3.4: SUN ALTITUDE DEGREES FOR YAZD CITY PROVIDED BY SOLAR TOOL IN ECOTECT ANALYSIS 2011

In order to find the Sun Altitude for other times of the day throughout the year in Yazd please see the appendix. 
Having the information in the table 4.3.4 and using it in the equation 4.13, it is possible to solve for the outdoor daylight illumination. Table 4.3.5 shows the calculated outdoor daylight illumination for the specific dates. When you compare the outdoor daylight illumination in table 4.3.5 with the required illumination levels for office tasks in figure 4.3.7 on average, the outdoor levels are 54 times greater than the required illumination levels for the office tasks. This drastic difference goes to show how tough it is to design comfortable building spaces in Yazd.

\begin{tabular}{|c|c|c|c|c|c|}
\hline & Date & March 21 & June 21 $^{\text {st }}$ & September 21 $^{\text {st }}$ & December 21 $^{\text {st }}$ \\
\cline { 2 - 6 } & $8: 00$ & 684 & 1479 & 906 & 1019 \\
\cline { 2 - 6 } & $10: 00$ & 2109 & 2799 & 2294 & 1207 \\
\cline { 2 - 6 } & $12: 00$ & 2958 & 3540 & 3049 & 1922 \\
\cline { 2 - 6 } & $14: 00$ & 2966 & 3507 & 2951 & 1866 \\
\cline { 2 - 6 } & $16: 00$ & 2125 & 2708 & 2028 & 1053 \\
\hline \multirow{2}{*}{}
\end{tabular}

TABLE 4.3.5: CALCULATING THE OUTDOOR DAYLIGHT ILLUMINATION BASED ON THE EQUATION 4.13.

\subsubsection{Calculate the Daylight Illumination in Air Cavity \#2 $\left(P_{1}\right)$}

Figures 4.3.8 and 4.3.9 show plan and section views of the designed building skin for the $10^{\text {th }}$ floor. In order to determine the available daylight illumination at $\mathrm{P}_{2}$ and $\mathrm{P}_{3}$ inside the building, we need to find the available daylight illumination at the center of air cavity \#2 which is labeled $\mathrm{P}_{1}$ in the figures 4.3.8 and 4.3.9. Although we calculated the outdoor daylight illumination in the step 4.3.2.1, the daylight illumination of air cavity \#2 will be used as the outdoor daylight illumination for the interior spaces in the figures 4.3.8-9. In order to find the provided illumination at $\mathrm{P}_{1}$ in air cavity $\# 2$ for figures $4.3 .8-9$, 
we should follow equation 4.12. Therefore, the outdoor daylight illumination levels and the Daylight Factor at $P_{1}$ are required to be calculated. Since we already calculated the outdoor daylight illumination levels based on equation 4.12 in section 4.3.2.1, we only now need to find the Daylight Factor at $\mathrm{P}_{1}$ in the figures 4.3.8-9 and multiply the Daylight factor by the Outdoor daylight illuminations in table 4.3.5.

Therefore, in the next step we learn how to calculate the Daylight Factor for the $\mathrm{P}_{1}, \mathrm{P}_{2}$ and $\mathrm{P}_{3}$.

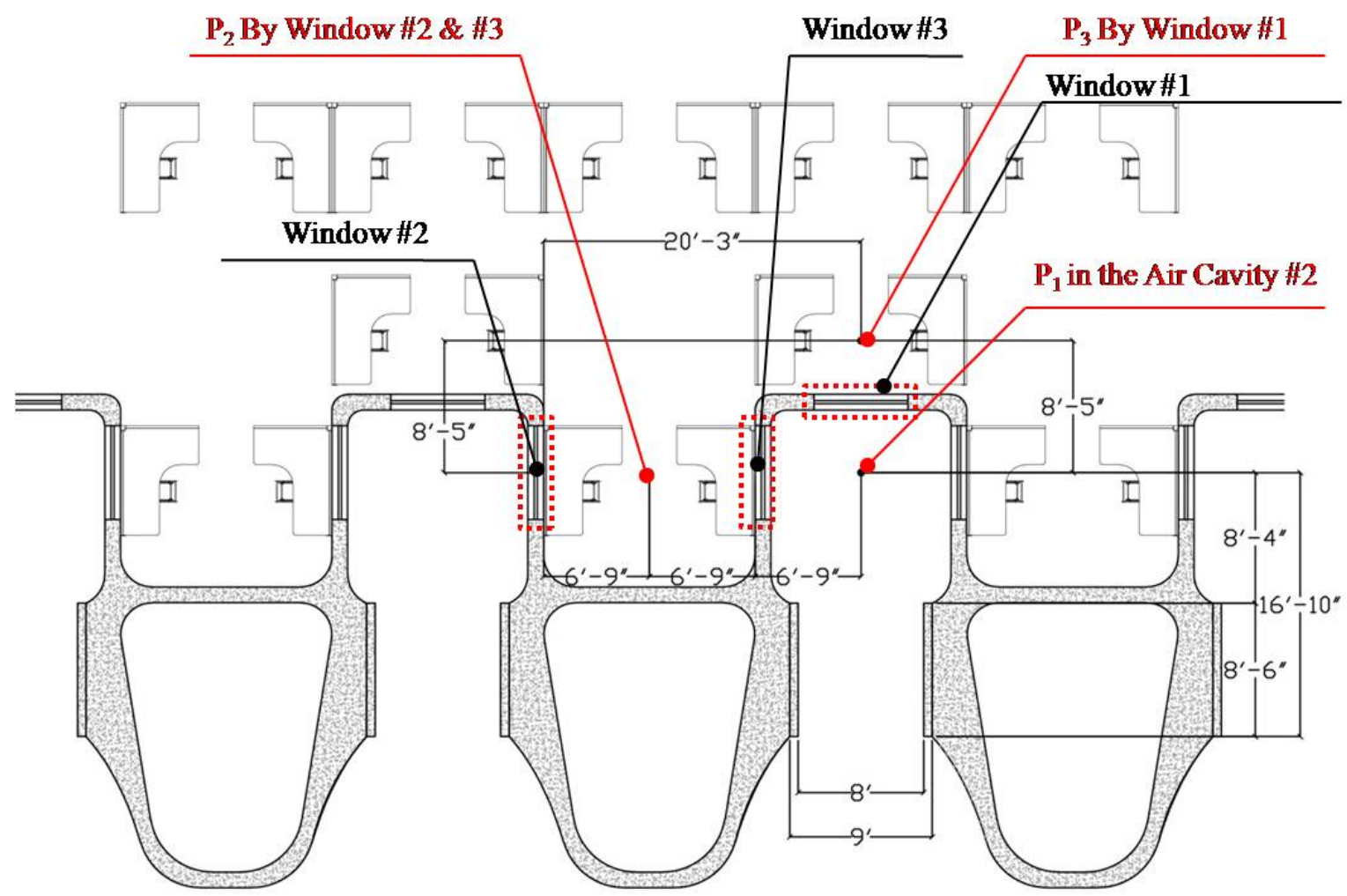

FIGURE 4.3.8: PLAN SECTION AT $10^{\mathrm{TH}}$ FLOOR SHOWING THE CONSIDERED POSITIONS REGARDING THE DAYLIGHT ILLUMINATION CALCULATION 


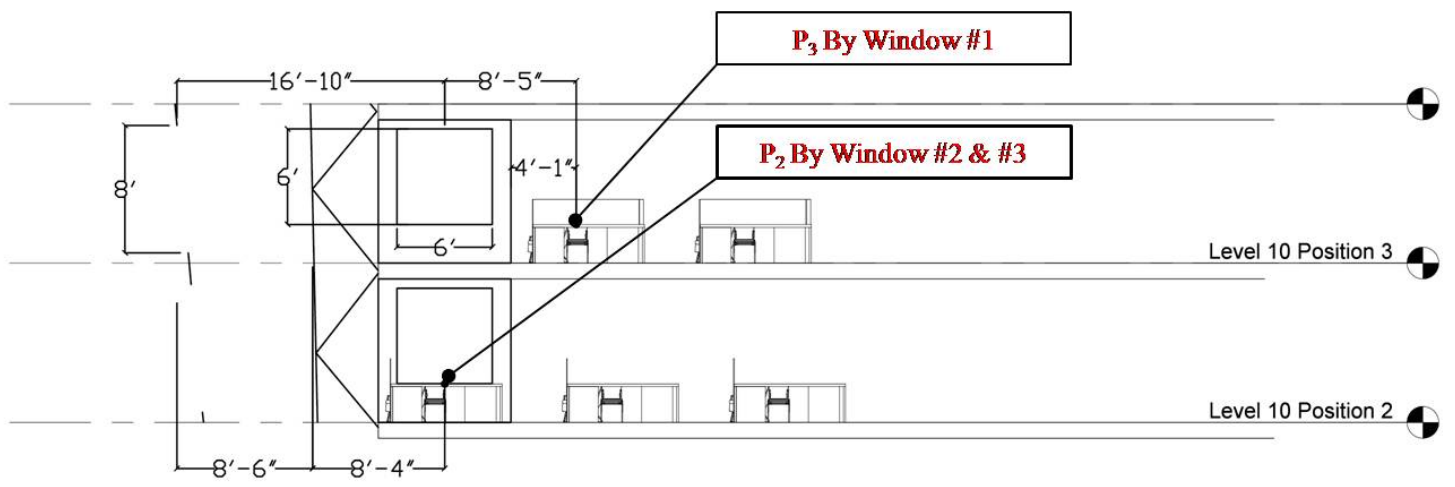

FIGURE 4.3.9: SECTION AT $10^{\mathrm{TH}}$ FLOOR SHOWING THE CONSIDERED POSITIONS REGARDING THE DAYLIGHT ILLUMINATION CALCULATION

\subsubsection{Calculate the Daylight Factor in the Air Cavity \#2 $\left(P_{1}\right)$}

The second part of equation 4.12 is calculating the "Daylight Factor". The "Daylight Factor" expresses the illumination available on a horizontal surface inside a building as a percentage of the illumination provided by the whole sky on a horizontal surface located outside the building ${ }^{72}$. Therefore, the "Daylight Factor (DF)" is the sum of the sky component (SC) and the Externally Reflected Component (ERC) and the Internally Reflected Component (IRC) ${ }^{73}$. Since there are no tall buildings obstructing the path of daylight from the Sun to designed building, the ERC (Externally Reflected Component) will be considered zero in equation 4.14 .

$$
\mathrm{DF}(\%)=\mathrm{SC}+\mathrm{ERC}+\mathrm{IRC}
$$

$\mathrm{DF}=$ Daylight Factor $(\%)$

$\mathrm{SC}=$ Sky Component $(\%)$

$\mathrm{ERC}=$ Externally Reflected Component $(\%)$

$\mathrm{IRC}=$ Internally Reflected Component $(\%)$

EQUATION 4.14: DAYLIGHT FACTOR CALCULATION ${ }^{74}$ 
Based on the information in the Building Science book by Jens Pohl on page 116, "The British Research Station (BRS) has published a very convenient set of Sky Component (SC) tables ... based on simple geometric ratios." Table 4.3.6 is the BRS table. These ratios (table 4.3.6) take into account the geometry of a side window in respect to its distance, height, and horizontal displacement from the point $(\mathrm{P})$ at which the daylight factor is to be determined ${ }^{75}$. Figure 4.3.10 and 4.3.11 are examples to help explain the calculation method to solve for the $\mathrm{SC}$ factor.

$\mathrm{SC}(\%)=\left(\mathrm{W}_{1} / \mathrm{D} \& \mathrm{H} / \mathrm{D}\right.$ ratios in the BRS Table $)(\%)+\left(\mathrm{W}_{2} / \mathrm{D} \& \mathrm{H} / \mathrm{D}\right.$ ratios in the BRS Table) $(\%)$

$\mathrm{W} / \mathrm{D}=[(\mathrm{W})$ Window width to one side of "P" (Figure 4.3.8)] (D) Distance of "P" from Window (Figure 4.3.8-9)]

$\mathrm{H} / \mathrm{D}=[(\mathrm{H})$ Window head height above "P" (Figure 4.3.9) $] /(\mathrm{D})$ Distance of "P" from Window (Figure 4.3.8-9)]

\section{EQUATION 4.15: SC FACTOR CALCULATION BASED ON THE BRS TABLE SIMPLIFIED SKY COMPONENT (SC) TABLES BASED ON SIMPLE W/D AND H/D GEOMETRIC RELATIONSHIPS}

Based on equation 4.15 the SC factor is the sum of the results of the H/D and $\mathrm{W} / \mathrm{D}$ ratios in the BRS table (table 4.3.6). Based on the position of the "P" to the adjacent window, the $H / D$ values and W/D values may change.

Table 4.3.7 shows the H/D values and W/D value for $P_{1}$ at the center of the air cavity in the figure 4.3.8. 


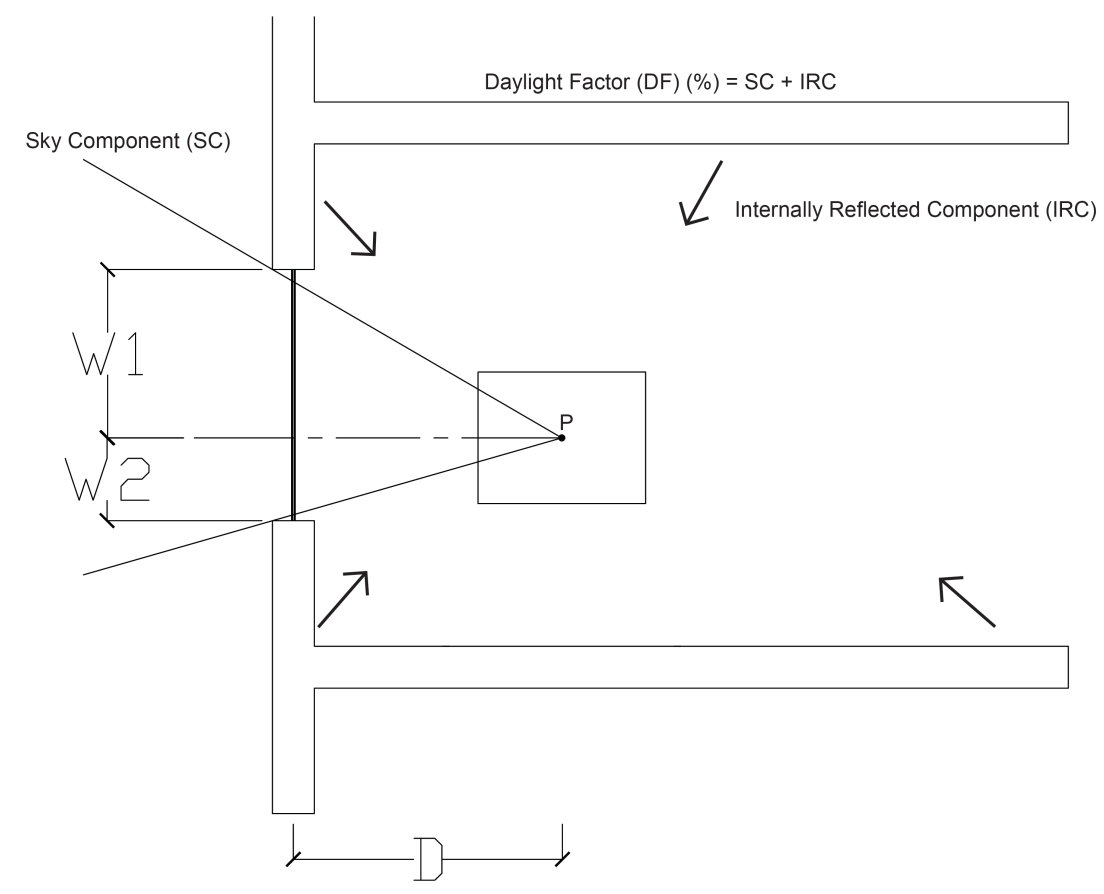

FIGURE 4.3.10: BRS SKY FACTOR TABLE PARAMETERS; W/D BASED ON THE POSITION OF THE "P"

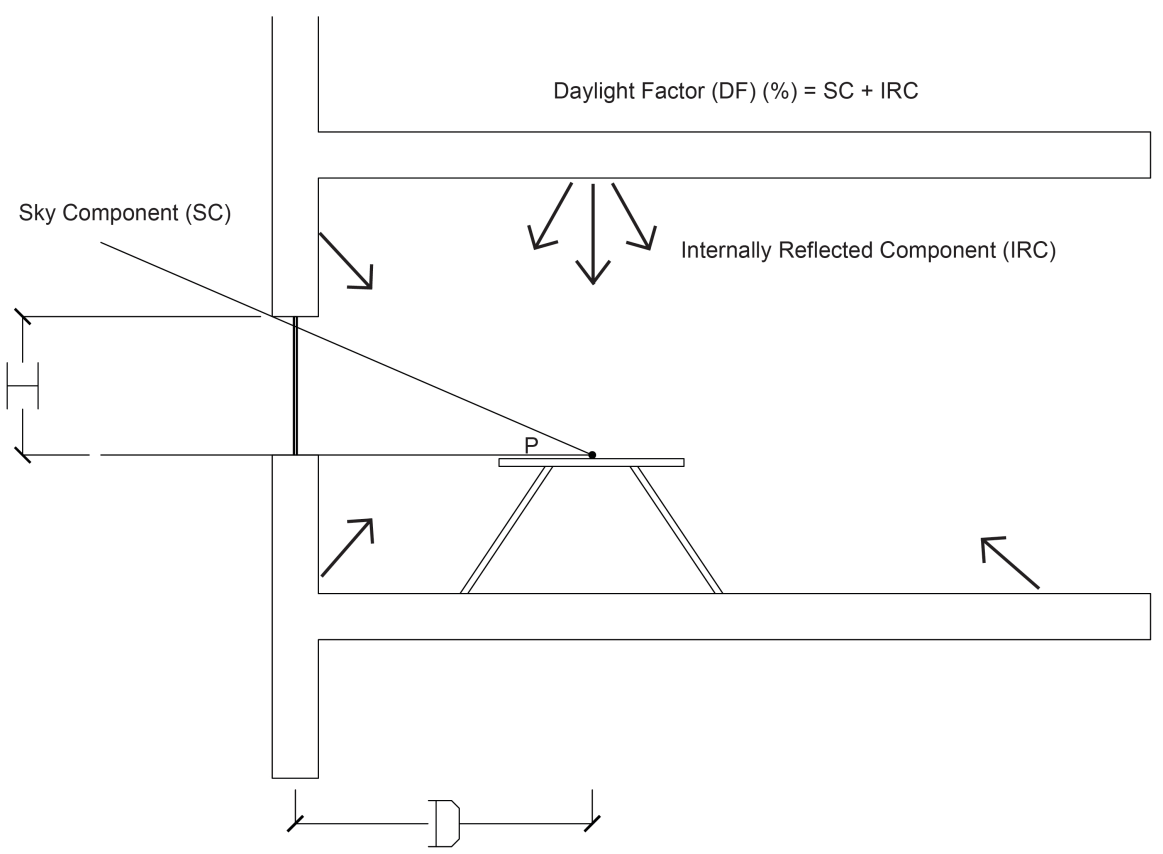

FIGURE 4.3.11: BRS SKY FACTOR TABLE PARAMETERS; H/D BASED ON THE POSITION OF THE "P" 


\begin{tabular}{|c|c|c|c|c|c|c|c|c|c|c|c|c|c|c|c|}
\hline infinity & 1.300 & 2.500 & 3.700 & 4.900 & 6.900 & 8.400 & 9.600 & 10.700 & 11.600 & 12.200 & 12.600 & 13.000 & 14.200 & 15.000 & $90^{\circ}$ \\
\hline 5 & 1.200 & 2.400 & 0.700 & 4.800 & 6.800 & 8.300 & 9.400 & 10.500 & 11.100 & 11.700 & 12.300 & 12.700 & 13.700 & 14.200 & $79^{\circ}$ \\
\hline 4 & 1.200 & 2.400 & 3.600 & 4.700 & 6.700 & 8.200 & 9.200 & 10.300 & 10.900 & 11.400 & 12.000 & 12.400 & 13.300 & 13.700 & $76^{\circ}$ \\
\hline 3.5 & 1.200 & 2.400 & 3.600 & 4.600 & 6.600 & 8.000 & 9.000 & 10.100 & 10.600 & 11.100 & 11.800 & 12.200 & 12.900 & 12.900 & $74^{\circ}$ \\
\hline 3 & 1.200 & 2.300 & 3.500 & 4.500 & 6.400 & 7.800 & 8.700 & 9.800 & 10.200 & 10.700 & 11.300 & 11.700 & 12.400 & 12.700 & $72^{\circ}$ \\
\hline 2.8 & 1.100 & 2.300 & 3.400 & 4.500 & 6.300 & 7.600 & 8.600 & 9.600 & 10.000 & 10.500 & 11.100 & 11.400 & 12.000 & 12.300 & $70^{\circ}$ \\
\hline 2.6 & 1.100 & 2.200 & 3.400 & 4.400 & 6.200 & 7.500 & 8.400 & 9.300 & 9.800 & 10.200 & 10.800 & 11.100 & 11.700 & 11.900 & $69^{\circ}$ \\
\hline 2.4 & 1.100 & 2.200 & 3.300 & 4.300 & 6.000 & 7.300 & 8.100 & 9.100 & 9.500 & 10.000 & 10.400 & 10.700 & 11.200 & 11.500 & $67^{\circ}$ \\
\hline 2.2 & 1.100 & 2.100 & 3.200 & 4.100 & 5.800 & 7.000 & 7.900 & 8.700 & 9.100 & 9.600 & 10.000 & 10.200 & 10.700 & 10.900 & $66^{\circ}$ \\
\hline 2 & 1.000 & 2.000 & 3.100 & 4.000 & 5.600 & 6.700 & 7.500 & 8.300 & 8.700 & 9.100 & 9.500 & 9.700 & 10.000 & 10.300 & $63^{\circ}$ \\
\hline 1.9 & 1.000 & 2.000 & 3.000 & 3.900 & 5.400 & 6.500 & 7.300 & 8.100 & 8.500 & 8.800 & 9.200 & 9.400 & 9.700 & 9.900 & $62^{\circ}$ \\
\hline 1.8 & 0.970 & 1.900 & 2.900 & 3.800 & 5.300 & 6.300 & 7.100 & 7.800 & 8.200 & 8.500 & 8.800 & 9.000 & 9.300 & 9.500 & $61^{\circ}$ \\
\hline 1.7 & 0.940 & 1.800 & 2.800 & 3.600 & 5.100 & 6.100 & 6.800 & 7.500 & 7.800 & 8.200 & 8.500 & 8.600 & 8.900 & 9.100 & $60^{\circ}$ \\
\hline 1.6 & 0.900 & 1.700 & 2.700 & 3.500 & 4.900 & 5.800 & 6.500 & 7.200 & 7.500 & 7.800 & 8.100 & 8.200 & 8.500 & 8.600 & $58^{\circ}$ \\
\hline 1.5 & 0.860 & 1.600 & 2.600 & 3.300 & 4.600 & 5.600 & 6.200 & 6.800 & 7.100 & 7.400 & 7.600 & 7.800 & 8.000 & 8.100 & $56^{\circ}$ \\
\hline 1.4 & 0.820 & 1.500 & 2.400 & 3.200 & 4.400 & 5.200 & 5.900 & 6.400 & 6.700 & 7.000 & 7.200 & 7.300 & 7.500 & 7.600 & $54^{\circ}$ \\
\hline 1.3 & 0.770 & 1.400 & 2.300 & 2.900 & 4.100 & 4.900 & 5.500 & 5.900 & 6.200 & 6.400 & 6.600 & 6.700 & 6.900 & 7.000 & $52^{\circ}$ \\
\hline 1.2 & 0.710 & 1.300 & 2.100 & 2.700 & 3.800 & 4.500 & 5.000 & 5.400 & 5.700 & 5.900 & 6.000 & 6.100 & 6.200 & 6.300 & $50^{\circ}$ \\
\hline 1.1 & 0.650 & 1.100 & 1.900 & 2.500 & 3.400 & 4.100 & 4.600 & 4.900 & 5.100 & 5.300 & 5.400 & 5.400 & 5.600 & 5.700 & $48^{\circ}$ \\
\hline 1 & 0.570 & 0.990 & 1.700 & 2.200 & 3.000 & 3.600 & 4.000 & 4.300 & 4.500 & 4.600 & 4.700 & 4.700 & 4.800 & 5.000 & $45^{\circ}$ \\
\hline 0.9 & 0.500 & 0.830 & 1.500 & 1.900 & 2.600 & 3.100 & 3.400 & 3.700 & 3.800 & 3.900 & 4.000 & 4.000 & 4.100 & 4.200 & $42^{\circ}$ \\
\hline 0.8 & 0.420 & 0.680 & 1.200 & 1.600 & 2.200 & 2.600 & 2.900 & 3.100 & 3.200 & 3.300 & 3.300 & 3.300 & 3.400 & 3.400 & $39^{\circ}$ \\
\hline 0.7 & 0.330 & 0.530 & 0.970 & 1.300 & 1.700 & 2.100 & 2.300 & 2.500 & 2.500 & 2.600 & 2.600 & 2.600 & 2.700 & 2.800 & $35^{\circ}$ \\
\hline 0.6 & 0.240 & 0.390 & 0.740 & 0.980 & 1.300 & 1.600 & 1.800 & 1.900 & 1.900 & 2.000 & 2.000 & 2.000 & 2.100 & 2.100 & $31^{\circ}$ \\
\hline 0.5 & 0.160 & 0.250 & 0.520 & 0.700 & 0.970 & 1.100 & 1.300 & 1.400 & 1.400 & 1.400 & 1.400 & 1.500 & 1.500 & 1.500 & $27^{\circ}$ \\
\hline 0.4 & 0.100 & 0.140 & 0.340 & 0.450 & 0.620 & 0.750 & 0.890 & 0.920 & 0.950 & 0.950 & 0.960 & 0.960 & 0.970 & 0.980 & $22^{\circ}$ \\
\hline 0.3 & 0.060 & 0.060 & 0.180 & 0.260 & 0.340 & 0.420 & 0.470 & 0.490 & 0.500 & 0.500 & 0.510 & 0.510 & 0.520 & 0.530 & $17^{\circ}$ \\
\hline 0.2 & 0.030 & 0.020 & 0.090 & 0.110 & 0.140 & 0.200 & 0.210 & 0.220 & 0.220 & 0.220 & 0.220 & 0.230 & 0.230 & 0.240 & $11^{\circ}$ \\
\hline 0.1 & 0.010 & 0.020 & 0.020 & 0.030 & 0.040 & 0.050 & 0.050 & 0.060 & 0.060 & 0.060 & 0.060 & 0.070 & 0.070 & 0.080 & $6^{\circ}$ \\
\hline 0 & 0.1 & 0.2 & 0.3 & 0.4 & 0.6 & 0.8 & 1 & 1.2 & 1.4 & 1.6 & 1.8 & 2 & 3 & infinity & $0^{\circ}$ \\
\hline
\end{tabular}

\section{TABLE 4.3.6: THE BRS SKY COMPONENT SC TABLES ${ }^{76}$}

\begin{tabular}{|c|c|}
\hline $\begin{array}{c}\text { SC Parameters in the Equation } \mathbf{4 . 1 5} \\
\text { for at } \mathbf{P}_{\mathbf{1}} \text { inside the Air Cavity \#2 }\end{array}$ & Position 1 \\
\hline $\mathrm{H}_{1} / \mathrm{D}$ & 0.4752 \\
\hline $\mathrm{H}_{2} / \mathrm{D}$ & 0.4752 \\
\hline $\mathrm{W}_{1} / \mathrm{D}$ & 0.2376 \\
\hline $\mathrm{W}_{2} / \mathrm{D}$ & 0.2376 \\
\hline
\end{tabular}

\section{TABLE 4.3.7: H/D AND W/D VALUES FOR THE POSITION 1 AT THE CENTER OF THE AIR CAVITY \#2}

Based on the results in the table 4.3.7 and BRS table, the final SC number at $\mathrm{P}_{1}$ is

$1 \%$. 
Another factor in Equation 4.14 to calculate for the Daylight Factor is to calculate the IRC factor. The following equation solves for the IRC factor.

$$
\operatorname{IRC}(\%)=\left[\frac{0.85\left(\mathrm{~A}_{\mathrm{G}}\right)}{\left(1-\left(\mathrm{R}_{\mathrm{T}}\right)\right) *\left(\mathrm{~A}_{\mathrm{S}}\right)}\right] *\left[\mathrm{C}\left(\mathrm{R}_{\mathrm{B}}\right)+5\left(\mathrm{R}_{\mathrm{A}}\right)\right](\%)
$$

$\mathrm{A}_{\mathrm{G}}=$ Total Window Area

$\mathrm{R}_{\mathrm{T}}=$ Average Surface Reflectance

$\mathrm{A}_{\mathrm{s}}=$ Total Surface Area

$\mathrm{C}=$ Factor Dependent on Angle of Obstruction (See Table 4.3.8)

$\mathrm{R}_{\mathrm{B}}=$ Average Reflectance Below Mid-Height

$\mathrm{R}_{\mathrm{A}}=$ Average Reflectance Above Mid-Height

EQUATION 4.16: CALCULATION FOR IRC FACTOR ${ }^{77}$

\begin{tabular}{|c|c|c|c|c|c|c|c|c|c|}
\hline $\begin{array}{c}\text { Angle of External } \\
\text { Obstruction }\end{array}$ & $0^{\circ}$ & $10^{\circ}$ & $20^{\circ}$ & $30^{\circ}$ & $40^{\circ}$ & $50^{\circ}$ & $60^{\circ}$ & $70^{\circ}$ & $80^{\circ}$ \\
\hline C value & 39 & 35 & 31 & 25 & 20 & 14 & 10 & 7 & 5 \\
\hline
\end{tabular}

TABLE 4.3.8: C FACTOR DEPENDENT ON THE ANGLE OF OBSTRUCTION ${ }^{78}$

\begin{tabular}{|c|c|}
\hline IRC Parameters in the Equation 4.16 & $\mathbf{P}_{\mathbf{1}}$ \\
\hline Average Surface Reflectance & 0.1 \\
\hline Average Surface Reflectance Above Surface & 0.1 \\
\hline Average Surface Reflectance Below Surface & 0 \\
\hline C Value based on the Table 4.3.8 at $\mathbf{P}_{\mathbf{1}}$ & 39 \\
\hline
\end{tabular}

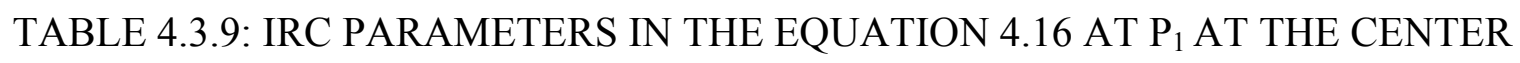
OF THE AIR CAVITY \#2

Based on the information in the tables 4.3.8-9, it is possible to solve for the IRC factor at $\mathrm{P}_{1}$. The IRC factor at $\mathrm{P}_{1}$ is then calculated to be $47.22 \%$. 
Now that we have both SC and IRC factors in the equation 4.14, we are able to solve for the Daylight Factor at $\mathrm{P}_{1}$ at the center of air cavity \#2. The Daylight Factor is $48.26 \%$ at $\mathrm{P}_{1}$. Therefore, based on the equation 4.12 we can solve for the available amount of daylight illumination at $P_{1}$ at the center of the air cavity $\# 2$ when the outdoor daylight illumination passing through the apertures designed on the curved portion of the exterior building skin. Figure 4.3.12 shows the apertures on the curved portion of the exterior surfaces and how the outdoor daylight is passing through them to get to the air cavity surrounded the by the designed windows.

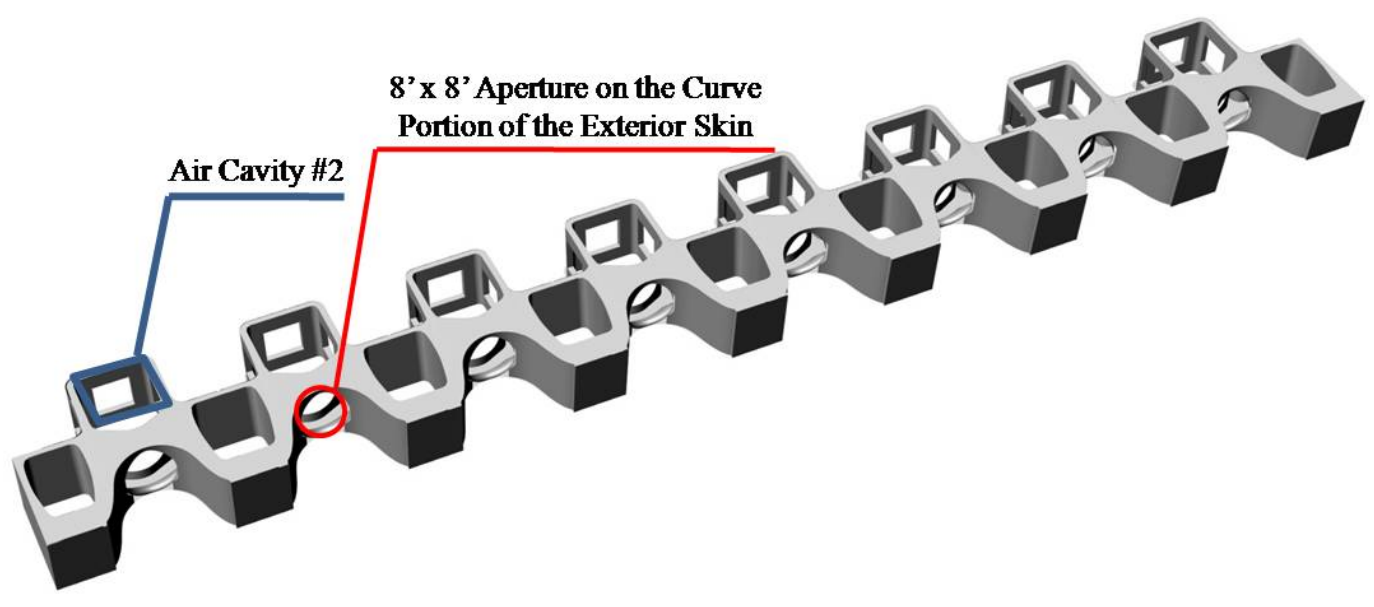

FIGURE 4.3.12: 8'x8' APERTURES ON THE CURVE PORTION OF THE EXTERIOR SKIN

Table 4.3.10 shows the amount of daylight at $\mathrm{P}_{1}$ in air cavity \#2. Based on the results in the tables 4.3.10 and comparing them with the available daylight illumination outdoor (table 4.3.5), the amount of available illumination in air cavity $\# 2$ is on average half of the amount of daylight illumination outside. This proves that design of the double facade system incorporated with the passive design strategies not only increases the ventilation rate inside the building (section 4.3.1), but also may decrease the amount of 
unpleasant daylight to half and so preventing the interior spaces from extra heat gain and glare. This reduction in unpleasant daylight is enhanced further when you consider that the curved and flat ribs of the exterior skin cast shade on to the air cavities thus lowering the amount of unpleasant daylight even more. The shade of the ribs is not figured into the daylight calculations shown below, as it is difficult to accurately model its affect on the daylight calculation methods employed by the author.

\begin{tabular}{|c|c|c|c|c|c|}
\hline \multirow{2}{*}{\begin{tabular}{c|c|c|c|c|}
\hline \multirow{2}{*}{} \\
\cline { 2 - 6 }
\end{tabular}} & Date & March 21 $^{\text {st }}$ & June 21 $^{\text {st }}$ & September 21 $^{\text {st }}$ & December 21 $^{\text {st }}$ \\
\cline { 2 - 6 } & $8: 00$ & 345 & 746 & 457 & 60 \\
\cline { 2 - 6 } & $10: 00$ & 1064 & 1412 & 1157 & 608 \\
\cline { 2 - 6 } & $12: 00$ & 1492 & 1785 & 1537 & 969 \\
\cline { 2 - 6 } & $14: 00$ & 1496 & 1768 & 1488 & 941 \\
\cline { 2 - 6 } & $16: 00$ & 1072 & 1365 & 1023 & 531 \\
\hline
\end{tabular}

\section{TABLE 4.3.10: DAYLIGHT ILLUMINATION AT THE CENTER OF AIR CAVITY \#2 AT $P_{1}$}

As Mentioned before, the results of the table 4.3 .10 are not only the daylight illumination levels for $\mathrm{P}_{1}$, but are also to be considered as the outdoor daylight illumination when using Equation 4.12 to solve for the indoor daylight illumination at positions $\mathrm{P}_{2}$ and $\mathrm{P}_{3}$ as shown in figures 4.3.8-9. Now that we have the outdoor daylight illumination value for positions $\mathrm{P}_{2}$ and $\mathrm{P}_{3}$, we will need calculate the Daylight Factor for locations $\mathrm{P}_{2}$ and $\mathrm{P}_{3}$ to find the final daylight illumination at these interior points. 


\subsubsection{Interior Daylight Illumination based on Illumination in Air Cavity \#2 and the Daylight Factors at $P_{2}$ and $P_{3}$}

Table 4.3.11 shows the calculated SC parameters at $\mathrm{P}_{1}$ and $\mathrm{P}_{2}$ in the figures 4.3.8-

9. Based on the figures $4.3 .8-9, \mathrm{P}_{3}$ is only by the Window $\# 1$, but since there are reflections form the Windows \#2 and \#3 toward $\mathrm{P}_{3}$, it is more accurate to consider the effect of the daylight coming from these windows toward $\mathrm{P}_{3}$ in the calculation as well.

\begin{tabular}{|c|c|c|c|c|c|}
\hline \multirow{2}{*}{$\begin{array}{c}\text { SC Parameters at } \\
P_{2} \text { and } P_{3} \\
\text { (Figures 4.3.8-9) }\end{array}$} & \multicolumn{2}{|c|}{ Position2 } & \multicolumn{3}{|c|}{ Position3 } \\
\hline & $\begin{array}{c}\text { Window } \\
\# 2\end{array}$ & $\begin{array}{c}\text { Window } \\
\# 3\end{array}$ & $\begin{array}{c}\text { Window } \\
\# 1\end{array}$ & $\begin{array}{c}\text { Window } \\
\# 2\end{array}$ & $\begin{array}{c}\text { Window } \\
\# 3\end{array}$ \\
\hline$H_{1} / D$ & 0.889 & 0.889 & 0.7128 & 0.2962 & 0.2962 \\
\hline $\mathrm{H}_{2} / \mathrm{D}$ & 0.889 & 0.889 & 0.7128 & 0.2962 & 0.2962 \\
\hline$W_{1} / D$ & 0.444 & 0.444 & 0.3564 & 0.1481 & 0.1481 \\
\hline $\mathbf{W}_{2} / \mathbf{D}$ & 0.444 & 0.444 & 0.3564 & 0.1481 & 0.1481 \\
\hline
\end{tabular}

TABLE 4.3.11: CALCULATED SC PARAMETERS AT $\mathrm{P}_{2}$ AND $\mathrm{P}_{3}$ IN FIGURES 4.3.8-9

Based on equation 4.15 and information provided in the table 4.3.11 and the BRS table (table 4.3.6), it is possible to solve for the $\mathrm{SC}$ factor at $\mathrm{P}_{2}$ and $\mathrm{P}_{3}$. Table 4.3.12 shows the results for the SC factor at $\mathrm{P}_{2}$ and $\mathrm{P}_{3}$.

\begin{tabular}{|c|c|c|c|c|}
\hline \multirow{2}{*}{$\begin{array}{c}\text { SC (\%) Calculation based on } \\
\text { the Equation 4.15 at } \mathbf{P}_{\mathbf{2}} \text { and } \mathbf{P}_{\mathbf{3}}\end{array}$} & \multirow{2}{*}{$\mathbf{P}_{\mathbf{2}}$} & \multicolumn{3}{|c|}{$\mathbf{P}_{\mathbf{3}}$} \\
\cline { 3 - 5 } & & Window \#1 & Window \#2 & Window \#3 \\
\cline { 2 - 5 } & 5.2 & 3.2 & 0.1 & 0.1 \\
\hline
\end{tabular}

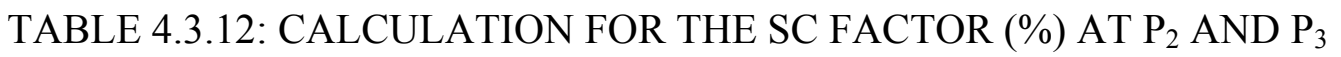


Tables 4.3 .13 and 4.3.14 are the background information necessary to calculate the IRC Factors at $\mathrm{P}_{2}$ and $\mathrm{P}_{3}$ based on the Equation 4.16.

\begin{tabular}{|c|c|c|c|c|}
\hline $\begin{array}{c}\text { IRC Parameters in the } \\
\text { Equation 4.16 for } \mathbf{P}_{\mathbf{2}} \text { and } \mathbf{P}_{\mathbf{3}}\end{array}$ & $\mathbf{P}_{\mathbf{2}}$ & \multicolumn{3}{|c|}{$\mathbf{P}_{\mathbf{3}}$} \\
\cline { 4 - 5 } (Figures 4.3.10-11) & & Window \#1 & Window \#2 & Window \#3 \\
\hline Average Surface Reflectance & 0.4218 & 0.4917 & 0.4609 & 0.4609 \\
\hline $\begin{array}{c}\text { Average Surface Reflectance } \\
\text { Above Surface }\end{array}$ & 0.32258 & 0.3918 & 0.3598 & 0.3598 \\
\hline $\begin{array}{c}\text { Average Surface Reflectance } \\
\text { Below Surface }\end{array}$ & 0.09925 & 0.0997 & 0.1010 & 0.1010 \\
\hline $\begin{array}{c}\text { C Value based on the table 4.3.8 } \\
\text { at } \mathbf{P}_{\mathbf{2}} \text { and } \mathbf{P}_{\mathbf{3}}\end{array}$ & 5 & 39 & 5 & 5 \\
\hline
\end{tabular}

TABLE 4.3.13: IRC PARAMETERS TO SOLVE FOR THE IRC (\%) AT $\mathrm{P}_{2}$ AND $\mathrm{P}_{3}$ IN THE FIGURES 4.3.8-9

\begin{tabular}{|c|c|c|c|c|c|}
\hline \multicolumn{7}{|c|}{ Indoor Material Factors at $\mathbf{P}_{\mathbf{3}}$} \\
\hline & Window $\mathbf{\# 1}$ & \multicolumn{2}{|c|}{ Window $\mathbf{\# 2}$ and \#3 Individually } \\
\hline Material & $\begin{array}{c}\text { Area } \\
\left(\mathbf{S F}^{\mathbf{2}}\right)\end{array}$ & $\begin{array}{c}\text { Reflectance Ratio } \\
\text { by Material }\end{array}$ & Material & $\begin{array}{c}\text { Area } \\
\left.\mathbf{S F}^{\mathbf{2}}\right)\end{array}$ & $\begin{array}{c}\text { Reflectance Ratio } \\
\text { by Material }\end{array}$ \\
\hline Windows & 36 & 0.1 & Windows & 36 & 0.1 \\
\hline Ceilings & 1640.25 & 0.8 & Ceilings & 345 & 0.8 \\
\hline Floors & 1640.25 & 0.2 & Floors & 345 & 0.2 \\
\hline Walls & 144 & 0.4 & Walls & 229.5 & 0.4 \\
\hline Total & 3460.5 & & Total & 955.5 & \\
\hline
\end{tabular}

\begin{tabular}{|c|c|c|}
\hline \multicolumn{3}{|c|}{ Indoor Material Factors at $\mathbf{P}_{\mathbf{2}}$} \\
\hline Material & Area (SF2) & Reflectance Ratio by Material \\
\hline Windows & 72 & 0.1 \\
\hline Ceilings & 135 & 0.8 \\
\hline Floors & 135 & 0.2 \\
\hline Walls & 230 & 0.4 \\
\hline Total & 572 & \\
\hline
\end{tabular}

TABLE 4.3.14: IRC PARAMETERS TO SOLVE FOR THE IRC (\%)AT $\mathrm{P}_{2}$ AND $\mathrm{P}_{3}$ IN THE FIGURES 4.3.8-9 
Based on the information in the tables 4.3.12-14, it is possible to solve for the IRC and Daylight Factor at $\mathrm{P}_{2}$ and $\mathrm{P}_{3}$ in the figures 4.3.8-9 and therefore solve for the indoor daylight illumination based on the equation 4.12. Table 4.3.15 is the calculated IRC (\%) factor at $\mathrm{P}_{2}$ and $\mathrm{P}_{3}$. Table 4.3.16 is the final results for the Daylight factor based on the equation 4.14 at $\mathrm{P}_{2}$ and $\mathrm{P}_{3}$.

\begin{tabular}{|c|c|c|c|c|}
\hline \multirow{2}{*}{ IRC(\%) } & \multirow{2}{*}{ Position } & \multicolumn{3}{|c|}{ Position3 } \\
\cline { 3 - 5 } Calculation based on the & $\mathbf{2}$ & Window \#1 & Window \#2 & Window \#3 \\
\cline { 3 - 5 } Equation 4.16 at $\mathbf{P}_{\mathbf{2}}$ and $\mathbf{P}_{\mathbf{3}}$ & 42.47 & 10.28 & 14.22 & 14.22 \\
\hline
\end{tabular}

TABLE 4.3.15: CALCULATION FOR THE IRC FACTOR (\%) AT $\mathrm{P}_{2} \mathrm{AND}_{3}$

\begin{tabular}{|c|c|c|c|c|}
\hline DF(\%) & Position & \multicolumn{3}{|c|}{ Position3 } \\
\cline { 3 - 5 } Calculation based on the & $\mathbf{2}$ & Window \#1 & Window \#2 & Window \#3 \\
\cline { 3 - 5 } Equation 4.14 at $\mathbf{P}_{\mathbf{2}}$ and $\mathbf{P}_{\mathbf{3}}$ & 47.67 & 13.48 & 14.34 & 14.34 \\
\hline
\end{tabular}

TABLE 4.3.16: CALCULATION FOR THE IRC FACTOR (\%) AT $\mathrm{P}_{2} \mathrm{AND}_{3}$

\begin{tabular}{|c|c|c|c|c|c|}
\hline & Date & March 21 ${ }^{\text {st }}$ & June $21^{\text {st }}$ & September $21^{\text {st }}$ & December $21^{\text {st }}$ \\
\hline \multirow{5}{*}{ 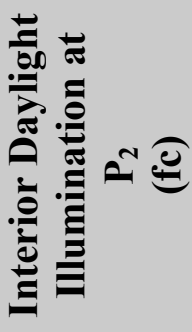 } & $8: 00$ & 74 & 159 & 98 & 13 \\
\hline & 10:00 & 227 & 301 & 247 & 130 \\
\hline & $12: 00$ & 318 & 381 & 228 & 207 \\
\hline & $14: 00$ & 319 & 378 & 318 & 201 \\
\hline & $16: 00$ & 228 & 292 & 282 & 113 \\
\hline \multirow{5}{*}{ 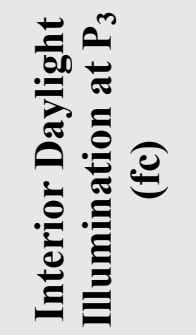 } & $8: 00$ & 62 & 135 & 83 & 11 \\
\hline & $10: 00$ & 192 & 255 & 209 & 110 \\
\hline & $12: 00$ & 270 & 333 & 278 & 175 \\
\hline & $14: 00$ & 270 & 320 & 269 & 170 \\
\hline & $16: 00$ & 193 & 247 & 185 & 96 \\
\hline
\end{tabular}

TABLE 4.3.17: INDOOR DAYLIGHT ILLUMINATION AT $\mathrm{P}_{2} \mathrm{AND}_{3}$ 
Table 4.3.17 is the result of the provided daylight illumination by the designed three windows at two points of $\mathrm{P}_{2}$ and $\mathrm{P}_{3}$. The results in the tables 4.3 .17 compared to the tables 4.3.5 and 4.3.10 shows that the available daylight inside the building by the windows at $\mathrm{P}_{2}$ is averagely $10 \%$ of the outdoor illumination and $20 \%$ of the available illumination in the air cavity \#2. Although the results of table 4.3.17 shows that only a portion of the solar rays from air cavity \#2 actually pass through the designed windows (which are oriented $90^{\circ}$ toward east and west), the available daylight by the windows are still on average 5 times greater than the required daylight for office tasks based on the figure 4.3.7. This amount of daylight should be able to provide enough illumination for the rest of the office areas if we consider the plan as an open office space. This amount of daylight though has potential to create glare and heat gain for the users nearest the windows. Therefore, the author in the next step will propose a solution to reduce the direct sunlight (glare) and so the heat gain. Similar to what was mentioned in the section 4.3.1, the proposed solution is not fully analyzed or included in any calculations in this paper and will only remain as an idea since the purpose of the paper is to show the role of passive design strategies and more specifically biomimicry in architecture. A more formal analysis of this designed solution would be appropriate to consider as a future studies opportunity.

\subsubsection{Proposed Daylight Design Solution to Reduce the Direct Daylight Illumination at $\mathbf{P}_{\mathbf{2}}$ and $\mathbf{P}_{3}$}

The simple solution in order to reduce the amount of daylight is to reduce the sizes of the windows. Designing the windows around air cavity \#2 is a better solution 
when compared to the typical building skin since the windows around the air cavity \#2 are each oriented to different direction and provide daylight for different times of the day and years. However, the size of the windows around air cavity $\# 2$ may be changed to reduce the amount of daylight. The only problem regarding the resizing of the windows may be the glare; reducing the size of the windows does not necessarily reduce the glare. To overcome the glare designer may want to increase the percentage of the diffused daylight vs. direct daylight. Figure 4.3.13, a perspective section through the $10^{\text {th }}$ floor, shows that the outdoor daylight illumination enters air cavity \#2 and the surrounded windows through the 8'x8' opening. The amount of daylight entering through this opening is calculated in section 4.3.2.3. In order to increase the amount of indirect/diffused daylight entering air cavity $\# 2$, while helping to eliminate a percentage of the direct amount of daylight entering the opening, the author proposes to add an element (figure 4.3.14-15) to the 8 'x8' opening. This element will help to block most of the direct solar rays especially in the summertime and increases the reflected and diffused daylight in the wintertime. The designed element not only decreases the total daylight illumination throughout the year, but also the amount of the illumination coming into the air cavity \#2 is more controllable during the summertime when heat gain is so critical. Figures 4.3.1415 show the elevation section of the designed daylight element with the dimensions and how it works in the summer and winter. 


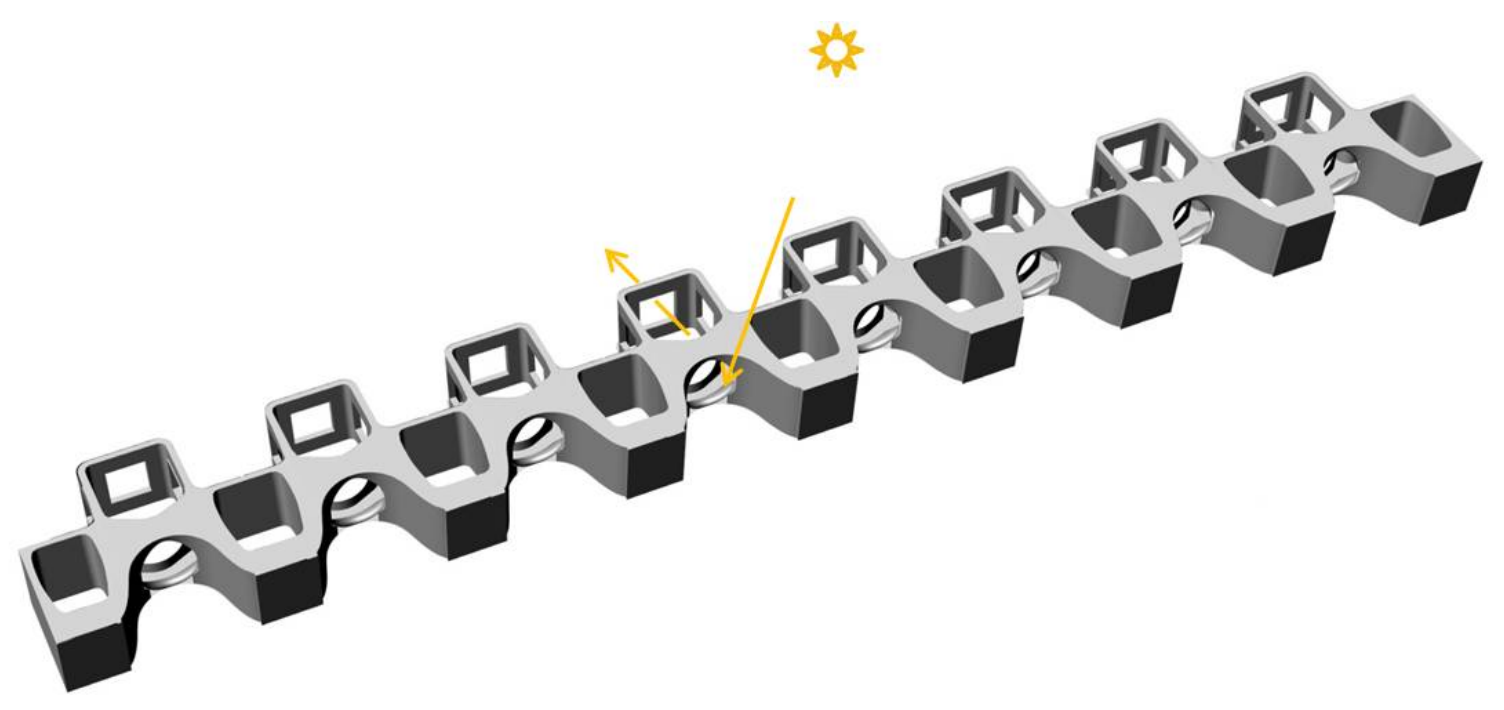

FIFGURE 4.3.13: THE OUTDOOR DAYLIGHT ILLUMINATION ENTERS AIR CAVITY \#2 AND THE SURROUNDED WINDOWS THROUGH THE 8'x8' OPENING

\section{Summer Time}

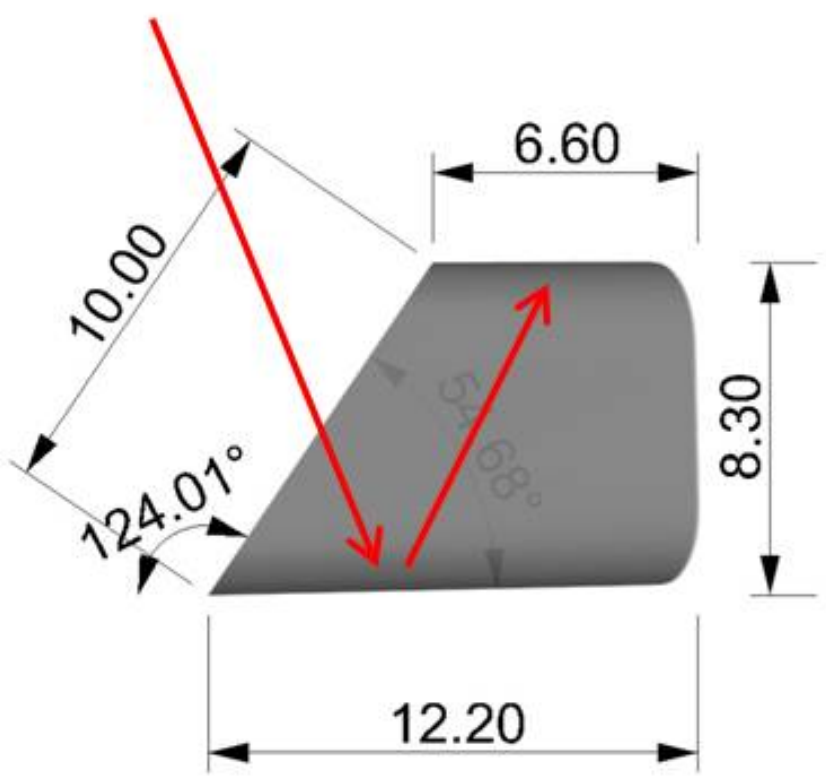

FIGURE 4.3.14: DESIGNED DAYLIGHT ELEMENT BLOCKING THE DAYLIGHT IN THE SUMMERTIME AND PROVIDING MORE DIFFUSED DAYLIGHT FOR THE INTERIOR SPACES 


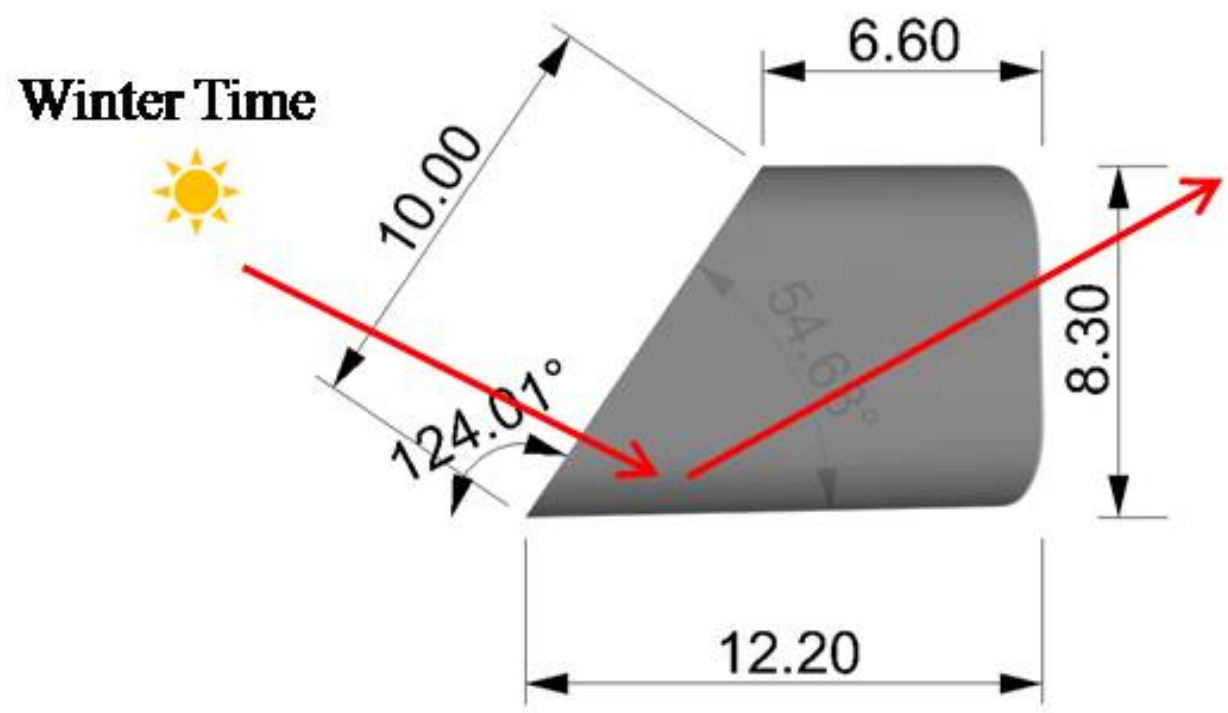

FIGURE 4.3.15: DESIGNED DAYLIGHT ELEMENT REDUCING THE AMOUNT OF DIRECT DAYLIGHT WHILE IT IS STILL REFLECTING CERTAIN AMOUNT OF DIFFUSED DAYLIGHT FOR THE INTERIOR SPACES

In the first section of this chapter we found out that the most critical time in terms of the level of heat gain and surface temperature on June $21^{\text {st }}$ is at noon. Therefore, the author designed the interior corrugated skin to orient two out of the three windows of each bay to face east and west in order to minimize the amount of glazing that was facing directly south (figure 4.3.6). The designed corrugated interior layer of the building skin was able to include $50 \%$ more glazing when compared to the amount of glazing included in the flat typical building skin. While simultaneously, the designed corrugated skin was able to absorb 3,000 BTUs less heat gain into the interior of the building when compared to the amount of heat gain absorbed by the typical building design. These amounts of glazing on the corrugated interior layer on average provide more than 5 times the amount of required daylight illumination for normal office tasks ( $200 \mathrm{fc}$ vs. $40 \mathrm{fc}$ ). Although this 
greater than required amount of daylight will provide enough illumination for a large portion of the open office area, it may bring unwanted heat gain and glare for the users nearest the windows. In order to reduce the amount of daylight for the users next to the windows, a simple solution may be to reduce the size of the windows; this design change might not be as successful in reducing the amount of glare. Reducing the direct daylight by diffusing the daylight at the entrance of air cavity $\# 2$ seems to be a better solution than reducing the size of the windows. Adding daylight elements at the entrance of air cavity $\# 2$ around the $8^{\prime} \times 8^{\prime}$ apertures (figure 4.3.16) helps to control the amount of direct daylight entering the air cavity in the summertime, but instead provides diffused daylight. Figure 4.3.16 shows that how these elements are attached to the $8^{\prime} \times 8^{\prime}$ apertures on the curved portion of the exterior skin. During the winter months, the daylight elements allow the direct daylight to penetrate into the air cavity to help warm the building and provide better natural daylight illumination for the building users (figures 4.3.14-15). Due to the level of complexity, it was not possible to calculate the effect of the designed daylight elements on the provided illumination inside the building at $\mathrm{P}_{2}, \mathrm{P}_{2}$ and $\mathrm{P}_{3}$. 


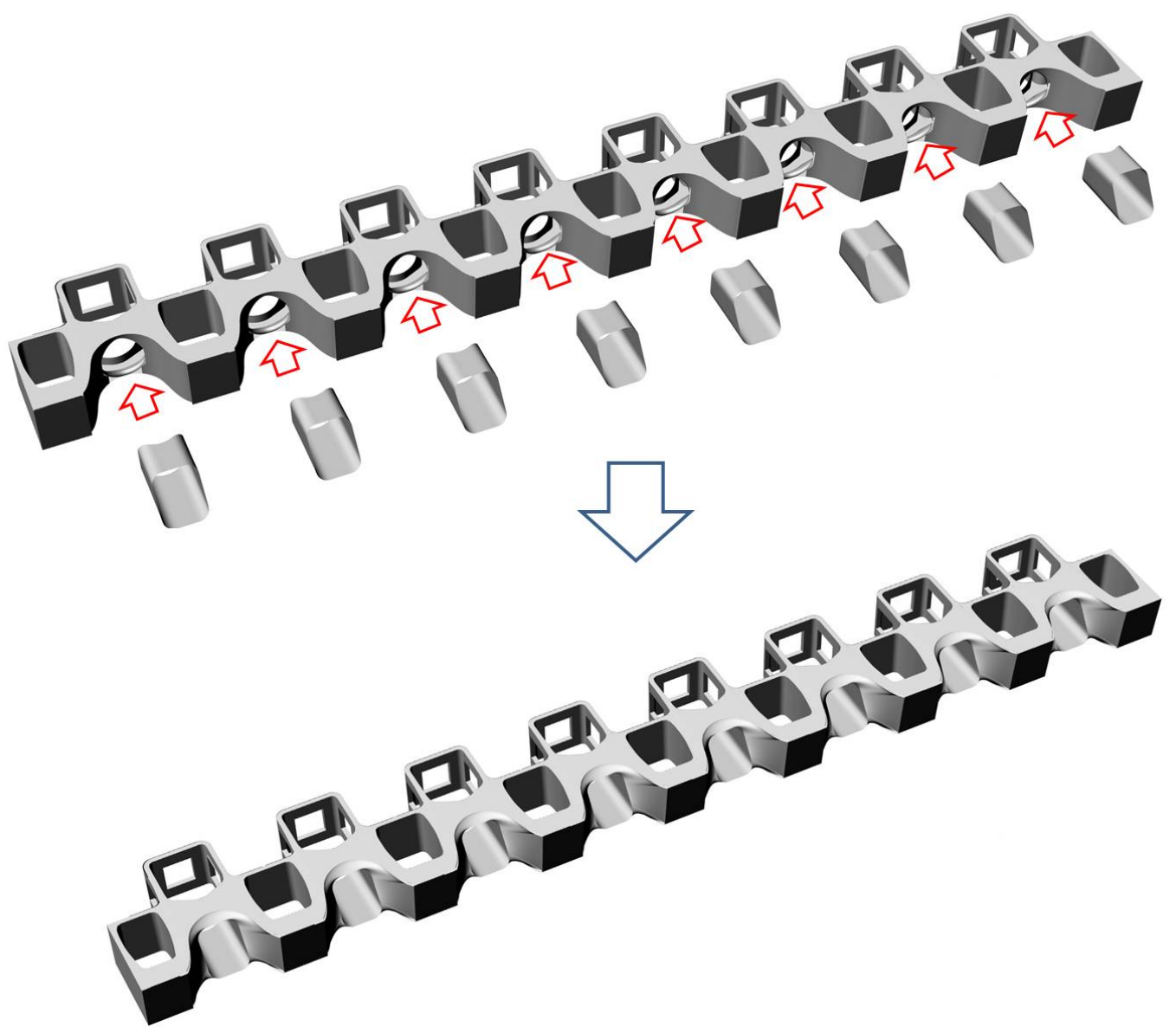

FIGURE 4.3.16: DAYLIGHT ELEMENTS ON THE 8'x8' APERTURES OF THE EXTERIOR SKIN

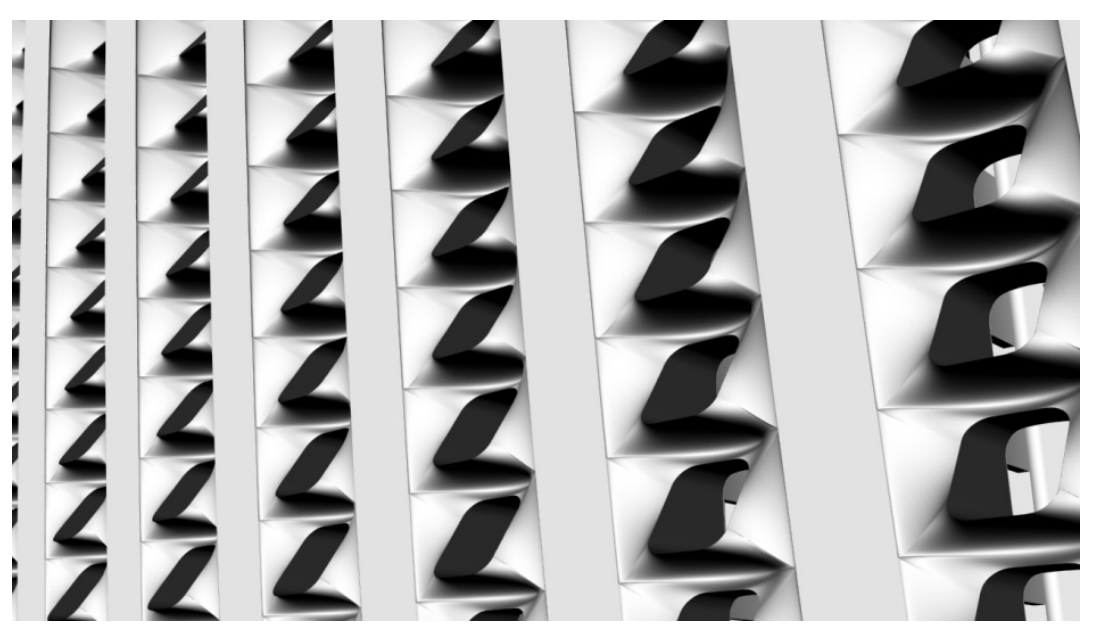

FIGURE 4.3.17: DAYLIGHT ELEMENTS ON THE EXTERIOR SKIN 


\section{CONCLUSION}

All natural species have adaptively evolved over millions of years in order to survive in environmental stresses such as a severe local climate. In a hot dry climate, a major environmental stress is a lack of water i.e. precipitation, as well as intense solar radiation due to extended periods of exposure to direct solar gain. Therefore, the species of hot dry climates have evolved over millions of years to develop adaptable solutions to increase their water storage and protect themselves from direct solar radiation/heat gain. Among all the species of the hot dry climate, the Barrel Cactus' general form and exterior skin has the potential to be studied and learned from by the field of architecture. While the main goal of the Barrel Cactus' evolutionary adaptations is to protect itself from intense desert heat gain and maintain its water storage, the goal of the architectural exterior skin in a hot dry climate is to maintain a user comfort zone by balancing the heat gain and natural daylight. Hence, moderate interior temperature and daylight is something that both types of exterior skin (Barrel Cactus skin or Architectural skin) are seeking to balance in a hot dry climate zone.

Adaptability of the Barrel Cactus skin could be categorized into two major groups: dynamic/instant and evolutionary adaptations. These two distinct types of adaptations are separated by the amount of time that has passed in order for the adaptation to occur. Although the reason for both types of adaptabilities is evolution, the author prefers to call the first adaptation, dynamic adaptation instead of evolutionary adaptation, since dynamic adaptation happens in a shorter amount of time (usually daily or seasonal adaptation) compared to millions of years that evolutionary adaptations such as form, material, structure and growth adaptability happen in. Dynamic adaptability of 
the Barrel Cactus skin such as CAM Metabolism that needs the dynamic mechanism to perform, could be translated into the architectural filed as moveable and dynamic exterior openings, that help balance the air change of the interior spaces. On the other hand, the evolutionary adaptation is capable of being translated as passive design strategies that highlight the role of the design and designer rather than technology. Hence, dynamic/instant adaptability of the Barrel Cactus skin is capable of being translated as active and mechanical design strategies and self-supporting evolutionary adaptation is capable of being translated as passive designs strategies.

Looking at the currently deigned architecture of a hot dry climate, in the case of this paper, Yazd city in Iran shows that local people and regional architects might not have analyzed the local plant life to inform their design decisions but when the author analyzed the passive design strategies used with the traditional buildings of Yazd, some obvious connections between traditional architecture and the local plant life occurred. Most of these strategies are to provide natural ventilation and cooling system without the help of any mechanical solutions. Therefore, the passive design strategies of the traditional buildings in Yazd could be compared with the evolutionary adaptation of the Barrel Cactus as described in Chapter 3. The dynamic and evolutionary solutions of the Barrel Cactus exterior skin discussed in this paper are:

- Photosynthesis functions of the Barrel Cactus skin known as "CAM Metabolism", a dynamic adaptation that could be compared with the nightly natural ventilation occurring in most of the traditional buildings in Yazd.

- The numbers of stomata on the exterior skin of Barrel Cactus could be compared with the numbers of the windows on the exterior skin of the traditional 
buildings in Yazd. Both types of the strategies are showing that the number of the openings on the exterior skin are less than the typical plant skin's or Building skin's of a more moderate climate. This strategy is to help reduce heat gain by controlling the external (hot) to internal (moderate) air changes.

- Global Configuration of the Barrel Cactus form can be compared with the dome-shaped roofs of many traditional buildings in Yazd. Both strategies prove the role of the Globe Configuration in terms of reducing the surface temperature by using the geometry of the dome to minimize the amount of surface area exposed to direct solar radiation.

- The reflective waxy coating of the Barrel Cactus helps to reduce the solar radiation absorption by reflecting the direct sunlight away. This strategy of the Barrel Cactus could be compared with the traditional buildings of Yazd and their light colored clay building materials that help to reflect the direct sunlight away from the building rather than absorbing it.

- $\quad$ The thick exterior skin of the Barrel Cactus could be compared with the high thermal mass of the exterior skin structure of the traditional buildings of Yazd.

While many current responsive solutions of the Barrel Cactus skin are similar to the current and traditional architecture of Yazd, further design studies in this paper show that mimicking further adaptable solutions of the Barrel Cactus Skin such as structural solutions (Cooling Ribs effect in Barrel Cactus) can bring the opportunity to design a tall modern day office building while still maintaining a naturally controlled comfort zone for the users. 
When comparing the current strategies of the traditional architecture of Yazd with the evolutionary adaptation of the Barrel Cactus skin shows that even though the traditional architects didn't study the Barrel Cactus prior to designing the buildings, it is obvious to see that some of the most successful features of one of these occurs in the other. Therefore, it seems it is possible to learn from nature and apply the natural evolutionary adaptable behaviors, of the nature, into architecture. Lessons taken from nature can go beyond the human expectation of what design could be and teach us to overcome the stresses of climatic changes in a more efficient way. Therefore, it is true to say that once we start to design for a specific climate, we should first look at nature, then second look at the current local architecture and then propose a design solution based on designer's interpretation of the findings and their own design style. In the case of this paper, the proposed design solution is a tall office building skin with a double façade system that includes a large air barrier in between the two facades. These individual components of the total façade system are identified as: the exterior skin, skin/air gap and the interior skin. This multi-layered façade system is capable of not only self-shading and self-ventilating the exterior skin but is also able to provide a Self-ventilation system and natural daylight for the building interior.

\section{Exterior Skin Design Process}

The proposed designed exterior skin is mimicking the Barrel Cactus exterior skin since the exterior layer of the building in Yazd is directly dealing with the environmental factors such as diurnal and seasonal changes of this hot dry climate as did the Barrel Cactus. Cooling Ribs effect combined with the Globe Configuration adaptation create the 
self-ventilating and self-shading system on the south facade and roof system to decrease the exterior skin temperature when compared to the flat typical building skin. The final calculation results show that looking at nature in order to design the exterior layer of the double facade system provides us with solutions that reduce the climatic stresses such as surface temperature and heat gain. These solutions are passive design strategies performing without the help of any mechanical system. The results presented based on the proposed design may not be as successful as the author initially envisioned, but the proposed design is more efficient than the typical modern building design it is compared with. If the author had made modifications to the design based on the results of the design analysis, the actual performance of the proposed building could be improved. By completing this project, the author realized the importance of utilizing advanced programs and tools to analyze the design at the early stages of the design process. In order to get a better understanding of how the building might perform in the future prior to determining the final design or locking in a certain design feature or layout.

The final exterior skin design mimicking the Barrel Cactus exterior skin includes two portions: the flat ribs and the curved portion of the skin (figure 4.1.21)

\section{Curved Portion of the Exterior Skin:}

a. Globe Configuration Effect of the Exterior Skin: Changing the flat typical skin to a flat corrugated skin reduces the surface temperature of the Vertical exterior south-facing skin by $12^{\circ} \mathrm{F}$ at noon when compared to the temperature of the flat typical skin in Yazd, Iran. Changing the flat corrugated skin to a curved corrugated skin in order to mimic the Globe Configuration effect reduced the surface temperature of the vertical 
exterior south-facing skin by an additional $14^{\circ} \mathrm{F}$ during the most critical time of the day. This additional temperature reduction means that when compared to the flat typical exterior skin in Yazd, the curved corrugated skin produces a total reduction in temperature by $26^{\circ} \mathrm{F}$. Therefore, the maximum surface area exposed to the solar radiation during the critical time of the day (at noon) is lower on the curved corrugated skin than the flat corrugated skin and the typical flat building skin. Not to mention that even the exposed curved corrugated surfaces exposed to solar radiation are consistently changing due to the Globe effect and therefore, the real surface temperature is even less than what is calculated in the table 4.1.8.

Learning form the Globe Configuration of the Barrel Cactus skin which to some degree has been applied as a passive strategy of the architecture of Yazd proves to us that looking at nature, in this case, Globe Configuration of the Barrel Cactus skin, can bring us efficient solutions to reduce the climatic effects on the building skin such as high surface temperature in summer in a hot dry climate. What the author learned in this section is when we are designing in a hot dry climate we should consider the role of the curved forms in designing any small or large scale buildings; we may prefer curved forms rather than straight and cubical forms when it comes to designing in such a climate. The author learned to design forms which created shadows and hence, the lower surface temperature; forms that are less exposed to the solar radiation or exposed for a shorter amount of time will help to reduce the surface temperature and heat gain of the exposed surfaces. 
b. Cooling Ribs Effect (Self-ventilating system) of the Exterior Skin: Heat loss due to the convection (difference in the temperature of the adjacent surfaces) that occurs on the designed exterior curved corrugated skin is total 58.44 BTU for 5 hours on June $21^{\text {st }}$. The amount of the heat loss is not as much as expected but proves the existence of the Self-ventilation on the exterior skin due to the difference in temperature and air density of the adjacent surfaces which causes air movement. The amount of the ventilation rate on the exterior vertical skin is between adjacent east facing and south facing surfaces (figure 4.1.21) is 0.52 CFM (almost $0.006 \mathrm{MPH}$ ) at noon and between adjacent west facing and south facing surfaces (figure 4.1.21) is $0.46 \mathrm{CFM}$ (almost 0.005 $\mathrm{MPH})$.

The self-ventilating system calculation process (Cooling Ribs effect) of the exterior skin was only analyzed and calculated for the curved portion of the exterior skin and assumed to exist on the flat ribs of the exterior skin as well since there is a difference in surface temperature of the exposed adjacent surfaces of the flat ribs.

What is learnt during this step is that creating forms and structures that are different in orientations, hence creating different lights and shadows like a corrugated structure or a curved form for the facade system creates different exposed surfaces to the solar radiation and therefore different surface temperatures. The differences in surface temperature cause the surfaces to become a self-ventilating system. Therefore, considering the corrugated forms or curved forms instead of the flat forms in such a climate could be an efficient design solution for a facade system. Once again this solution has been learned from nature and could be applied as passive design strategies without the help of any mechanical system. 
However, the author was not able to calculate the reduction in the surface temperature due to the level of complexity associated with calculating the combined effects of the self-ventilation, Globe Configuration and the air movements' impact on the surface temperature. By not including the temperature reduction of these known effects as the author continued the rest of the heat gain calculations, adds a level of conservativeness to the results.

These mimicked passive design solutions, self-ventilation and Globe Configuration effects, could be further studied on the design of the facade system to create more efficient results in design of the building skin. If the designer had access to more advanced programs to analyze these design solutions, the facade system could minimize the effects of climate on the building skin and reduce a considerable amount of energy usage in the building.

\section{Flat Ribs of the Exterior skin:}

Flat Ribs of the exterior skin offer two major passive design strategies inspired by the long-term evolutionary adaptations of the Barrel Cactus. They are self-shading (figure 1.2.4.1) and thermal mass (figure 1.2.2.2).

a. Self-shading Behavior of the Ribs: Mentioned in the first chapter, the Barrel Cactus grows toward the Sun to cast shade on the body of the barrel cactus. That way, there are less exposed surfaces to the solar radiation and therefore, less water evaporation. Angling the south façade at $95^{\circ}$ instead of the typical $90^{\circ}$ (figure 4.1.21) reduces the surface temperature by $20^{\circ} \mathrm{F}$ on the lower levels (table 4.1.12) at noon on 
June $21^{\text {st }}$ as the Sun approaches its highest position. The lower levels of the building skin are absorbing less solar radiation based on the incident solar radiation analysis provided by Ecotect (figures 4.1.22-26). Another benefit of this reduction in temperature is that it supplies the inlet of the air cavity \#1 at the bottom of the air cavity with cooler air (figures 4.1.30 and 4.2.3). This cooler air is a critical component of the natural ventilation strategy employed by the author in the second section of the Chapter 4 .

The author learned similar lessons in this section to those in the previous section. That by creating forms that self-shade the body of the facade system is an efficient passive design solution for a building skin design.

b. Thermal Mass: The self-shading behavior of the flat ribs gives an extra thermal mass as an air gap to the building skin, which may delay the heat transfer to the interior side of the building. The thermal mass strategy has been proved to work in hot dry climate for hundreds of years. Not only is it clearly shown in the current traditional buildings of Yazd, but also different sections of the plant life in this climate show that thermal mass is an efficient passive design strategy for a building skin system to reduce the heat gain during the hottest time of the day and to provide the users with heat when it is needed, like at night. Therefore, the result of the extra air gap as thermal mass for the building skin has not been calculated in this paper and could be an area of further studies.

The final results of the exterior skin design process in the last chapter are calculated for the vertical surfaces (south-facing facade system). Since the calculations show that by changing the flat vertical exterior skin to be a curved corrugated skin can minimize the exterior surface temperature, heat loss and self-ventilating system on the 
exposed surfaces, the same type of design has been assumed to be successful for the roof system. Therefore, the roof of the designed tall building skin is a curved corrugated skin which creates different exposed surfaces, different surface temperatures and hence, a selfventilating system on the roof as well.

\section{Skin Gap Design Process}

The air gap layer of the proposed building skin is mimicking the passive architectural solutions that have been successfully applied in the design of the traditional buildings in Yazd. The air gap layer for the most part decreases the heat gain of the exterior thermal mass by natural ventilation through the air cavities and the material thickness.

The air gap of the included in the designed building skin in this paper has two air cavities. Air cavity \#1, capable of being compared with Windcatchers in traditional architecture of Yazd, is applying Stack Effect with the help of the Summer Wind effect and Venturi effect to create natural ventilation through the air cavity. Since the inlet/outlet area ratio of the air cavity \#1 is 1 to 4 (figure 4.2.2), based on the Venturi Effect the ventilation rate should increase by roughly $37 \%$ compared to if the inlet and out let are equal (figure 4.2.3). There is a $1.10 \mathrm{MPH}$ (or 7,154.36 CFM) ventilation rate in air cavity \#1 due to the difference in temperature of each floor from bottom to top of the air cavity \#1 (Stack Effect and Venturi Effect). Total heat dissipated due to the Stack Effect and Venturi Effect is 4,306 BTUs during the noon hour on June $21^{\text {st }}$ per flat rib or per air cavity \#1, therefore, the Stack Ventilation combined with the Venturi Effect are capable of removing a portion (5\%) of the total heat gain per air cavity (table 4.2.7). 
The results mentioned previously are not as successful as hoped to be but proves that applying passive design strategies incorporated with the design of the air gap of the double facade system, is reducing the portion of the heat gain of the exposed exterior skin.

Summer Wind on the month of June in Yazd is coming from the north and east directions which also creates negative air pressure areas around the south side of the building. These pockets of negative air pressure increase the efficiency of natural ventilation mentioned previously (1.10 MPH) for air cavity \#1. The calculated ventilation rate due to the Summer Wind Effect is 2.20 MPH (table 4.2.8) which is twice as effective when compared to the Stack Effect alone.

The amount of heat dissipated due to the combination of the Stack Ventilation, Summer Wind Effect and the Venturi Effect is a reduction in heat gain of $11 \%$ of the total heat gain of the south facade at noon on June $21^{\text {st }}$ (table 4.2.10). The calculation process shows the possibility of dissipating heat absorbed by the exterior building skin due to the natural ventilation occurring in the air gap designed between the interior and exterior skin.

The thickness of the concrete walls on each side of the air cavity \#1 also reduces the heat gain and therefore makes a difference in the temperature at the center of air cavity\#1. This reduction in temperature in the air cavity translates to a reduction in temperature for the interior of the building.

These results in this section tells us that once the heat passes the exterior skin, there is a chance to reduce the heat going through the interior skin by ventilating the air gap between the two skins. Different ventilation methods such as Venturi Effect, affected 
by design of the inlet/outlet ratio, can affect the natural ventilation of the air gap. Another lesson taken from this step is to look at the traditional architecture of the climate we are to design architecture in and really into understand the passive design strategies the local people have been applying to ease the climatic stresses. Yazd is very successful is this case; natural ventilation strategies are the first passive design strategies taken to consideration in the design of their buildings (section 2.3).

\section{Interior Skin Design Process}

While the exterior layer and the interstitial layer of the proposed building skin mimic the Barrel Cactus Skin (first chapter) and Passive architectural solutions in Yazd (second chapter), the interior proposed layer follows the comfort factors for office users. Interior temperature and daylight are the main concern in this section of the chapter.

Air Cavity \#2 included as part of the air gap is also part of the design of the interior skin since it is providing the natural ventilation and daylight for the interior spaces.

1. Natural Ventilation within the Air Cavity \#2: The required Ventilation rate for the designed open office area is 1,469.55 CFM or 1.4 MPH through the window vents from the interior of the building into the air cavity $\# 2$ in order to maintain an indoor temperature of $75^{\circ} \mathrm{F}$ during the warmest time of the year. The following are the proposed solutions the author included in the design to ensure a comfortable environment exists for the user: 
a. Solar Chimney on Top of the Air Cavity \#2: The main surface of the designed Solar Chimney on top of the air cavity \#2 is facing south and therefore receives a large amount of direct solar radiation (heat gain). The Solar Chimney becomes extremely hot and then creates a pressure differences between the air in the air cavity and the air inside the building (figure 4.3.2). The pressure differences then create an airflow in the air cavity which ventilates the air inside the building through the air cavity and out through the top of the Solar Chimney. This strategy helps to create the conditions necessary in order to achieve the desired $1.4 \mathrm{MPH}$ ventilation rate.

b. Evaporation System: On the north side of the building envelope, there are Evaporation Systems (could be small water storages) to help to create a greater pressure differences between the air in the air cavity and the air inside the building to achieve the required 1.4MPH ventilation rate. Creating a series of evaporation ponds (evaporation system) on the north side of the building, which is a cooler shaded part of the building, brings the local wind coming from the north and the west inside the building, passes it over the evaporation ponds and drops the temperature of the airflow closer to the comfort temperature. The cooler airflow then gets warm by the users and the facilities inside the building and so rises up and pulled out through the Solar Chimney on top of the air cavity \#2 (figure 4.3.5).

During the design processes of the "Exterior Skin" and "Skin Gap", the author learned that it is possible to mimic the traditional architecture of Yazd and bring the traditional passive design strategies into the modern architecture to reduce the climatic impacts on the interior spaces. The Solar Chimney and the Evaporation System designed in this section are examples of the traditional passive design strategies of the architecture 
of Yazd; the combination of the Solar Chimney (or Windcatcher) and Qanat system were fully explained in the second chapter on how they can create a cooling system for the interior spaces of the Yazd buildings. This type of cooling/ventilation system (combination of the Solar Chimney/Windcatcher and evaporation system) accelerates the imbalance of the air pressure between the air inside the building and the air inside air cavity \#2. When combined, they help to create the required ventilation rate of $1.4 \mathrm{MPH}$.

2. Natural Daylight within the Air Cavity \#2: The interior layer of the building skin is a flat corrugated skin having a total of 50\% more glazing when compared to the typical building skin. The extra glazing brings more daylight for the entire open office floor plan while reducing the total heat gain of each floor by 3,000 BTUs per hour.

Although the percentage of the glazing of the designed corrugated skin is more compared to the typical building skin, the designed windows surrounded the air cavity \#2 are oriented toward three directions of south, east and west, therefore, they bring less direct solar rays in during the critical time of the day. The glazing on the typical building skin is only south facing. Therefore, more heat gain and glare are able to enter the interior of the building.

In Yazd, the available outdoor daylight illumination is on average 54 times greater than the required daylight illumination for office tasks; which is roughly $40 \mathrm{fc}$. Designing the air cavity (air cavity \#2) as an air gap between the interior skin and exterior skin reduces the outdoor daylight illumination on average by half if you measure the amount of light present in the center of air cavity \#2 (table 4.3.10). The final available daylight illumination for the interior locations next to the three designed windows are on 
average as 5 times greater than the required daylight illumination for office tasks.

Although the amount of available daylight is still greater than the required daylight, this amount of daylight provides natural light for the entire open office areas despite the fact that it creates heat gain and glare for the users next to the windows. What is important is in order to reduce the glare and heat gain for the users next to the windows is to reduce the amount of direct daylight. Reducing the size of the glazing may help to reduce the amount of daylight but it does not necessarily reduce the glare. Glare could be reduced by adding daylight elements (figures 4.3.14-15) at the entrance of the air cavity \#2 (figure 4.3.16). These designed daylight elements block the daylight coming inside air cavity \#2 in the summertime and brings the diffused daylight in during the wintertime when it is needed. The daylight analysis and calculation proved to the author that designing a curved-corrugated self-shading double facade system does not necessarily block the daylight. However, with an efficient design we can still bring a considerable amount of daylight into the interior spaces to provide enough daylight for the large open office areas.

After all of the analysis and calculation results in this paper, it has been learned that the major goal in designing a building skin in a hot dry climate is to reduce the heat gain of the building skin. In order to achieve this goal, there are many passive design solutions taken either from the Barrel Cactus skin or traditional architecture of Yazd.

In order to reduce the heat gain of the exterior layer of the building skin, using curved corrugated forms that create less surface temperature and Self-ventilating system on the exterior skin help to get closer to that goal. Also self-shading the body of the 
exterior skin is a solution to reduce the heat gain of the skin. All of these strategies learnt from nature demonstrate the role of biomimicry in architecture.

The second step regarding the reduction of the heat gain of the building skin is to ventilate the trapped heat of the air gap between the interior and exterior skin. Traditional architecture of Yazd has great examples to teach us different methods of creating natural ventilation within the building skin.

The third step in designing a building skin in a hot dry climate is to take the heat that passes through the building skin out by the solutions learned in steps 1 and 2. For example, folding the interior layer of the building and designing it as a corrugated skin causes not only the reduction in the interior surface temperature but also the glazing of the interior skin will be facing different directions and hence, less heat gain for the interior spaces. This strategy, corrugated skin, is a lesson taken from the first step, "Cooling Ribs Effect". Also cooling the interior spaces by the combination of natural ventilation and evaporation system is the passive design strategies learned from the traditional architecture of Yazd. Figure 5.1 shows the perspective section of the entire designed building skin with all the design strategies explained in this chapter.

Therefore, these results helped the author to understand that once we start to design in a specific climate, it is possible to learn from nature and the current traditional architecture of the climate we are designing in at the early stage of the design. Not only can we learn from nature and the traditional architecture of the climate, but we can also quantify our design solutions to see what the effects of our decisions are during the design process. The calculation and analysis of the form, material and structure of the final layered building skin helped to teach the author that it is possible to quantify our 
design decision and have a better understanding how our passive design strategies have an effect on the building's energy consumption.

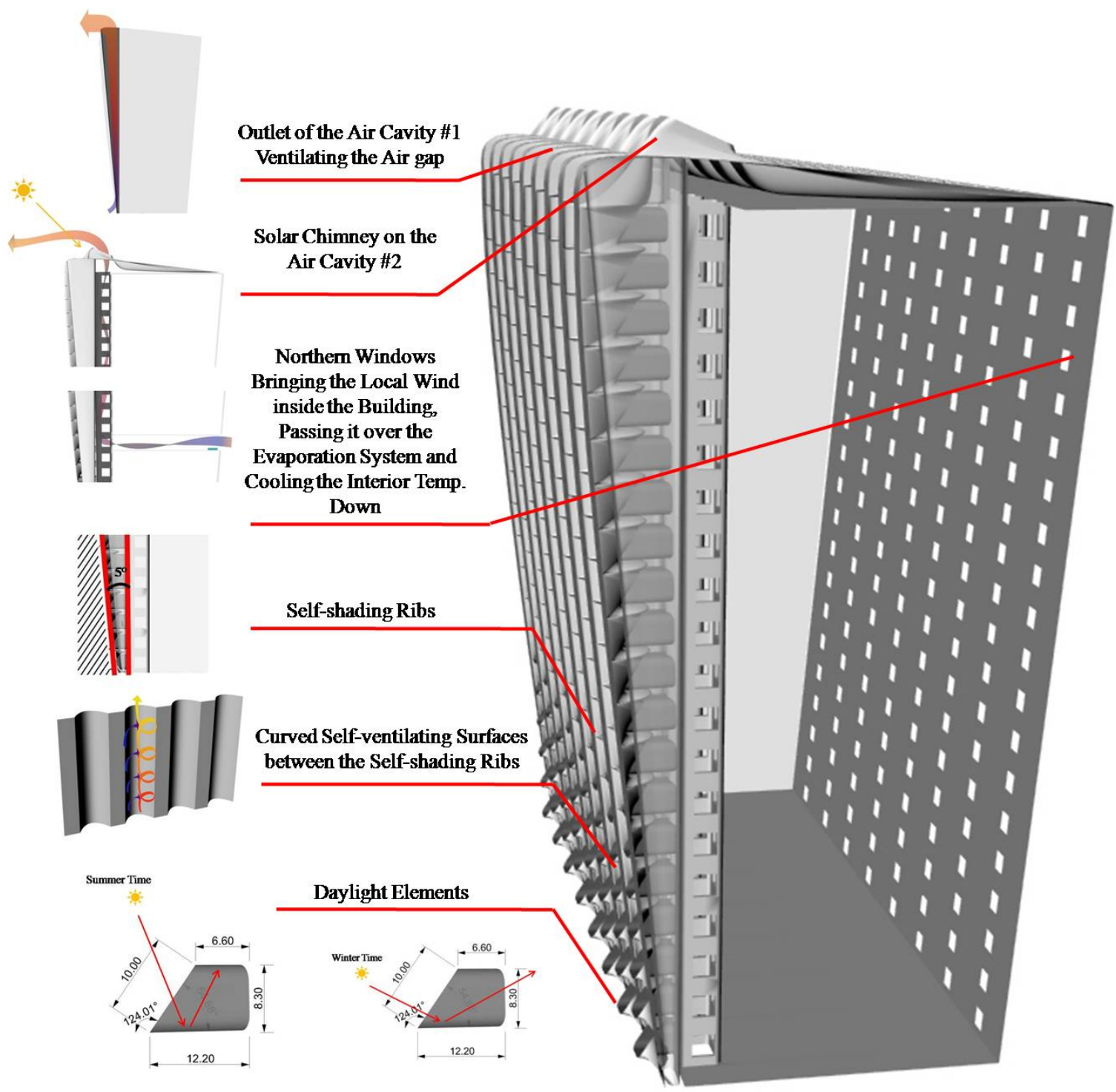

FIGURE 5.1: PERSPECTIVE SECTION OF THE BUILDING SKIN SHOWING ALL THE DESIGN STRATEGIES 


\section{FURTHER STUDIES}

The author would suggest that further studies of the following topics addressed in this paper would be beneficial.

1. Further refinement and optimization of the passive design strategies based on the results of the current design process. The author would suggest that areas of the design that could be developed further should be: reducing the surface temperature of the exterior skin, the interior natural ventilation system and increasing the efficiency of the natural daylight design.

2. Further research into biomimicy to understand what aspects of other native species could be applied to the design of the building envelope.

In regards to topic one mentioned above, the author suggests exploring the following details:

\section{a. Reducing the Surface Temperature of the Building Skin:}

- $\quad$ Creating the Self-shading design solution for the entire building skin instead of partially Self-shading the exterior skin.

- $\quad$ Optimizing the Globe Configuration of the exterior building skin and increasing the portion of the curved skin for the entire building skin. In this section, the flat self-shaded ribs could be optimized as curved self-shaded ribs and the results could be analyzed and compared. 


\section{b. Optimizing the Natural Ventilation and Cooling System of the Building}

Skin:

- $\quad$ Optimizing the design of Cooling Ribs in order to create further surface temperature differences to create better Self-ventilating system on the skin.

- $\quad$ Optimizing the Venturi effect by increasing the inlet/outlet ratio of the air cavities within the skin gap to increase the natural ventilation occurring in the air cavities.

- Increasing the thermal mass to reduce the heat gain and therefore to increase the difference in temperature of the inside and outside of the air gap in order to increase the Stack Effect and natural ventilation occurring in the air cavities.

- $\quad$ Optimizing the natural ventilation inside the building; calculating the effect of the evaporation system on the natural ventilation inside the building and trying to increase the efficiency of that by using the local wind.

\section{c. Increasing the Efficiency of the Daylight Design:}

- Calculating the effect of the daylight elements on the exterior skin in terms of reducing the glare and increasing the diffused daylight illumination.

- Changing the sizes of the windows to see the effect of that on the interior daylight illumination as well as its impact on the thermal gain.

In regards to the further design studies in developing the ideas of biomimicry, the topic two, the author suggests exploring the following details:

The design process analysis could be performed and calculated not only for the roof skin to see the effect of biomimicry and passive design strategies on the design of 
the roof system, but also to see these effects on the whole building envelope. For example, the other aspects of the evolutionary adaptation of the Barrel Cactus such as the ventilation system at the center of the Barrel Cactus which cools down the interior layers of the Cactus could be brought into the architecture. In this case, the entire building envelope could be designed with ventilating branches at the middle of the interior spaces to ventilate the heat gain inside the building. Other species in hot dry climate such as camels and snails could be also studies on to design tall buildings with the required comfort zones for the users. Biomimicry in architecture could be further studied to learn from other natural species in other climates that have considerable climatic changes which make the design of the buildings more difficult for the architect. The lessons from nature and local architecture could be translated into modern architecture to design more efficient buildings for the users. In addition, there are many traditional passive design strategies utilized throughout traditional cities such as Yazd that were not discussed in this paper. These additional strategies could also be explored and evaluated to see what effects they might have on user comfort and energy consumption when integrated into modern building design. 


\section{ENDNOTES}

1. The Pennsylvania State University, What Kinds Of Leaves Do We See On The Trees Found On The Nature Trail?, Penn State New Kensington Web", last Updated On July $12^{\text {th }}, 2009$, http://www.psu.edu/dept/nkbiology/naturetrail/leaves.htm

2. Kerstin Koch, Bharat Bhushan and Wilhelm Barthlott, Multifunctional Surface Structures Of Plants: An Inspiration For Biomimetics,(Progress in Materials Science 54, 137-178, 2009), 139.

3. "Stoma", Wikipedia Web, Last Accessed October $19^{\text {th }}, 2012$, http://en.wikipedia.org/wiki/Stoma

4. William C. Dickison, Integrative Plant Anatomy; Academic Press, (San Diego: Harcourt Science And Technology Company, 2000), 304.

5. Kristi Waterworth, "Adaptations for Barrel Cactus; Crassulacean Acid Metabolism", eHow Web, Last Visited May 2013,eHow.com http://www.ehow.com/info_ 11384273_adaptations-barrel-cactus.html\#ixzz2QEp9qoIx

6. Matt, "Life of a Cactus Part 5: CAM Photosynthesis", Practical biology Blog, Last Modified May $21^{\text {st }}$ 2012,http://practicalbio.blogspot.com/2012_05_01_archive.html

7. Ibid.

8. Ibid.

9. Ibid.

10. Ibid.

11. Cathryn Chaney, "Types of Globose Cacti", eHow Web, Last Accessed May $22^{\text {nd }}, 2013$, http://www.ehow.com/info_8506063_types-globose-cacti.html

12. Image by Anna Faherty, "How to spot low altitude cacti", Kew Royal Botanical Gardens Web, Last Accessed May 22 ${ }^{\text {nd }}, 2013$, http://www.kew.org/webimage/low-altitude-cacti.htm?gallery=KPPCONT_039312

13. Last Accessed May 22 $2^{\text {nd }}, 2013$, http://www.cactus art.biz/notebook/Dictionary/Dictionary_V/dictionary_vascular_bundle.htm

14. Emily Harrington, "Shape Shades and Enhances Heat Radiation: Cactus", Ask Nature andBiomimicry $3.8 \mathrm{Web}$, Last Updated Jan $19^{\text {th }}$, 2013,http://www.asknature.org/strategy/0aaa42953466bee0b1f530ac73a28312 
15. Jens Pohl, Building Science: Concepts and Application, (Chichester, Wiely-Blackwell 2011), 52.

16. Author/Photographer/Artist: Emily Harrington, "Shape Shades and Enhances Heat Radiation: Cactus" Ask Nature and Biomimicry 3.8 Web, Last Updated January $19^{\text {th }}$

2013,http://www.asknature.org/strategy/0aaa42953466bee0b1f530ac73a28312

17. "Barrel Cactus", Wikipedia Web, Last Accessed June $4^{\text {th }}, 2013$, http://en.wikipedia.org/wiki/Barrel_cactus

18. Ibid.

19.Image by Rui Felix, Author: Carl Hastrich,"Learning from a Barrel Cactus", Bouncing Idea blog, Last Updated Dec 14, 2011, http://bouncingideas.wordpress.com/2011/12/14/learning-from-a-barrel-cactus/

20. "Qanat", Wikipedia Web, Last Accessed June $4^{\text {th }}, 2013$, https://en.wikipedia.org/wiki/Qanat

21. "Yazd", Wikipedia Web, Last Accessed June $4^{\text {th }}, 2013$, http://en.wikipedia.org/wiki/Yazd

22."Qanat", Wikipedia Web, Last Accessed June 4 ${ }^{\text {th }}, 2013$, https://en.wikipedia.org/wiki/Qanat

23. Adriana de Aguinaga, "The Qanats and Water Reservoirs in Iran: Tradiational Water Supply and Storage Systems in Desert", PPIAF Web, Posted September 2011, http://www.ppiaf.org/feature-story/qanats-and-water-reservoirs-iran-traditionalwater-supply-and-storage-systems-desert

24. "Yazd", Wikipedia Web, Last Accessed June $4^{\text {th }}, 2013$, http://en.wikipedia.org/wiki/Yazd

25. "Yakhchal", Wikipedia Web, Last Accessed June $4^{\text {th }}, 2013$, http://en.wikipedia.org/wiki/Yakhchal

26. Ibid.

27. "Yazd, Remarkable "the Pearl of Desert", World Travel News Web, Posted October 24, 2011, http://news.cheapflighthouse.co.uk/2011/10/24/yazd-remarkable-thepearl-of-desert/

28. Pastaiteken, "Yakhchal of Yazd province", Wikipedia Web, Last Modified September $25^{\text {th }}, 2008$, http://en.wikipedia.org/wiki/File:Yakhchal_of_Yazd_province.jpg 
29. "Yazd, Climate", Wikipedia Web, Last Accessed June $4^{\text {th }}, 2013$, http://en.wikipedia.org/wiki/Yazd

30. "Yazd", Wikipedia Web, Last Accessed June $4^{\text {th }}, 2013$, http://en.wikipedia.org/wiki/Yazd

31. Richard Slater, "Rooftops- Yazd", Royal Geographical Society Enterprise Web, Last Accessed November $15^{\text {th }}, 2012$, http://images.rgs.org/webimages/0/0/20000/4000/100/S0024116.jpg

32. "Yazd, Amir Chakmak", Wikipedia Web, Last Accessed June $4^{\text {th }}, 2013$, http://en.wikipedia.org/wiki/Yazd

33. Travel Web, Last Accessed May $19^{\text {th }}, 2013$, http://www.cyrustravel.com/uploadedfiles/yazd1.jpg

34. Edna Shaviv, Issac G. Capeulto and Abraham Yezioro, A simple Design Tool for Determining the Effectiveness of Thermal Mass and Night Ventilation as Passive Cooling Design Strategy, Faculty of Architecture and Town Planning Technion Israel Institute of Technology, Haifa 21000, Israel. (Elsevier Science Ltd., 2000), 881-882.

35. Last Accessed November $15^{\text {th }}, 2012$, http://www.pic2fly.com

36. "Windcatcher", Wikipedia Web, Last Accessed June $4^{\text {th }}, 2013$, http://en.wikipedia.org/wiki/Windcatcher

37. "Yazd Travel Guide", Travel Web, Last Accessed May 25 ${ }^{\text {th }}, 2013$, http://www.virtualtourist.com/travel/Middle_East/Iran/Ostan_e_Yazd/Yazd1757723/TravelGuide-Yazd.html

38. "Windcatcher", Wikipedia Web.

39. Fereshteh Tavakolinia, WIND-CHIMNEY: Integrating the Principles of a WindCatcher and a Solar-Chimney to Provide Natural Ventilation, (California Polytechnic State University, 2011), 3.

40. Ibid.

41. Ibid, 5 .

42. " Bernoulli's Principle", Wikipedia Web, Last Accessed November $24^{\text {th }}, 2013$, http://en.wikipedia.org/wiki/Bernoulli's_principle

43. Hugh D. Young and Roger A. Freedman, Sear and Zemansky's University Physics, $12^{\text {th }}$ ed., (Pearson Addison/Wesley, 2008), 466. 
44. Ibid, 468.

45. Ibid, 471.

46. "Stack Effect", Wikipedia Web, Last Accessed November $24^{\text {th }}, 2013$, http://en.wikipedia.org/wiki/Stack_effect

47. Fereshteh Tavakolinia, WIND-CHIMNEY: Integrating the Principles of a WindCatcher and a Solar-Chimney to Provide Natural Ventilation, 2.

48. "Al Hamra Tower", Wikipedia Web, Last Accessed June $7^{\text {th }}, 2013$, https://en.wikipedia.org/wiki/Al_Hamra_Tower

49. "Al Hamra Tower", 2:48 Web, Last Updated March 28, 2011, http://248am.com/mark/interesting/sneak-peek-al-hamra-tower-tour/

50. Stephanie Vierra, "Biomimicry: Designing to Model Nature", WBDG Web, Last Updated August $9^{\text {th }}$, 2011, http://www.wbdg.org/resources/biomimicry.php

51. Michael Pearce, "Termite-Inspired Air Conditioning", Biomimicry Institute Web, Last Accessed May 15 2013, http://biomimicryinstitute.org/case-studies/casestudies/termite-inspired-air-conditioning.html

52. BioArch Group, "Life in Desert, Biomimicry Design Challenge 2011", Autodesk Web, Last Accessed November 15 2013, http://sustainabilityworkshop.autodesk.com/project-gallery/bio-arch-desertarchitecture-inspired-desert-snail

53. Ibid.

54. Ibid.

55. "Absorbed Solar Radiation by Material", The Engineering Toolbox Web. Last Accessed November $24^{\text {th }}, 2013$, http://www.engineeringtoolbox.com/solarradiation-absorbed-materials-d_1568.html\#.UpMSesRJOxd

56. Hugh D. Young and Roger A. Freedman, Sear and Zemansky's University Physics, $12^{\text {th }}$ ed., 597.

57. "Density of Air", Wikipedia Web, Last Accessed November $24^{\text {th }}, 2013$, http://en.wikipedia.org/wiki/Density_of_air

58. Jens Pohl, Building Science: Concepts and Application, 53.

59. Ibid, 48. 
60. Ibid, 67.

61. "Flow Due to Thermal Forces (Stack Effect)", Natural Ventilation ppt., eng Web, Last Accessed December $12^{\text {th }}, 2012$, www.eng.utoledo.edu/ akumar/IV/PowerPoint/IV3.ppt, 3.

62. G. Z. Brown and Mark Dekay, Sun, Wind and Light: Architectural Design Strategies, $2^{\text {nd }}$ ed., (John Wiley \&Sons, Inc., 2001), 187.

63. "Calculation of Air Flow(due to Wind)", Natural Ventilation ppt., eng Web, 5.

64. Ibid, 6.

65. Jens Pohl, Building Science: Concepts and Application, 55-57.

66. Ibid, 114.

67. Ibid, 115.

68. Ibid.

69. Ibid.

70. Ibid, 110 .

71. Ibid.

72. Ibid, 114.

73. Ibid, 115.

74. Ibid.

75. Ibid, 116.

76. Ibid, 117.

77. Ibid, 121.

78. Ibid. 


\section{BIBLIOGRAPHY}

"Absorbed Solar Radiation by Material", The Engineering Toolbox Web. Last Accessed November $24^{\text {th }}, 2013$. http://www.engineeringtoolbox.com/solar-radiationabsorbed-materials-d_1568.html\#.UpMSesRJOxd.

Allen, Robert. Bulletproof Feathers: How Science Uses Nature's Secrets to Design Cutting-Edge Technology, The University of Chicago Press, 2010.

Ball, Philip. Nature's patterns: a tapestry in three parts, Oxford University Press, 2009.

Bar-Cohen, Yoseph. Biomimetics; Biologically Inspired technologies. Jet Propulsion laboratory (JPL), California Institute of Technology Pasadena, California, USA., 2006.

Bergman, David. Sustainable Design A Critical Guide, Architecture briefs, Princeton Architectural Press, New York, 2012.

BioArch Group. Life in Desert, Biomimicry. Design Challenge 2011. Autodesk Web, 2013. http://sustainabilityworkshop.autodesk.com/project-gallery/bio-arch-desertarchitecture-inspired-desert-snail.

Brown, G.Z. and Mark Dekay. Sun, Wind and Light, Architectural Design Strategies. $2^{\text {nd }}$ ed. John Wiley and Sons, Inc. 2001.

DeYoung, Donald and Derrik Hobbs. Discovery of Design: Searching Out the Creator's Secrets, Master Books, 2009.

Dickison, William C. Integrative Plant Anatomy; Academic Press. San Diego: Harcourt Science And Technology Company, 2000.

Godfaurd, John, Derek Clements-Croome and George Jeronimidis. "Sustainable building solutions: a review of lessons from the natural world", School of Construction Management and Engineering, The University of Reading, Whiteknights Sciense Direct, Building and Environment Journal, Accepted 27 May 2004.

http://www.researchgate.net/publication/223393834_Sustainable_building_solutio ns_a_review_of_lessons_from_the_natural_world.

Grondzik, Walter T., Alison G. Kwok, Benjamin Stein and John S. Reynolds. Mechanical and Electrical Equipment For Buildings, John Wiely and Sons, New Jersey, 2010.

Gruber, Petra. Biomimetics in Architecture; Architecture of Life and Buildings. New York, Springer Wien, 2011.

Harrington, Emily. "Shape Shades and Enhances Heat Radiation: Cactus." Ask Nature 
and Biomimicry 3.8 Web. 2013. http://www.asknature.org/strategy/0aaa 42953466bee0b1f530ac73a28312.

Hastrich, Carl. "Learning from a Barrel cactus", Bouncing Ideas, emerging design ideas of biomimicry, critical creativity, sustainability and strategic thinking Blog, December 2011. http://bouncingideas.wordpress.com/tag/biomimicry-inspiredby-the-barrel-cactus.

Hauer, Erwin. Erwin Hauer Continua, Architectural Screens and walls, Princeton Architectural Press, New York, 2004.

Hausladen, Gerhard, Michael de Saldanha, Petra Liedl and Christina Sager. ClimateDesign, Birkhauser, 2005.

Hensel, Michael and Achim Menges. Versatility and Vicissitude; Performance in Morpho-Ecological Design, Architectural Design, Wiley-Academy, 2006.

Hensel, Michael, Achim Menges and Michael Weinstock. Techniques and Technologies in Morphogenetic Design, Architectural Design, Wiley-Academy , 2006.

Hensel, Michael, Achim Menges and Michael. Emergence: Morphogenetic Design Strategies, Architectural Design, Wiley-Academy, 2004.

Koch, Kerstin, Bharat Bhushan and Wilhelm Barthlott. "Multifunctional Surface Structures Of Plants: An Inspiration For Biomimetics". Progress in Materials Science 54, (2009): 137-178. http://www.sciencedirect.com/science/ journal/00796425/54/2.

Lovell, Jenny. Building Envelopes An Integrated Approach, Architecture briefs, Princeton Architectural Press, New York, 2010.

Matt. "Life of a Cactus Part 5: CAM Photosynthesis." Practicalbio Blog. 2012. http://practicalbio.blogspot.com/2012_05_01_archive.html.

Natural Ventilation ppt., eng Web, Last Accessed December $12^{\text {th }}, 2012$. www.eng.utoledo.edu/ akumar/IV/PowerPoint.

Olgyay, Aladar and Victor Olgyay. Solar Control and Shading Devices, Princeton University Press, Princeton, New Jersey, 1957.

Pawlyn, Michael. Biomimicry in Architecture, RIBA Publishing, 2011.

Pohl, Jens. Building Science: Concepts and Application. Chichester, Wiely-Blackwell, West Sussex, United Kingdom, 2011.

Schittich, Christian. In Detail : Solar Architecture Strategies Vision Concepts, Birkhauser, 2003. 
Schittich, Christian. In Detail: Building Skins Concepts Layers Materials, Birkhauser, 2001.

Schulte, Anna Julia, Kerstin Koch, Manuel Spaeth and Wilhelm Barthlott. "Biomimetic replicas: Transfer of complex architectures with different optical properties from plant surfaces onto technical materials", Science Direct, Acta Biomaterialia 5, (31 January 2009): 1848-1854. http://www.deepdyve.com/lp/elsevier/biomimeticreplicas-transfer-of-complex-architectures-with-different-zRyY0evJaN.

Seki, Yasuaki. "Biological materials: Structure and mechanical properties", Science Direct, Progress in Materials Science 53 (2008): 1-206. Materials Science and Engineering Program, Department of Mechanical and Aerospace Engineering, University of California, San Diego, La Jolla, CA, United States.

Tavakolinia, Fereshteh. WIND-CHIMNEY: Integrating the Principles of a Wind-Catcher and a Solar-Chimney to Provide Natural Ventilation. California Polytechnic State University, 2011.

The Pennsylvania State University. "What Kinds Of Leaves Do We See On The Trees Found On The Nature Trail?" Penn State New Kensington Web, (2009). http://www.psu.edu/dept/nkbiology/naturetrail/leaves.htm.

Vierra, Stephanie. Biomimicry: Designing to Model Nature. WBDG Web, 2011. http://www.wbdg.org/resources/biomimicry.php.

Vincent, Julian F. V. "The Materials Revolution", ScienceDirect, Journal of Bionic Engineering, Volume 3, Issue 4, (December 2006):217-23. http://www.sciencedirect.com/science/article/pii/S1672652907600055.

Waterworth, Kristi. "Adaptations for Barrel Cactus; Crassulacean Acid Metabolism." eHow Web. 2013. http://www.ehow.com/info_11384273_adaptations-barrelcactus.html\#ixzz2QEp9qoIx .

Watson, Donald and Kenneth Labs. Climatic Design: Energy-Efficient Building Principles and Practices. McGraw-Hill, 1983.

Weinstock, Michael. The architecture of Emergence, John Wiley and Sons, Ltd, Publication, 2010.

Wikipedia. Al Hamra Tower. 2013. https://en.wikipedia.org/wiki/Al_Hamra.

Wikipedia. Barrel Cactus. 2013. http://en.wikipedia.org/wiki/Barrel_cactus.

Wikipedia. Bernoulli's Principle, 2013. http://en.wikipedia.org/wiki/Bernoulli's_ principle. 
Wikipedia. Density of Air, 2013. http://en.wikipedia.org/wiki/Density_of_air.

Wikipedia. Qanat, 2013. https://en.wikipedia.org/wiki/Qanat.

Wikipedia. Stack Effect, 2013. http://en.wikipedia.org/wiki/Stack_effect.

Wikipedia. Stomata. 2012. http://en.wikipedia.org/wiki/Stoma.

Wikipedia. Windcatcher. 2013. http://en.wikipedia.org/wiki/Windcatcher.

Wikipedia. Yakhchal, 2013. http://en.wikipedia.org/wiki/Yakhchal.

Wikipedia. Yazd, 2013. http://en.wikipedia.org/wiki/Yazd.

Young, Hugh D. and Roger A. Freedman. Sear and Zemansky's University Physics, $12^{\text {th }}$ ed. Pearson Addison/Wesley, 2008. 


\section{APPENDIX}

\begin{tabular}{|c|c|c|c|}
\hline \multicolumn{2}{|r|}{ Vertical Surface } & \multicolumn{2}{|c|}{ Horizontal Surface } \\
\hline Qsun & $196 \mathrm{~W} / \mathrm{m}^{\wedge} 2$ & Qsun & $700 \mathrm{~W} / \mathrm{m}^{\wedge} 2$ \\
\hline$\alpha$ & 0.6 & $\alpha$ & 0.6 \\
\hline Qin & $117.6 \mathrm{~W} / \mathrm{m}^{\wedge} 2$ & Qin & $420 \mathrm{~W} / \mathrm{m}^{\wedge} 2$ \\
\hline$\varepsilon$ & 0.88 & $\varepsilon$ & 0.88 \\
\hline$\sigma$ & $5.67 \mathrm{E}-08 \mathrm{~W} / \mathrm{m}^{\wedge} 2-\mathrm{K}^{\wedge} 4$ & $\sigma$ & $5.67 \mathrm{E}-08 \mathrm{~W} / \mathrm{m}^{\wedge} 2-\mathrm{K}^{\wedge} 4$ \\
\hline \multirow[t]{2}{*}{ To } & $303.15 \mathrm{~K}$ & To & $303.15 \mathrm{~K}$ \\
\hline & $86 \mathrm{~F}$ & & $86 \mathrm{~F}$ \\
\hline \multirow[t]{2}{*}{ Ts } & $322.3896 \mathrm{~K}$ & $\mathrm{Ts}_{\mathrm{s}}$ & $360.3582 \mathrm{~K}$ \\
\hline & $120.63 \mathrm{~F}$ & & $188.97 \mathrm{~F}$ \\
\hline
\end{tabular}

TABLE 1: HOURLY SURFACE TEMPERATURE CALCULATION JUNE $21^{\text {ST }} 8: 00$

YAZD, IRAN

\begin{tabular}{|lclc|}
\hline \multicolumn{1}{c}{ Vertical Surface } & \multicolumn{2}{c|}{} \\
Qsun & $280 \mathrm{~W} / \mathrm{m}^{\wedge} 2$ & Qsun & $1000 \mathrm{~W} / \mathrm{m}^{\wedge} 2$ \\
$\alpha$ & 0.6 & $\alpha$ & 0.6 \\
Qin & $168 \mathrm{~W} / \mathrm{m}^{\wedge} 2$ & Qin & $600 \mathrm{~W} / \mathrm{m}^{\wedge} 2$ \\
$\varepsilon$ & 0.88 & $\varepsilon$ & 0.88 \\
$\sigma$ & $5.67 \mathrm{E}-08 \mathrm{~W} / \mathrm{m}^{\wedge} 2-\mathrm{K}^{\wedge} 4$ & $\sigma$ & $5.67 \mathrm{E}-08 \mathrm{~W} / \mathrm{m}^{\wedge} 2-\mathrm{K}^{\wedge} 4$ \\
To & $306.483 \mathrm{~K}$ & To & $306.483 \mathrm{~K}$ \\
& $91.9994 \mathrm{~F}$ & & $91.9994 \mathrm{~F}$ \\
Ts & $332.2788 \mathrm{~K}$ & Ts & $379.9856 \mathrm{~K}$ \\
\cline { 2 - 4 } & $\mathbf{1 3 8 . 4 3 ~ F}$ & & $\mathbf{2 2 4 . 3 0 ~ F}$ \\
\hline
\end{tabular}

TABLE 2: HOURLY SURFACE TEMPERATURE CALCULATION

JUNE $21^{\text {ST }}$ 10:00

YAZD, IRAN 


\begin{tabular}{|c|c|c|c|}
\hline \multicolumn{2}{|r|}{ Vertical Surface } & \multicolumn{2}{|c|}{ Horizontal Surface } \\
\hline Qsun & $363 \mathrm{~W} / \mathrm{m}^{\wedge} 2$ & Qsun & $1110 \mathrm{~W} / \mathrm{m}^{\wedge} 2$ \\
\hline$\alpha$ & 0.6 & $\alpha$ & 0.6 \\
\hline Qin & $217.8 \mathrm{~W} / \mathrm{m}^{\wedge} 2$ & Qin & $666 \mathrm{~W} / \mathrm{m}^{\wedge} 2$ \\
\hline$\varepsilon$ & 0.88 & $\varepsilon$ & 0.88 \\
\hline$\sigma$ & $5.67 \mathrm{E}-08 \mathrm{~W} / \mathrm{m}^{\wedge} 2-\mathrm{K}^{\wedge} 4$ & $\sigma$ & $5.67 \mathrm{E}-08 \mathrm{~W} / \mathrm{m}^{\wedge} 2-\mathrm{K}^{\wedge} 4$ \\
\hline \multirow[t]{2}{*}{ To } & $309.817 \mathrm{~K}$ & To & $309.817 \mathrm{~K}$ \\
\hline & $98.0006 \mathrm{~F}$ & & $98.0006 \mathrm{~F}$ \\
\hline \multirow[t]{2}{*}{ Ts } & $341.3603 \mathrm{~K}$ & Ts & $387.5614 \mathrm{~K}$ \\
\hline & $154.78 \mathrm{~F}$ & & $237.94 \mathrm{~F}$ \\
\hline
\end{tabular}

TABLE 3: HOURLY SURFACE TEMPERATURE CALCULATION JUNE $21^{\text {ST }} 12: 00$

YAZD, IRAN

\begin{tabular}{|lclc|}
\hline & Vertical Surface & & Horizontal Surface \\
Qsun & $216 \mathrm{~W} / \mathrm{m}^{\wedge} 2$ & Qsun & $800 \mathrm{~W} / \mathrm{m}^{\wedge} 2$ \\
$\alpha$ & 0.6 & $\alpha$ & 0.6 \\
Qin & $129.6 \mathrm{~W} / \mathrm{m}^{\wedge} 2$ & Qin & $480 \mathrm{~W} / \mathrm{m}^{\wedge} 2$ \\
$\varepsilon$ & 0.88 & $\varepsilon$ & 0.88 \\
$\sigma$ & $5.67 \mathrm{E}-08 \mathrm{~W} / \mathrm{m}^{\wedge} 2-\mathrm{K}^{\wedge} 4$ & $\sigma$ & $5.67 \mathrm{E}-08 \mathrm{~W} / \mathrm{m}^{\wedge} 2-\mathrm{K}^{\wedge} 4$ \\
To & $312.04 \mathrm{~K}$ & To & $312.04 \mathrm{~K}$ \\
& $102.002 \mathrm{~F}$ & & $102.002 \mathrm{~F}$ \\
Ts & $331.5124 \mathrm{~K}$ & Ts & $371.7598 \mathrm{~K}$ \\
\cline { 5 - 5 } & $\mathbf{1 3 7 . 0 5 \mathrm { F }}$ & & $\mathbf{2 0 9 . 5 0 \mathrm { F }}$ \\
\hline
\end{tabular}

TABLE 4: HOURLY SURFACE TEMPERATURE CALCULATION

JUNE $21^{\text {ST }} 14: 00$

YAZD, IRAN 


\begin{tabular}{|lclc|}
\hline & Vertical Surface & & Horizontal Surface \\
Qsun & $104 \mathrm{~W} / \mathrm{m}^{\wedge} 2$ & Qsun & $400 \mathrm{~W} / \mathrm{m}^{\wedge} 2$ \\
$\alpha$ & 0.6 & $\alpha$ & 0.6 \\
Qin & $62.4 \mathrm{~W} / \mathrm{m}^{\wedge} 2$ & Qin & $240 \mathrm{~W} / \mathrm{m}^{\wedge} 2$ \\
$\varepsilon$ & 0.88 & $\varepsilon$ & 0.88 \\
$\sigma$ & $5.67 \mathrm{E}-08 \mathrm{~W} / \mathrm{m}^{\wedge} 2-\mathrm{K}^{\wedge} 4$ & $\sigma$ & $5.67 \mathrm{E}-08 \mathrm{~W} / \mathrm{m}^{\wedge} 2-\mathrm{K}^{\wedge} 4$ \\
To & $313.71 \mathrm{~K}$ & To & $313.71 \mathrm{~K}$ \\
& $105.008 \mathrm{~F}$ & & $105.008 \mathrm{~F}$ \\
Ts & $323.3804 \mathrm{~K}$ & Ts & $346.982 \mathrm{~K}$ \\
\hline & $\mathbf{1 2 2 . 4 1 \mathbf { F }}$ & & $\mathbf{1 6 4 . 9 0 \mathbf { F }}$ \\
\hline
\end{tabular}

TABLE 5: HOURLY SURFACE TEMPERATURE CALCULATION JUNE $21^{\text {ST }} 16: 00$ YAZD, IRAN

\begin{tabular}{|c|c|c|c|}
\hline \multicolumn{2}{|r|}{ Vertical Surface } & \multicolumn{2}{|c|}{ Horizontal Surface } \\
\hline Qsun & $246 \mathrm{~W} / \mathrm{m}^{\wedge} 2$ & Qsun & $300 \mathrm{~W} / \mathrm{m}^{\wedge} 2$ \\
\hline$\alpha$ & 0.6 & $\alpha$ & 0.6 \\
\hline Qin & $147.6 \mathrm{~W} / \mathrm{m}^{\wedge} 2$ & Qin & $180 \mathrm{~W} / \mathrm{m}^{\wedge} 2$ \\
\hline$\varepsilon$ & 0.88 & $\varepsilon$ & 0.88 \\
\hline$\sigma$ & $5.67 \mathrm{E}-08 \mathrm{~W} / \mathrm{m}^{\wedge} 2-\mathrm{K}^{\wedge} 4$ & $\sigma$ & $5.67 \mathrm{E}-08 \mathrm{~W} / \mathrm{m}^{\wedge} 2-\mathrm{K}^{\wedge} 4$ \\
\hline \multirow[t]{2}{*}{ To } & $281.483 \mathrm{~K}$ & To & $281.483 \mathrm{~K}$ \\
\hline & $46.9994 \mathrm{~F}$ & & $46.9994 \mathrm{~F}$ \\
\hline \multirow[t]{2}{*}{ Ts } & $310.0064 \mathrm{~K}$ & Ts & $315.3172 \mathrm{~K}$ \\
\hline & $98.34 \mathrm{~F}$ & & $107.90 \mathrm{~F}$ \\
\hline
\end{tabular}

TABLE 6: HOURLY SURFACE TEMPERATURE CALCULATION DECEMBER $21^{\text {ST }}$ 8:00

YAZD, IRAN 


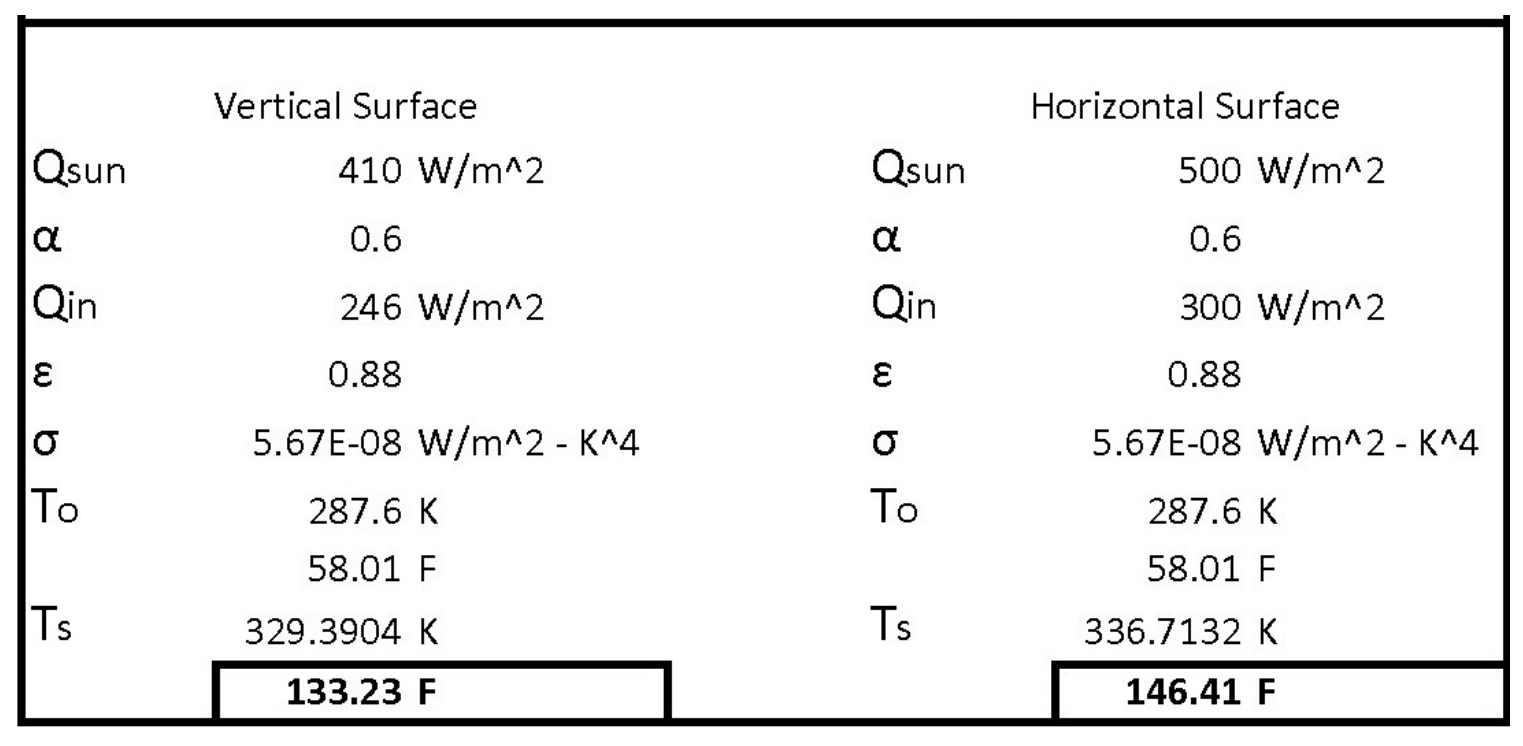

TABLE 7: HOURLY SURFACE TEMPERATURE CALCULATION DECEMBER $21^{\text {ST }} 10: 00$

YAZD, IRAN

\begin{tabular}{|lclc|}
\hline & Vertical Surface & & Horizontal Surface \\
Qsun & $410 \mathrm{~W} / \mathrm{m}^{\wedge} 2$ & Qsun & $550 \mathrm{~W} / \mathrm{m}^{\wedge} 2$ \\
$\alpha$ & 0.6 & $\alpha$ & 0.6 \\
Qin & $246 \mathrm{~W} / \mathrm{m}^{\wedge} 2$ & Qin & $330 \mathrm{~W} / \mathrm{m}^{\wedge} 2$ \\
$\varepsilon$ & 0.88 & $\varepsilon$ & 0.88 \\
$\sigma$ & $5.67 \mathrm{E}-08 \mathrm{~W} / \mathrm{m}^{\wedge} 2-\mathrm{K}^{\wedge} 4$ & $\sigma$ & $5.67 \mathrm{E}-08 \mathrm{~W} / \mathrm{m}^{\wedge} 2-\mathrm{K}^{\wedge} 4$ \\
To & $289.82 \mathrm{~K}$ & To & $289.82 \mathrm{~K}$ \\
& $62.006 \mathrm{~F}$ & & $62.006 \mathrm{~F}$ \\
Ts & $330.8752 \mathrm{~K}$ & Ts & $341.9278 \mathrm{~K}$ \\
\cline { 4 - 5 } & $\mathbf{1 3 5 . 9 1 ~ \mathbf { ~ }}$ & & $\mathbf{1 5 5 . 8 0 ~ \mathbf { ~ }}$ \\
\hline
\end{tabular}

TABLE 8: HOURLY SURFACE TEMPERATURE CALCULATION DECEMBER $21^{\text {ST }} 12: 00$

YAZD, IRAN 


\begin{tabular}{|lclc|}
\hline \multicolumn{1}{c}{} & Vertical Surface & & Horizontal Surface \\
Qsun & $273 \mathrm{~W} / \mathrm{m}^{\wedge} 2$ & Qsun & $273 \mathrm{~W} / \mathrm{m}^{\wedge} 2$ \\
$\alpha$ & 0.6 & $\alpha$ & 0.6 \\
Qin & $163.8 \mathrm{~W} / \mathrm{m}^{\wedge} 2$ & Qin & $163.8 \mathrm{~W} / \mathrm{m}^{\wedge} 2$ \\
$\varepsilon$ & 0.88 & $\varepsilon$ & 0.88 \\
$\sigma$ & $5.67 \mathrm{E}-08 \mathrm{~W} / \mathrm{m}^{\wedge} 2-\mathrm{K}^{\wedge} 4$ & $\sigma$ & $5.67 \mathrm{E}-08 \mathrm{~W} / \mathrm{m}^{\wedge} 2-\mathrm{K}^{\wedge} 4$ \\
To & $287.6 \mathrm{~K}$ & To & $287.6 \mathrm{~K}$ \\
& $58.01 \mathrm{~F}$ & & $58.01 \mathrm{~F}$ \\
Ts & $317.2066 \mathrm{~K}$ & Ts & $317.2066 \mathrm{~K}$ \\
& $\mathbf{1 1 1 . 3 0 ~ F}$ & & $\mathbf{1 1 1 . 3 0 ~ \mathbf { ~ }}$ \\
\hline
\end{tabular}

TABLE 9: HOURLY SURFACE TEMPERATURE CALCULATION DECEMBER $21^{\text {ST }} 14: 00$

YAZD, IRAN

\begin{tabular}{|lclc|}
\hline & Vertical Surface & & Horizontal Surface \\
Qsun & $0 \mathrm{~W} / \mathrm{m}^{\wedge} 2$ & Qsun & $0 \mathrm{~W} / \mathrm{m}^{\wedge} 2$ \\
$\alpha$ & 0.6 & $\alpha$ & 0.6 \\
Qin & $0 \mathrm{~W} / \mathrm{m}^{\wedge} 2$ & Qin & $0 \mathrm{~W} / \mathrm{m}^{\wedge} 2$ \\
$\varepsilon$ & 0.88 & $\varepsilon$ & 0.88 \\
$\sigma$ & $5.67 \mathrm{E}-08 \mathrm{~W} / \mathrm{m}^{\wedge} 2-\mathrm{K}^{\wedge} 4$ & $\sigma$ & $5.67 \mathrm{E}-08 \mathrm{~W} / \mathrm{m}^{\wedge} 2-\mathrm{K}^{\wedge} 4$ \\
To & $282.04 \mathrm{~K}$ & To & $282.04 \mathrm{~K}$ \\
& $48.002 \mathrm{~F}$ & & $48.002 \mathrm{~F}$ \\
Ts & $282.04 \mathrm{~K}$ & Ts & $282.04 \mathrm{~K}$ \\
\cline { 2 - 4 } & $\mathbf{4 8 . 0 0 ~ F}$ & & $\mathbf{4 8 . 0 0 ~ F}$ \\
\hline
\end{tabular}

TABLE 10: HOURLY SURFACE TEMPERATURE CALCULATION DECEMBER $21^{\text {ST }} 16: 00$

YAZD, IRAN 


\begin{tabular}{|lc|}
\hline \multicolumn{2}{|c|}{ Vertical Surface East Facing } \\
Qsun & $133 \mathrm{~W} / \mathrm{m}^{\wedge} 2$ \\
$\alpha$ & 0.6 \\
Qin & $79.8 \mathrm{~W} / \mathrm{m}^{\wedge} 2$ \\
$\varepsilon$ & 0.88 \\
$\sigma$ & $5.67 \mathrm{E}-08 \mathrm{~W} / \mathrm{m}^{\wedge} 2-\mathrm{K}^{\wedge} 4$ \\
To & $303.15 \mathrm{~K}$ \\
& $86 \mathrm{~F}$ \\
\hline Ts & $316.5823 \mathrm{~K}$ \\
\hline
\end{tabular}

\begin{tabular}{|lc|}
\hline \multicolumn{3}{|c|}{ Vertical Surface West facing } \\
Qsun & $70 \mathrm{~W} / \mathrm{m}^{\wedge} 2$ \\
$\alpha$ & 0.6 \\
Qin & $42 \mathrm{~W} / \mathrm{m}^{\wedge} 2$ \\
$\varepsilon$ & 0.88 \\
$\sigma$ & $5.67 \mathrm{E}-08 \mathrm{~W} / \mathrm{m}^{\wedge} 2-\mathrm{K}^{\wedge} 4$ \\
To & $303.15 \mathrm{~K}$ \\
& $86 \mathrm{~F}$ \\
Ts & $310.4365965 \mathrm{~K}$ \\
\hline & $\mathbf{9 9 . 1 2 ~ F}$ \\
\hline
\end{tabular}

TABLE 11: HOURLY SURFACE TEMPERATURE CALCULATIONS OF THE CORRUGATED SKIN

JUNE $21^{\text {ST }} 8: 00$

YAZD, IRAN

\begin{tabular}{|lc|}
\hline \multicolumn{3}{|c|}{ Vertical Surface East Facing } \\
Qsun & $250 \mathrm{~W} / \mathrm{m}^{\wedge} 2$ \\
$\alpha$ & 0.6 \\
Qin & $150 \mathrm{~W} / \mathrm{m}^{\wedge} 2$ \\
$\varepsilon$ & 0.88 \\
$\sigma$ & $5.67 \mathrm{E}-08 \mathrm{~W} / \mathrm{m}^{\wedge} 2-\mathrm{K}^{\wedge} 4$ \\
To & $306.483 \mathrm{~K}$ \\
& $91.9994 \mathrm{~F}$ \\
Ts & $329.7927 \mathrm{~K}$ \\
\hline
\end{tabular}

\begin{tabular}{|lc|}
\hline & Vertical Surface West facing \\
Qsun & $70 \mathrm{~W} / \mathrm{m}^{\wedge} 2$ \\
$\alpha$ & 0.6 \\
Qin & $42 \mathrm{~W} / \mathrm{m}^{\wedge} 2$ \\
$\varepsilon$ & 0.88 \\
$\sigma$ & $5.67 \mathrm{E}-08 \mathrm{~W} / \mathrm{m}^{\wedge} 2-\mathrm{K}^{\wedge} 4$ \\
To & $306.483 \mathrm{~K}$ \\
& $91.9994 \mathrm{~F}$ \\
Ts & $313.5449308 \mathrm{~K}$ \\
\hline & $\mathbf{1 0 4 . 7 1 ~ F}$ \\
\hline
\end{tabular}

TABLE 12: HOURLY SURFACE TEMPERATURE CALCULATION OF THE CORRUGATED SKIN

JUNE $21^{\text {ST }} 10: 00$

YAZD, IRAN 

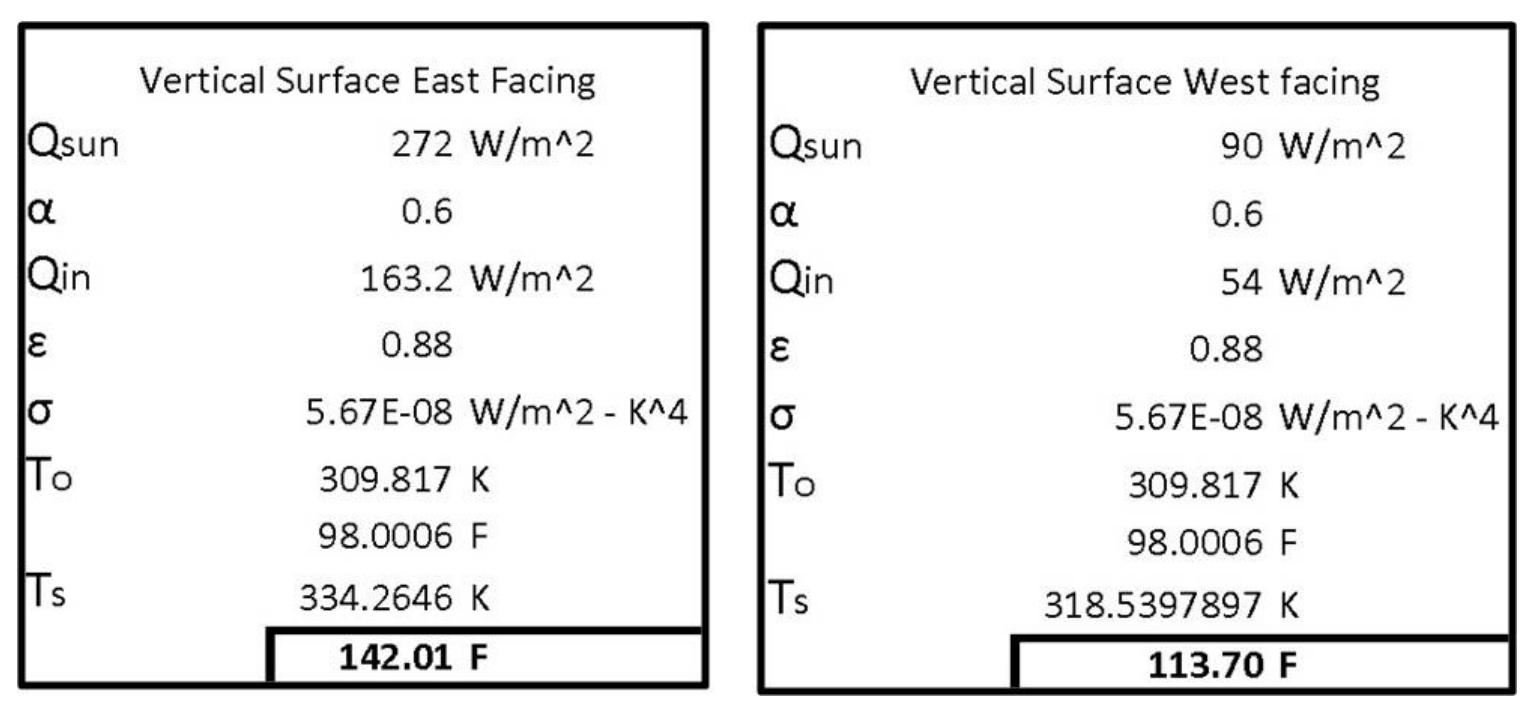

TABLE 13: HOURLY SURFACE TEMPERATURE CALCULATION OF THE CORRUGATED SKIN

$$
\begin{gathered}
\text { JUNE } 21^{\text {ST }} 12: 00 \\
\text { YAZD, IRAN }
\end{gathered}
$$

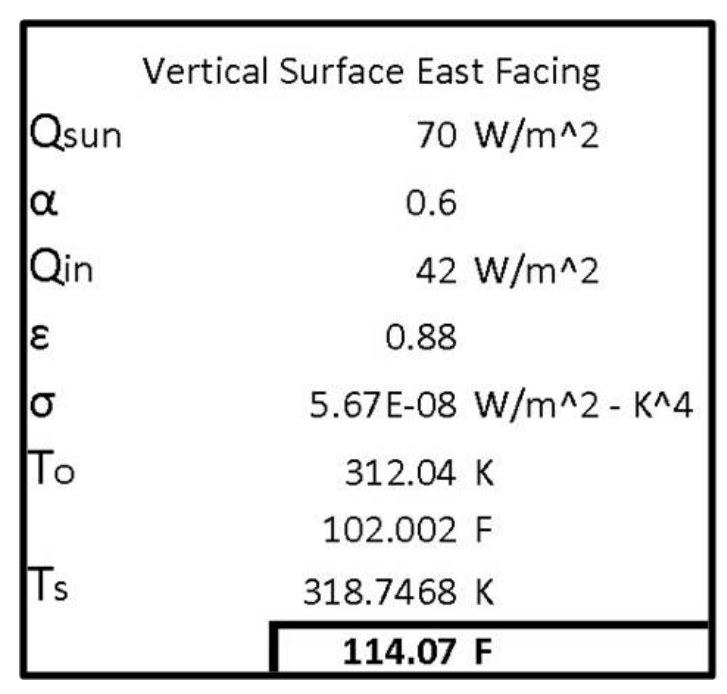

\begin{tabular}{|lc|}
\hline \multicolumn{2}{|c|}{ Vertical Surface West facing } \\
Qsun & $170 \mathrm{~W} / \mathrm{m}^{\wedge} 2$ \\
$\alpha$ & 0.6 \\
Qin & $102 \mathrm{~W} / \mathrm{m}^{\wedge} 2$ \\
$\varepsilon$ & 0.88 \\
$\sigma$ & $5.67 \mathrm{E}-08 \mathrm{~W} / \mathrm{m}^{\wedge} 2-\mathrm{K}^{\wedge} 4$ \\
To & $312.04 \mathrm{~K}$ \\
& $102.002 \mathrm{~F}$ \\
Ts & $327.6498097 \mathrm{~K}$ \\
\hline & $\mathbf{1 3 0 . 1 0 ~ F}$ \\
\hline
\end{tabular}

TABLE 14: HOURLY SURFACE TEMPERATURE CALCULATION OF THE CORRUGATED SKIN

JUNE $21^{\text {ST }} 14: 00$
YAZD, IRAN 

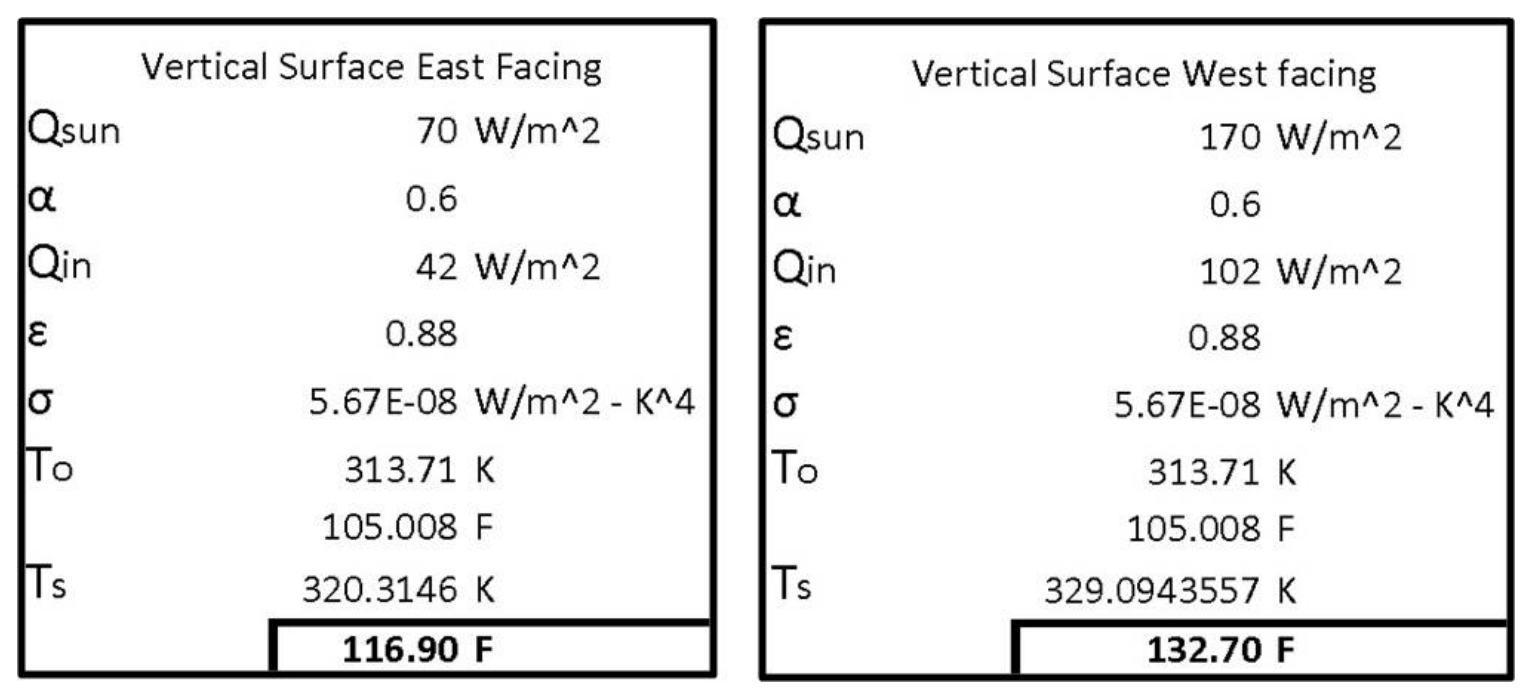

TABLE 15: HOURLY SURFACE TEMPERATURE CALCULATION OF THE CORRUGATED SKIN

JUNE $21^{\text {ST }} 16: 00$

YAZD, IRAN
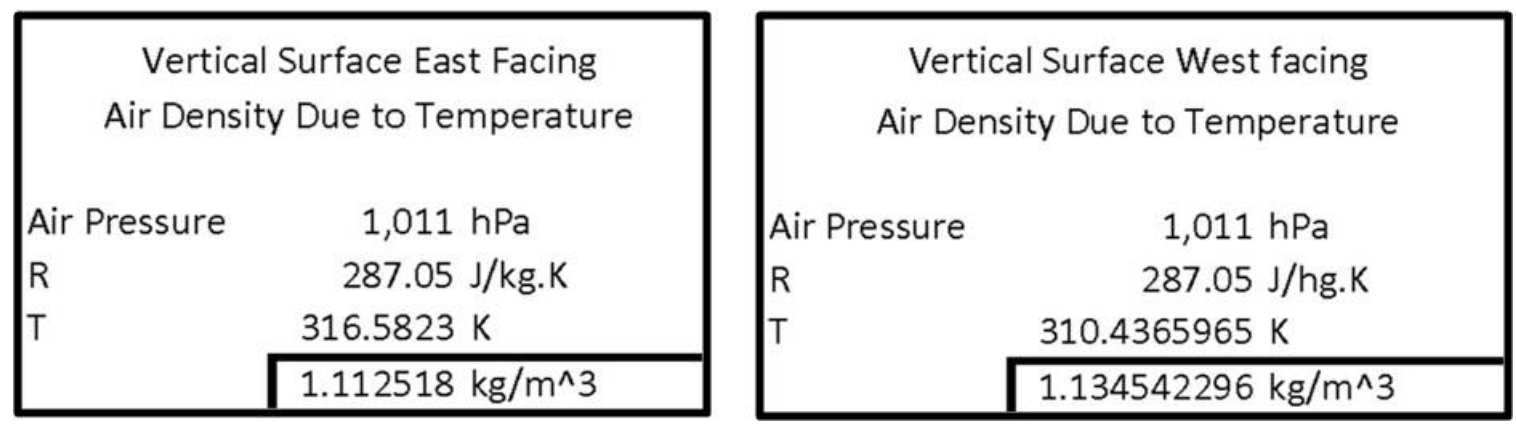

TABLE 16: AIR DENSITY CALCULATION DUE TO THE TEMPRATURE OF THE CORRUGATED SKIN

JUNE $21^{\text {ST }} 8: 00$ 

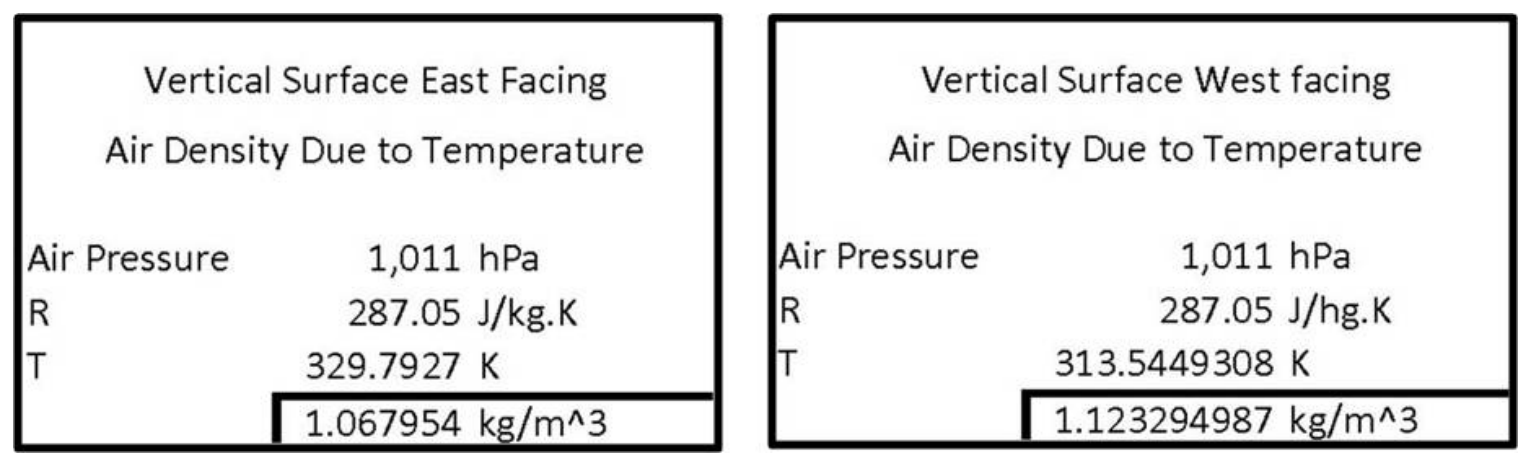

TABLE 17: AIR DENSITY CALCULATION DUE TO THE TEMPRATURE OF THE CORRUGATED SKIN

JUNE $21^{\text {ST }} 10: 00$
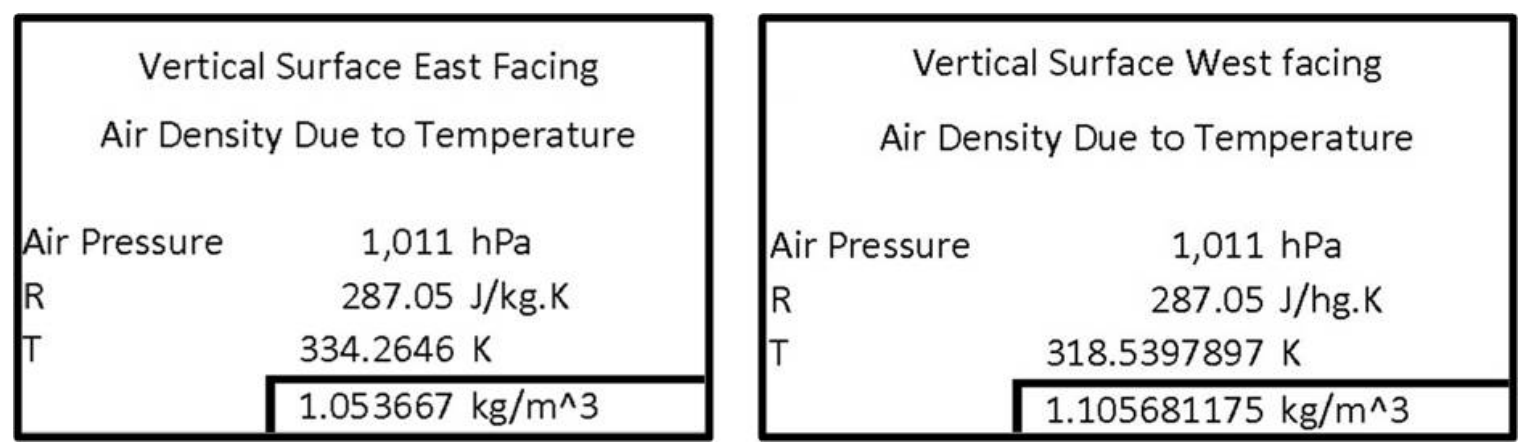

TABLE 18: AIR DENSITY CALCULATION DUE TO THE TEMPRATURE OF THE CORRUGATED SKIN

JUNE $21^{\text {ST }} 12: 00$

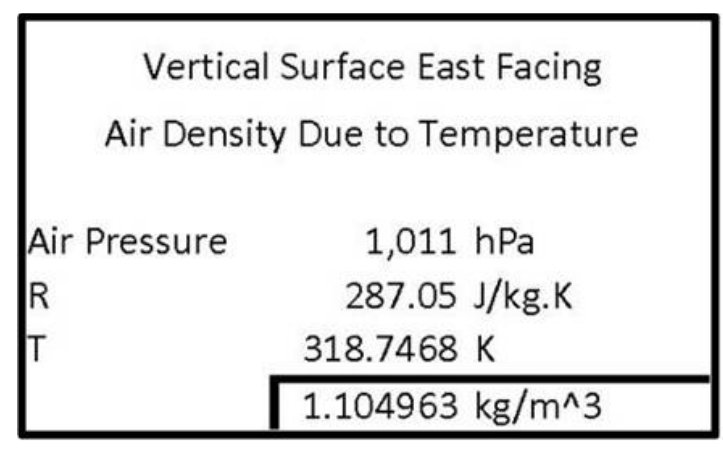

\begin{tabular}{|lc|}
\hline \multicolumn{3}{|c|}{ Vertical Surface West facing } \\
& Air Density Due to Temperature \\
& \\
Air Pressure & $1,011 \mathrm{hPa}$ \\
$\mathrm{R}$ & $287.05 \mathrm{~J} / \mathrm{hg} . \mathrm{K}$ \\
$\mathrm{T}$ & $327.6498097 \mathrm{~K}$ \\
\cline { 2 - 2 } & $1.074938665 \mathrm{~kg} / \mathrm{m}^{\wedge} 3$ \\
\hline
\end{tabular}

TABLE 19: AIR DENSITY CALCULATION DUE TO THE TEMPRATURE OF THE CORRUGATED SKIN

JUNE $21^{\text {ST }} 14: 00$ 

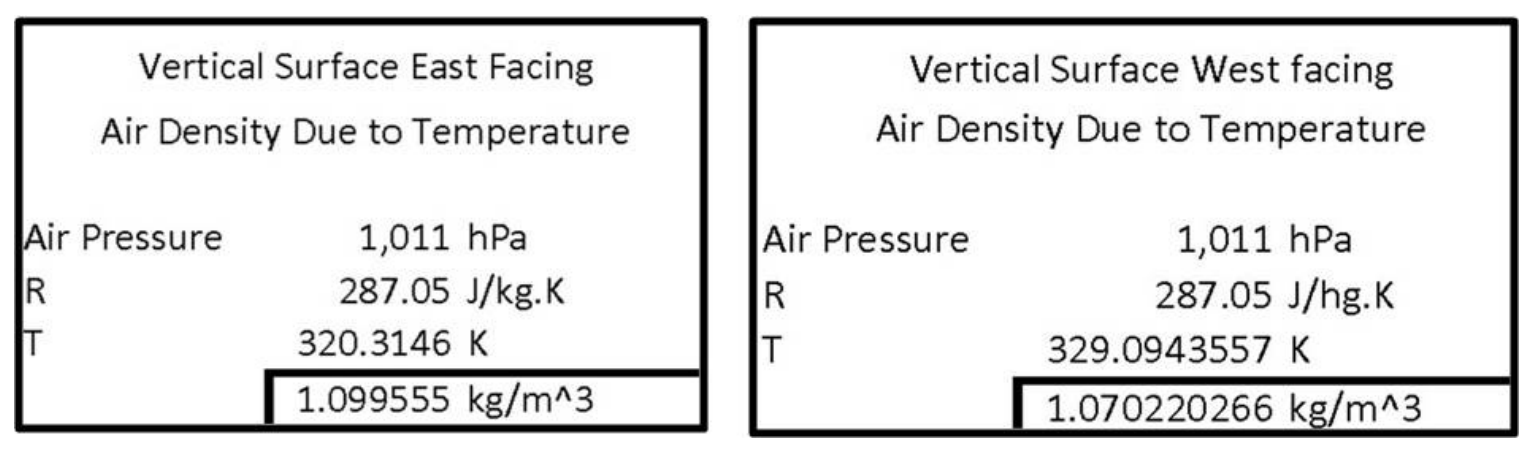

TABLE 20: AIR DENSITY CALCULATION DUE TO THE TEMPRATURE OF THE CORRUGATED SKIN

JUNE $21^{\text {ST }} 16: 00$

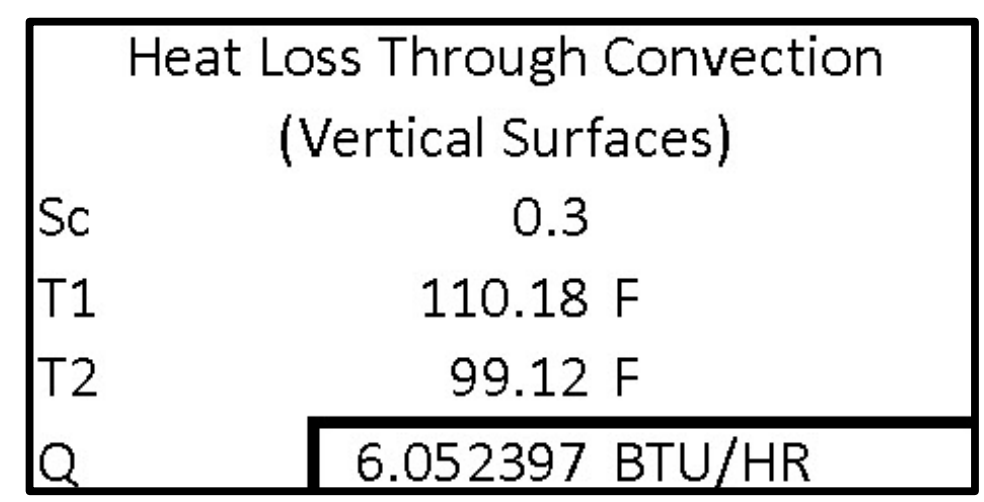

TABLE 21: HEAT LOSS THROUGH THE CONVETION OF THE CORRUGATED SKIN

JUNE $21^{\text {ST }} 8: 00$

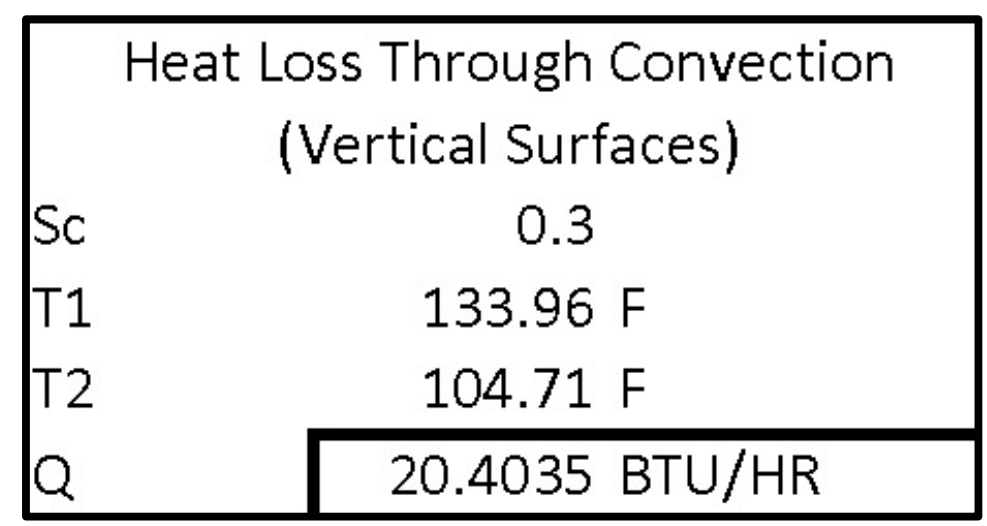

TABLE 22: HEAT LOSS THROUGH THE CONVETION OF THE CORRUGATED SKIN

JUNE $21^{\text {ST }} 10: 00$ 


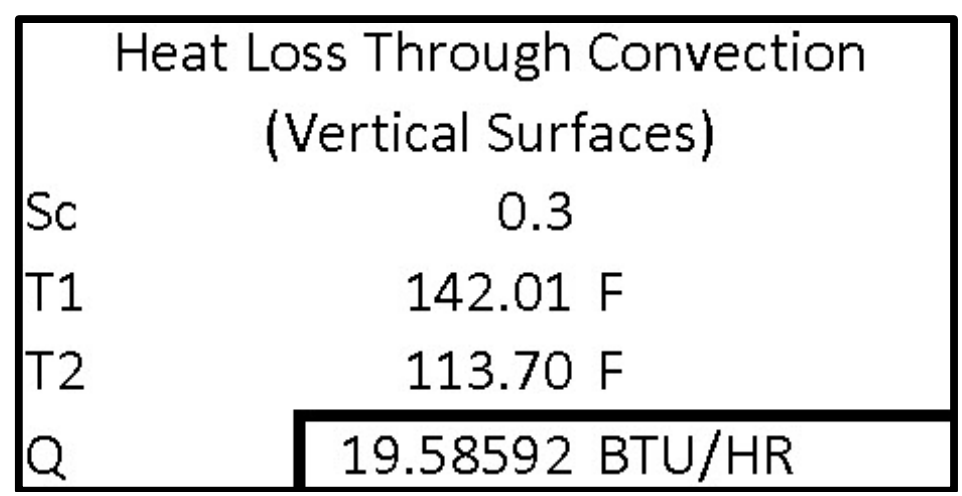

TABLE 23: HEAT LOSS THROUGH THE CONVETION OF THE CORRUGATED SKIN

JUNE $21^{\text {ST }} 12: 00$

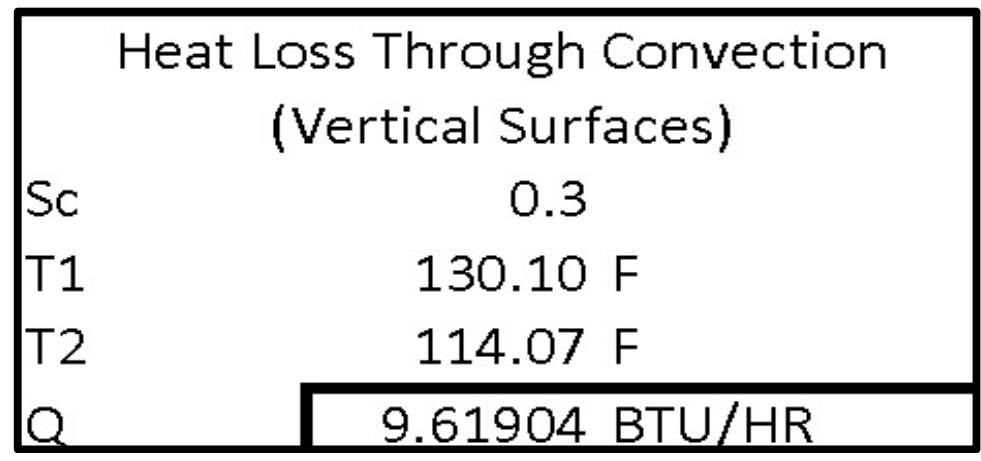

TABLE 24: HEAT LOSS THROUGH THE CONVETION OF THE CORRUGATED SKIN

JUNE $21^{\text {ST }} 14: 00$

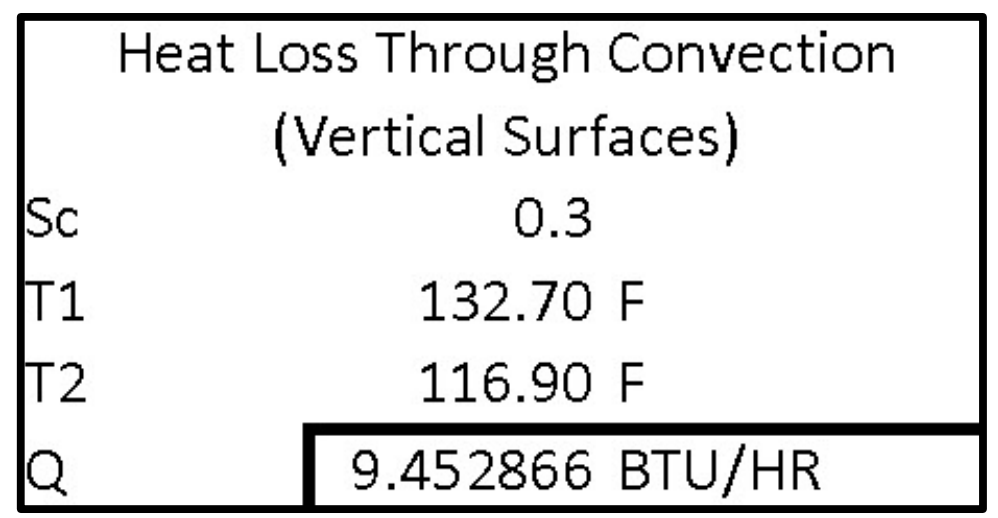

TABLE 25: HEAT LOSS THROUGH THE CONVETION OF THE CORRUGATED SKIN

JUNE $21^{\text {ST }} 16: 00$ 

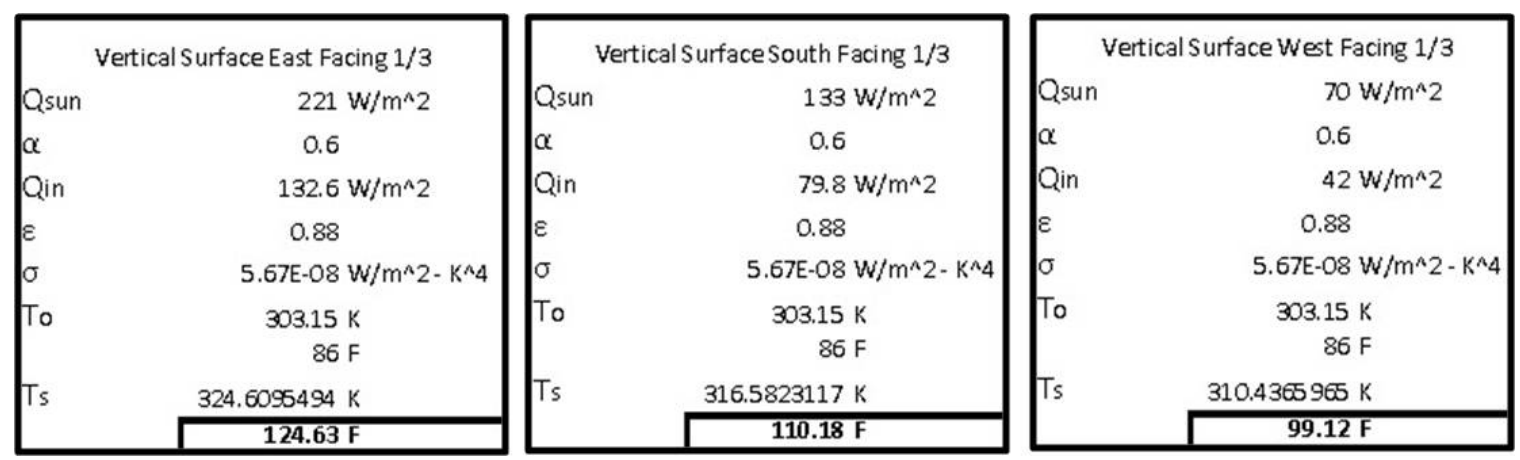

TABLE 26: HOURLY SURFACE TEMPERATURE CALCULATION

OF THE CURVED SKIN

JUNE $21^{\text {ST }} 8: 00$

YAZD, IRAN
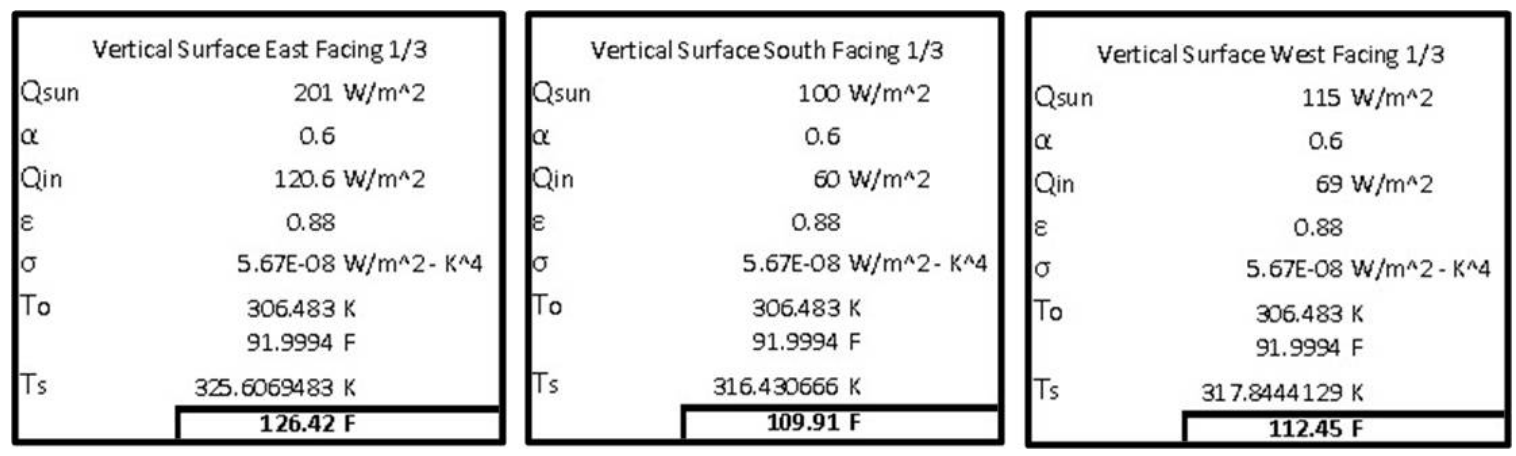

TABLE 27: HOURLY SURFACE TEMPERATURE CALCULATION OF THE CURVED SKIN

JUNE $21^{\text {ST }} 10: 00$

$$
\text { YAZD, IRAN }
$$
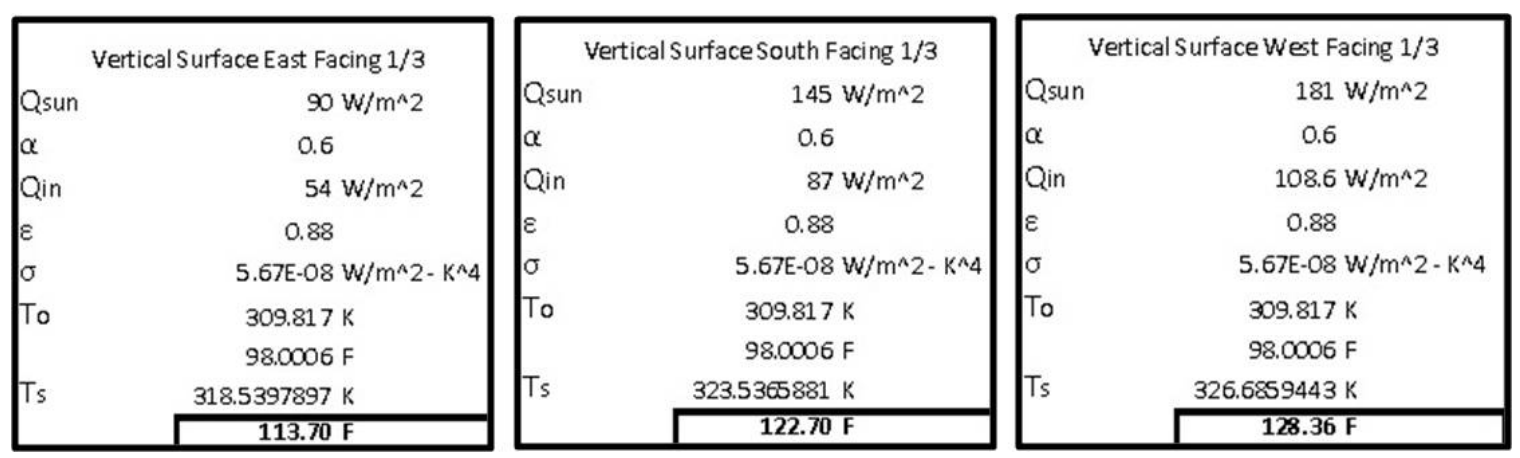

TABLE 28: HOURLY SURFACE TEMPERATURE CALCULATION

OF THE CURVED SKIN

JUNE $21^{\text {ST }} 12: 00$

YAZD, IRAN 

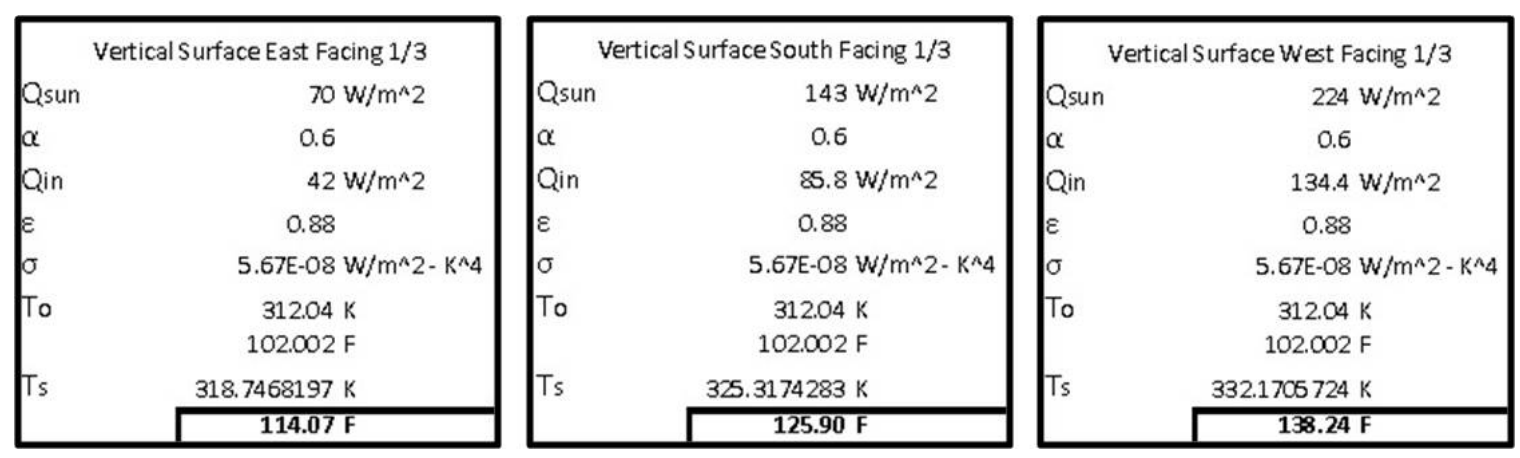

TABLE 29: HOURLY SURFACE TEMPERATURE CALCULATION

OF THE CURVED SKIN

JUNE $21^{\text {ST }} 14: 00$

YAZD, IRAN
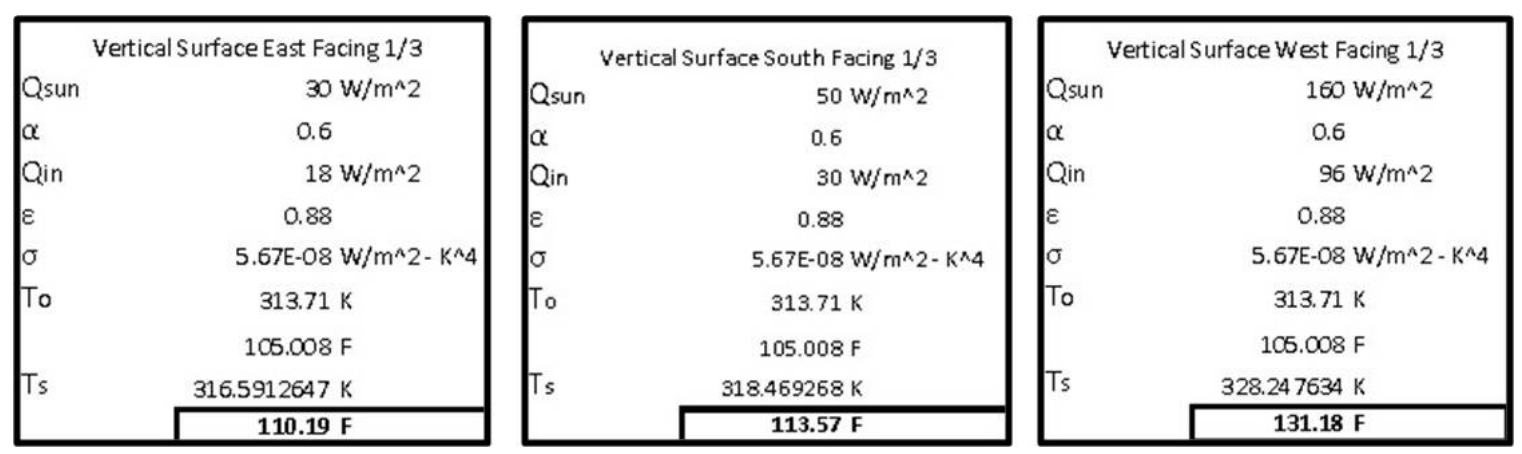

TABLE 30: HOURLY SURFACE TEMPERATURE CALCULATION

OF THE CURVED SKIN

JUNE $21^{\text {ST }} 16: 00$

YAZD, IRAN
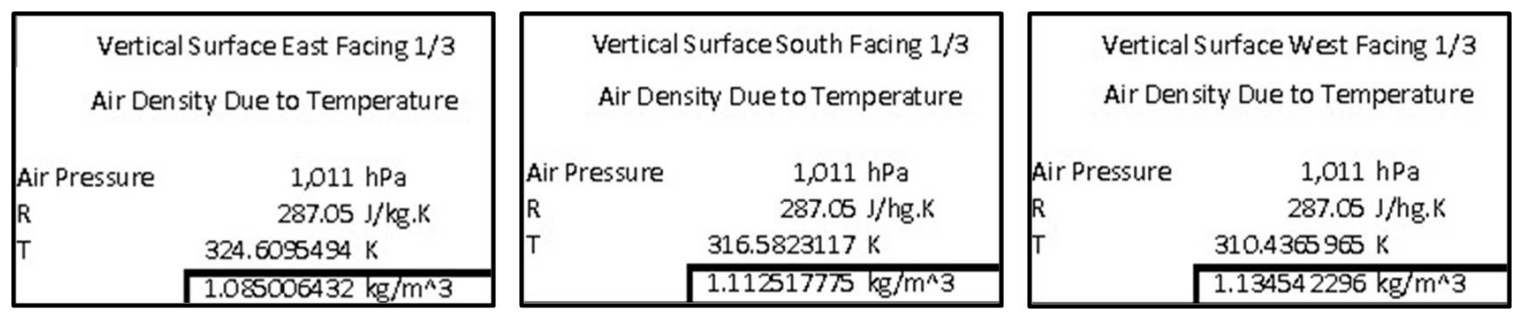

TABLE 31: AIR DENSITY CALCULATION DUE TO THE TEMPRATURE DIFFERENCE

OF THE CURVED CORRUGATED SKIN

JUNE $21^{\text {ST }} 8: 00$ 

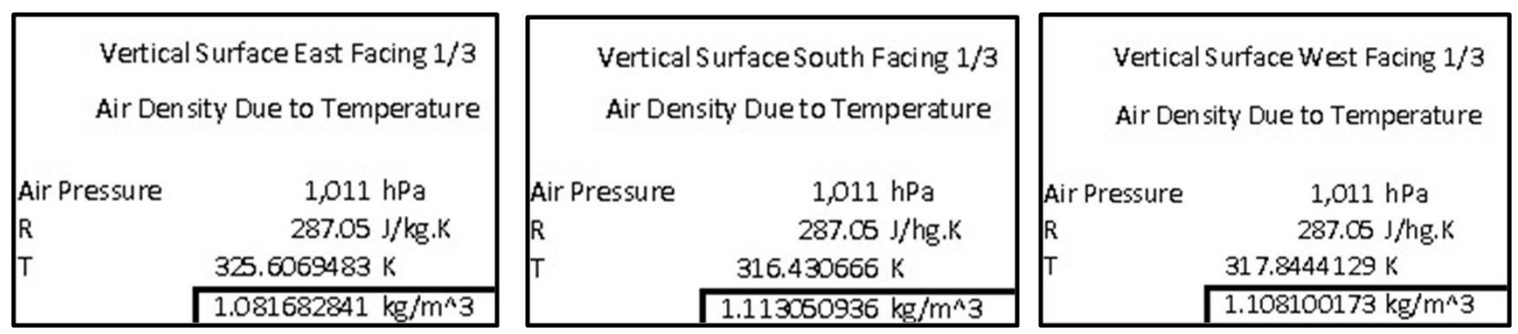
TABLE 32: AIR DENSITY CALCULATION DUE TO THE TEMPRATURE DIFFERENCE OF THE CURVED CORRUGATED SKIN JUNE $21^{\text {ST }} 10: 00$
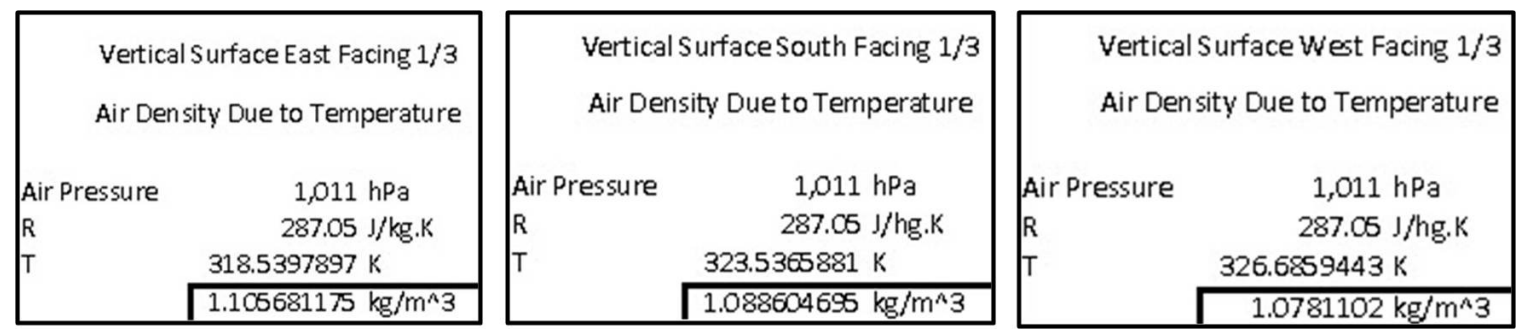

TABLE 33: AIR DENSITY CALCULATION DUE TO THE TEMPRATURE DIFFERENCE

OF THE CURVED CORRUGATED SKIN JUNE $21^{\text {ST }} 12: 00$
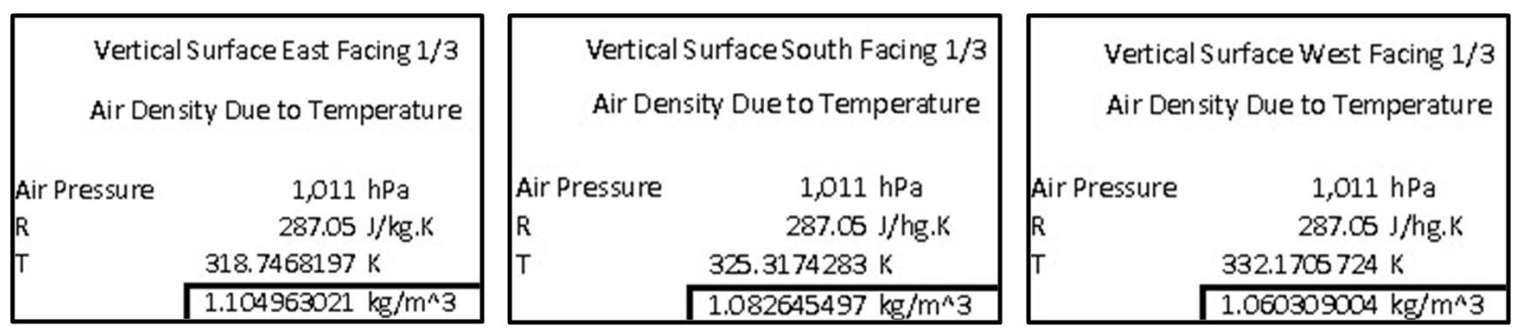

\section{TABLE 34: AIR DENSITY CALCULATION DUE TO THE TEMPRATURE DIFFERENCE OF THE CURVED CORRUGATED SKIN JUNE $21^{\text {ST }}$ 14:00}



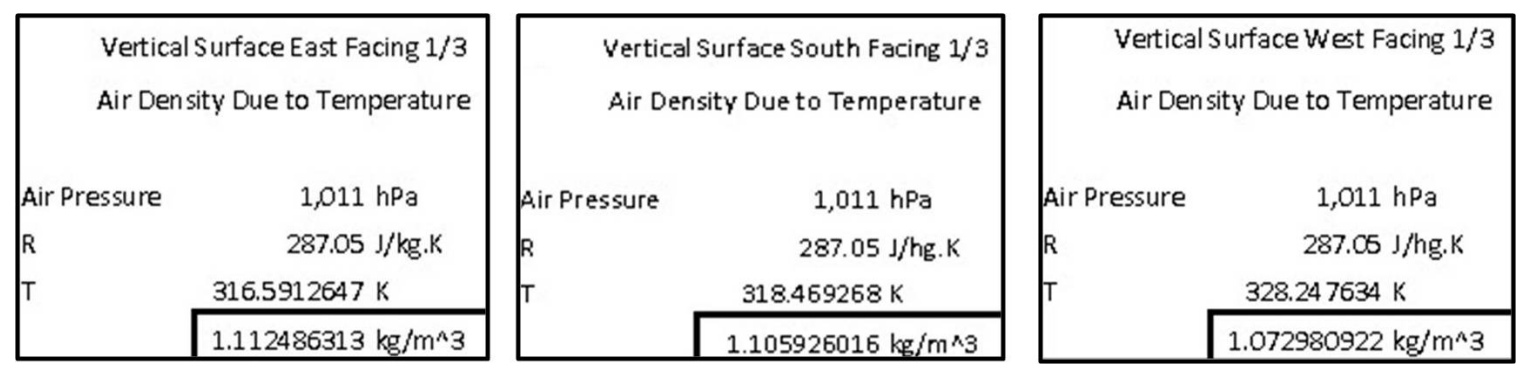

TABLE 35: AIR DENSITY CALCULATION DUE TO THE TEMPRATURE DIFFERENCE

OF THE CURVED CORRUGATED SKIN

JUNE $21^{\text {ST }} 16: 00$
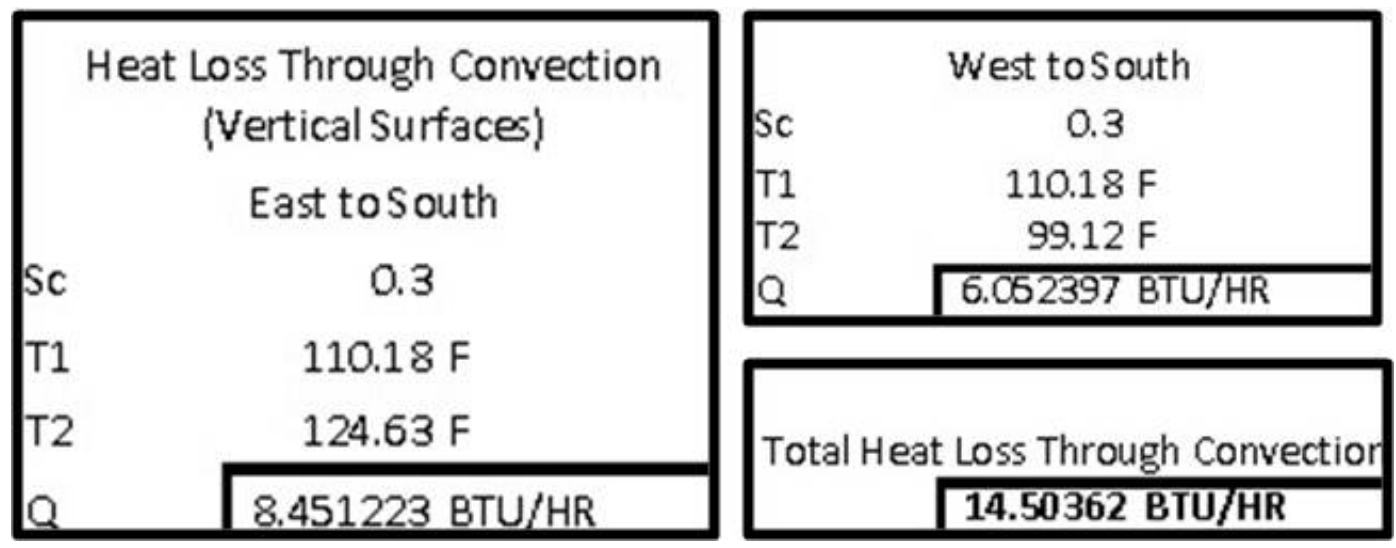

TABLE 36: HEAT LOSS THROUGH THE CONVETION ON THE CURVED CORRUGATED SKIN JUNE $21^{\text {ST }} 8: 00$
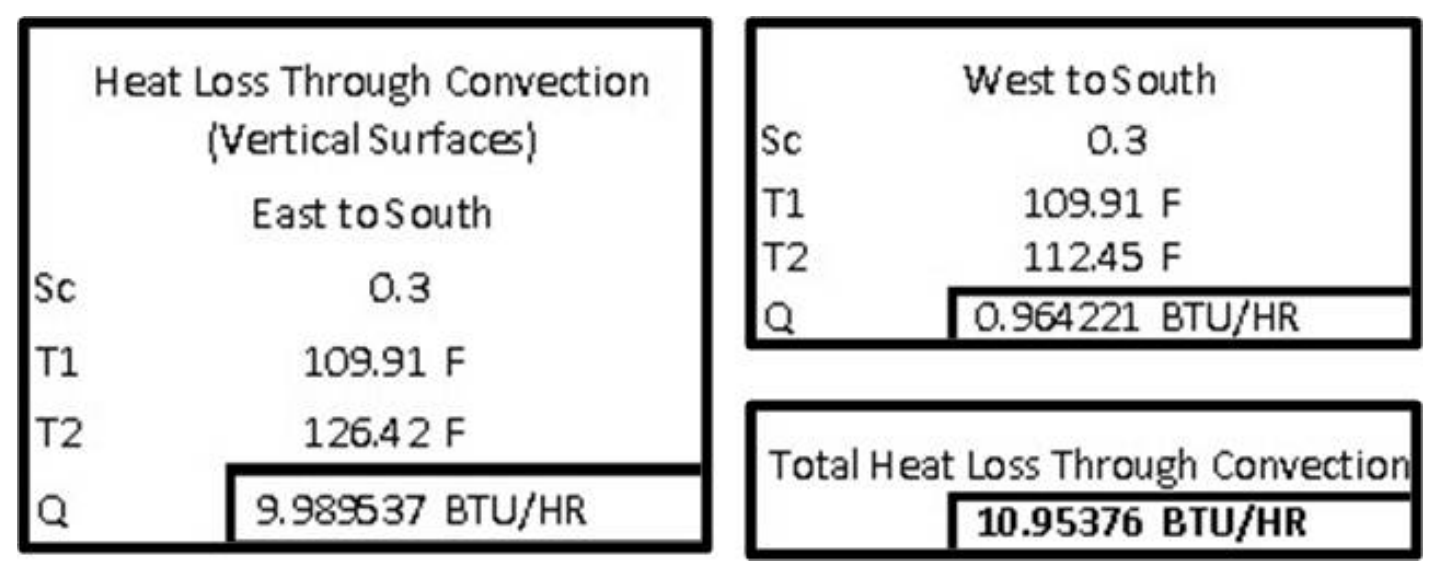

TABLE 37: HEAT LOSS THROUGH THE CONVETION ON THE CURVED CORRUGATED SKIN

JUNE $21^{\text {ST }} 10: 00$ 

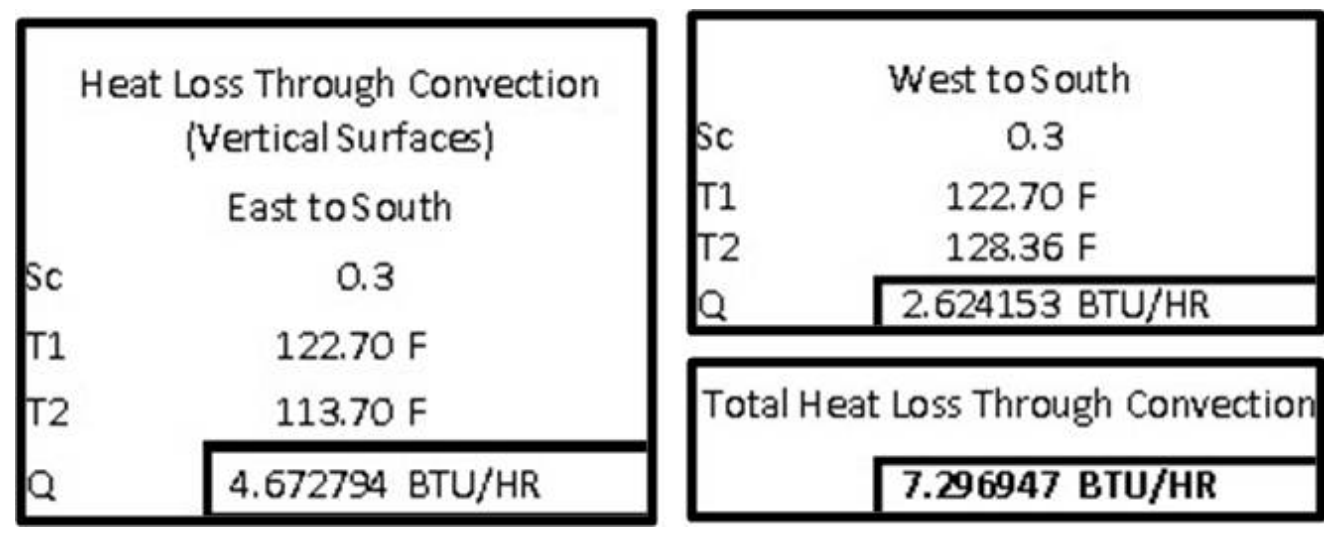

Total Heat Loss Through Convection

7.296947 BTU/HR

TABLE 38: HEAT LOSS THROUGH THE CONVETION ON THE CURVED CORRUGATED SKIN

JUNE $21^{\text {ST }} 12: 00$
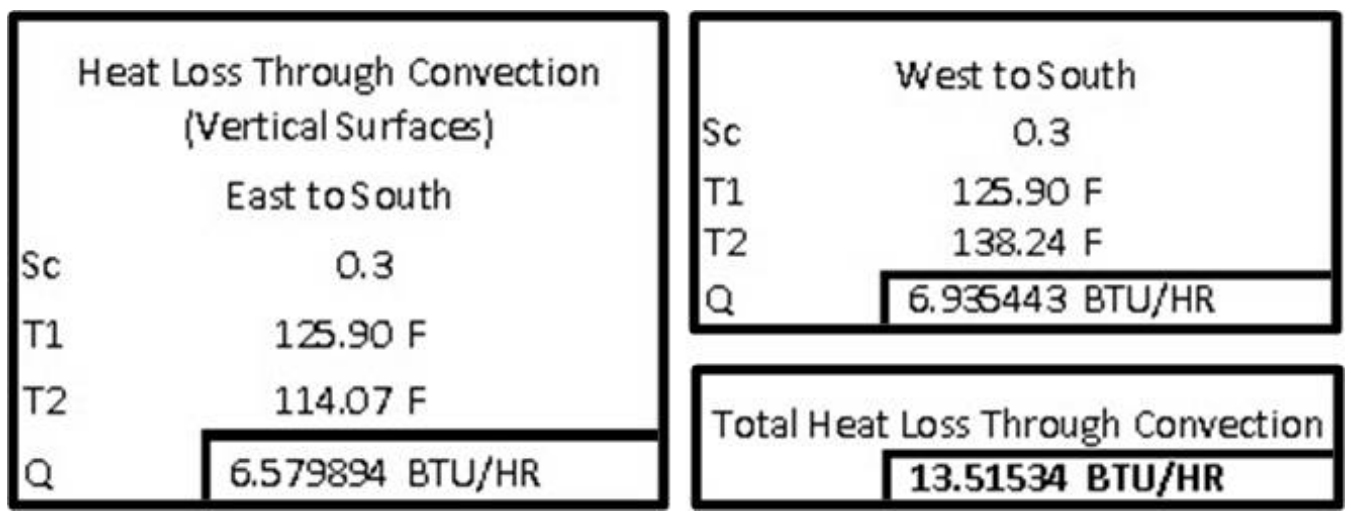

TABLE 39: HEAT LOSS THROUGH THE CONVETION ON THE CURVED CORRUGATED SKIN JUNE $21^{\text {ST }} 14: 00$
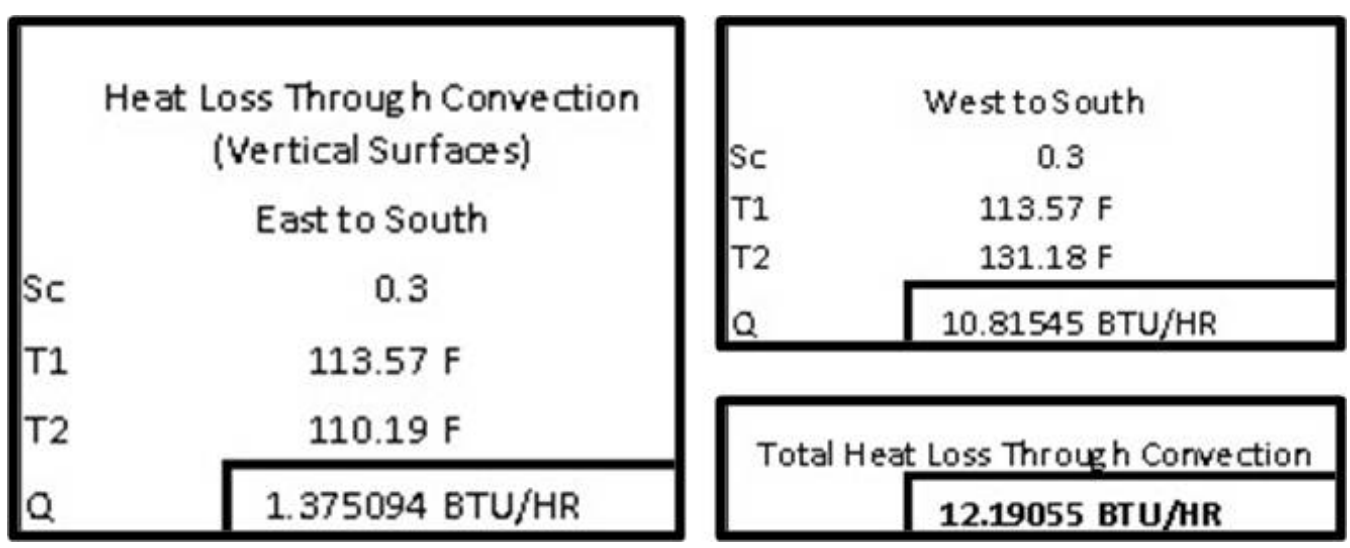

TABLE 40: HEAT LOSS THROUGH THE CONVETION ON THE CURVED CORRUGATED SKIN

JUNE $21^{\text {ST }} 16: 00$ 


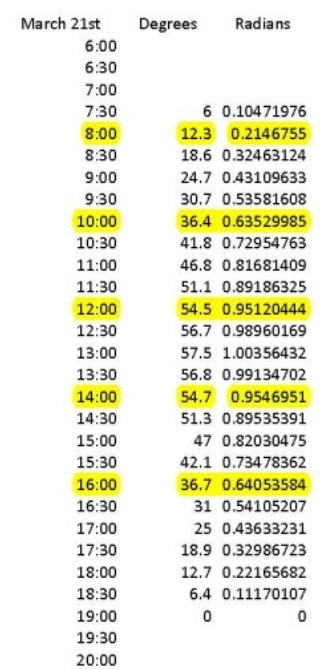

\begin{tabular}{rrr} 
June 21st & \multicolumn{1}{c}{ Degrees } & \multicolumn{2}{c}{ Radians } \\
$6: 00$ & 1.5 & 0.02617994 \\
$6: 30$ & 7.3 & 0.12740904 \\
$7: 00$ & 13.2 & 0.23038346 \\
$7: 30$ & 19.2 & 0.33510322 \\
$8: 00$ & 25.4 & 0.44331363 \\
$8: 30$ & 31.6 & 0.55152404 \\
$9: 00$ & 37.9 & 0.66147979 \\
$9: 30$ & 44.2 & 0.77143553 \\
$10: 00$ & 50.6 & 0.8831366 \\
$10: 30$ & 56.9 & 0.99309234 \\
$11: 00$ & 63.2 & 1.10304809 \\
$11: 30$ & 69.3 & 1.20951317 \\
$12: 00$ & 75 & 1.30899694 \\
$12: 30$ & 79.6 & 1.38928208 \\
$13: 00$ & 81.2 & 1.41720735 \\
$13: 30$ & 78.3 & 1.3665928 \\
$14: 00$ & 73.2 & 1.27758101 \\
$14: 30$ & 67.3 & 1.17460659 \\
$15: 00$ & 61.2 & 1.0681415 \\
$15: 30$ & 54.9 & 0.95818576 \\
$16: 00$ & 48.5 & 0.84648469 \\
$16: 30$ & 42.2 & 0.73652894 \\
$17: 00$ & 35.9 & 0.6265732 \\
$17: 30$ & 29.6 & 0.51661746 \\
$18: 00$ & 23.4 & 0.40840704 \\
$18: 30$ & 17.3 & 0.30194196 \\
19900 & 11.3 & 0.19722221 \\
$19: 30$ & 5.4 & 0.09424778
\end{tabular}

$\begin{array}{rrr}\text { September } 21 \text { st } & \text { Degrees } & \text { Radians } \\ 6: 00 & & \\ 6: 30 & & \\ 7: 00 & 3.3 & 0.05759587 \\ 7: 30 & 937 & 16.3537351 \\ 8: 00 & 16 & 0.27925268 \\ 8: 30 & 22.2 & 0.38746309 \\ 9: 00 & 28.3 & 0.49392818 \\ 9: 30 & 34.2 & 0.5969026 \\ 10: 00 & 39.9 & 0.69638637 \\ 10: 30 & 45.2 & 0.78888882 \\ 11: 00 & 49.9 & 0.8709193 \\ 11: 30 & 53.9 & 0.94073247 \\ 12: 00 & 56.9 & 0.99309234 \\ 12: 30 & 58.5 & 1.02101761 \\ 13: 00 & 58.6 & 1.02276294 \\ 13: 30 & 57.2 & 0.99832833 \\ 14: 00 & 54.3 & 0.94771378 \\ 14: 30 & 50.4 & 0.87964594 \\ 15: 00 & 45.7 & 0.79761547 \\ 15: 30 & 40.5 & 0.70685835 \\ 16: 00 & 34.9 & 0.60911991 \\ 16: 30 & 29 & 0.50614548 \\ 17: 00 & 22.9 & 0.3996804 \\ 17: 30 & 16.7 & 0.29146999 \\ 18: 00 & 10.4 & 0.18151424 \\ 18: 30 & 4.1 & 0.0715585 \\ 19: 00 & & \\ 19: 30 & & \\ 20: 00 & & \end{array}$

$\begin{array}{rrr}\text { December 21st } & \text { Degrees } & \text { Radians } \\ 6: 00 & & \\ 6: 30 & & \\ 7: 00 & & \\ 7: 30 & & \\ 8: 00 & 0.9 & 0.01570796 \\ 8: 30 & 6.4 & 0.11170107 \\ 9: 00 & 11.6 & 0.20245819 \\ 9: 30 & 16.4 & 0.286234 \\ 10: 00 & 20.9 & 0.36477381 \\ 10: 30 & 24.9 & 0.43458698 \\ 11: 00 & 28.3 & 0.49392818 \\ 11: 30 & 31 & 0.53105207 \\ 12: 00 & 33 & 0.57595865 \\ 12: 30 & 34.1 & 0.59515727 \\ 13: 00 & 34.3 & 0.59864793 \\ 13: 30 & 33.6 & 0.58643063 \\ 14: 00 & 32 & 0.55850536 \\ 14: 30 & 29.6 & 0.51661746 \\ 15: 00 & 26.4 & 0.46076692 \\ 15: 30 & 22.7 & 0.39618974 \\ 16: 00 & 18.4 & 0.32114058 \\ 16: 30 & 13.7 & 0.23911011 \\ 17: 00 & 8.7 & 0.15184364 \\ 17: 30 & 3.3 & 0.05759587 \\ 18: 00 & & \\ 18: 30 & & \\ 19: 00 & & \\ 19: 30 & & \\ 20: 00 & & \end{array}$

TABLE 41: ANNUAL SUN ALTITUDE YAZD, IRAN 